\title{
Seasonal Variation in Material Properties of a Flexible Pavement
}

\author{
by \\ Dennis Keith Watson \\ B.Sc (Civil Engineering)
}

A Thesis

Submitted to the Faculty of Graduate Studies

in Partial Fulfillment of the Requirements

for the Degree of

Master of Science

Department of Civil and Geological Engineering

University of Manitoba

Winnipeg, Manitoba

(C) July, 1996 
The author has granted an irrevocable non-exclusive licence allowing the National Library of Canada to reproduce, loan, distribute or sell copies of his/her thesis by any means and in any form or format, making this thesis available to interested persons.
L'auteur a accordé une licence irrévocable et non exclusive permettant à la Bibliothèque nationale du Canada de reproduire, prêter, distribuer ou vendre des copies de sa thèse de quelque manière et sous quelque forme que ce soit pour mettre des exemplaires de cette thèse à la disposition des personnes intéressées.

L'auteur conserve la propriété du droit d'auteur qui protège sa thèse. Ni la thèse ni des extraits substantiels de celle-ci ne doivent être imprimés ou autrement reproduits sans son autorisation. 
Name

Dissertation Abstracts International and Masters Abstracls International are arranged by broad, general subject categories.

Please select the one subject which mosi nearly describes the content of your dissertation or thesis. Enter the corresponding four-digit code in the spaces provided.

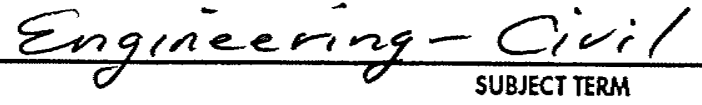

\section{Subject Categories}

\section{THE HUMANITIES AND SOCIAL SCIENCES}

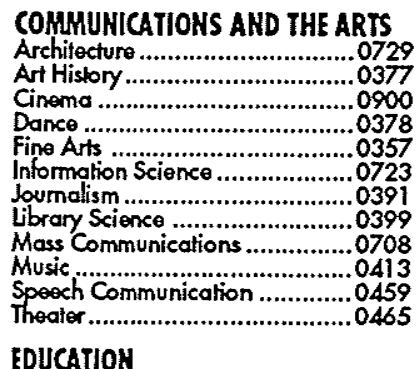

\section{EDUCATION}

General

Administration ..........................0514

Adult and Continuing .....................0516

Agricultural 0517

Bilingual and Mülicultural ............0282

Business ................068

Community College......................... 0275

Curriculum and Instruction ..........0727

Earty Childhood .........................0518

Elementary ................................... 0524

Finance ......................................027

Guidance and Counseling .......... 0519

Heglth .......................................0680

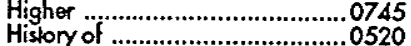

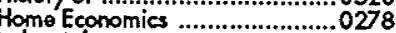

Industrial ..... 0521

Language and Lilerature ............. 0279

Mathematics....................................

Music .

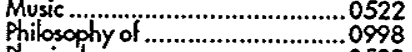

Physicd....................................... 0523
Psychology .................................0525

Reading …………............................0535

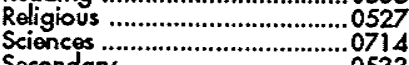

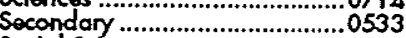

Social Sciences ..............................0534

Sociotogy of ................................0340

Special ...................................0529

Toachor Training .......................0530

Tochnology ..............................0710
Tests and Measurements ...........0288

Vocational..................................0747

LANGUAGE, UTERATURE AND

LINGUISTICS

Language

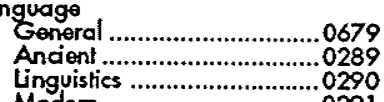

Literalure

General ................................0401

Classical .............................0294

Medieval ................................0297

Modern …….........................0298

African .................................0316

American ..............................059

Asion …..........................0305

Cancodian (English) ...............0352

Canadian (French) ...............0355

English ...............................0593

Latin American ..........................031

Middle Easiem …….................0315

Slavic and Easi European .....0314
PHILOSOPHY, RELIGION AND

THEOLOGY

Philosophy................................0422

Religion

General ..............................0318

Biblical Studios ........................0321

Clergy ...............................0319

History of .......................0320

Theology ......................................0469

SOCLAL SCIENCES

American Sludies

Anthropology

Archooology .........................0324

Cultural ……..........................0326

Business Administration

General ...............................0310

Accounting ……........................0270 0272

Accounting …........................0272

Management ..........................0454

Marketing ............................0338

Canadian Studies ........................0385

Economies

General ............................0501

Agnural ........................0503

Commerce-Business ...............0505

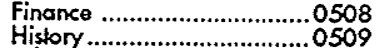

Labor .............................................

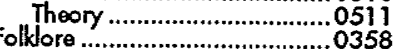

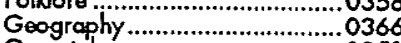

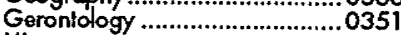

History

General

.0578

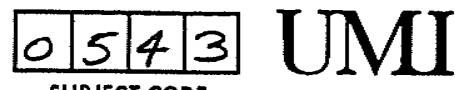

SUBJECT CODE

\section{THE SCIENCES AND ENGINEERING}

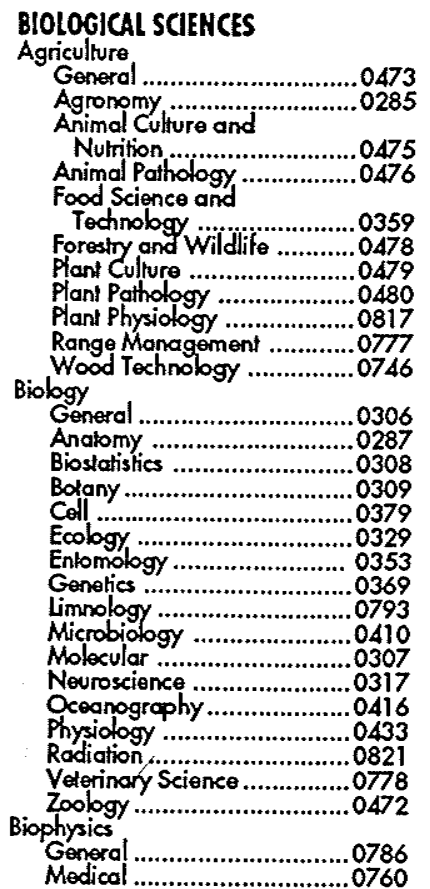

EARTH SCIENCES

Biogeochemistry.........................0425
Geodesy ..................................0370

Geology ...............................................

Geophysics...................................0373

Hydrology ..................................0388

Mineralogy .................................0411

Patooocology .................................... 0426

Paloontology ......................................... 0418

Paloozology ………...................0985

Palynotogy .............................0427

Physical Ocoanography...............0415

HEALTH AND ENVIRONMENTAL

SCIENCES

Environmental Sciences .............0768 Health Sciences

General ...............................0566

Audiology ..............................0300

Chemotherapy ...................... 0992

Dentisty ..................................0567

Education .........................0350

Hospital Management ..........0769

Human Development ............0758

Mediaine and Surgery ..............0564

Mental Hoalth ......................0347

Nursing ...................................0569

Nutrition ............................0570

Obsletrics ond Gypecotogy ..0380

Occupational Hoalth and

Therapy f.........................0354

Ophthalmology ………........0381

Pharmacotogy ..........................0419

Pharmacy ……………….....0572

Public Health ……...................038

Radiatogy ...............................0574

Recreation .............................0575
Speoch Pathology ................0460

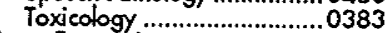

Home Economics …………...........0386

PHYSICAL SCEHCES

Pure Sciences

Chemistry

General ..............................0485

Agricultural ..........................0749

Analytical .................................0486

Biochemistry ...........0487

Inorganic ...............................0488

Nuclear ................................0738

Organic ...................................... 0490

Pharmaceutical ........................0491

Physical ...................................0494

Polymer ...............................0495

Mathematics

Physics

General ...........................0605

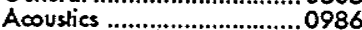

Astronomy and

Astrophysics ......................0606

Atmospheric Science...............0608

Atomic .....................0748

Elementary Particles and

High Energy .....................0798

Fluid and Plasma ................0798

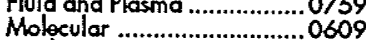

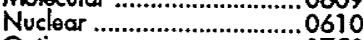

Opties .......................................0752

Radiation ................................0756

Statistics ……..................................0463

Applied Sciences

Applied Mechanics ....................0346

Computer Science ..........................0984

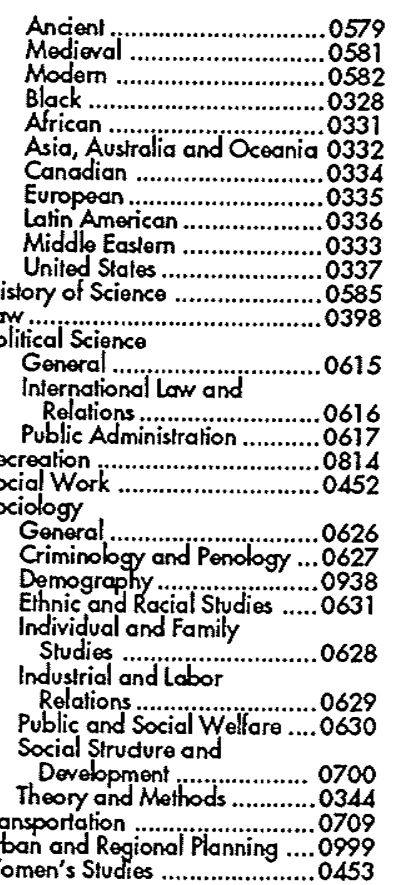

Engineoring

General ...........................0537

Aerospace .............................. 0538

Agriculiural............................ 0539

A blomotive .......................... 0540

Chemical ...........................0542

Givil ................................... 0543

Electronics and Electrical ....... 0544

Heat and Thermodynamics ...0348

Hydraulic .............................0545

Industrial .............................. 0546

Materidi Seience .................... 0794

Mechanical ............................. 0548

Melallurgy ................................0743

Mining ................................ 0551

Nuclear...........................0552

Padkaging ............................. 0549

Pelroleum................................ 0765

Sanitary and Municipali.........0554

Syslem Science .................... 0790

Geolechnotogy .........................0428

Pporations Research .................. 0796

Textile Technology ......................... 0994

PSYCHOLOGY

General...................................0621

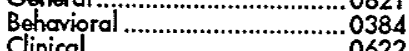

Denical..................

Experimental ...............................0623

Personality ..........................................0625

Physiotogical ..................................... 0989

Psychobiology ............................ 0349

Socychometrics ............................0632 
THE UNIVERSITY OF MANITOBA

FACULTY OF GRADUATE STUDIES

COPYRIGHT PERMISSION

SEASONAL VARIATION IN MATERIAL PROPERTIES OF A FLEXIBIE PAVEMENT

BY

DENNIS REITH WATSON

A Thesis/Practicum submitted to the Faculty of Graduate Studies of the University of Manitoba in partial fulfillment of the requirements for the degree of

MASTER OF SCIENCE

Dennis Keith Watson (C) 1996

Permission has been granted to the LIBRARY OF THE UNIVERSITY OF MANITOBA to lend or sell copies of this thesis/practicum, to the NATIONAL LIBRARY OF CANADA to microfilm this thesis/practicum and to lend or sell copies of the film, and to UNIVERSITY MIICROFILMS INC. to publish an abstract of this thesis/practicum..

This reproduction or copy of this thesis has been made available by authority of the copyright owner solely for the purpose of private study and research, and may only be reproduced and copied as permitted by copyright laws or with express written authorization from the copyright owner. 


\section{Abstract}

Seasonal variation of temperature and moisture cause considerable changes in the loadcarrying capacity of pavements in geographical areas subject to extreme freeze/thaw conditions. Pavement engineers in these areas must be able to quantify the variation in the load-carrying capacity of a pavement in order to design it adequately. The Seasonal Monitoring Program (SMP) of the Long Term Pavement Performance (LTPP) study of the U.S.A. Federal Highway Administration (FHWA) is monitoring seasonal variations in Falling Weight Deflectometer (FWD) deflections, air temperature, rainfall, soil temperature, moisture content, and soil electrical resistance at numerous sites across North America. The present study relates changes in pavement load carrying capacity represented by the pavement layer resilient moduli to selected environmental factors. SMP data collected from the Oak Lake, Manitoba test site from February, 1994 through June, 1995 is used to model the relationship. The pavement layer elastic moduli are backcalculated from FWD readings taken monthly throughout the year and bi-weekly during the critical spring thaw period. The backcalculation is based on the Washington State DOT EVERCALC Version 4.0 software. Frozen base and subgrade layer thicknesses are determined from soil temperatures, moisture content, and electrical resistivity data and included as additional layers in backcalculation. The most significant environmental parameters causing seasonal variation in pavement layer resilient moduli are identified as surface temperature (asphalt layer) and Thawing Index (base

and subgrade layers). The relationships show that resilient moduli of pavement layers show an exponential decrease in magnitude caused by their respective environmental parameter. These mechanistic models are now available for use in determining the validity and accuracy of the empirical pavement design and rehabilitation practices currently in use. The examination of the load-carrying capacity of this single pavement site during any time of the year is an important first step towards the adoption of mechanistic pavement design and rehabilitation processes at the Manitoba Department of Highways and Transportation. 


\section{Acknowledgements}

The author wishes to express his appreciation for the time, advice and guidance which Dr. R. K. N. D. Rajapakse has contributed towards the completion of the present study. Without his interest and support, the present study would never have been undertaken nor completed as such.

Scholarships were awarded by the Transportation Association of Canada through the General Chemical of Canada Jim Lyon Memorial fund and the International Road Federation. Without this financial support the author would not have been able to undertake the Master of Science program and as such is most thankful to these agencies. The author thanks Professor Alan Clayton for providing the motivation needed for a sceptical student to begin the Master of Science program.

All of the data used in the present study was collected under the authority of the U.S.A. Federal Highway Administration through the Long Term Pavement Performance (LTPP) study, Seasonal Monitoring Program. This data was provided to the Manitoba Department of Highways and Transportation under the terms of the partnering arrangement of this important research initiative. The author is extremely thankful to both the LTPP and Manitoba Department of Highways and Transportation for the data which was made available for use in the present study.

The staff of Braun Intertec Corporation, the LTPP Regional Contractor from 1988 through June, 1996, were always an excellent source of information and advice whenever they were contacted. These staff were responsible for the excellent professional manner in which the data collection took place. High quality data was collected regardless of the temperature and wind extremes which the Manitoba climate presented. The author acknowledges the special efforts which were made by Bob Van Sambeek, Erland Lukanen, P. E., and Ben Worel, P. 
E. in providing insight and advice on a wide variety of topics.

A great deal of effort was expended by Bob and Mavis Van Sambeek proofreading the draft of the present study. The author appreciates that Bob contributed so much of his technical expertise, and Mavis her legal experience in the review of this document.

The author had tremendous and never-failing support from all of his family but especially from his parents. Their confidence in the author's ability to complete the present study helped buoy his spirits a great deal.

The present study would have ended many times except for the support and encouragement of Robbin, Carley, and Chelsea, the author's wife and daughters. Words of appreciation fail to adequately compensate them for all of the hours which were spent helping their husband and father dedicate the time required to complete the present study. Their support, love, and sacrifices have not gone unnoticed and will never be forgotten. 


\section{Table of Contents}

Abstract $\ldots \ldots \ldots \ldots \ldots \ldots \ldots \ldots \ldots \ldots \ldots \ldots \ldots \ldots \ldots \ldots \ldots \ldots$

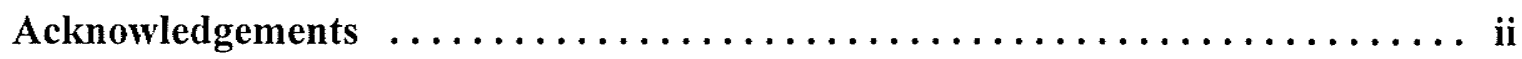

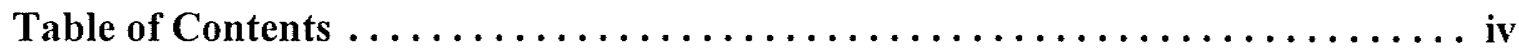

List of Tables $\ldots \ldots \ldots \ldots \ldots \ldots \ldots \ldots \ldots \ldots \ldots \ldots \ldots \ldots \ldots \ldots \ldots \ldots \ldots$

List of Figures $\ldots \ldots \ldots \ldots \ldots \ldots \ldots \ldots \ldots \ldots \ldots \ldots \ldots \ldots \ldots \ldots \ldots \ldots \ldots \ldots \ldots \ldots$

1: Introduction $\ldots \ldots \ldots \ldots \ldots \ldots \ldots \ldots \ldots \ldots \ldots \ldots \ldots \ldots \ldots \ldots \ldots \ldots$

1.1 Literature Review . . . . . . . . . . . . . . . . . . . 3

1.2 Scope and Objectives of the Present Study $\ldots \ldots \ldots \ldots \ldots \ldots \ldots$

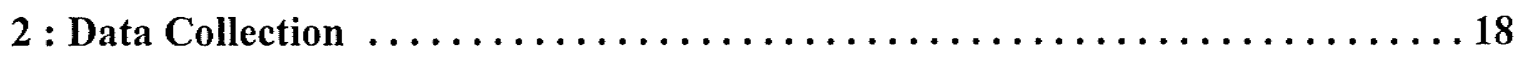

2.1 Air Temperature and Rainfall $\ldots \ldots \ldots \ldots \ldots \ldots \ldots \ldots \ldots \ldots \ldots \ldots \ldots \ldots \ldots \ldots$

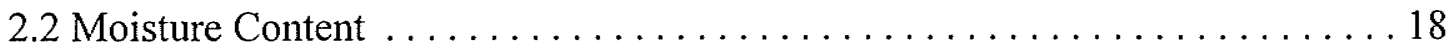

2.3 Pavement Layer Temperatures $\ldots \ldots \ldots \ldots \ldots \ldots \ldots \ldots \ldots \ldots \ldots \ldots \ldots \ldots \ldots \ldots \ldots \ldots$

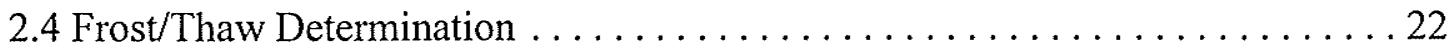




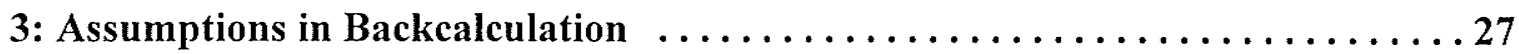

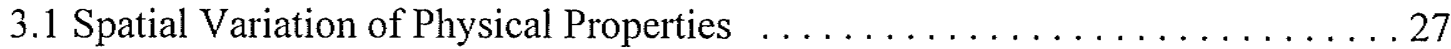

3.2 Idealizations Required in Backcalculation $\ldots \ldots \ldots \ldots \ldots \ldots \ldots \ldots \ldots$

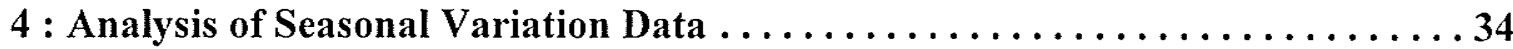

4.1 Falling Weight Deflectometer ............................. 34

4.2 Electrical Resistance of Soil $\ldots \ldots \ldots \ldots \ldots \ldots \ldots \ldots \ldots \ldots \ldots \ldots \ldots$

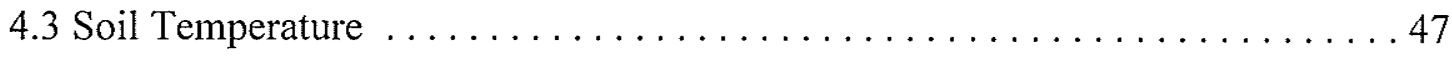

4.4 Soil Moisture Content $\ldots \ldots \ldots \ldots \ldots \ldots \ldots \ldots \ldots \ldots \ldots \ldots \ldots . \ldots 48$

4.5 Determination of Frozen Layer Extent $\ldots \ldots \ldots \ldots \ldots \ldots \ldots \ldots \ldots \ldots$

4.6 Backcalculation Using EVERCALC . . . . . . . . . . . . . . . . 57

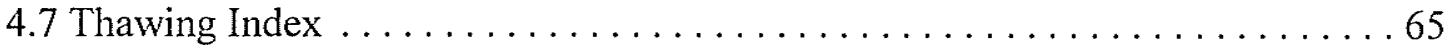

5 : Modelling of Seasonal Variation of Material Properties $\ldots \ldots \ldots \ldots \ldots \ldots 6$

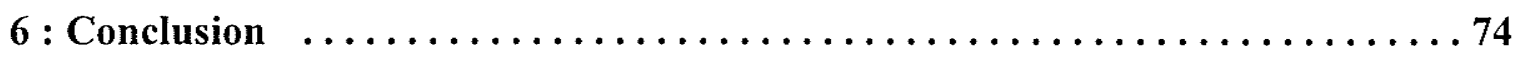

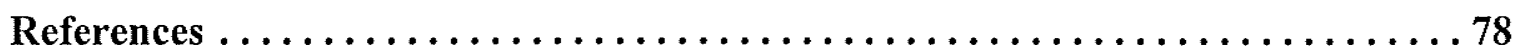


Appendix A : Surface Deflection Data $\ldots \ldots \ldots \ldots \ldots \ldots \ldots \ldots \ldots \ldots \ldots$

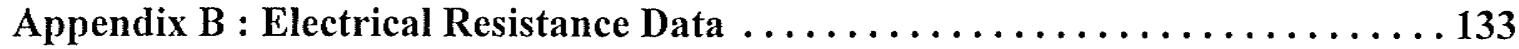

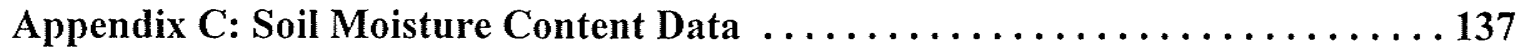

Appendix D: Backcalculated Layer Moduli Output From EVERCALC . . . . 139 


\section{List of Tables}

Table 4.1 Moduli Ranges for 3 Layer Analysis.................................... 60

Table 4.2 Allowable Moduli Ranges.................................................. 61

Table 4.3 Thawing Indices Values.......................................................... 66

Table 5.1 Correlation Values for AC Layer Temperature Models............... 69 


\section{List of Figures}

Figure 1.1 Backcalculated AC Moduli versus Mid-Pavement Temperature............... 4

Figure 1.2 Typical FWD Sensor Deflections and Pavement Temperatures.............. 6

Figure 1.3 Seasonal Variation of Subgrade Moduli by Month and Site Location...... 7

Figure 1.4 AC Moduli versus Pavement Temperature Relationship...................... 10

Figure 1.5 AC Moduli by MODULUS and BOUSDEF programs vs Temperature... 12

Figure 1.6 Typical Layout of SMP Site Instrumentation.................................. 16

Figure 2.1 FHWA Moisture Probe............................................................... 19

Figure 2.2 MRC Model\#TP101 Thermistor Probe........................................... 21

Figure 2.3 CRREL Resistivity Probe .......................................................... 23

Figure 2.4 Schematic Diagram of FWD Deflection Test................................. 25

Figure 3.1 Variation of Sensor Deflections \#1 -\#7 on One Test Pass...................... 28

Figure 3.2 Typical Load/Sensor \# Deflection Curves from FWD Deflection Test.... 30

Figure 4.1 Outer Wheelpath FWD Deflection Test Pass Sept 21, 1994................. 34

Figure 4.2 Mid-Lane FWD Deflection Test Pass Sept 21, 1994_.......................... 35

Figure 4.3 Seasonal Variation of Sensor \#1 Deflection.......................................... 36

Figure 4.4 Seasonal Variation of Sensor \#4 Deflection...................................... 37

Figure 4.5 Seasonal Variation of Sensor \#7 Deflection.......................................... 37

Figure 4.6 Seasonal Variation of Deflections During 1994 Spring Thaw Period...... 38

Figure 4.7 Seasonal Variation of Deflection Data During 1994 Unfrozen Conditions 39 
Figure 4.8 Seasonal Variation of Deflections During Winter 1994 to Spring $1995 \ldots . .40$

Figure 4.9 Seasonal Variation of Deflections During Spring 1995........................ 41

Figure 4.10 Seasonal Variation of Resistance Data............................................ 42

Figure 4.11 Seasonal Variation of Resistance Data........................................ 42

Figure 4.12 Seasonal Variation of Resistance Data............................................ 43

Figure 4.13 Seasonal Variation of Resistance Data......................................... 44

Figure 4.14 Seasonal Variation of Resistance Data............................................ 44

Figure 4.15 Manual Resistance Data for Spring 1994..................................... 45

Figure 4.16 Manual Resistance Data for Spring 1995..................................... 46

Figure 4.17 Soil Temperature During Spring 1994......................................... 47

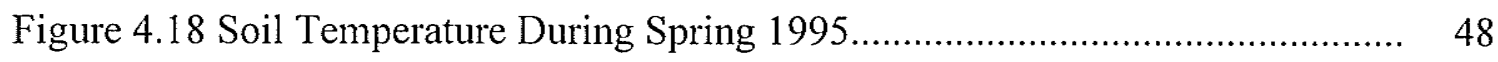

Figure 4.19 1994 Baseline Moisture Content Readings.................................... 49

Figure 4.20 1994 Soil Moisture Contents...................................................... 50

Figure 4.21 Spring 1994 Resistance Data......................................................... 51

Figure 4.22 Soil Temperatures During Spring 1994....................................... 52

Figure 4.23 1995 Spring Moisture Content Readings.................................... 54

Figure 4.24 1995 Spring Resistance Data....................................................... 55

Figure 4.25 1995 Spring Soil Temperatures...................................................... 55

Figure 4.26 Schematic of Backcalculation Process...................................... 58

Figure 4.27 Backcalculated Layer Moduli February through August, 1994........... 62

Figure 4.28 Backcalculated Layer Moduli September, 1994 through June, 1995.... 63 
Figure 4.29 Backcalculated Layer Moduli.................................................... 64

Figure 5.1 Third Degree Polynomial Fit of the Data.......................................... 69

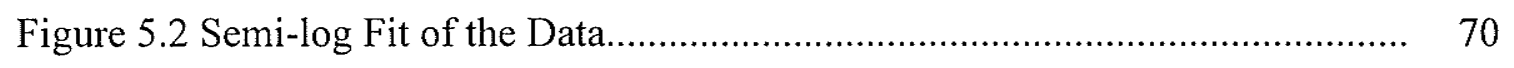

Figure 5.3 Exponential Fit of the Data........................................................ 71

Figure 5.4 Third Degree Polynomial Fit of the Data........................................ 72

Figure 5.5 Comparison of AC Moduli from Past and Present Studies..................... 73 


\section{1 : Introduction}

Pavements in a freeze/thaw environment undergo drastic changes in material properties which influence their ability to carry heavy loads without failing or sustaining severe damage. In a severe freeze/thaw environment such as the Province of Manitoba, Canada, recorded pavement temperatures range from $-40{ }^{\circ} \mathrm{C}$ to $50^{\circ} \mathrm{C}$. Granular base and subgrade soil layers have been known to freeze to depths of two metres or more under pavement surfaces. Once thawing has commenced in the spring season, the granular layers reach a state of near-saturation which reduces the load-carrying capacity. Obviously these environmental conditions cause significant variation in the ability of a pavement to support traffic loads imposed upon it. Pavement authorities in Manitoba and other agencies have long understood that pavement structures are at their weakest state during the spring thaw period. The authorities in Manitoba try to minimize the effect of these environmental factors during the spring thaw period through the use of restrictions on the allowable maximum loads on secondary roads. Pavement designers acknowledge the existence of this weakness in the spring by using empirical relationships between the surface deflection and a maximum allowable deflection. Neither of these approaches consider the seasonal variation of the resilient moduli of the pavement layers which govern the load-carrying capacity.

Use of resilient moduli allows for mechanistic modelling of the relationship between stress and strain properties of the pavement material. These mechanistic laws govern the behaviour of any material and therefore should be used to characterize the reactions of pavement materials to environmental factors. The use of mechanistic models instead of empirical relationships would allow for formal mathematical modelling of the problem under consideration. Such modelling would be able to predict the degree of damage which would occur on any given pavement structure based on any set of environmental and load factors. This predictive capability would allow pavement authorities to determine the effect of 
variation of pavement material properties, layer thicknesses, etc. on mitigating the damage effects due to environmental factors and loading regimes.

Therefore the understanding of seasonal variation of material properties of a flexible pavement is a major step towards the design of longer lasting new pavements and rehabilitation of existing pavement structures. The importance of the understanding and modelling of seasonal variation in flexible pavement material properties is summed up by Irwin, (1994);

"There is a deep and abiding need to develop models that can account for the effect of seasonal environmental variables on the properties of pavement layers. Until such models are available with a sufficient degree of accuracy it will be nearly impossible to relate the results of field tests taken on any arbitrary day of the year to the load sufficiency of the pavement."

Before modelling of seasonal variation in pavement layer properties can occur, a research approach must be adopted which is able to define the material properties while satisfying the mechanistic constraints that govern the response of a pavement. Most research characterising material properties of pavement layers involves modelling existing pavement structure as a series of elastic layers. The theory of elastic layers requires material property parameters such as the elastic modulus and Poisson's ratio to characterize the load-carrying capacity of the pavement layers. These parameters, when used together with a known load, cause a particular deflection profile on the surface of a pavement. This calculated deflection profile is compared to the deflection profile obtained from nondestructive testing equipment such as the Falling Weight Deflectometer (FWD). If the calculated deflection points are not within a specified tolerance of the measured deflection points, then a new set of material properties are assigned and the process is repeated until such time as the specified tolerance is met. This process is known as backcalculation, an iterative process to establish a set of 
material properties which cause a similar deflection profile to that measured through the use of the FWD. Once this set of pavement layer properties has been established, then the loadcarrying capacity may be calculated according to allowable stresses and strains within the layers.

Studies into quantification of the seasonal variation in the material properties of flexible pavements have been undertaken in other locales. A literature review into previouslyconducted studies was undertaken to determine whether previously used research approaches could be used in an environment such as that in Manitoba. The degree of success of previous investigations into the quantification of seasonal variation of pavement material properties could then be used in the present study as a guide.

\subsection{Literature Review}

Janoo and Berg, (1991) conducted research to quantify changes in the load-carrying capacity of a pavement during the spring thaw period in a freeze/thaw environment. Their research was conducted at the Frost Effects Research Facility at the Cold Regions Research and Engineering Laboratory (CRREL) at Hanover, New Hampshire. Several test sections of various cross sections were built and subjected to freeze/thaw cycles and changes in the structural capacity were monitored. The Janoo study dealt only with results from one of the test sections, referred to as TS1, which consisted of a full depth asphalt concrete pavement $150 \mathrm{~mm}$ thick over $145 \mathrm{~mm}$ of compacted clay soil. The natural foundation was a fine sand subgrade. A rigid layer was not present within $20 \mathrm{~m}$ of the surface. The sites were instrumented with thermocouples, CRREL resistivity gauges, and psychrometers. Frost and thaw extents were determined from the depth of the $0^{\circ}$ Celsius isotherm and from electrical resistivity readings from the CRREL gauges. An observation was made by the authors that the use of the electrical resistivity readings were especially useful when the subsurface temperatures became nearly isothermal at $0^{\circ} \mathrm{C}$. 
The testing program involved freezing the pavement from the top down through the use of cooling panels in two separate cycles. The frost depth was determined to lie between 1,220 and $1,520 \mathrm{~mm}$, for the two freezing cycles, respectively. Thawing was then initiated by removing the cooling panels and allowing the ambient temperature of the indoor facility to provide the energy. Surface deflection measurements were taken daily with a FWD during the thawing periods. FWD tests were taken at four locations on the test site at load levels ranging from 20 to $67 \mathrm{kN}$. The backcalculation of layer moduli was based on the deflection data for a normalized $40 \mathrm{kN}$ load level by using linear regression on data for three load levels. A representative deflection basin was obtained using a computer program named BASIN which averaged the deflections at each sensor location for a given load level and calculates an average deflection basin area. The program then chooses a measured deflection basin that is closest to the averaged basin deflections and area as the representative basin.

The WESDEF backcalculation program was then used to backcalculate the layer moduli. WESDEF uses the WESLEA layered elastic program for calculating stresses, strains, and deflections in the pavement system. The solution from WESDEF is a set of layer moduli values which will minimize the error between the measured and calculated sensor deflections. WESDEF terminates when the absolute sum of the errors between the calculated and measured sensor deflections is less than ten percent.

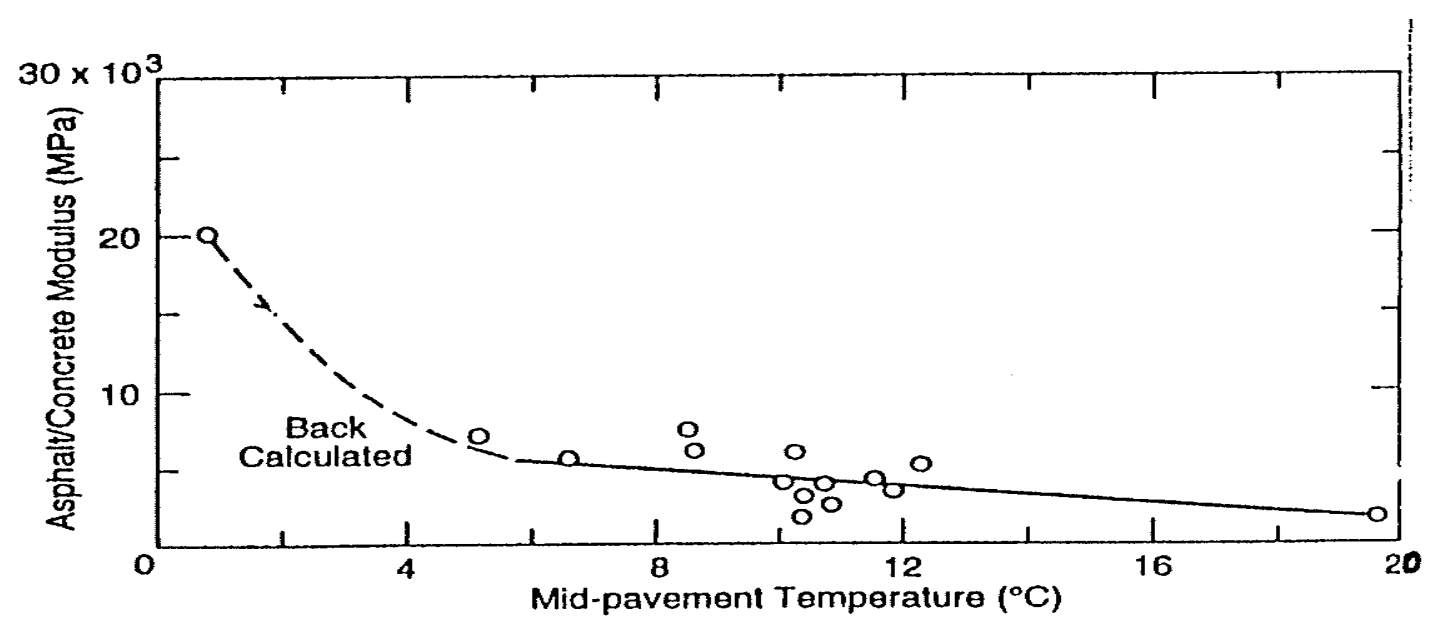

Figure 1.1 Backcalculated AC Moduli versus Mid-pavement Temperature 
Figure 1.1 shows the Asphalt Concrete (AC) layer modulus calculated from the analysis plotted against mid-pavement temperature. Backcalculation of layer moduli during the thawing period was first attempted with no accommodation for the presence of frozen or thawed layers. Thus the analysis used a three layer system consisting of a full-depth asphalt concrete, a composite layer of thawed and frozen sub-layers, and the sand subgrade. The magnitude of errors from the analysis proved the three layer system to be unacceptable. Therefore frozen and thawed layers were accounted for separately in the second analysis which showed that the consideration of frozen layers is critical to the modelling of seasonal variation.

Another study to quantify damage to a pavement caused by the seasonal variation of flexible pavement material properties in the freeze/thaw environment was conducted by Han, Lukanen, and Van Sambeek, (1994). This study was based on data from the Strategic Highway Research Program (SHRP), Long-Term Pavement Performance (LTPP) Seasonal Monitoring Program (SMP) pilot study. The data was collected on flexible pavements in the LTPP North Central Region prior to the sites being instrumented. The five sections selected for use in this study were all built on fine-grained subgrades in the LTPP dry-freeze zone. One of the test sites used in this study was situated on Provincial Trunk Highway (PTH) No. 1 near the town of Oak Lake, Manitoba.

On the Oak Lake test site, FWD deflection testing was run monthly from November, 1991 through August, 1992 according to the following protocols:

-two drops at four target load levels: $26.7,40.0,53.3,71.1 \mathrm{kN}$; -both the outer wheelpath and middle of travelling lane tested; -outer wheelpath test chainages $0-30,0-25,0-10$, then $0,0+25,0+50, \ldots, 2+00$; -and FWD sensor configuration: 0, 203,305, 457, 610, 914, and $1524 \mathrm{~mm}$ 
Analysis of the deflection data was undertaken for a typical station and date which were selected to show seasonal and daily variations in deflection and pavement temperature. Figure 1.2 shows the mid-lane deflection data at the $27 \mathrm{kN}$ load level for the Oak Lake, Manitoba test site:

Figure 1.2 (a) sensor deflections \#1, 4, 7 versus testing date at Station 25;

Figure 1.2 (b) sensor deflections \#1, 4, 7 through the test section on July 16, 1992;

Figure 1.2 (c) a typical daily deflection basin variation; and

Figure 1.2 (d) pavement temperature variation versus time for one day.

Plotted points represent the average of the four drops at each point. Multiple points plotted at any station represent the daily multiple FWD passes. Two backcalculation programs were used to analyse the deflection profiles; MODULUS and WESDEF. MODULUS was not
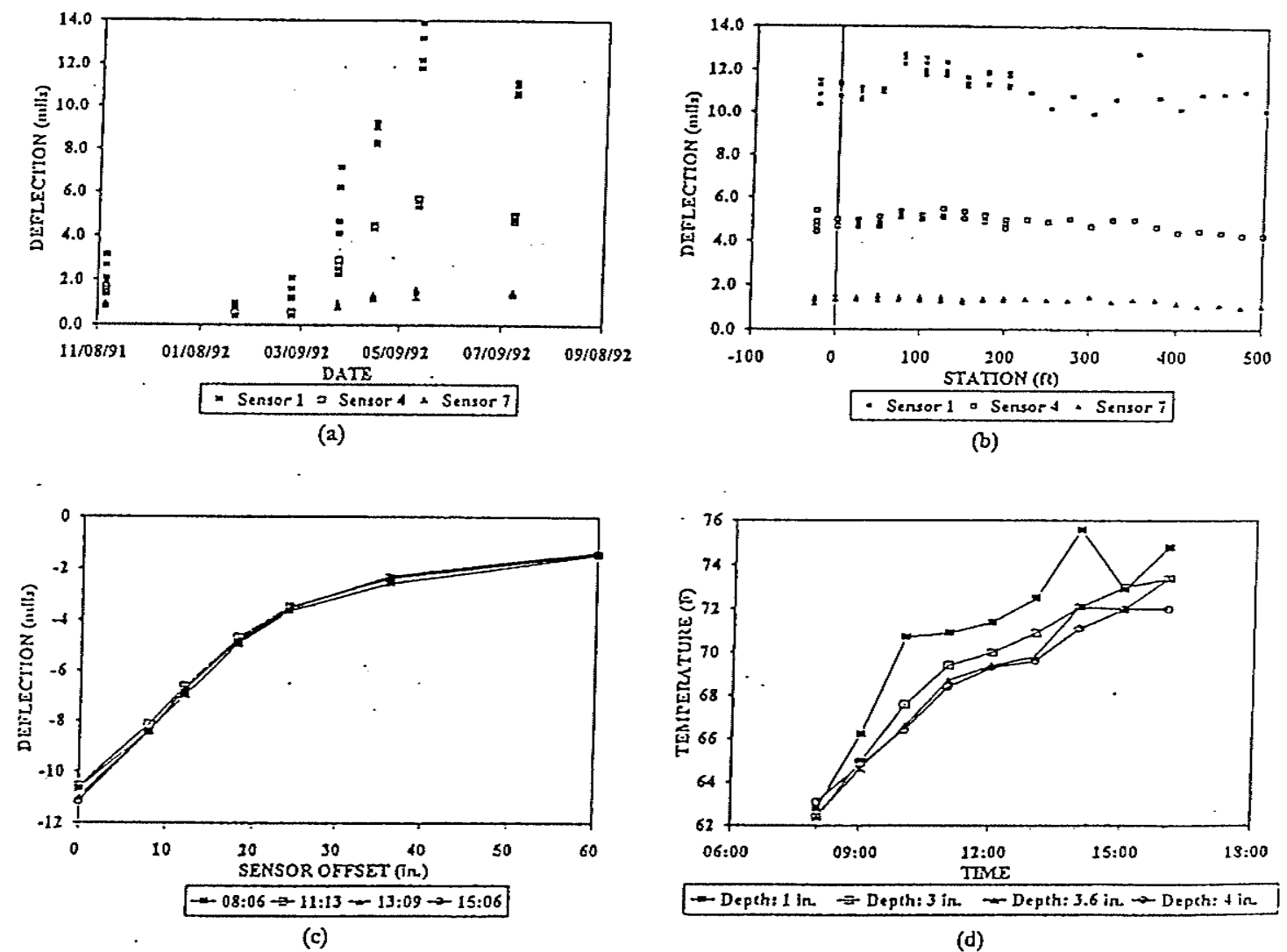

(d)

Figure 1.2 Typical FWD Sensor Deflections and Pavement Temperatures 
capable of analysing a pavement system consisting of four layers or handling low deflections during the frozen periods. Thus WESDEF was used to backcalculate the moduli values.

The following relationship between calculated asphalt modulus and mid-depth temperature of the asphalt concrete layer was determined to be:

$$
E_{A C}=10^{\left(\log _{10} E_{0}-\alpha T\right)}
$$

where,

$$
\begin{gathered}
E_{A C}=\text { is the asphalt modulus }(k s i) \\
T=i s \text { the mid-depth temperature }\left({ }^{\circ} F\right) \\
\log _{10} E_{0}, \alpha=\text { regression coefficients }
\end{gathered}
$$

Han et al concluded that FWD testing along with field instrumentation is effective in seasonally monitoring the long-term structural performance of pavements. Another conclusion was that on a semilog scale, the backcalculated asphalt modulus is linearly related to the mid-depth temperature of the asphalt layer. The backcalculated subgrade moduli were plotted against the month to represent the seasonal variation as shown in Figure 1.3. Data from the Oak Lake test site were backcalculated on a fixed pavement layer structure as no frost extent data was available at this site.

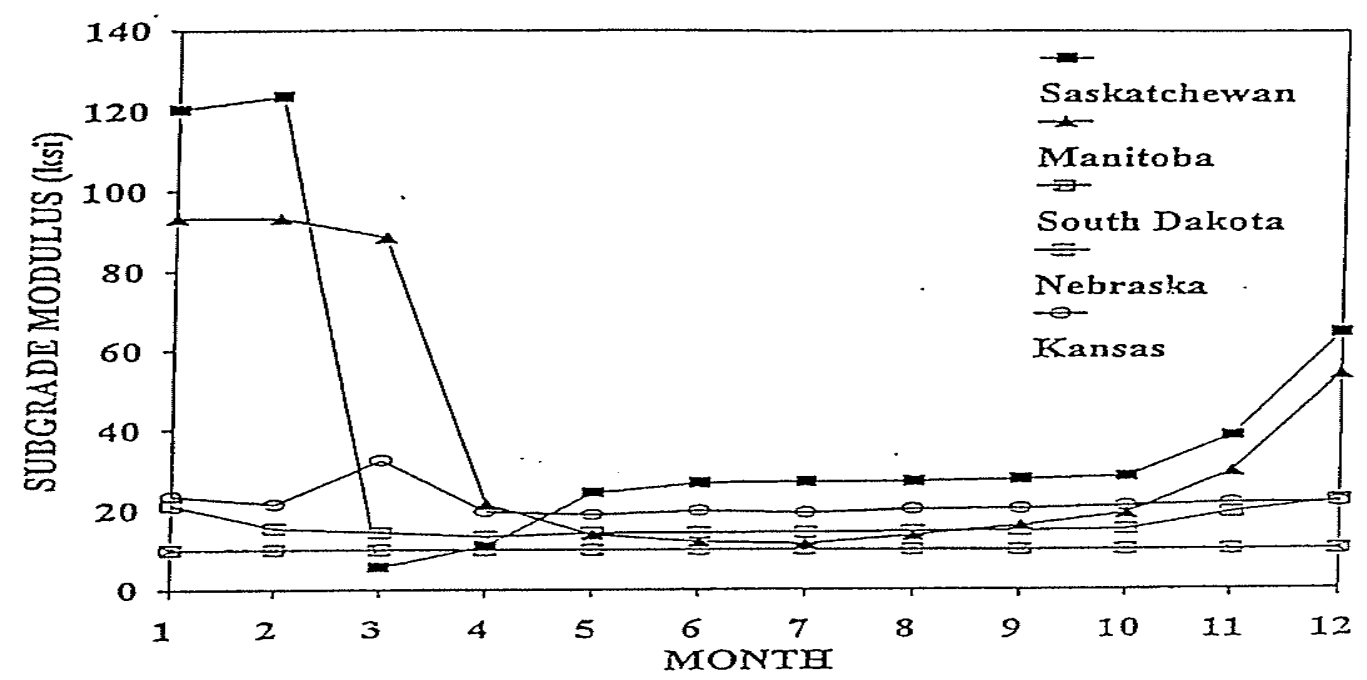

Figure 1.3 Seasonal Variation of Subgrade Moduli by Month and Site Location 
A study into the seasonal variation of pavement material properties was also undertaken by Van Deusen and Newcomb, (1994). Their objectives were to ascertain the precise timing of the spring thaw period and to model the environmental variable associated with this event. They also assessed the significance of the variation in strain response during the spring thaw periods of 1992 and 1993. The study involved testing four asphalt concrete sections at the Minnesota Road Research Project (Mn/ROAD) on Interstate 94 west of Minneapolis, Minnesota. $\mathrm{Mn} / \mathrm{ROAD}$ is composed of 40 different pavement test sections instrumented with sensors to measure responses and variables which influence the performance of the pavement test sections. The FWD was used to measure deflections of the pavement surface during first the frozen, then the thawed, and finally the recovered conditions of the pavement structure. Instrumentation of the site includes electrical resistivity probes for determining the extent of frozen layers.

Changes in the temperatures of the pavement sections were modelled as the independent variables against the measured deflections and backcalculated moduli. The four test sections considered in this study are composed of three conventional designs and one full-depth design. Only the full depth asphalt (TS1) cell, consisting of a $220 \mathrm{~mm}$ thick asphalt concrete layer, was used in the analysis. The subgrade soil underlying the four $150 \mathrm{~m}$ long sections consists of a silty clay. The environmental data collection consisted of air temperatures measured at a weather station located $30 \mathrm{~km}$ northeast of the Mn/ROAD site. FWD testing was conducted at $15 \mathrm{~m}$ spacing at three metre offsets either side of the roadway centerline. The maximum FWD loads ranged from 30 to $60 \mathrm{kN}$ applied to a $150 \mathrm{~mm}$ radius load plate.

The environmental variable modelled in the Van Deusen study consisted of calculation of the Thawing Index or TI. The TI is calculated as the deviation of the mean daily air temperature relative to $-1.7^{\circ} \mathrm{C}$ and summing the values greater than zero, thus: 
where,

$$
T I=\Sigma\left(T_{a v e}-\left(-1.7^{\circ} \mathrm{C}\right)\right)
$$

$$
T_{\text {ave }} \text { is the mean daily air temperature }\left({ }^{\circ} \mathrm{C}\right)
$$

Changes in the soil moisture state were monitored by resistivity probes which show a dramatic increase in electrical resistance in the soil as it freezes. The $2.5 \mathrm{~m}$ long resistivity probe contains sensors spaced at $50 \mathrm{~mm}$. Profiles obtained from these resistivity measurements during mixed frozen-thawed conditions of the soil were compared to those taken during thawed times to locate frozen layers.

The FWD load and deflection data were used in the the Washington State Department of Transportation's backcalculation program EVERCALC, to backcalculate the resilient moduli for each layer in the analysis. The resilient moduli characterise the stress and strain properties of the pavement layers. EVERCALC is based on the CHEVNL linear elastic layer analysis program. The pavement structures were modelled as three layer systems: the asphalt concrete, granular base, and subgrade soil. The study made no attempt to isolate the frozen from the thawed layers within the unbound layers. The subgrade was modelled as being semi-infinite. The Poisson's ratios chosen for the layers were $0.35,0.40$, and 0.45 for the asphalt concrete, granular base, and subgrade soil layers respectively.

The air and asphalt concrete surface temperatures were used to derive a relationship between the backcalculated asphalt concrete layer modulus and the mid-depth pavement layer temperature. The mid-depth pavement temperatures were estimated with the measured surface temperature and the five day average air temperature using Southgate's Method (Southgate, (1969)). The results for test cell TS1 and a similar relationship for a study conducted in Washington State (Lee, Mahoney and Jackson, (1988)) are shown in Figure 1.4. 


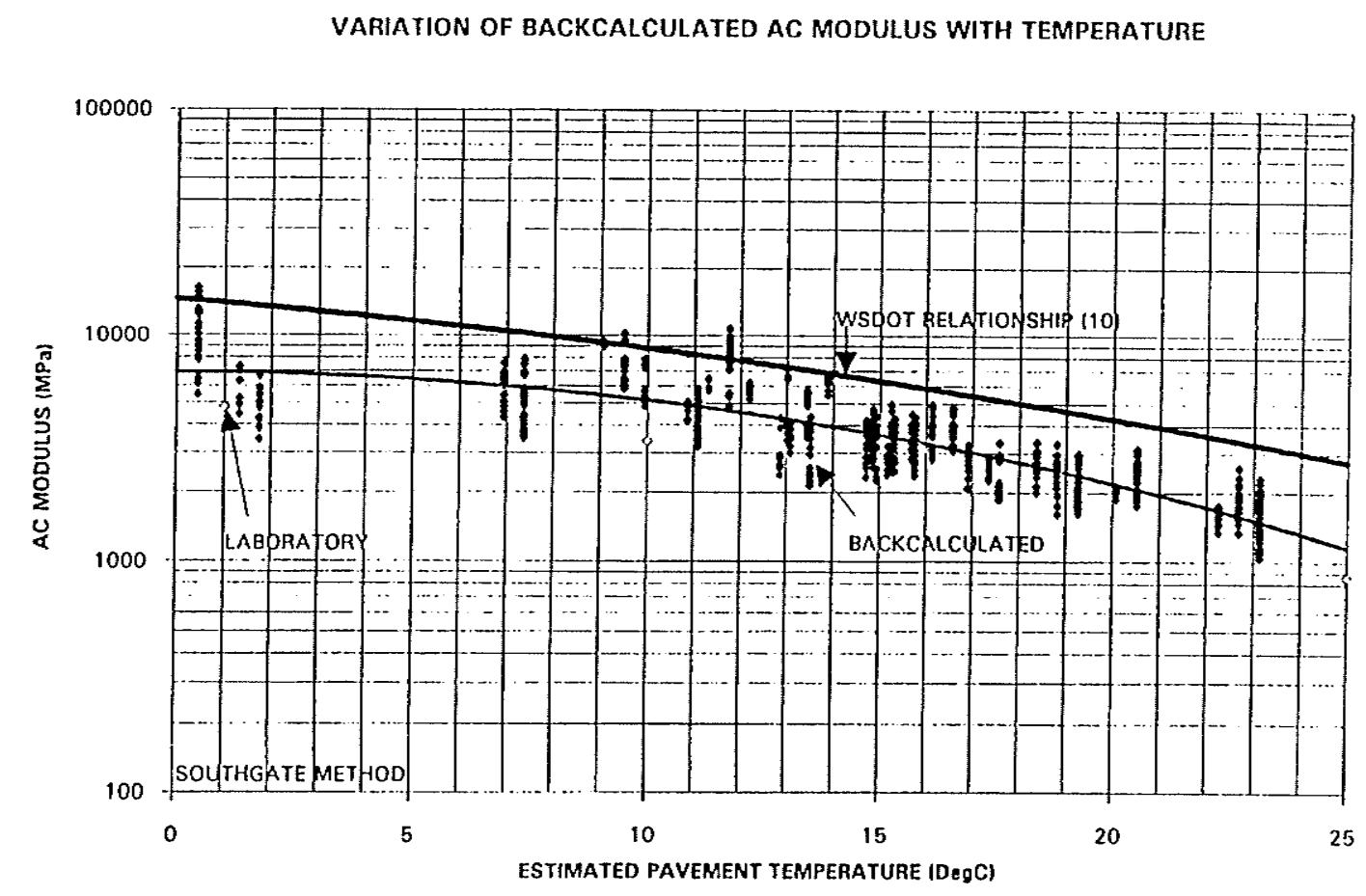

Figure 1.4 AC Moduli versus Pavement Temperature Relationship

The Van Deusen study reached the following conclusions:

- accumulated degree-days of thawing coupled with soil resistivity probe measurements can detect timing of thawing occurring in the soil layers;

- meaningful backcalculation of moduli during frozen conditions is difficult;

- subgrade moduli increased slightly during the recovery period following spring thaw; and

- all four of the test sections were designed in the same manner, ie. using the granular equivalency method, yet the full-depth asphalt concrete test section was observed to be stronger than the rest.

Pavement response to seasonal variation was also studied by Zhou and Elkins, (1994). This 
study was a summary evaluation of data collected in a pilot study of the SHRP LTPP Seasonal Monitoring Program conducted on a site near Billings, Montana. The summary includes data on the backcalculation of the layer moduli from the FWD deflection data, analyses of the temperature monitoring data, contact resistance measurement data, and the Time Domain Reflectometer (TDR) data. The pavement structure on this site consists of 75 $\mathrm{mm}$ of asphalt concrete over $480 \mathrm{~mm}$ of granular base on a sandy clay to silty sand subgrade. The thermistor probe (soil temperature), TDR probe (soil moisture), and resistivity probe (soil electrical resistivity and resistance) were installed in the outer wheelpath of the lane monitored. An observation well was installed approximately $30 \mathrm{~m}$ from the instrumentation hole.

The thermistor probe used was composed of a $300 \mathrm{~mm}$ long metal rod connected to a string of 15 thermistors encased in a clear plastic rod approximately $2 \mathrm{~m}$ long manufactured by Measurement Research Corporation. The metal rod has three thermistors used to measure the temperature of the asphalt concrete layer at the near-surface, mid-depth and near-bottom of the asphalt concrete layer. TDR sensors were used to estimate the soil moisture contents at $229,381,508,686,838,991,1143,1280,1448$, and $1600 \mathrm{~mm}$. A CRREL electrical resistivity probe was used to determine frozen layer extents.

Collection of deflection data, subsurface temperatures, electrical contact resistance data, and TDR data was performed on a monthly basis from August, 1992 through May, 1993. Extra testing occurred during the months of March and April, 1993 in order to collect more data during the critical spring thaw period. Deflection data was collected through the use of the FWD using four load levels from approximately 26 to $70 \mathrm{kN}$. The FWD deflection sensors were set at $0,203,305,457,610,914$, and $1525 \mathrm{~mm}$ offsets from the centre of the load plate.

The Zhou study reached the following conclusions: 
- deflections from the 0 and $203 \mathrm{~mm}$ offset sensors varied due to temperature change more than the other sensors;

- deflections were higher in the summer months than in the winter;

- the shape of the deflection basin had greater curvature in the summer months than in the winter months when the basin was quite flat; and

- the March 12, 1993 data appear to show the pavement structure was undergoing thawing since the relatively small change in temperature from near-freezing to above-freezing caused a considerable change in the defection response up to the outer most sensor.

The deflection data was run through two backcalculation programs, MODULUS and BOUSDEF. The pavement structure was modelled as a three layer system. The AC layer modulus values were not fixed nor were the default temperature - AC layer modulus relationships used in either of the backcalculation programs. The backcalculated AC moduli were observed to range from relatively low values in the summer months to high values in the winter months. Zhou and Elkins, (1994) noted that the AC moduli values from February,

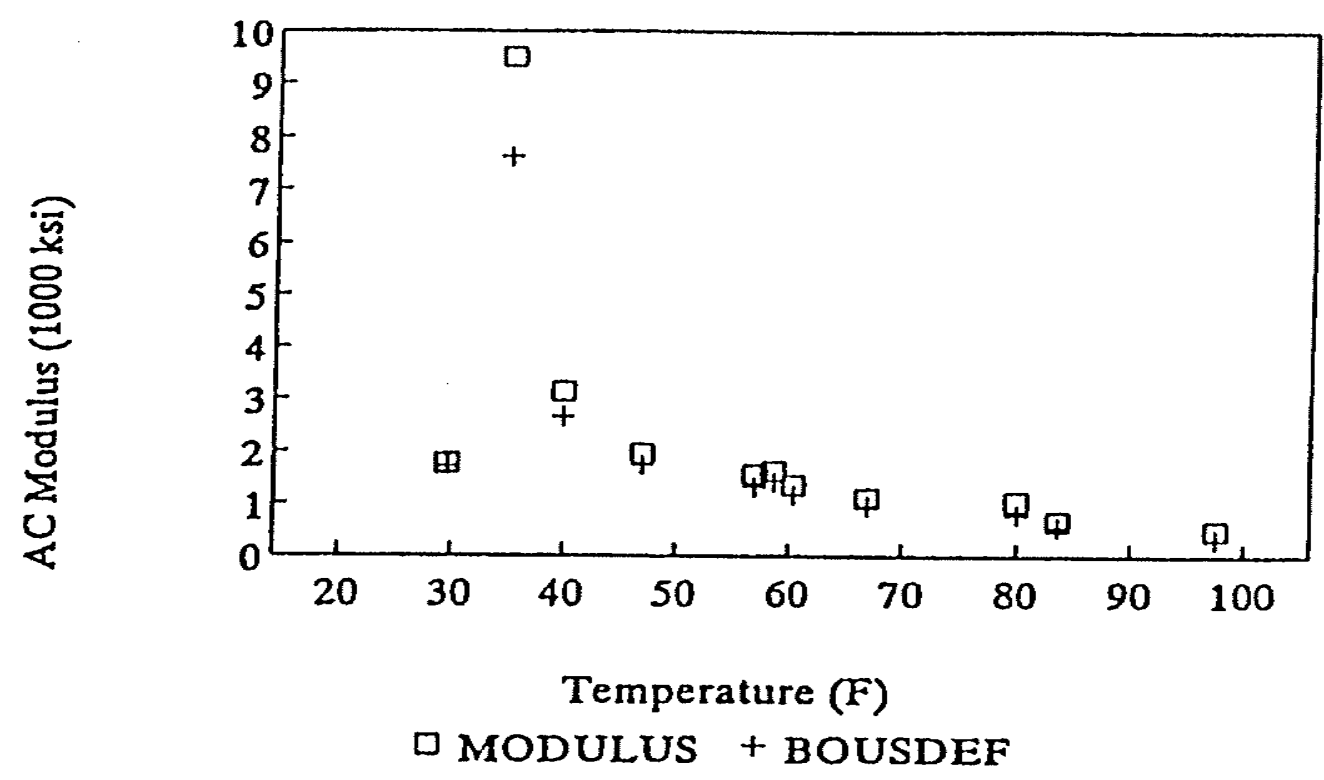

Figure 1.5 AC Moduli by MODULUS and BOUSDEF programs vs Temperature 
1993 test date appear lower than the expected trend, and suggest that this low value may be due to an ill conditioned matrix which was solved for within the backcalculation program. The ill conditioned matrix was caused by the thin layer, high base and subgrade layer moduli, and by not modelling the top of the frozen subgrade layer as a separate layer. The base and subgrade layer moduli increased dramatically during the winter months when the electrical resistivity measurements indicated that freezing had occurred in the layers. Figure 1.5 shows the average backcalculated AC layer moduli values versus the average temperature of the AC layer over the monitoring period of August, 1992, through May, 1993. Zhou and Elkins, (1994) noted that the moduli of the base and subgrade layers remained nearly unchanged as observed during the backcalculation analysis. Although MODULUS and BOUSDEF backcalculation programs use very different algorithms to backcalculate the modulus values, their output were similar.

Temperature analysis indicated daily variation in the upper $510 \mathrm{~mm}$ of the pavement structure experienced a daily variation in temperatures, while the seasonal variation of temperature occurred at greater depths. Freezing temperatures were observed to a depth of 1,270 $\mathrm{mm}$ in February, 1993. Electrical resistance data was collected using a Simpson Model 420 D function generator and two Beckman HD-110 digital multimeters. One multimeter measured the voltage while the other measured the electric current. The authors noted that since the electrical contact resistance is sensitive to changes in moisture content or frost penetration, either could be responsible for changes in electrical resistance.

The Zhou study reached the following conclusions:

- pavement layer moduli vary with the season due to temperature and frozen layer effects;

- $\mathrm{AC}$ layer moduli varied with the $\mathrm{AC}$ layer temperature even during the day, while the base and subgrade layers did not;

- base and subgrade layer moduli increased substantially when frozen;

- although two different programs were used for backcalculation, results were very 
comparable and appeared reasonable;

- most temperature variations occurred in the upper $510 \mathrm{~mm}$ of the pavement structure;

- electrical resistance readings seem to be a good indicator of frozen layer extents;

- changes in moisture contents readings from the TDR were as expected from the seasonal effects and those expected from the formation of frozen layers as determined from electrical resistance and temperature readings.

The methodologies and conclusions from these four studies were used as a basis for the present study to analyse the seasonal variation of material properties in a flexible pavement structure in Manitoba. The following is a description of the scope and objectives of the present study.

\subsection{Scope and Objectives of the Present Study}

In a severe freeze/thaw environment such as Manitoba, Canada, the load-carrying capacity of flexible pavements during the critically weak spring thawing period has to date never been fully examined. Pavement Design Engineers in Manitoba have traditionally relied upon empirical relationships that have been developed between the deflection (rebound) of a flexible pavement measured by the Benkelman Beam Rebound test and a maximum allowable deflection. Irwin, (1994) suggested a more mechanistically-based examination of the seasonal variation in the material properties of flexible pavements is desirable to allow for greater flexibility in the modelling capabilities.

The present study seeks to quantify the relationship between environmental factors and flexible pavement material properties of one pavement section on PTH No. 1 located near the town of Oak Lake in southwestern Manitoba. The approach taken to develop these relational models was to use environmental and FWD deflection data collected under the 
SMP at the Oak Lake test site.

Seasonal environmental and deflection data was collected over the years of 1994 and 1995 in Manitoba. This effort was enabled through the data collection provided by the U.S.A. Federal Highway Administration (FHWA) Long Term Pavement Performance (LTPP) program. The LTPP in cooperation with the Manitoba Department of Highways and Transportation installed a Seasonal Monitoring Program (SMP) test site near the town of Oak Lake on Provincial Trunk Highway (PTH) \# 1 in Southwestern Manitoba. The data which was collected over 16 months and two freeze/thaw cycles is used in the present study to model the seasonal variation in the material properties of the pavement layers. The pavement layer structure at the Oak Lake test site is composed of:

- $111 \mathrm{~mm}$ of asphalt concrete;

$-478 \mathrm{~mm}$ of unbound granular material; and

-> $6000 \mathrm{~mm}$ of silty sand to sand subgrade material (no rigid layer within $6000 \mathrm{~mm}$ ).

Although the granular base layer is actually composed of two different classes of granular material, it was combined into a single layer for this analysis. The extent of the subgrade soil is far deeper than the $6 \mathrm{~m}$ indicated, however it was determined that including any more of the depth would have no significant effect on this analysis. The data which was collected on this SMP site by Braun Intertec Corporation (LTPP Regional Contractor) staff included:

- air temperature;

- rainfall;

- asphalt and unbound layer temperatures;

- unbound layer volumetric moisture contents and electrical resistance readings; and - FWD deflection measurements.

Figure 1.6 shows the typical instrumentation layout for a LTPP SMP site installation. The 


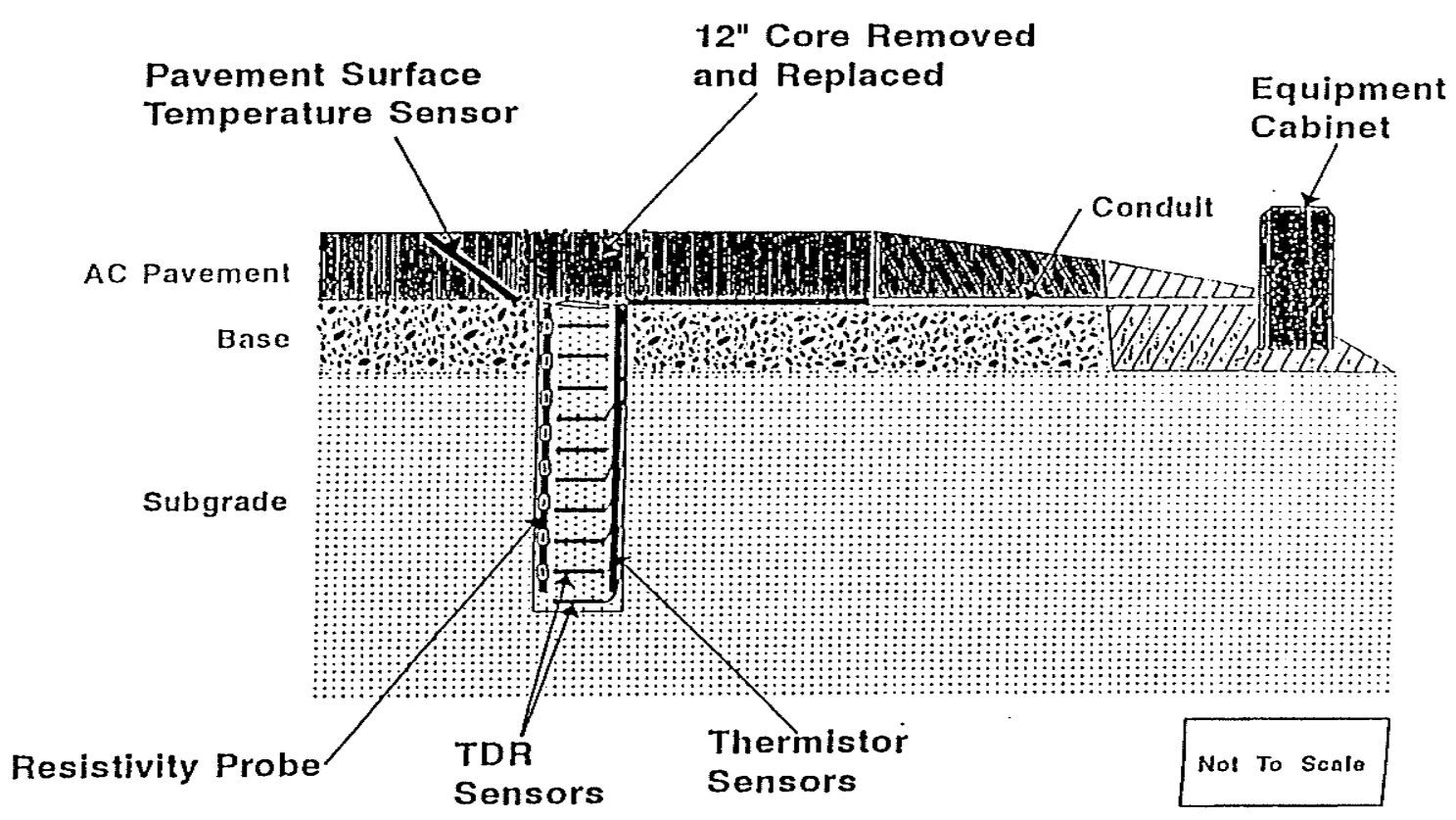

Figure 1.6 Typical Layout of SMP Site Instrumentation

air temperature, rainfall, and layer temperature data were collected and stored by an onsite datalogger which was uploaded during each monthly and bi-weekly visit to the site by the Braun Intertec staff. The TDR and electrical resistance readings from the unbound layers were collected using a mobile datalogger during each site visit. In addition, electrical resistance readings were also collected by manual methods. Multiple FWD readings were taken during each site visit.

Data analysis began with compiling the raw data files into spreadsheet files. This process involved importing the comma delimited ASCII text files into spreadsheet files. Graphs and tables were then produced within these spreadsheets to serve the analysis procedure. The soil temperature, moisture content, and electrical resistance data was evaluated in order to determine the extent of frozen layers present at the time of FWD testing. These frozen layers had much higher upper bounds on the resilient modulus assigned to them than those in an unfrozen state. Deflection data analysis used a three layer model during periods when the base and subgrade layers were completely thawed or frozen. A fourth layer was added 
whenever there was partial freezing of either the granular base or subgrade soil layers.

The FWD testing was done on both the outer wheelpath and the mid-lane locations within the travelling or outside lane at this location. Both of these sets of data were analysed in order to determine which location would be used for the modelling. The outer wheelpath deflection readings were used as the location matched that of the deflection testing by Benkelman Beam Rebound. Between one and four sets of FWD deflection readings were gathered during each site visit. EVERCALC was used to calculate the elastic moduli of each of the three or four pavement layers existing at this site. A model for each layer was then developed between the elastic moduli and the mid-depth asphalt layer temperature (in the case of the $\mathrm{AC}$ layer) and the Thawing Indices (in degree*days) for the granular base and the subgrade layers.

The scope of this study depends solely upon these data types collected by the LTPP - SMP. Each of the data types, collection methods, and other relevant details for the data used in this study are described in Chapter 2. There are a number of assumptions which had to be evaluated before proceeding with the analysis. Each of these assumptions is dealt with in detail in Chapter 3. Chapter 4 discusses the results of seasonal variation data analysis which is undertaken in the present study. Observed trends in each of the data types are discussed. These trends are used to identify and develop the environmental factors can be related to the seasonal variation of the pavement layer moduli. Chapter 5 contains the seasonal variation modelling results for each of the layers under consideration. Several different data model types are used to explain the relationship of the pavement layer moduli to the environmental factors. Chapter 6 contains the concluding remarks and recommendations for further study. 


\section{2 : Data Collection}

The data used in this study was collected under the authority of the LTPP Seasonal Monitoring Program. Details on each of the data collection and monitoring procedures are contained in Rada et al, (1994). Figures used to describe the monitoring equipment are taken from this source. This Chapter summarizes the relevant data details required for the present study from the above reference.

\section{1 Air Temperature and Rainfall}

Air temperature data was collected with a Campbell Scientific Model \# 107 temperature sensor and radiation shield. The temperature sensor has a range of -35 to $50^{\circ} \mathrm{C}$. A Texas Electronics Model \# TE525MM tipping-bucket rain gauge measures rainfall in $0.1 \mathrm{~mm}$ increments. As the rainfall collected reaches a calibrated level, the bucket tips and actuates a switch and the number of switch-pulses are recorded by the onsite datalogger.

\subsection{Moísture Content}

Granular base and subgrade soil moisture contents were determined through the use of Time Domain Reflectometer (TDR) probes. The TDR system is similar to a radar system as it transmits an electromagnetic waveform and records the reflected waveform to determine the distance and characterize the nature of the material which reflects the waves. The velocity of the waveform is influenced by the dielectric constant of the material surrounding the conductors. The ratio of dielectric permittivity of a material to the permittivity of a vacuum is the dielectric constant. Changes in dielectric constant of the surrounding material is determined from TDR data. The dielectric constant of a soil is mostly a function of its moisture content which ordinarily ranges from 3 to 5 for dry soil, depending on the soil type and density. Since water has a dielectric constant of approximately 80 , it is the primary determinant of the dielectric constant for the material (soil, water, air) surrounding the probes of the TDR conducting surfaces. The instrument is shown in Figure 2.1. 


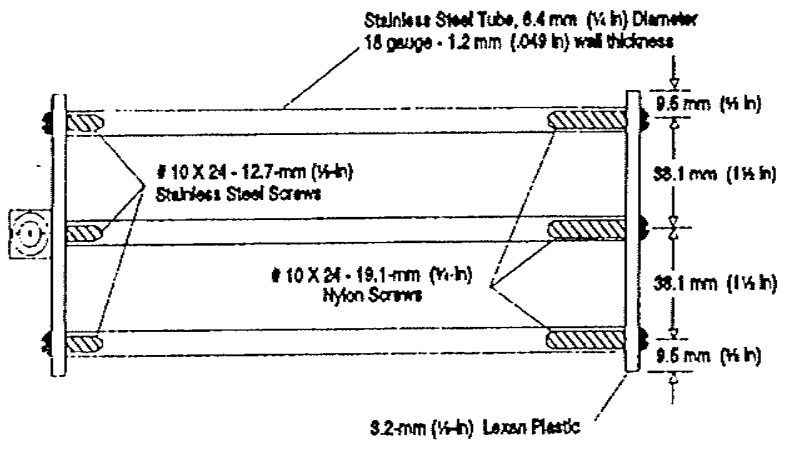

Top View

\section{FHWA Moisture Probe}

Specifications for the FHWA Moisture Probe:

The center rod of the FHWA probe is connected to the signal lead of the coax cable. The other rods are connected to the shield of the coax cable. The probe connect directly to a 50 ohm FG58 coax cable. The end view shows the drcuit board used to connect the $0.2 \mathrm{~m}$ (8-in) stainless steel rods to the coax cablo.
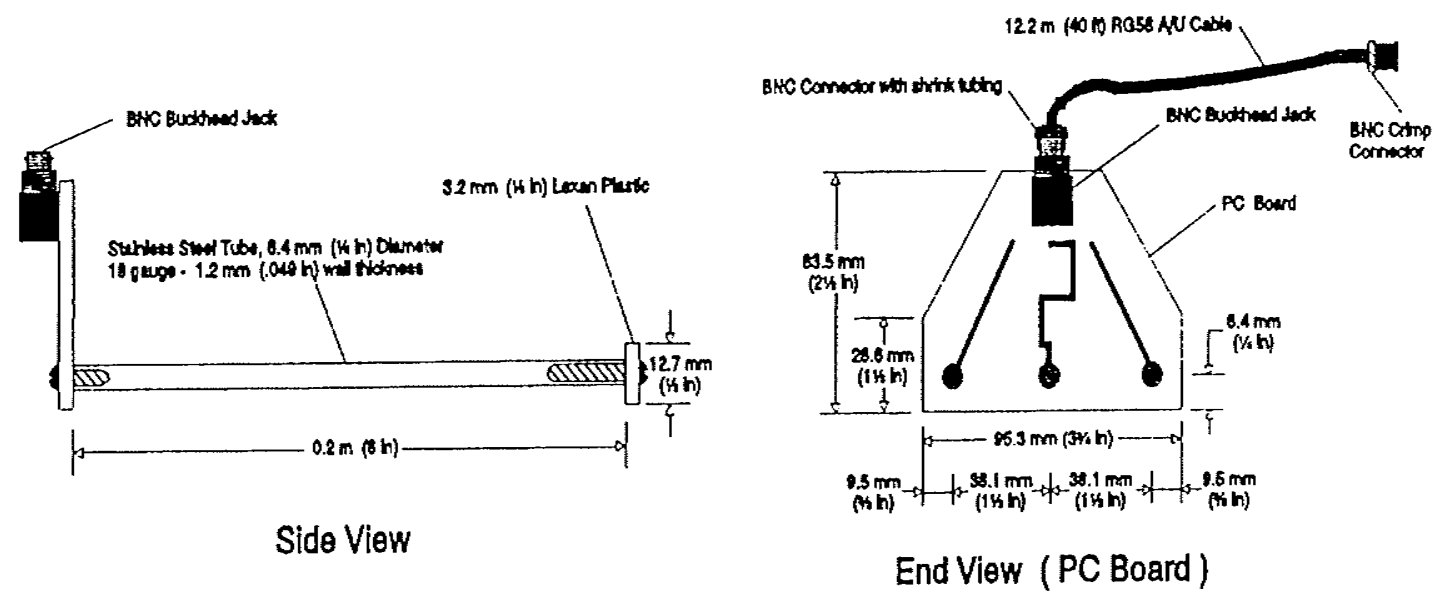

Note: 1 in $=25.4 \mathrm{~mm}$

HOT TO SCHE

Figure 2.1 FHWA Moisture Probe

The volumetric moisture content of the material surrounding the TDR probe is estimated from the measured dielectric constant through the use of Topp's equation in the present study:

$$
\theta=\left(-0.053+0.0293 \epsilon-0.00055 \epsilon^{2}+0.0000043 \epsilon^{3}\right) * 100
$$

where

$$
\begin{gathered}
\theta=\text { volumetric moisture content } \\
\epsilon=\text { dielectric constant }
\end{gathered}
$$

Although the volumetric 
moisture content is estimated for the SMP, the gravimetric moisture content is typically used in pavement engineering. The volumetric value may be converted to the gravimetric value when the dry density of the soil is known. An accurate estimate of the in-situ dry density of the material surrounding the TDR probes was made during the instrumentation installation.

At the Oak Lake test site the TDR probes were installed at approximate depths of 200,340 , $500,650,810,960,1110,1250,1550$, and $1850 \mathrm{~mm}$. Braun Intertec staff suggested exploring the possibility of using TDR data in frost extent analysis. This suggestion was followed and the TDR data used for this purpose during the present study.

\subsection{Pavement Layer Temperatures}

Pavement layer temperatures were measured by the Measurement Research Corporation model \# TP101 thermistor probe as shown in Figure 2.2. The thermistor probe is composed of thermally sensitive semiconductor material which has a large temperature coefficient of resistance.

The probe uses three thermistors installed within the surface layer, 15 thermistors spaced at 76 to $150 \mathrm{~mm}$ intervals beginning approximately $100 \mathrm{~mm}$ below the surface layer to a depth of approximately $2 \mathrm{~m}$. The soil around the thermistor was compacted so the temperature of the soil would be completely transferred to the thermistor. 


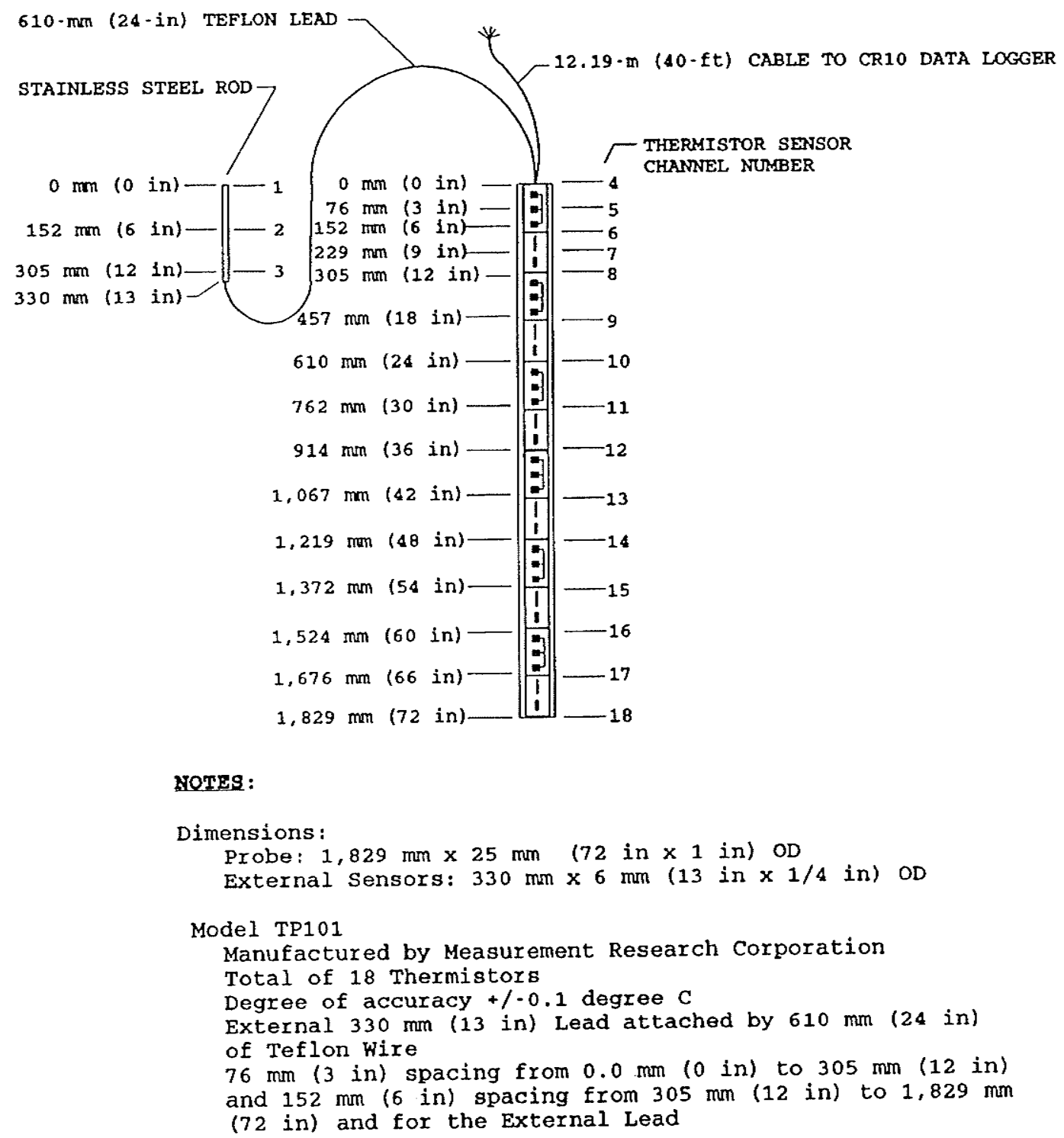

Figure 2.2 MRC Model \# TP101 Thermistor Probe 


\subsection{Frost/Thaw Determination}

Electrical resistance and TDR measurements were used to determine the extent of frozen soil layers. The traditional use of temperatures for the SMP to determine the extent of soil in a frozen state was rejected as unreliable since the salinity of the soil can actually depress the freezing point of water. As well, it was found that during the thaw period, an isothermal temperature can exist to the maximum frost depth.

The theory of electrical resistivity for frost extent determination is based on the fact that electrical resistivity of most soils is very high and virtually all electrical current flows via free ions in the pore water. Thus the electrical resistivity of a soil is primarily a function of its porosity, degree of pore water saturation, and electrical resistivity of the pore water itself. As the electrical resistivity of ice is many magnitudes greater than that of water, the formation of ice in pore water causes a net decrease in the effective porosity and a corresponding increase in the apparent or bulk electrical resistivity. Therefore, changes in moisture content may also be indicated by electrical resistivity measurements.

Distinctions must be drawn between electrical resistivity and electrical resistance in order to understand the use of this data. Electrical resistivity is a material property while electrical resistance is a function of the electrical resistivity of the material, the geometry of the body, and quality of the physical contact between the electrodes and the material. Electrical resistivity can be some function of the soil properties while the electrical resistance can only indicate these properties. 


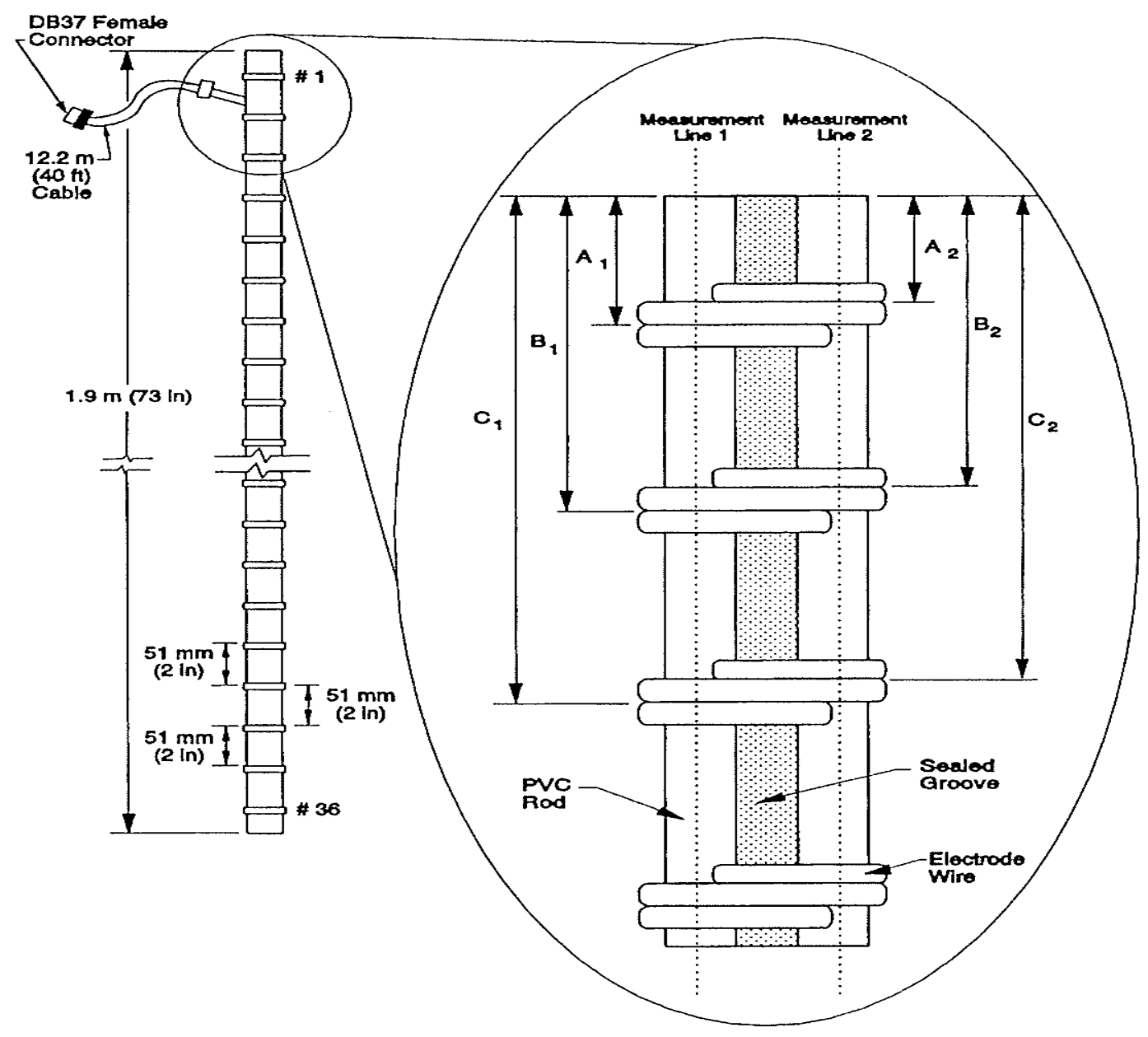

Figure 2.3 CRREL Resistivity Probe

To measure either the electrical resistivity or resistance for the SMP, a low frequency alternating current is imparted to the soil thereby minimizing the polarizing effect on ions in the pore water. The use of $100 \mathrm{~Hz}$ low frequency avoids effects of inductive and alternating current coupling effects, allowing use of direct current resistance and resistivity equations with no loss of accuracy. Electrical resistivity measurements are made using a group of four adjacent electrodes and inputting a current to the two outer electrodes and measuring the resulting current drop across the inner pair of electrodes. Polarization reactions which occur at the current electrodes on voltage measurements are thereby eliminated. The calculated resistivity are then plotted against the mid-depth of the group of 
electrodes and are compared to baseline unfrozen resistivity measurements in the same manner as the resistance values.

The electrical resistivity probe used in the SMP has 36 electrodes spaced at approximately $50 \mathrm{~mm}$ intervals on a PVC pipe $1.9 \mathrm{~m}$ in length. The probes were developed by CRREL and built by $\mathrm{ABF}$ Manufacturing as shown in Figure 2.3 .

Contact resistance is calculated using the electrical current transmitted through adjacent pairs of electrodes and the measured voltage drop across the electrodes. This process is repeated sequentially for each pair down the length of the probe. The contact resistance calculated for each pair is plotted versus the depth, and frost extents are identified by comparing the unfrozen baseline values with the values being evaluated for each pair of electrodes. These

frozen layers are identified by relatively large increases in resistance. As previously mentioned, the temperature and TDR readings were used to aid in the determination of the frozen layer extent.

\subsection{Deflection Data}

The FWD is currently the most widely accepted non-destructive testing equipment used in pavement analysis. The FWD is a trailer mounted load-imparting and response-measuring device which simulates the dynamic loading an in-service pavement experiences. The FWD is capable of imparting loads of between 6 and $107 \mathrm{kN}$ to the surface of the pavement and measures the deflection basin at seven points radially from 0 to $2500 \mathrm{~mm}$ offset from the centre of the load plate. The deflection points are measured by sensors which are lowered onto the pavement surface before the load is applied. 


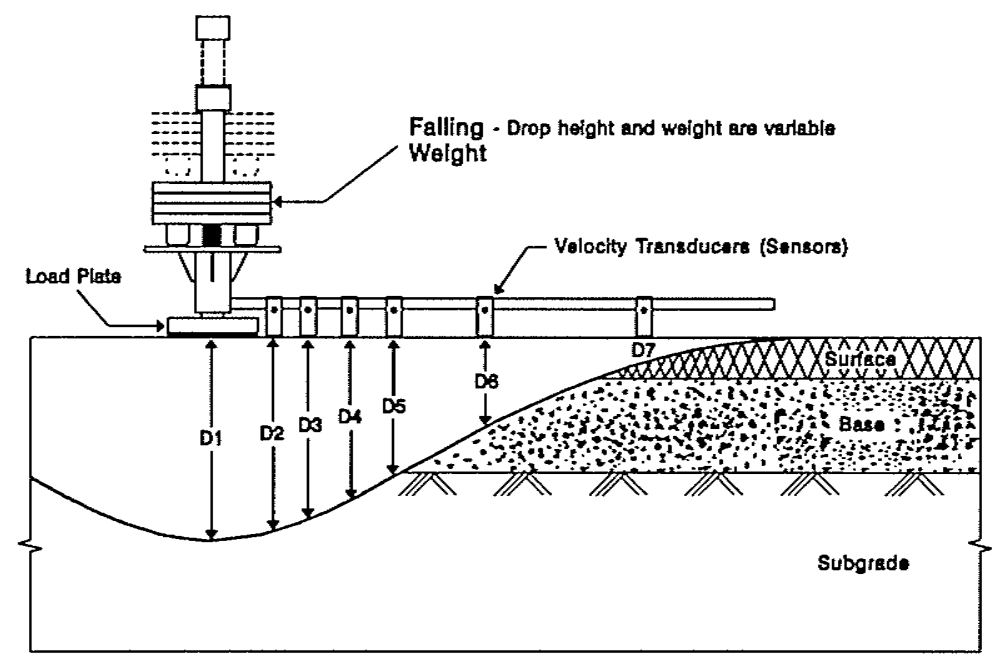

Figure 2.4 Schematic Diagram of FWD Deflection Test

All of the FWD data collected under the SMP at the Oak Lake test site was generated by the DYNATEST Model 8000 FWDs primarily using the testing protocols detailed in PCS Law et al, (1993). Deviations from this protocol include the number of test points, number of test cycles per day, and annual testing frequency detailed in Rada et al, (1994). To summarize the guidelines, this protocol for FWD testing requires that the LTPP Standard Drop Sequence be followed:

-four drops at four target load levels; $26.7,40.0,53.3,71.1 \mathrm{kN}$;

-both the outer wheelpath and middle of travelling lane tested;

-outer wheelpath test chainages $0-30,0-25,0-10$, then $0,0+25,0+50, \ldots, 2+00$; and

-FWD sensor configuration: $0,203,305,457,610,914$, and $1524 \mathrm{~mm}$ from load centre.

The FWD collects the magnitude of the load and deflection of each of the seven sensors every 0.2 milli-seconds over a 60 milli-second time period. The load application duration is typically about 30 milli-seconds which approximates the loading duration which a point 
in a pavement would experience from a truck tire in an in-situ application. The FWD software saves this data in two formats. The first is the peak load and sensor deflections with no temporal indication, while the second contains the load and deflection history over the complete 60 milli-second time period. These files are referred to as the peaks and history files respectively. 


\section{3: Assumptions in Backcalculation}

The pavement layer materials under consideration in the present study are complicated in their makeup of asphalt cement, granular particles, and soil. Modelling their structure for use in the calculation of the resilient moduli requires that assumptions which idealize the insitu materials. These idealized materials allow for the use of elastic theory in the backcalculation process to calculate the resilient moduli.

\section{1 Spatial Variation of Physical Properties}

Seemingly minor variations in pavement physical properties such as layer thickness, distress conditions such as cracking, soil types, or moisture contents create significant variability in FWD deflection readings obtained on any pavement section. Rada et al, (1994) recognizes this fact and requires a tolerance of $25 \mathrm{~mm}$ for the FWD placement to minimize variation. The pavement structure at the Oak Lake test site exhibited this spatial variability in FWD deflection profiles. A typical plot for one FWD testing pass on the outer wheelpath is shown in Figure 3.1. Research into the sensitivity that spatial variation of asphalt surface layer thickness alone has on the backcalculated asphalt layer moduli was conducted by Briggs, Scullion, and Maser, (1991). Their research was based on pavement layer thicknesses from four SHRP sites obtained from both the SHRP database and from Ground Penetrating Radar surveys. The results of their study indicated that variations in layer thicknesses were significant enough to cause up to $100 \%$ variation in the backcalculated modulus of the surface layer. The variation of the surface layer thickness resulted in variation of $80 \%$ in the base materials layer moduli backcalculations while not significantly affecting that of the subgrade. 


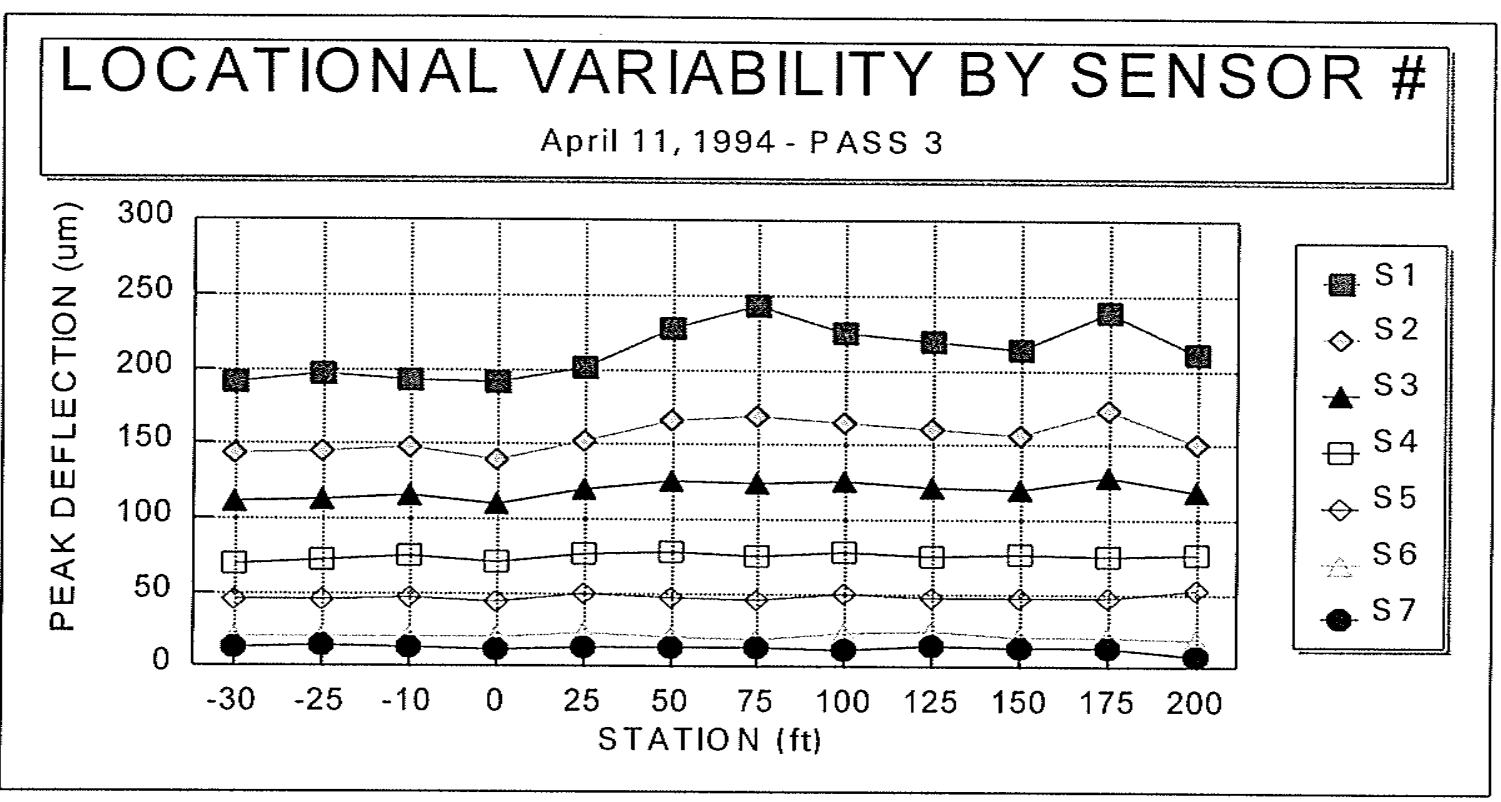

Figure 3.1 Variation of Sensor Deflections \#1 - \# 7 on One Test Pass

It is not within the scope of the present study to determine the causes of these spatial variabilities due to lack of any data which could identify the causes. The approach taken was to minimize the effect of these spatial physical variabilities by using the average value of each sensor deflection from each pass on every test date. A similar type of approach was used by Janoo and Berg, (1991) in their research into layer moduli calculation during freeze/ thaw periods.

\subsection{Idealizations Required in Backcalculation}

For the analysis method to be credible the assumptions upon which it is based must be proven to be correct. The backcalculation programs based on linear elastic material response depend upon a number of idealizations. These assumptions may lead to systematic errors if precautions are not taken to minimize their overall effect on a study. Sources of these systematic errors are:

- improper calibration of the equipment; 
- materials are continuous and infinite in the horizontal directions;

- linear stress-strain relationships and perfect bonding between layers;

- isotropic and homogeneous materials;

- AC layer has no damage, ie cracking, deformations, etc.;

- materials behave as a liquid (Winkler) or solid ;

- layers have constant thicknesses;

- location of frozen layers;

- depth to rigid layer;

- influence of pavement edge;

- static loading;

- frequency of loading rate;

- uniform pressure distribution under load plate;

- use of peak loads and deflections for analysis;

- uniform temperature gradients;

- uniform moisture content gradients; and

- expansion and contraction effects of pavement layers.

A major idealization results when the peak deflection measurements are used as input to the backcalculation programs. The peak load and peak sensor deflections are assumed to occur at the same time, a situation which never physically exists. Figure 3.2 shows a typical deflection history file from which the peak files would be built. 


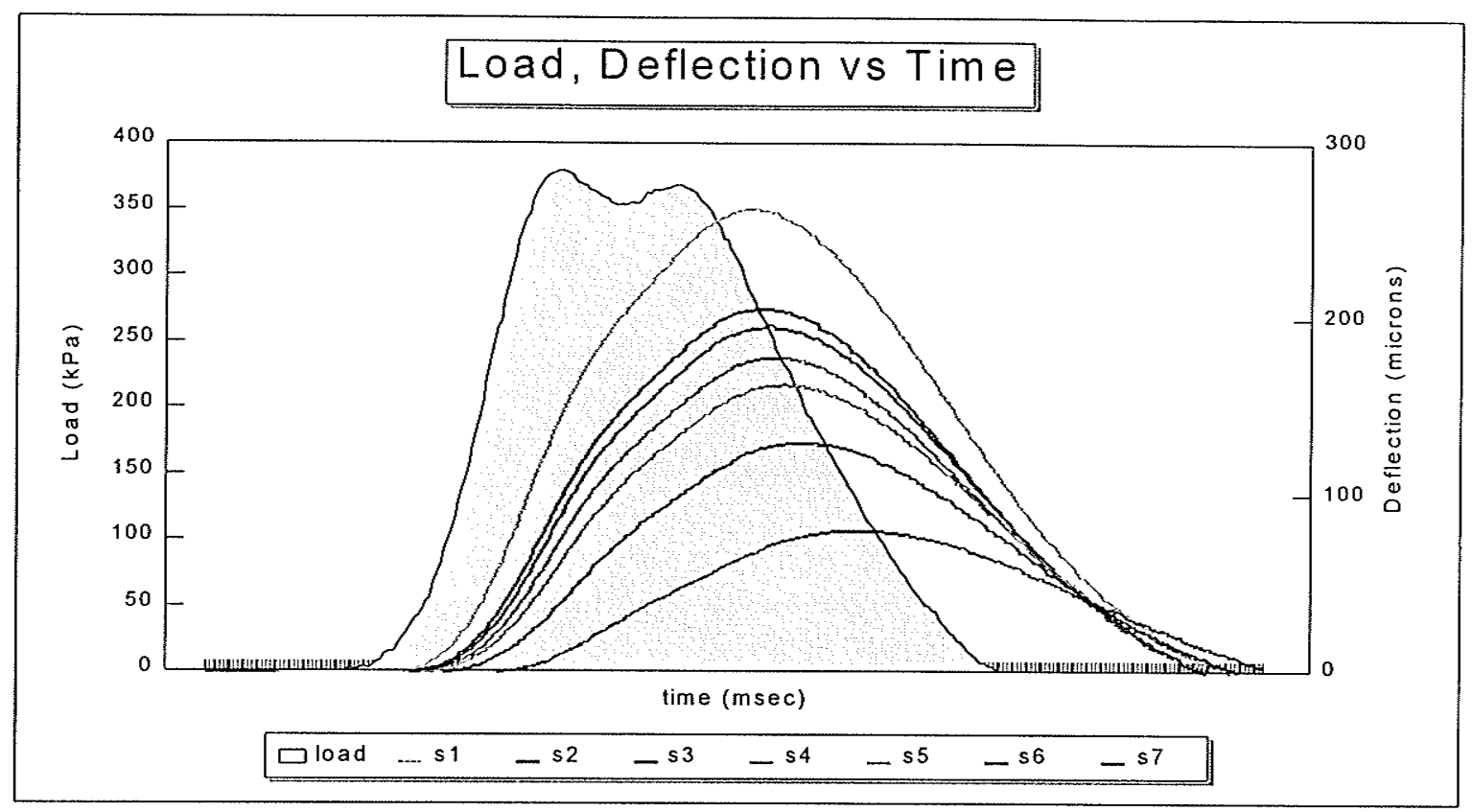

Figure 3.2 Typical Load/Sensor \# Deflection Curves from FWD Deflection Test

Even though certain of these assumptions are not representative of the in-situ real world case for pavement materials, all of the studies reviewed in the present study have accepted the idealizations and assumptions and have achieved reasonable results. The present study accepts the process of backcalculation as being a viable method for modelling the response of a linearly elastic pavement structure to load applications. It is beyond the scope of the present study to debate the validity of the theoretical assumptions used in the backcalculation process. Instead, the present study uses the backcalculation process to arrive at a set of pavement layer resilient moduli that will represent the load-carrying capacity of a pavement throughout the year. The degree of reasonableness of this process is then evaluated through the fit of the models of the backcalculated resilient moduli versus the environmental factors chosen.

The layered elastic backcalculation programs return one value of linear elastic modulus for each of the pavement layers. The non-bound layers (namely the granular base and subgrade soil) under consideration at the Oak Lake test site are known to exhibit non-linear stressstrain relationships similar to all other unbound materials. While a tangent or a secant 
modulus can be defined for non-linear materials, the value changes for each level of stress. Yet in the calculation of the elastic modulus of these layers a linear stress-strain relationship is used to characterize the layer material response. It seems a paradoxical approach when one considers that granular, unbound materials have no modulus possible unless they are confined by external stresses. The effect of this non-linearity is limited by the fact that the magnitude of the deflections and strains as measured by the FWD is so small.

Most backcalculation programs consider the materials to be isotropic to aid in the simplicity of the calculations. However, it is known that the method of distributing and compacting pavement layers creates differences in the material's vertical and horizontal stress states. A report by Yue and Svec, (1994) examined the effect of vertical non-homogeneity in calculating elastic layer moduli. The authors concluded that the conventional multilayer elastic model gave a good approximation of the vertical displacements in pavement. However the authors cautioned that the conventional multilayer elastic pavement model did not provide a good approximation of the critical strains in the elastic pavement layers of nonhomogeneous material properties.

The backcalculation method uses a revolved section as the 2-dimensional plane being analysed. This method uses the circular load plate and radial placement of the FWD's deflection sensors to create the symmetry required for the analysis to be properly applied. However, as the outer wheelpath of the travelling lane was chosen for the present study, the unrestrained pavement edge is within the revolved section limits. Thus a true revolved section is not really the actual case under investigation.

Hasim, Hameed, and Mustaffa, (1994) reported that the effect of edge restraint on most pavement structure deflections is significant. The deflections obtained may be higher and the backcalculated moduli lower for the outer wheelpath location than those obtained in the mid-lane location. The outer wheelpath location is selected due to the traditional practice 
of testing pavement deflections by the Benkelman Beam Rebound test, as well as being the location of the worst case of load support. Therefore this effect should be noted when considering the results of the present study. However this effect should not have a significant effect on the objective of quantifying the seasonal variation of material properties.

The assumption elastic layer models use that the materials under consideration are homogeneous is one that is not easily evaluated. Quantifying the effect of non-homogeneity in the vertical orientation only was mentioned previously. However, the overall effect of non-homogeneity would have to consider the particle distributions through laboratory tests at each test location. This data is not available through the SMP and its effect on the present study cannot be quantified. The presence of moisture in the soil creates a two-phase material whose material properties differ from the homogeneous and single phase material considered in the analysis. Again this effect is noted but is considered to be outside the scope of this study to quantify it. The majority of previous studies are based on a single phase material and as such the present study uses this same assumption.

For the scope of the present study only the FWD peak deflection files are analysed for input to the backcalculation program EVERCALC. When one plots the history files it becomes obvious that the load peak does not occur at the same time as any of the peak sensor deflections. Neither do the peak defections occur at the same time as one another. Therefore the load and deflection scenario which is analysed in the present study represents an artificial situation, a quasi-static simplification of the dynamic loading and deflection response which in fact never physically occurs. A justification for the static simplification is that a dynamic analysis would require intensive computational effort and additional parameters in the modelling. A full dynamic analysis would require parameters such as damping and viscoelastic material properties, material densities, and a more critical estimate of Poisson's Ratio.

McCullough and Taute, (1982) found that the assumption used in most layered theory 
modelling is that the subgrade layer is semi-infinite in thickness. Their study compared the results of deflection basins calculated for the same loads and pavement structures. The only factor varied was the thickness of the subgrade layer from $3 \mathrm{~m}$ to an arbitrary large value. The results showed that the effect of the subgrade thickness was significant over the range considered. However in the present study, the depth to the rigid bedrock layer is in the vicinity of $10 \mathrm{~m}$ or higher. The assumption of semi-infinite subgrade thickness used in the present study is therefore reasonable.

The backcalculation programs depend upon user inputs of data on the seed moduli, minimum and maximum moduli, and layer thicknesses. The redundancy of equations due to seven FWD deflection points and only three or four pavement moduli, allows the backcalculation program to minimize the error on several possible sets of layer moduli. Therefore some judgement is necessary to examine the values of moduli and determine the acceptability of the final results. Irwin, (1994) summarized the need for this expertise:

Thus there are no hard and fast rules as to acceptance of the moduli results from backcalculation. Each set of moduli must be examined on an individual basis to determine whether the testing conditions of the pavement structure agree with the results.

Many runs of the EVERCALC program are used in the present study to adjust the moduli ranges and seed values to arrive at a practical solution considering the ambient testing conditions. The assumptions and idealizations described in this chapter are used as the basis of the material characterisations used in the present study. The next chapter deals with the analysis of the seasonal variation data gathered in the present study. 


\section{4: Analysis of Seasonal Variation Data}

\section{1 Falling Weight Deflectometer}

The FWD data used in the present study was obtained from the peak files and not the entire load/deflection history files. The LTPP Standard Drop Sequence for the SMP is for two drops to occur at target load levels of $26.7,40.0,53.3$, and $71.1 \mathrm{kN}$ at each testing station. The first step in analysing this data was to import the text files into spreadsheets. The files had to be individually parsed to allow the data to be manipulated. The deflection data was collected in both metric and American units of which this analysis uses the metric data and

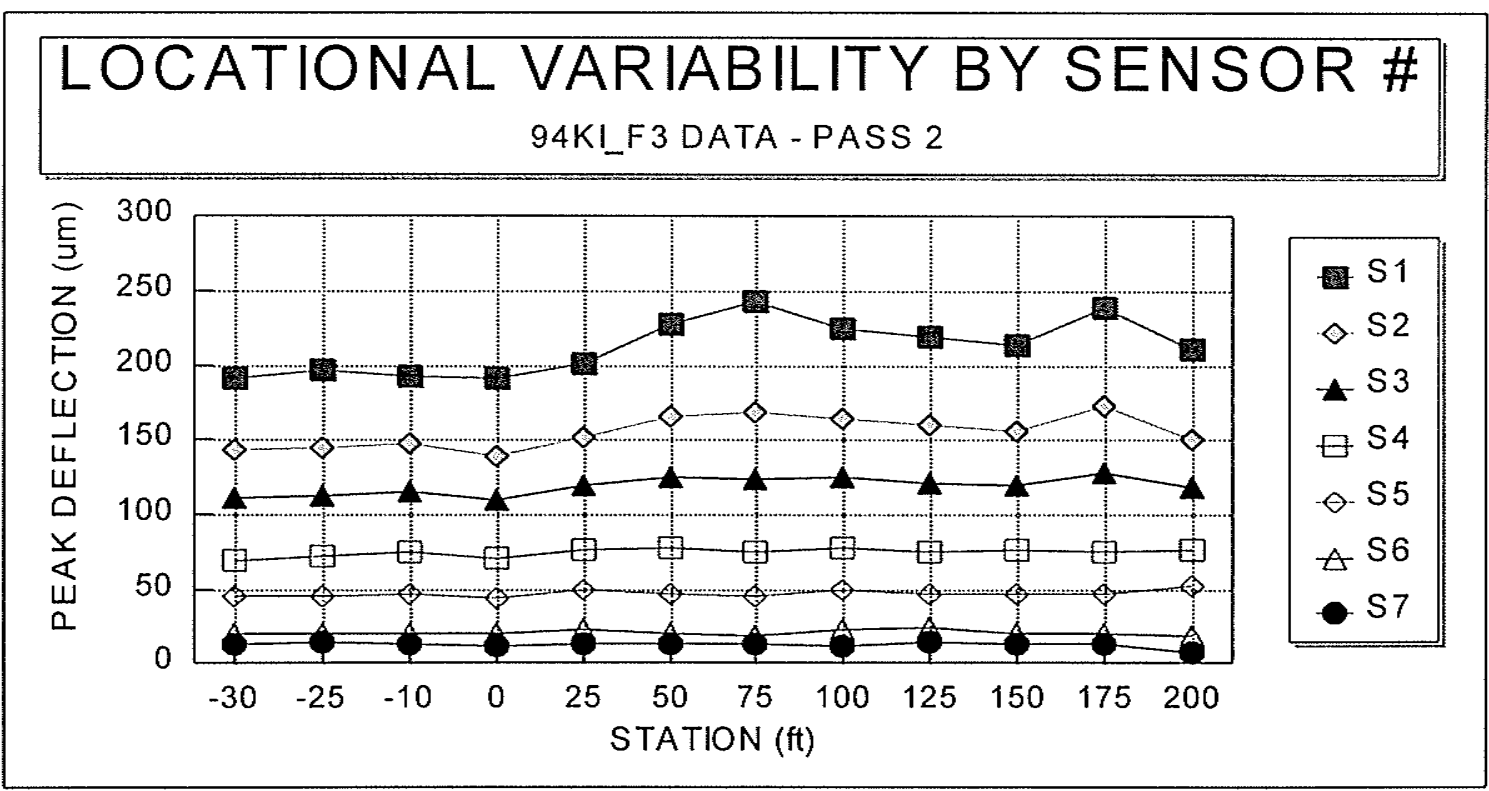

Figure 4.1 Outer Wheelpath FWD Deflection Test Pass Sept 21, 1994 
is included in Appendix A. The metric data had the second drop of each load level selected for use in normalizing the load to exactly $565 \mathrm{kPa}$ and the deflections to the corresponding normalized values. Eight regression analyses had to be run on the data from each testing

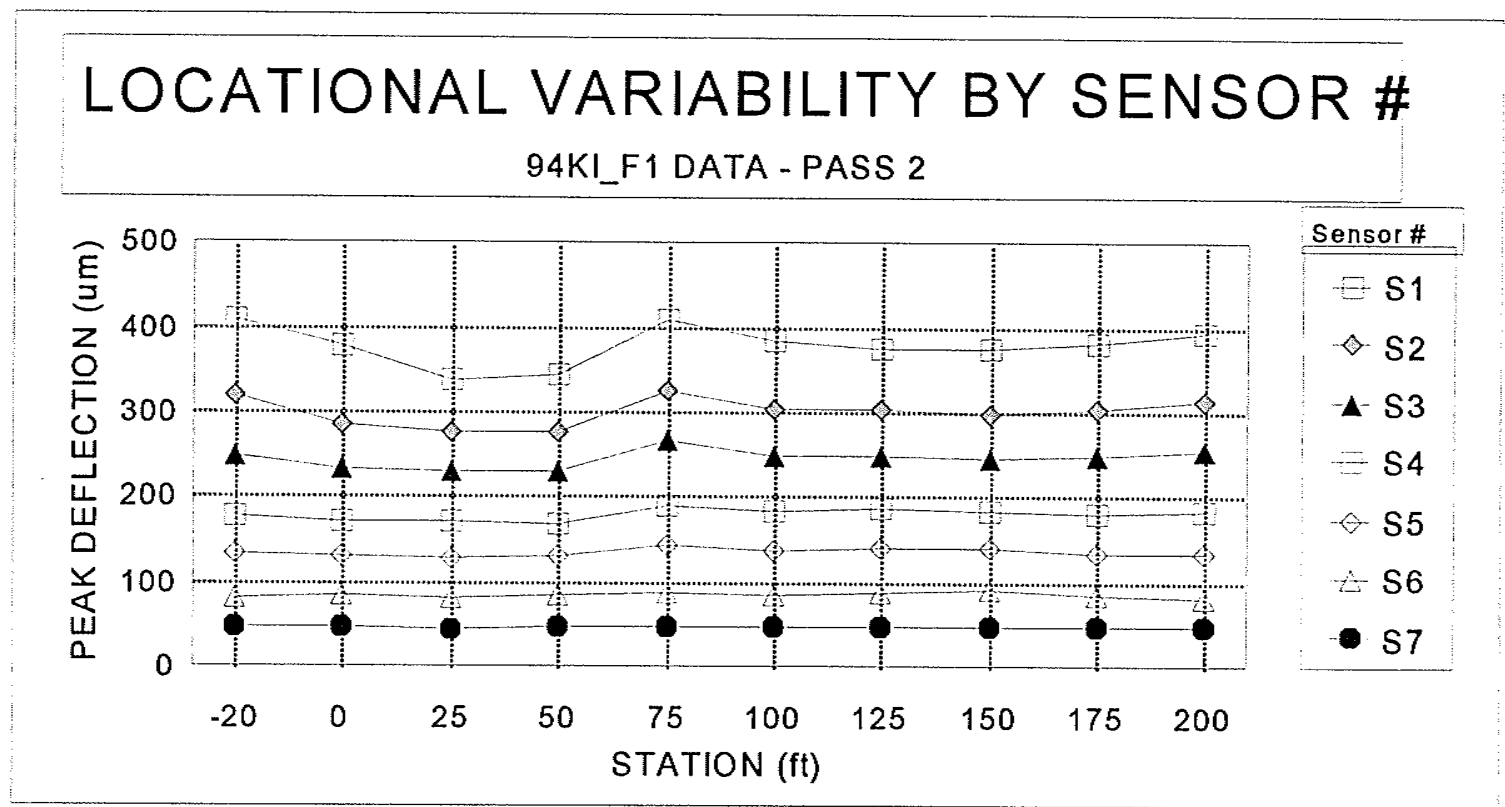

Figure 4.2 Mid-Lane FWD Deflection Test Pass Sept 21, 1994

station in order to arrive at the normalized load and deflection values. A total of 43 files were created in this manner to allow for detailed analysis. Each pass of FWD testing involved twelve station locations. There were between one and four test passes for each test date which occurred monthly and then bi-weekly during the spring thaw period. It was found that the FWD could not operate on the Oak Lake site during the month of January due to the extremely low temperatures encountered of -30 to $-40 \mathrm{C}$.

All of this data manipulation resulted in a set of deflections normalized to $565 \mathrm{kPa}$, and averaged for each test pass. This data was chosen to represent the overall response of the pavement structure to a $565 \mathrm{kPa}$ load at a particular temperature. The temperature for the test pass was assumed not to vary significantly during the test duration of approximately twenty minutes. The FWD peak files for both the mid-lane and outer wheelpath test pass locations 
were imported to determine whether there were any consistent trends. For example, if the outer wheelpath deflections were consistently higher then the trend should be noted in case it has any effect on the outcome of the analysis. No consistent trends were observed between the two test pass locations. Figures 4.1 and 4.2 show the deflections for the second pass on the same test date for the outer wheelpath and mid-lane pass locations. Comparison of these two figures shows that the magnitude of the deflections are quite similar but do not follow any trend throughout the test pass. As no clear trends were observed, the outer wheelpath test pass location data was chosen. This location corresponds to the worst case scenario for load support as well as being the similar location to the traditional Benkelman Beam Rebound test. The twelve station locations on the outer wheelpath were averaged to give one load-normalized deflection profile for each test pass.

The FWD deflection data was analysed to test for seasonal variation trends in the deflection before inputting it to the backcalculation program. The sensors at the 0,457 , and $1524 \mathrm{~mm}$ offsets from load plate centre were selected as the locations to represent the deflections

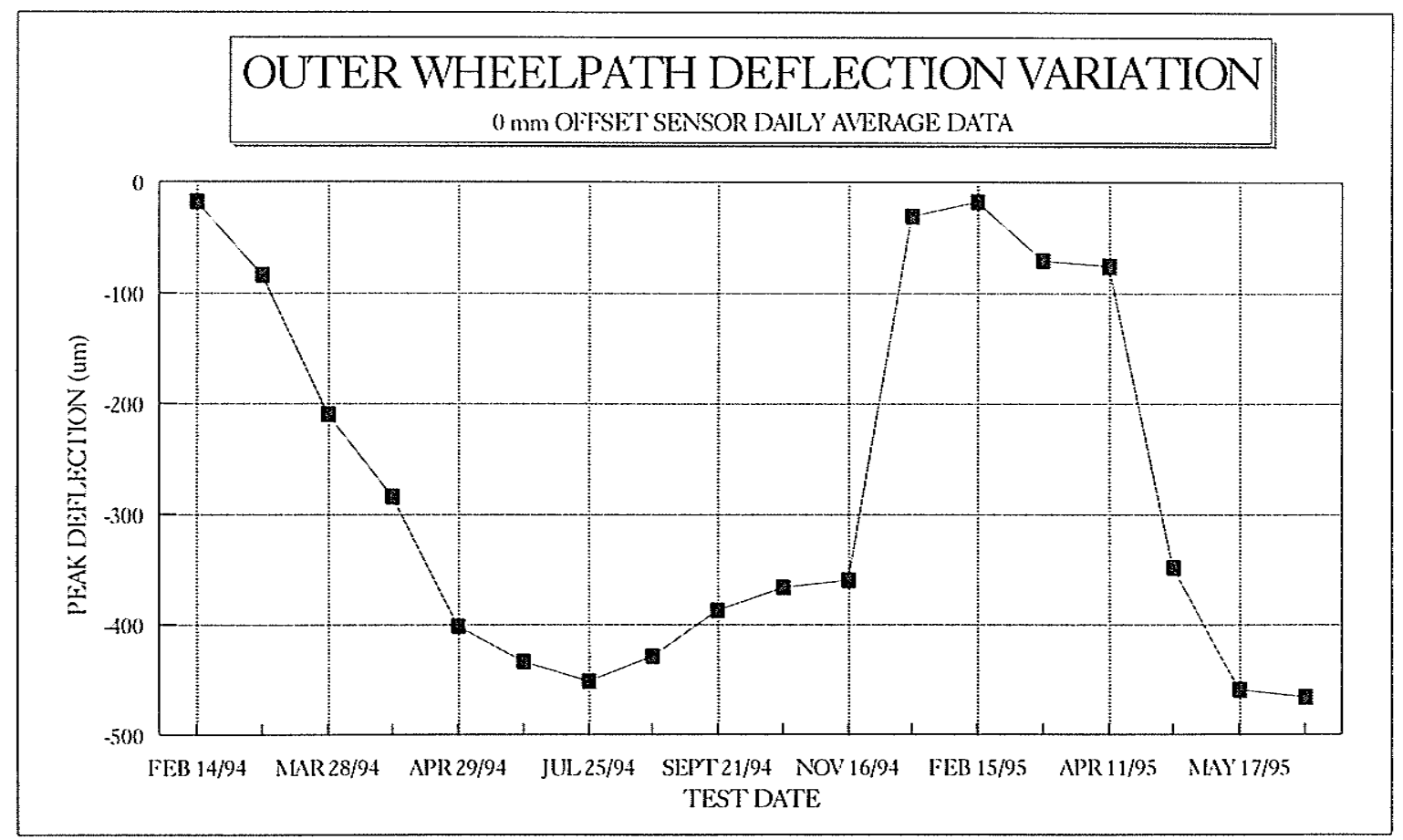

Figure 4.3 Seasonal Variation of Sensor \# 1 Deflection 
occurring. Graphs of the seasonal deflection variation of the 0,457 , and $1524 \mathrm{~mm}$ sensors are shown in Figures 4.3, 4.4, and 4.5, respectively.

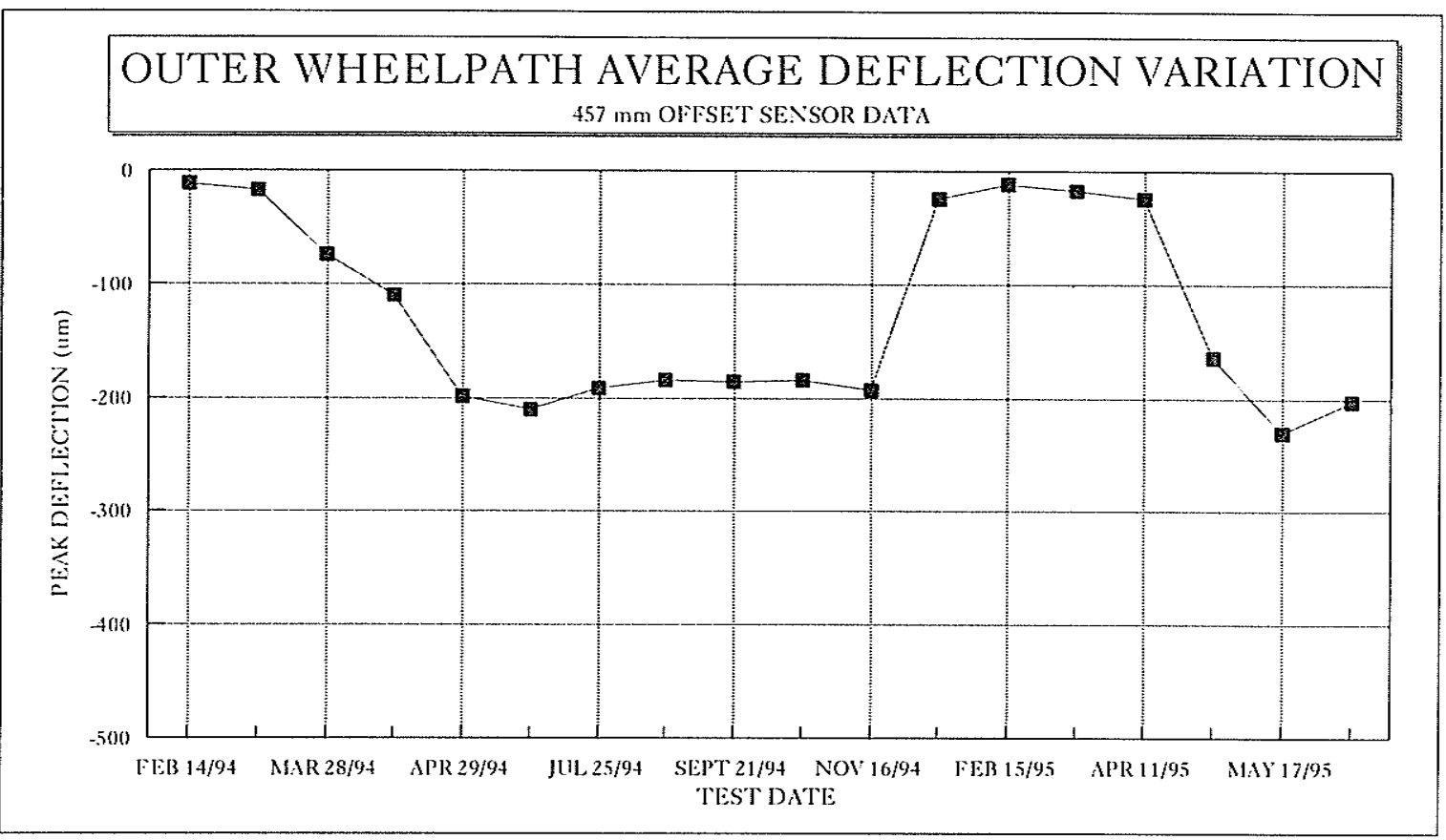

Figure 4.4 Seasonal Variation of Sensor \# 4 Deflection

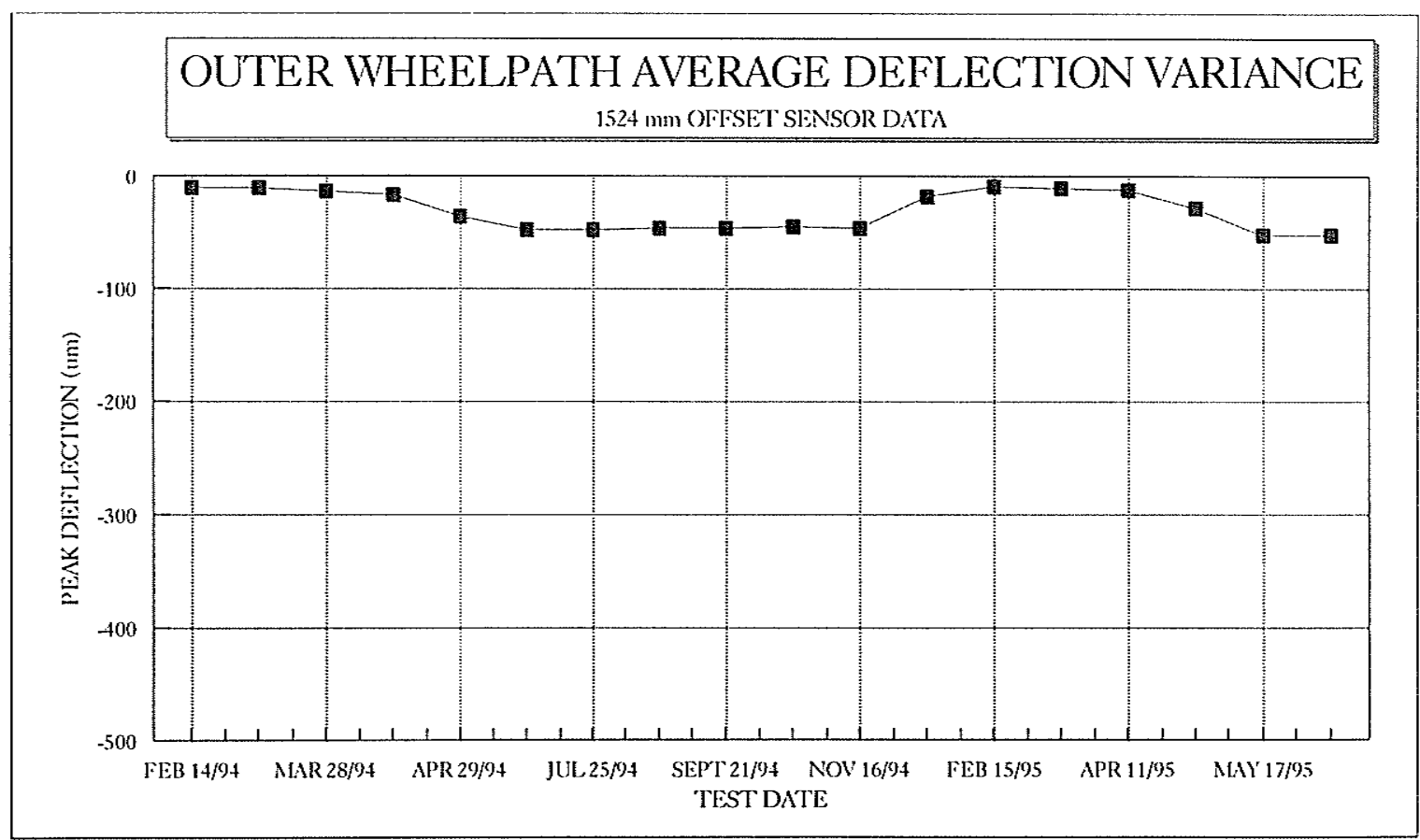

Figure 4.5 Seasonal Variation of Sensor \#7 Deflection 
As expected the $0 \mathrm{~mm}$ offset sensor experienced the largest deflection due to its location directly under the load plate. This sensor also showed the largest range of values for the seasonal variation. Figure 4.4 shows lesser values of deflections and seasonal variation than in Figure 4.3 as it deals with the $457 \mathrm{~mm}$ sensor. In Figure 4.5 the deflection levels are much less again which indicates a continuation of the trend towards deflections decreasing with distance from the load plate. The magnitude of the range of seasonal variation also decreases with distance from the centre of the load plate. The shape of the seasonal variation in deflection are similar which indicates that the layers all experience corresponding changes in deflection at nearly the same time.

The deflection data was next evaluated for changes within smaller time intervals to examine the stability of the data. Figure 4.6 shows the average daily deflection data for each test date during the spring thaw period of 1994 . The February 14 data shows little deflection at all

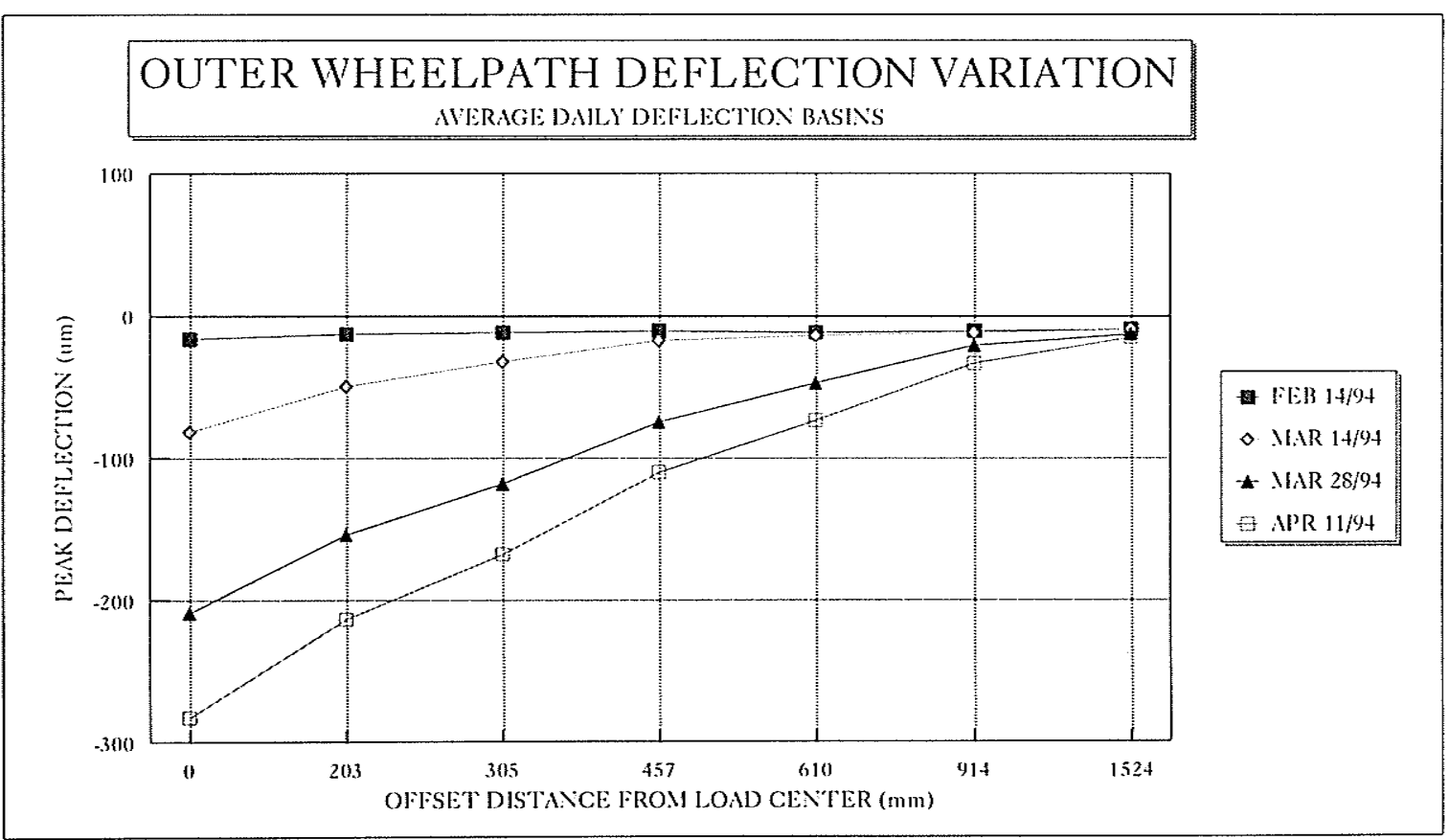

Figure 4.6 Seasonal Variation of Deflections During 1994 Spring Thaw Period

of the sensors indicating low temperature in the surface layer and frozen conditions in both the base and subgrade layers. There is a steady increase in the deflections at all of the sensor 
locations but the increase is far less pronounced the greater the offset distance from the load centre. While the deflection at the $1524 \mathrm{~mm}$ offset doubles over the time period the deflection at the $0 \mathrm{~mm}$ offset sensor changes by a factor of more than 16 . This indicates that the $1524 \mathrm{~mm}$ sensor does not experience the same magnitude of seasonal variation that the other sensors indicate.

Figure 4.7 shows the average daily deflections during the months of April through November, 1994. This graph shows that the deflections vary only slightly during this time

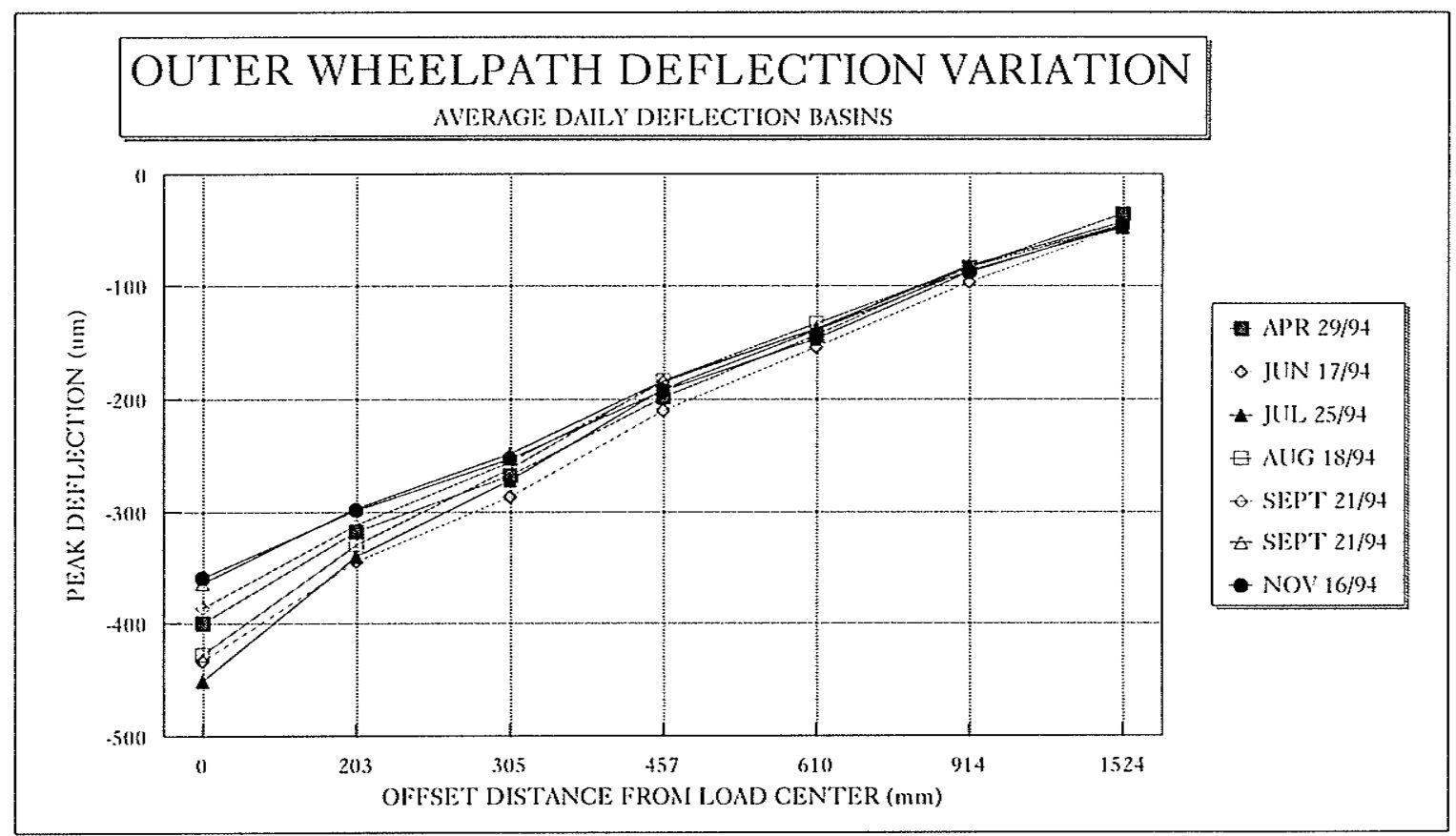

Figure 4.7 Seasonal Variation of Deflection Data During 1994 Unfrozen Conditions period. The $0 \mathrm{~mm}$ sensor varies by $30 \%$ while the $1524 \mathrm{~mm}$ sensor by $25 \%$ during this time period. The low variation suggests that very little change occurs in the environmental conditions during this time period. Thus the effect of rainfall, groundwater table, soil moisture content, and layer temperatures have very little effect on the deflections during this time of unfrozen conditions. 
The seasonal variation of the deflection data during the winter of 1994 and spring thaw

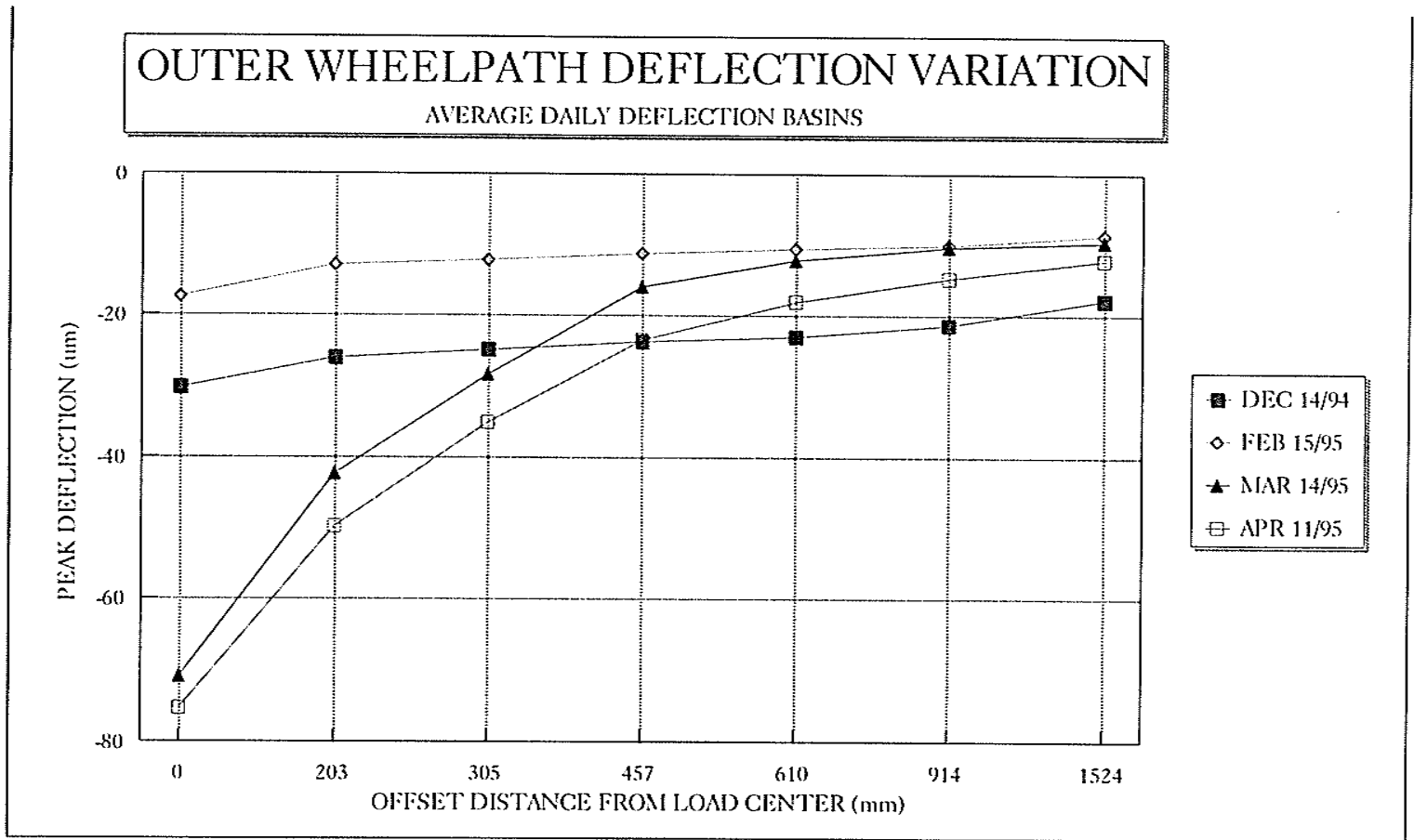

Figure 4.8 Seasonal Variation of Deflections During Winter 1994 to Spring 1995

period of 1995 is shown in Figure 4.8. The deflection values vary only slightly among the sensors during the December, 1994 and February, 1995 test dates. This shows the same trend as the February, 1994 test date. Once thawing commences in the March and April, 1995 test dates the deflections at the $0 \mathrm{~mm}$ offset sensor increase by a factor of 4 while the $1524 \mathrm{~mm}$ offset sensor by 2 . This confirms the trend that thawing and higher temperatures have influenced the upper layers more so than the subgrade by this time in the spring. Figure 4.9 shows the deflection data for the spring of 1995 . The $0 \mathrm{~mm}$ offset sensor shows variation of approximately $50 \%$ while the $1524 \mathrm{~mm}$ offset sensor shows a variation of $200 \%$. This indicates that thawing within the subgrade layer has taken place during this time. Thus there are distinct and repeating trends during the year on the average daily deflections which indicate that the use of the deflection data as input to the backcalculation program will result in a seasonal variation in the calculated resilient moduli. 


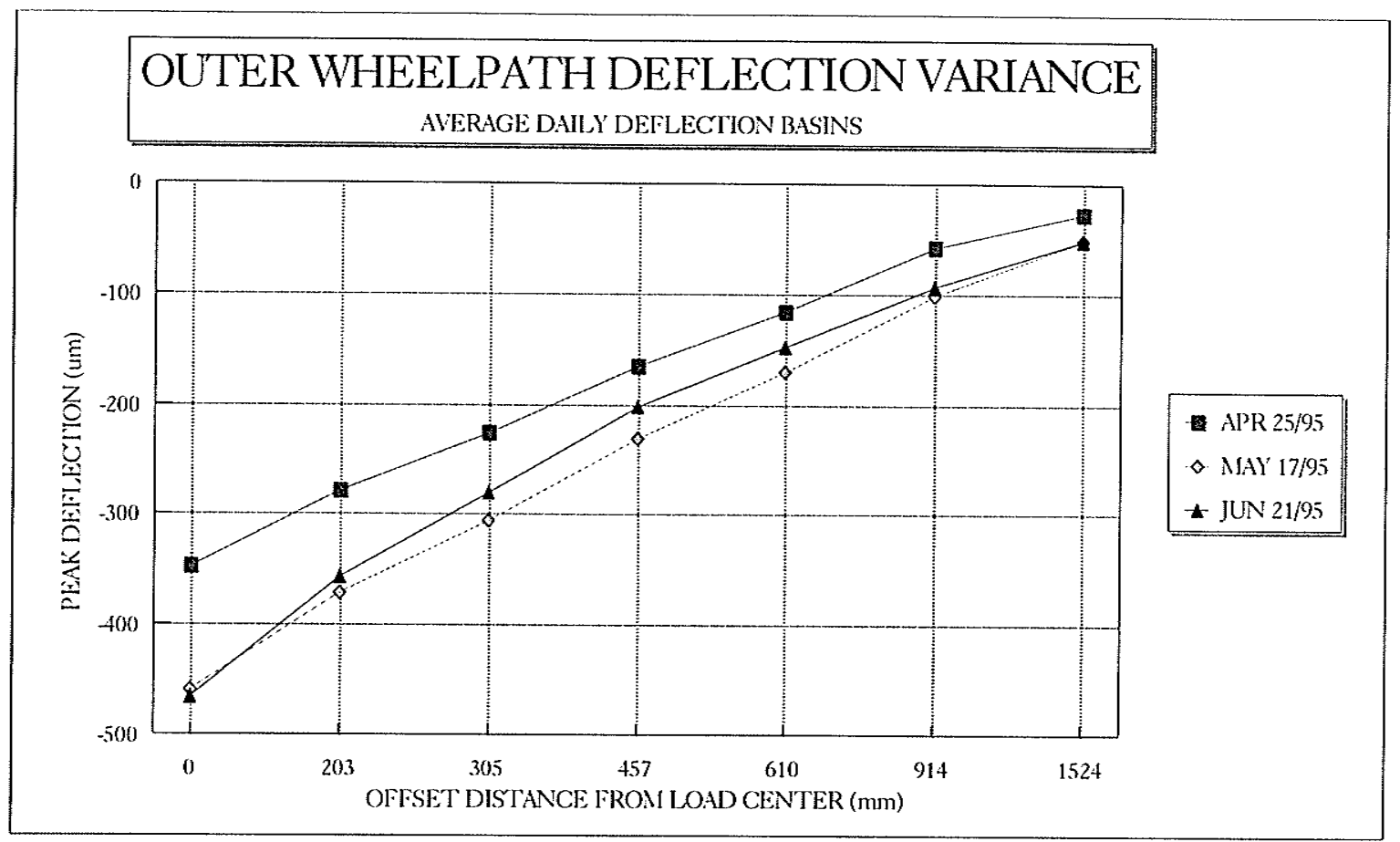

Figure 4.9 Seasonal Variation of Deflections During Spring 1995

\subsection{Electrical Resistance of Soil}

The SMP collects data on electrical resistance and resistivity both manually and through the use of a mobile datalogger. The electrical resistance data collected through the use of the datalogger was the first method of data collection to be analysed. This resistance data collected by the datalogger is included as Appendix B. During each site visit a mobile datalogger was used to collect the electrical resistance and resistivity data at pre-set times of the visit. Thirty-five readings of the resistivity probe sensors were taken once or twice for each site visit beginning at a depth of approximately $200 \mathrm{~mm}$ and extending down to $2 \mathrm{~m}$. The data was stored in text files which were imported into spreadsheets to allow for analysis. The spreadsheets allowed for plots of the resistance and resistivity readings to be assembled. These plots showed the readings for groupings of sensors during each site visit. 
The trends in the data were analysed to evaluate the use of the data in determining the extent

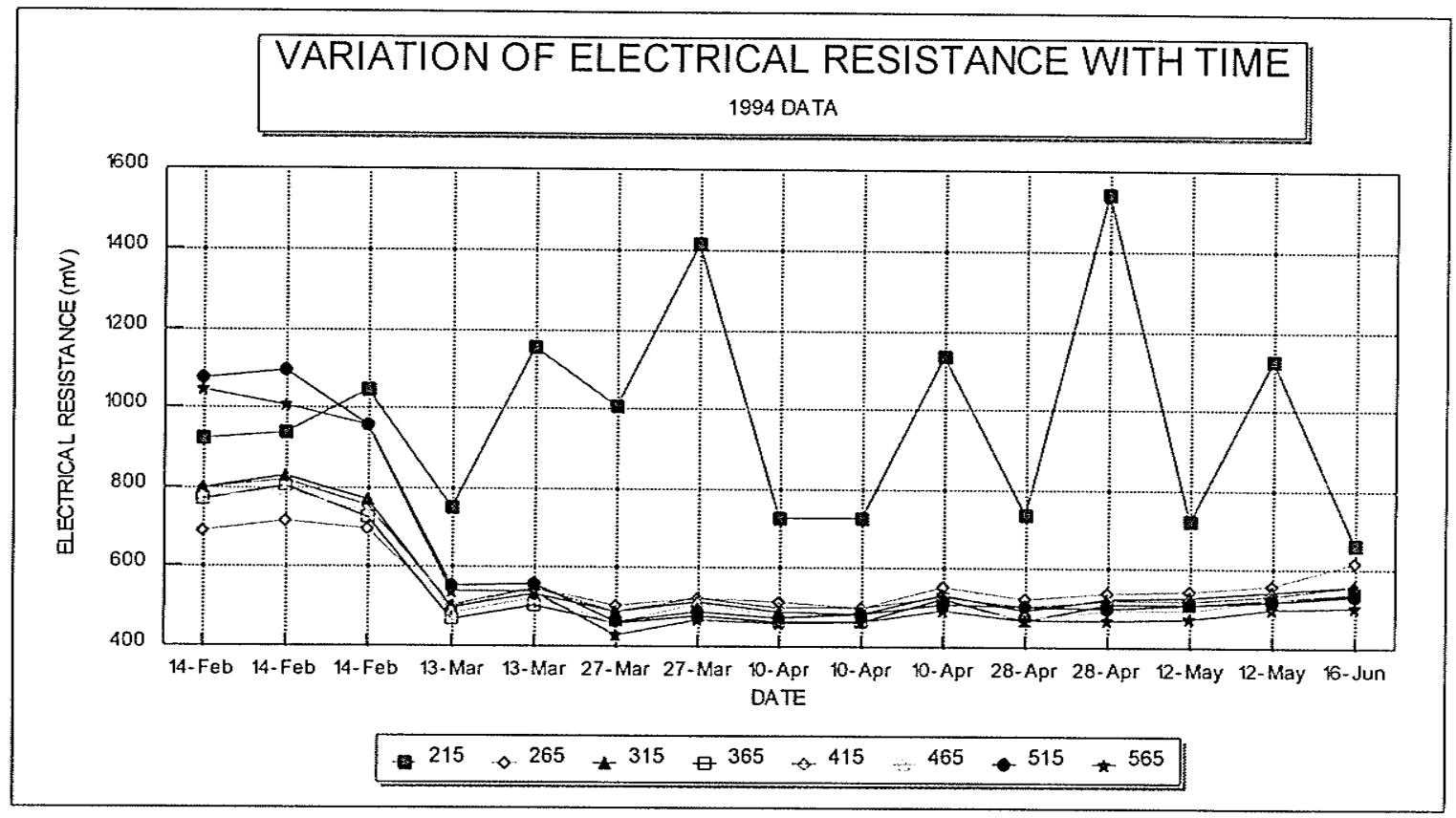

Figure 4.10 Seasonal Variation of Resistance Data

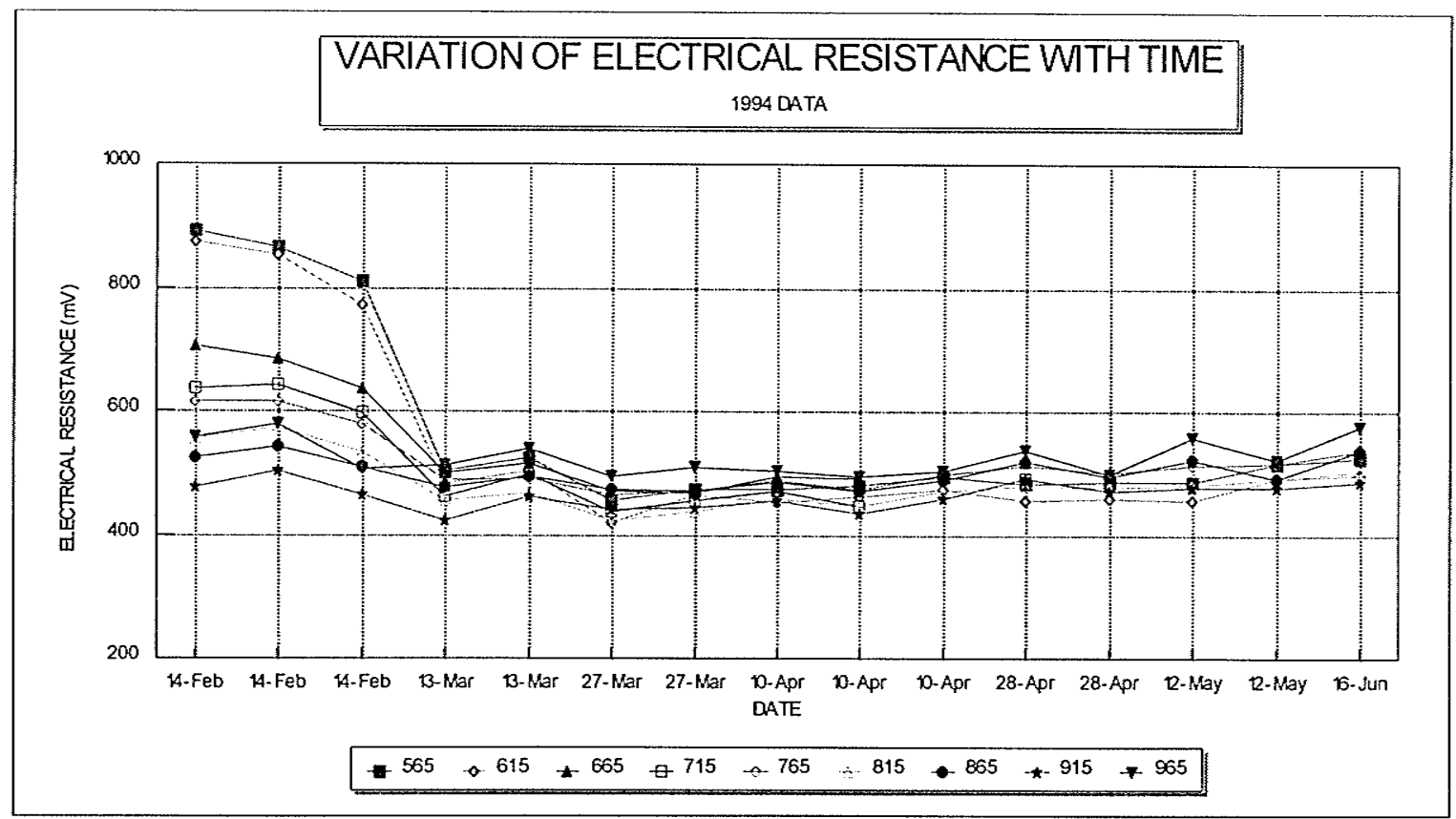

Figure 4.11 Seasonal Variation of Resistance Data

of frozen layers in the unbound layers. Electrical resistance should increase in the order of 
many magnitudes as the soil freezes. As thawing proceeds the resistance should indicate that

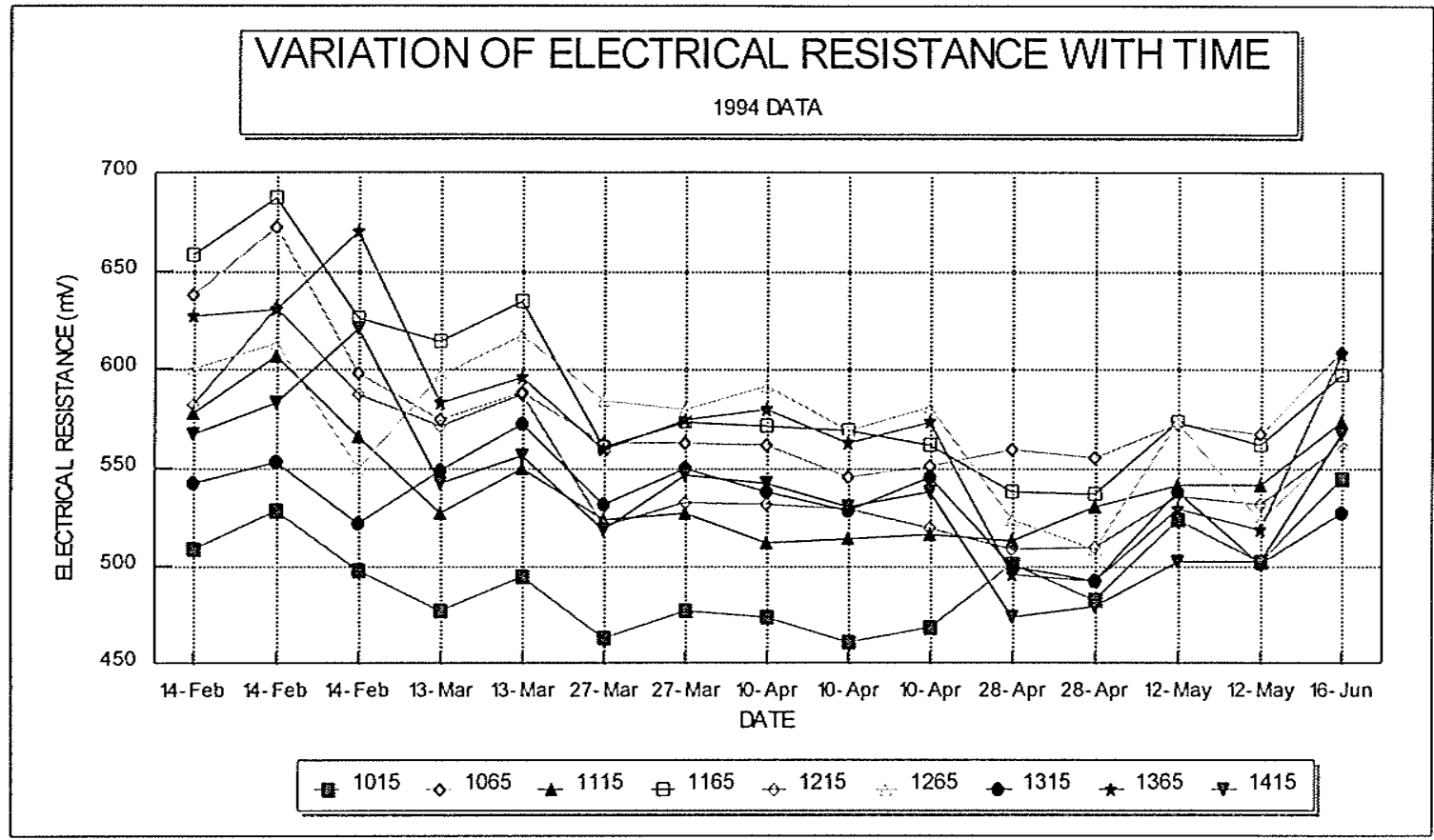

Figure 4.12 Seasonal Variation of Resistance Data

thawing is indeed occurring by a noticeable decrease in the resistance readings. The resistance readings obtained through the mobile datalogger did not show consistent trends to aid in the analysis of frost extent. For example, in Figure 4.10 the sensor at $215 \mathrm{~mm}$ depth showed a highly unstable resistance reading for the dates of February through June, 1994. As shown in Figure 4.11, the grouping of sensors from the 565 through $965 \mathrm{~mm}$ depths showed predictable trends, ie that the resistance decreased during thawing, in the same time period. In Figure 4.12 some of the sensors showed a decrease in resistance while others showed an increase which cannot be explained. Here the resistance readings declined as expected during the period from February through April, 1994 yet climbed significantly after that period. 


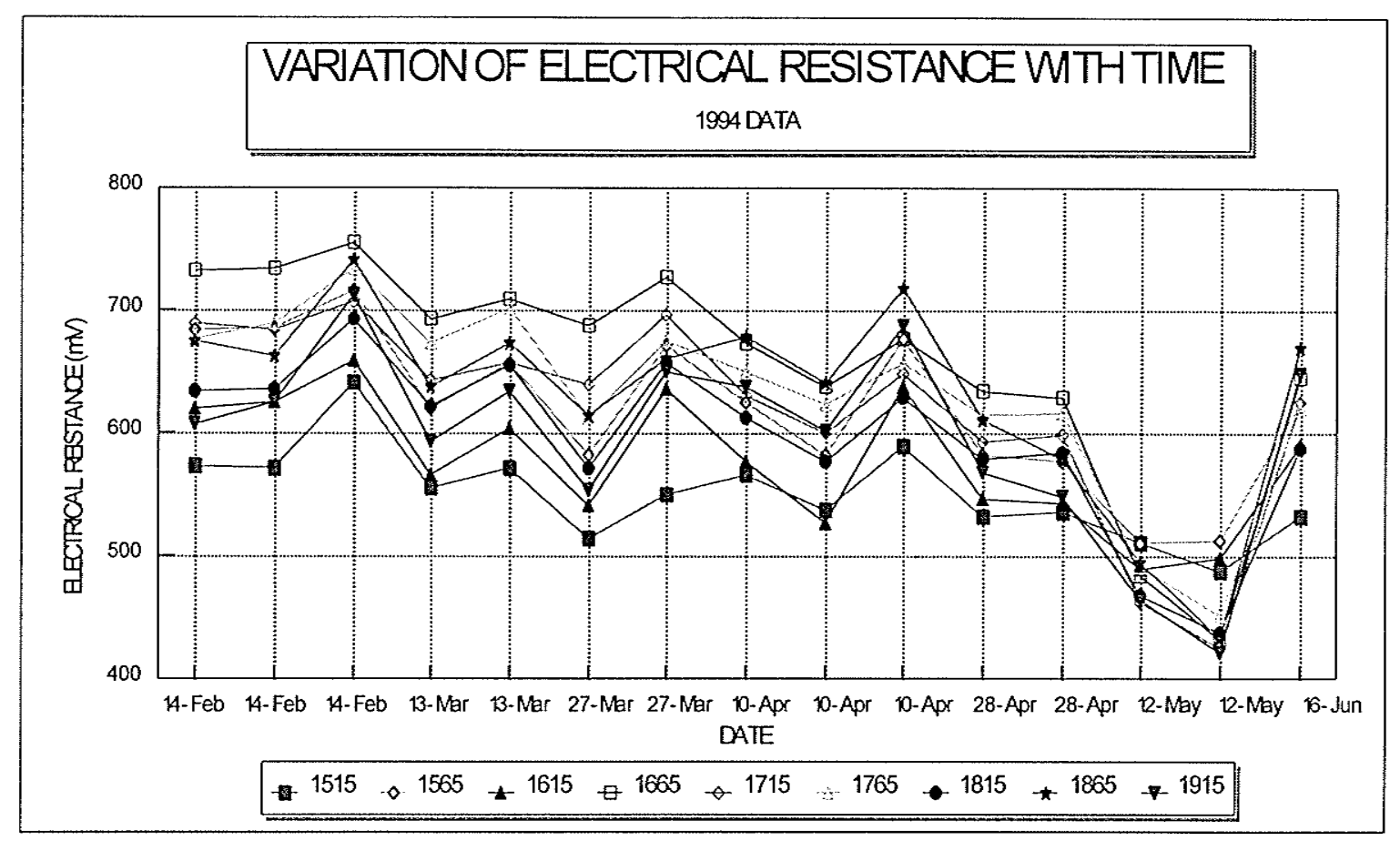

Figure 4.13 Seasonal Variation of Resistance Data

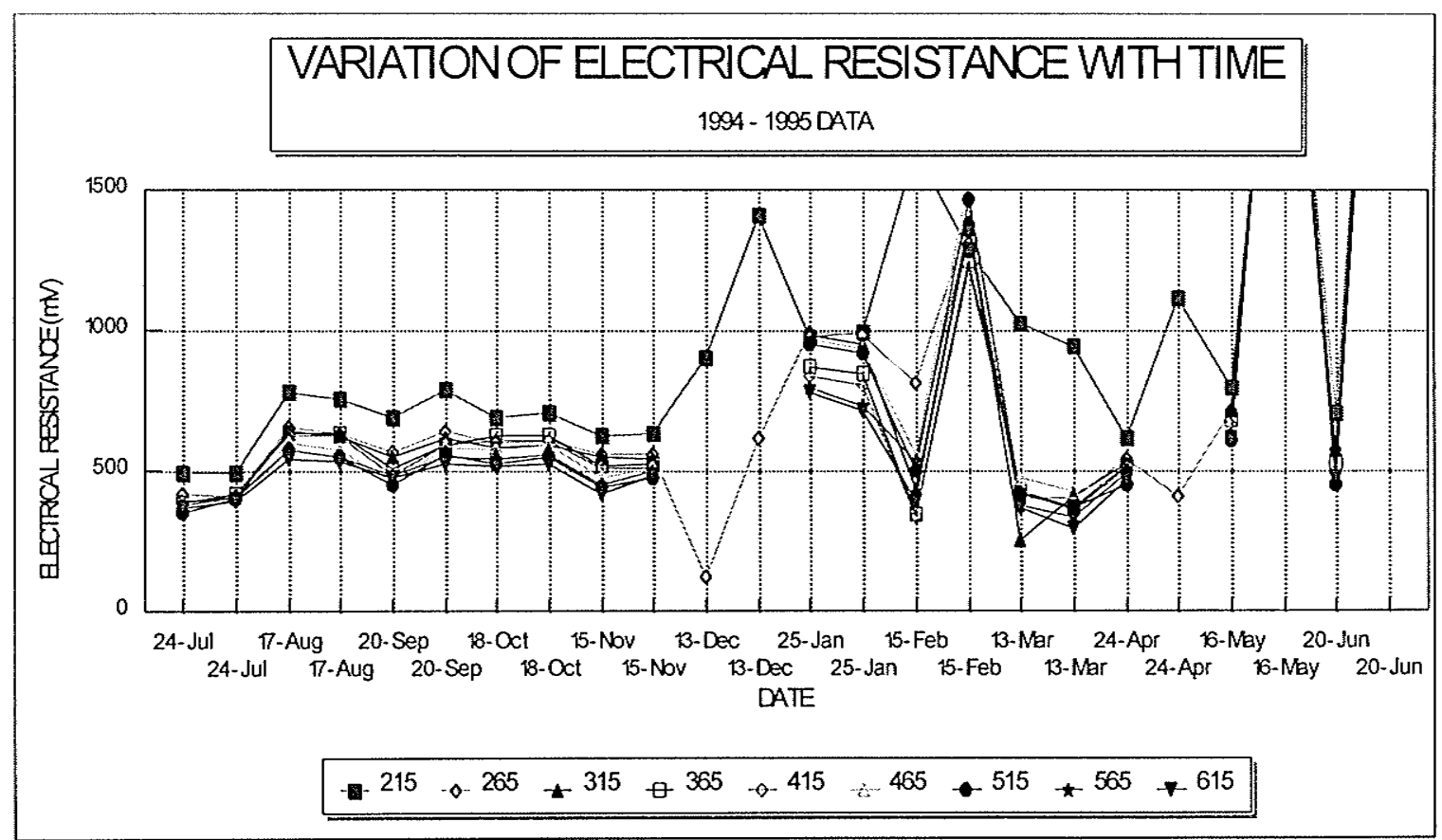

Figure 4.14 Seasonal Variation of Resistance Data 
Figure 4.13 shows the same inconsistent trend of increasing resistance during thawed conditions for the depths of 1515 through $1915 \mathrm{~mm}$ from May 12 to June 20, 1994. Figure 4.14 shows the resistance readings for the 215 through $615 \mathrm{~mm}$ depths to range between approximately 400 to $800 \mathrm{mV}$ for the months of July through November, 1994. The $215 \mathrm{~mm}$ depth sensor shows a large increase in resistance $(1400 \mathrm{mV})$ during the December, 1994 site visit which indicates that freezing has occurred. However the $265 \mathrm{~mm}$ depth sensor shows a significant decrease in resistance $(100 \mathrm{mV})$, which should not be the case. An error in the data excluded the analysis of the other sensors in this group. The January, 1995 readings showed an increase in the readings from all of the sensors to between approximately 800 and $1000 \mathrm{mV}$ which indicates frozen layers. However the $215 \mathrm{~mm}$ depth sensor reading decreased from approximately 1400 to $1000 \mathrm{mV}$, which is not possible unless thawing has occurred . The February, 1995 readings first showed a decrease in all but the $215 \mathrm{~mm}$ depth sensor, then a significant increase in all of the sensor readings to about 1300 to $1500 \mathrm{mV}$. All of the March, 1995 sensor readings decreased while those of the April, 1995 date increased. Obviously it was expected that the trend of lower resistance readings would continue at these

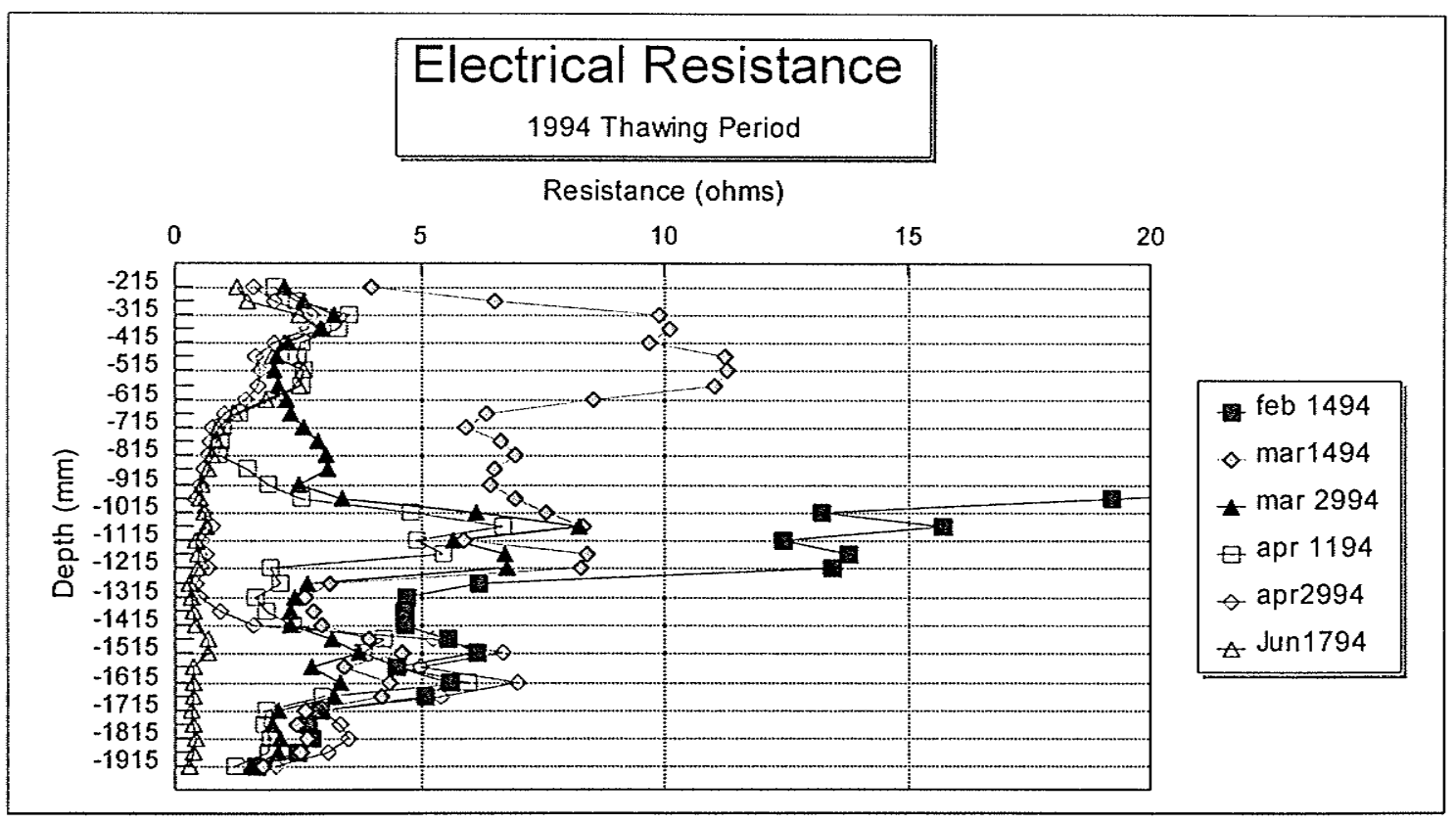

Figure 4.15 Manual Resistance Data for Spring 1994 
depths during the February through April, 1995 thaw period and remain constant during the unfrozen time period. However the readings increased dramatically in May and June, 1995. The other sensor depths also displayed these unpredictable trends which are included in Appendix B. The manual resistance readings were taken through the use of multimeters and a function generator with the readings manually recorded. These readings were made available in text files which were once again imported into spreadsheets. Figure 4.15 shows the electrical resistance at indicated depths for the spring thawing period of February, 1994 through June, 1994. These readings show a steady decrease throughout this period for all of the sensors.

Figure 4.16 shows a similar trend for the spring thawing period of February, 1995 through June, 1995. These manual resistance readings were used together with temperature and

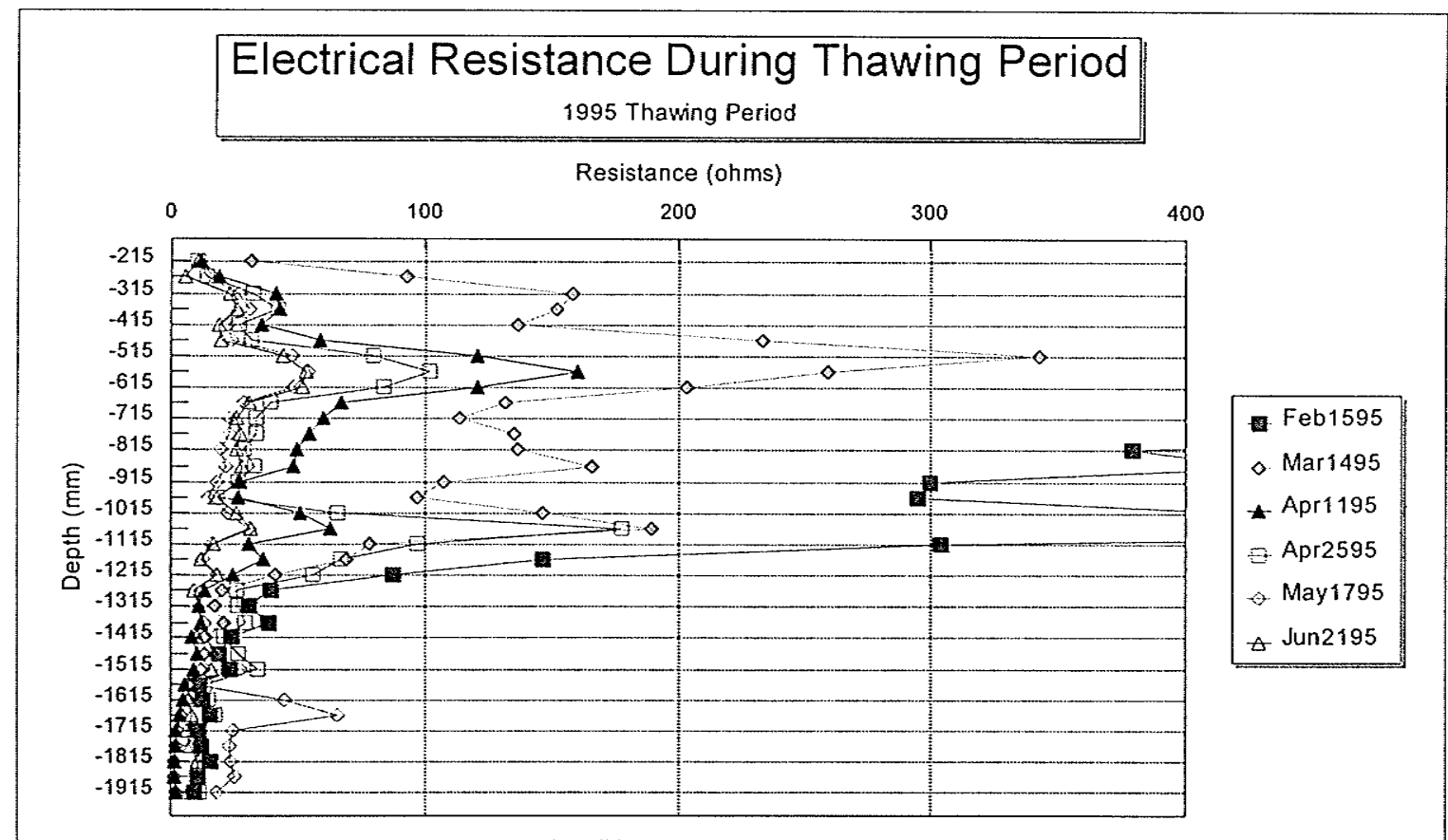

Figure 4.16 Manual Resistance Data for Spring 1995 moisture content data to determine the extent of frozen layers. 


\subsection{Soil Temperature}

Temperature readings of the soil proved to be the least valuable data used in the determination of frozen layer extent. As shown in Figure 4.17, the range of temperatures

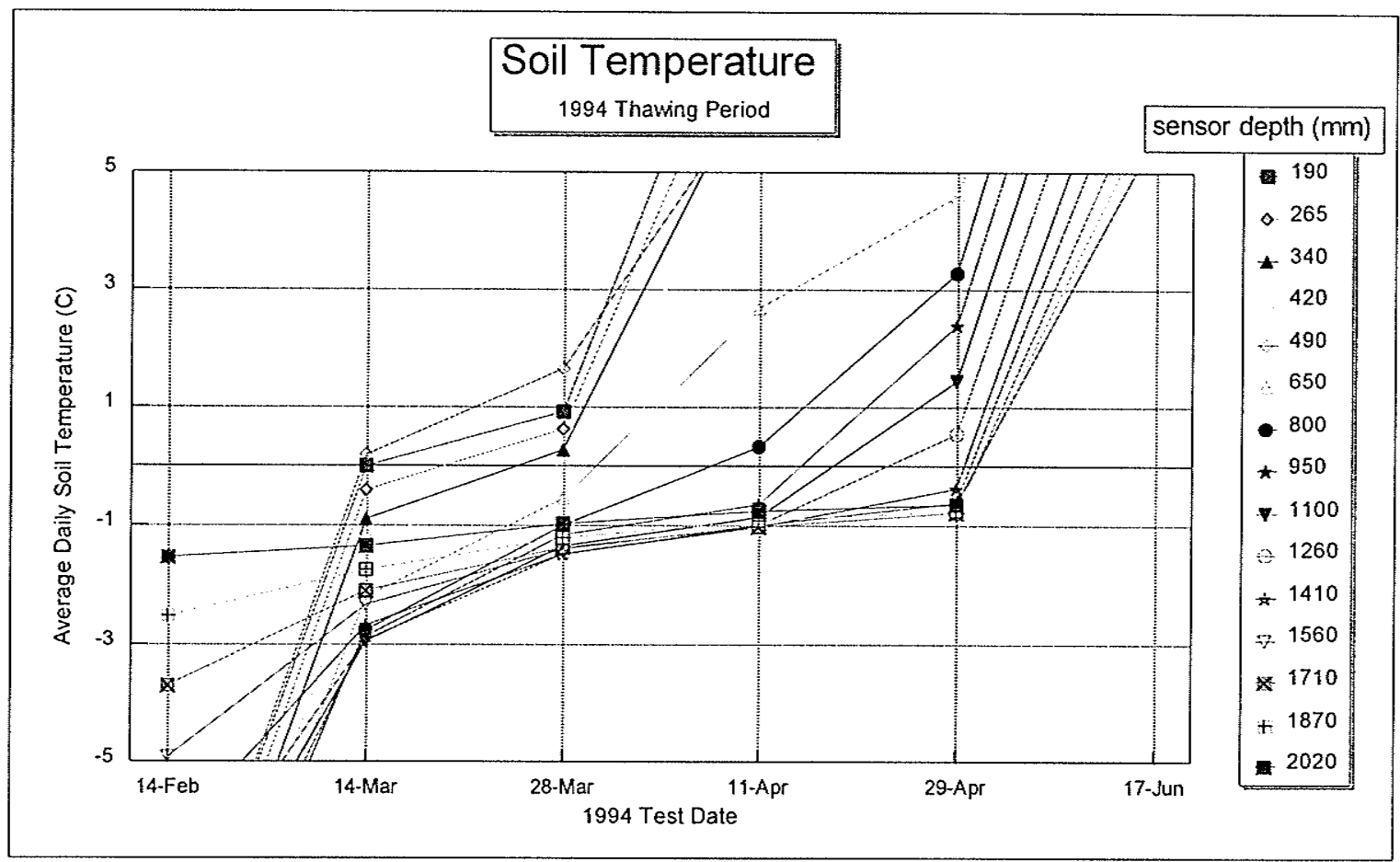

Figure 4.17 Soil Temperature During Spring 1994

during the spring thaw period of February through June, 1994 are not significant enough to ascertain the boundary of the frozen layer. For example, on March 14, 1994, soil temperatures ranged from -3 to $0.5^{\circ}$ Celsius for all of the sensors. This confirms the presence of a near-isothermal range during the thawing event. Even on the April 11, 1994 the temperatures on the sensors from the $650 \mathrm{~mm}$ depth down only ranges between 1 and +3 ${ }^{\circ} \mathrm{C}$. Figure 4.18 shows the temperatures for the spring thaw period of March through June, 1995. Again the temperature ranges are insignificant for the purpose of determining the frozen layer extent and it is not until after the April 25, 1995 that the sensors exhibit a wide range of readings. Temperature was not used as a significant indicator of frozen layer extent due to these observations. 


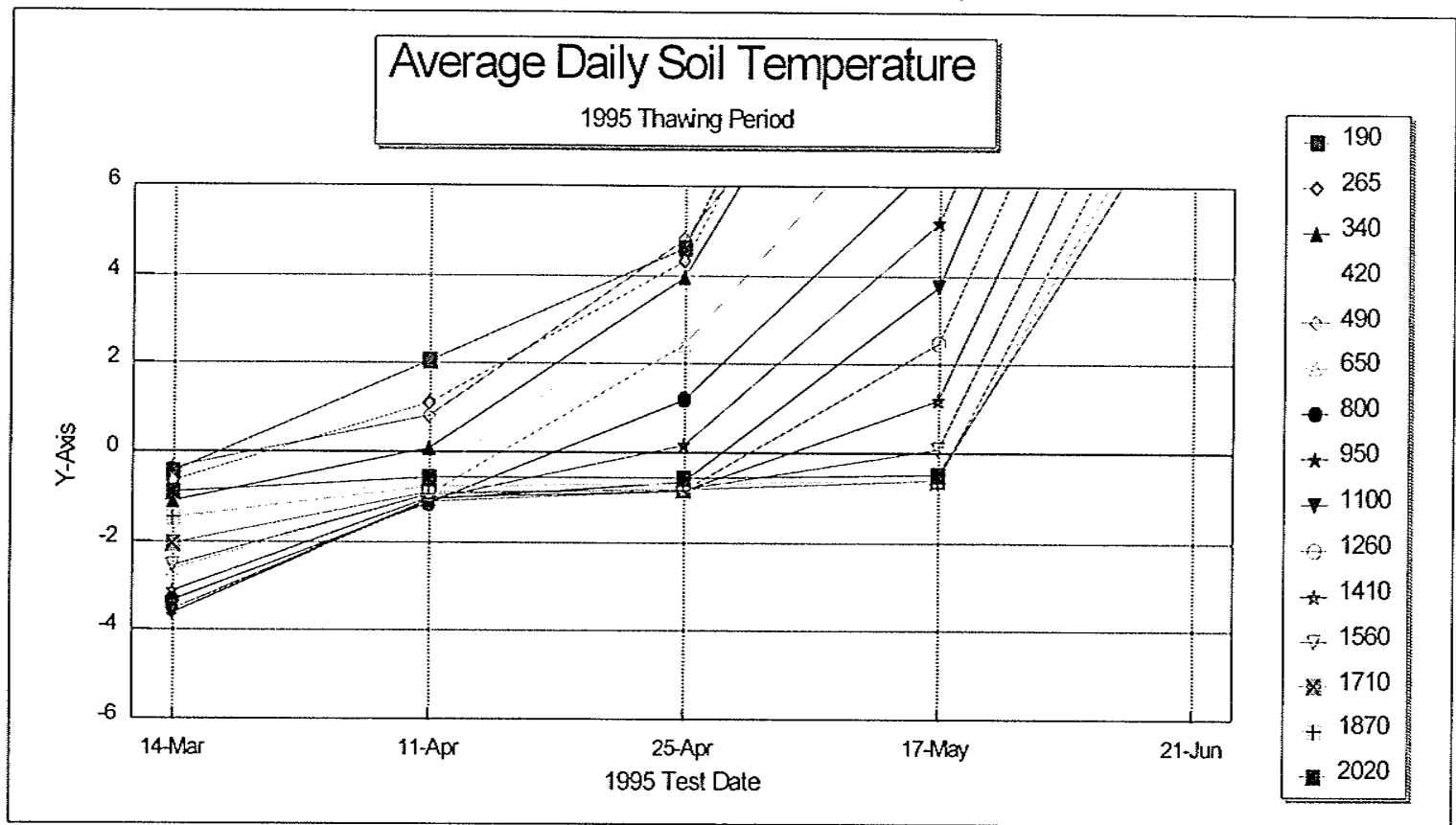

Figure 4.18 Soil Temperature During Spring 1995

\subsection{Soil Moisture Content}

TDR data were initially to be used for the determination of extents of saturated or near saturated weakened soil layers. During the manual assembly of the moisture content readings it was observed that the TDR data gave significantly lower readings when the resistance readings indicated that frozen soil surrounded the TDR probes. A table of the moisture content data is included as Appendix C. Thus another indicator of frozen layer extent was found to be the moisture content readings from the TDRs.

Figure 4.19 shows the unfrozen baseline values for the moisture content readings from 
June through November, 1994. The 200 through $650 \mathrm{~mm}$ depth sensors show a narrow variation however the $340 \mathrm{~mm}$ depth sensor is consistently lower than the others. No

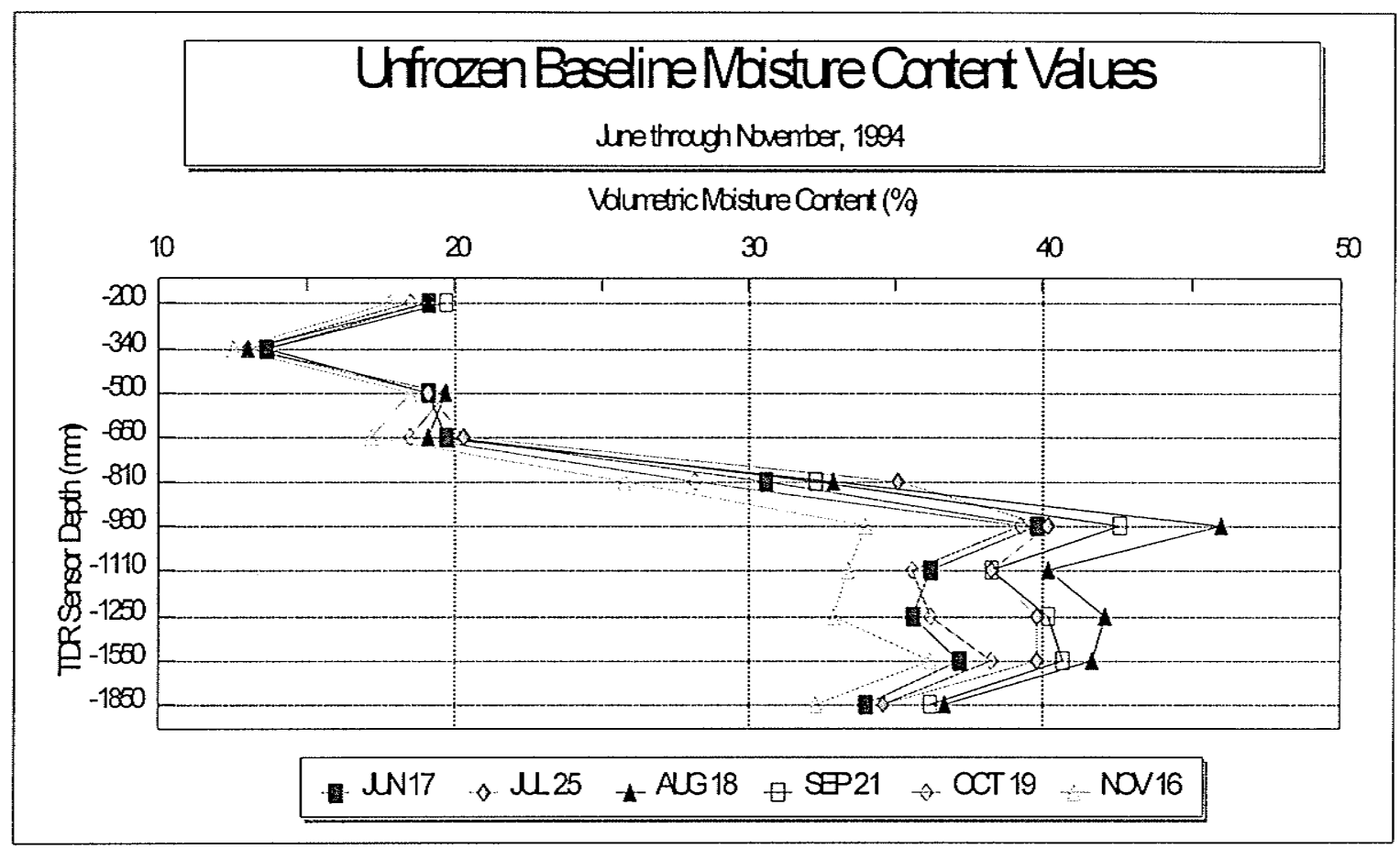

Figure 4.19 1994 Baseline Moisture Content Readings

physical change in the surrounding granular base material explain the lower readings of the $340 \mathrm{~mm}$ depth TDR sensor. Immediately after installation in October, 1993 the sensor was found to be reading very close to the samples which were weighed on the site. Perhaps some condition such as a void immediately beneath one or more of the TDR probes is causing the low moisture content reading. However as the unfrozen readings are stable an average value is used to determine the frozen layer extent for the purpose of this study. The sensors below this $650 \mathrm{~mm}$ depth are contained in the subgrade soil. These sensors show a much greater variation in readings than the sensors in the granular base layer during this same time period.

The trend in these readings is for the moisture contents to increase through August and then decline through the last of the unfrozen conditions in November. The magnitude of the 
variation is approximately $10 \%$ and is not considered to be excessive. The temperature of the surrounding soil may very well be another significant variable in this trend, however isolating temperature's effects on the TDR sensors is beyond the scope of the present study.

\subsection{Determination of Frozen Layer Extent}

The frozen layer extents are required in determining the allowable ranges of layer moduli for the granular base and subgrade soil in the backcalculation process. The moisture content readings together with the electrical resistance readings were used to confirm the presence of frozen layers. The thickness and depth of the frozen layer was input to the EVERCALC program and the pavement structure was then modelled as a four layer system. If the frozen layer was contained in either the granular base layer or the subgrade soil then that particular layer was divided up into appropriate thicknesses. Corresponding allowable moduli ranges and seed values were then selected for both the unfrozen and frozen portions of that particular layer.

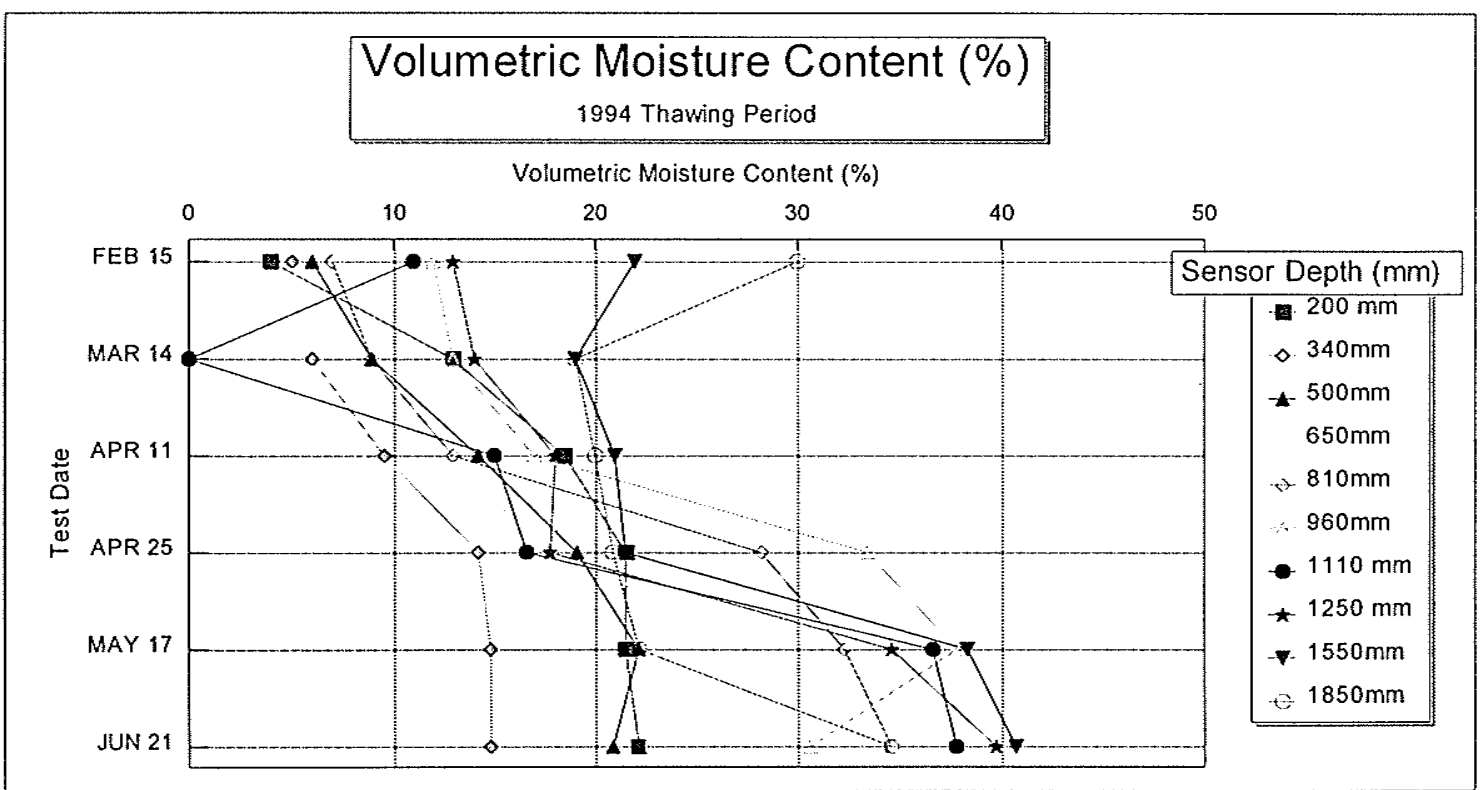

Figure 4.20 1994 Soil Moisture Contents 
Figures 4.20 and 4.21 show the thawing periods of February through June, 1994 for the moisture content readings and electrical resistance respectively. All of the soil is considered to be completely frozen in February 14, 1994, while all of the frost has thawed by June 21, 1994. For the March 14, 1994 date the first moisture content sensor at the $200 \mathrm{~mm}$ depth in Figure 4.20 shows only a slight increase from 8 to $12 \%$. The $215 \mathrm{~mm}$ depth manual resistance measurement in Figure 4.21 shows a huge decrease in resistance from the February 14 readings. While the decrease is very significant, the resistance reading is still not at the same value as the April 11 and subsequent dates which are considered to be thawed. Immediately below this sensor the $265 \mathrm{~mm}$ depth reading is significantly higher than the April 11 thawed value. Figure 4.22 shows the soil temperatures for the same

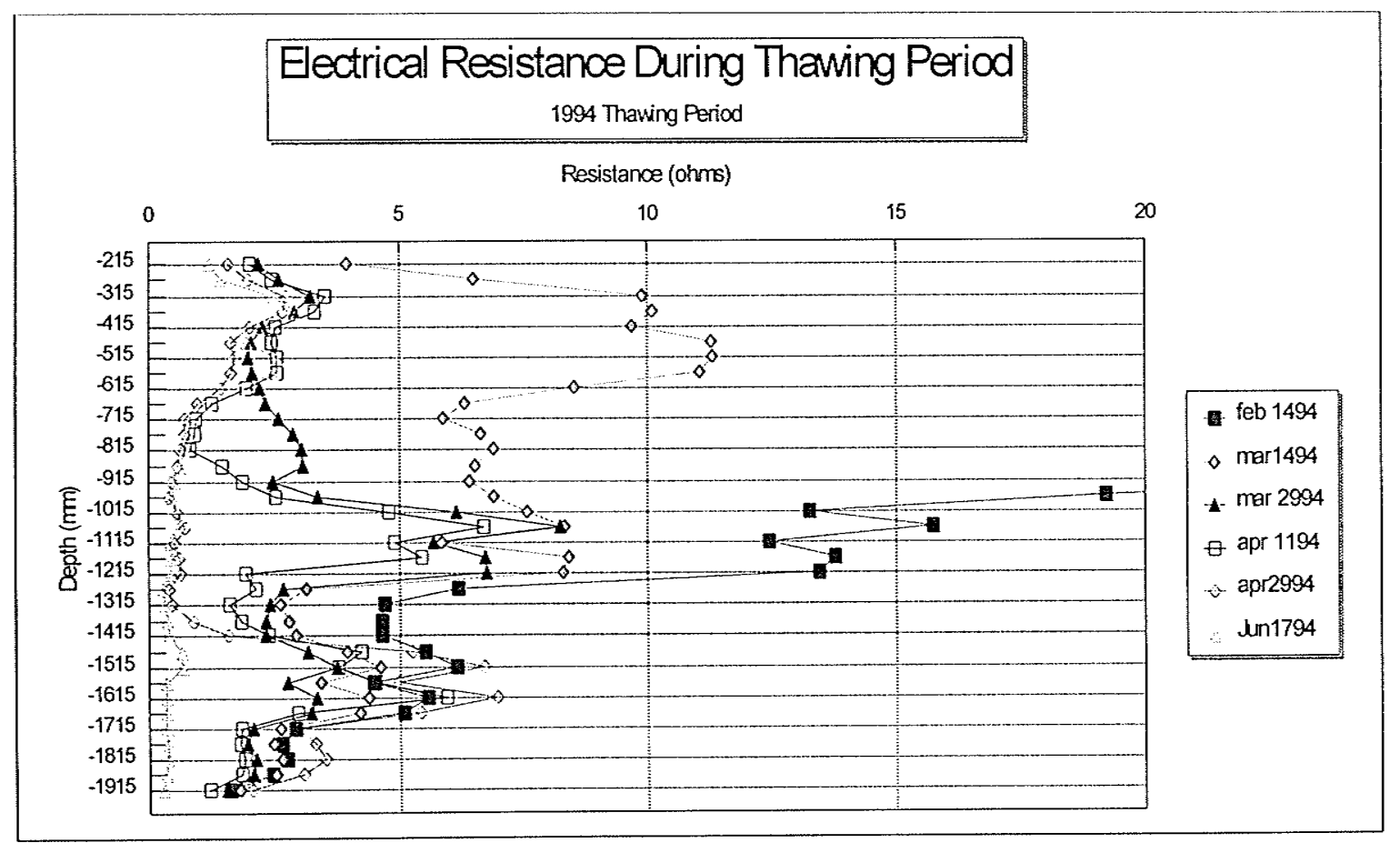

Figure 4.21 Spring 1994 Resistance Data 
thawing period of 1994 . The March 14 temperatures range from -3 to $0.5^{\circ} \mathrm{C}$ over the entire

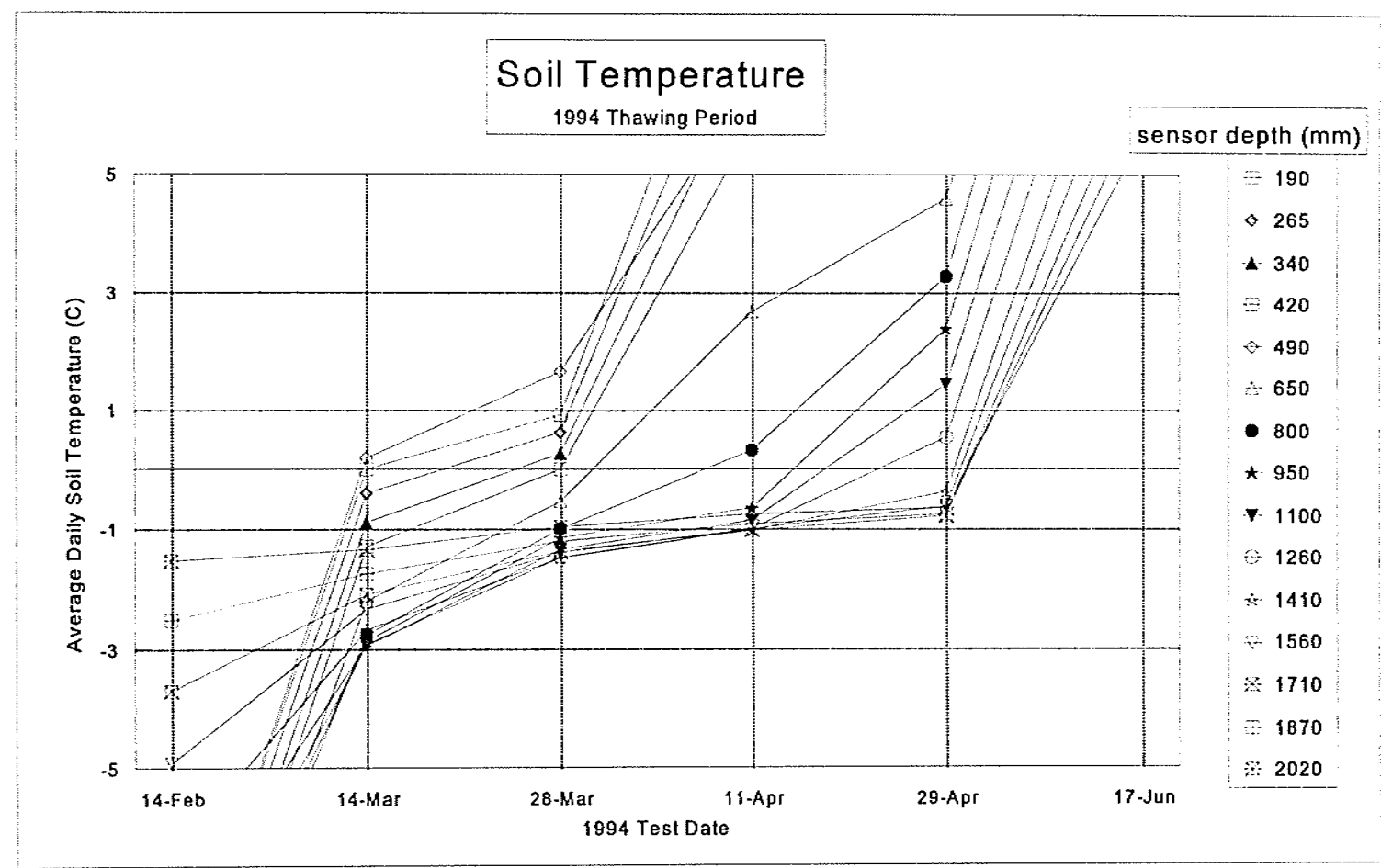

Figure 4.22 Soil Temperatures During Spring, 1994

range of sensors from $190 \mathrm{~mm}$ depth down to the $2020 \mathrm{~mm}$ depth. This temperature range does not distinguish the frozen layer extent. The conclusion for this date is that the thawing has just begun in the upper layer of the granular base creating a thawed layer of approximately $100 \mathrm{~mm}$.

The analysis of Figures 4.20 and 4.21 for the March 28, 1994 show that the moisture content for the sensors down to the $650 \mathrm{~mm}$ depth have reached their unfrozen (as indicated by the June values) state. The $810 \mathrm{~mm}$ depth sensor has increased slightly from 8 to $13 \%$, but still is well below the June value of just over 30\%. Therefore the upper limit of the frozen layer boundary, as indicated by the TDR traces only, lies between 650 and $810 \mathrm{~mm}$ depths. The electrical resistance values for the March 28, 1994 date indicate that the frozen layer exists around the $810 \mathrm{~mm}$ depth. The temperatures range from 1.5 to $-1.5{ }^{\circ} \mathrm{C}$ for the entire range of sensors as shown in Figure 4.22. Therefore the frozen layer extent was chosen at the 810 
mm depth.

Again referring to Figures 4.20 and 4.21 for the April 11, 1994 moisture contents have reached their near baseline value of $26 \%$ at the $810 \mathrm{~mm}$ depth. The $960 \mathrm{~mm}$ depth sensor has not increased from the $18 \%$ which is well below the June value of just under $40 \%$. The electrical resistance values for the April 11, 1994 date indicate that the frozen layer exists around the $960 \mathrm{~mm}$ depth. The temperatures range from 0.5 to $-1.1^{\circ} \mathrm{C}$ for the sensors locate at depths of $800 \mathrm{~mm}$ to $2020 \mathrm{~mm}$ in Figure 4.22. Therefore the frozen layer extent was chosen to begin at the $960 \mathrm{~mm}$ depth.

The April 29, 1994 data show that the moisture contents have reached $32 \%$ with their baseline value of $35 \%$ at the $1250 \mathrm{~mm}$ depth. The $1550 \mathrm{~mm}$ depth sensor has not reached the baseline value of $37 \%$ as it is still at $22 \%$. The electrical resistance values for the April 29, 1994 date indicate that the frozen layer exists around the $1500 \mathrm{~mm}$ depth. The temperatures range from 0.5 to $-0.8^{\circ} \mathrm{C}$ for the sensors located at depths of $1410 \mathrm{~mm}$ to 2020 $\mathrm{mm}$. Therefore the frozen layer extent was chosen to begin at the $1500 \mathrm{~mm}$ depth. This completes the analysis of frozen layers during the 1994 spring thaw period as the entire structure has thawed by the next test date of June 17, 1994 . 
The 1995 spring thaw period analysis refers to Figures 4.23 and 4.24 for moisture content

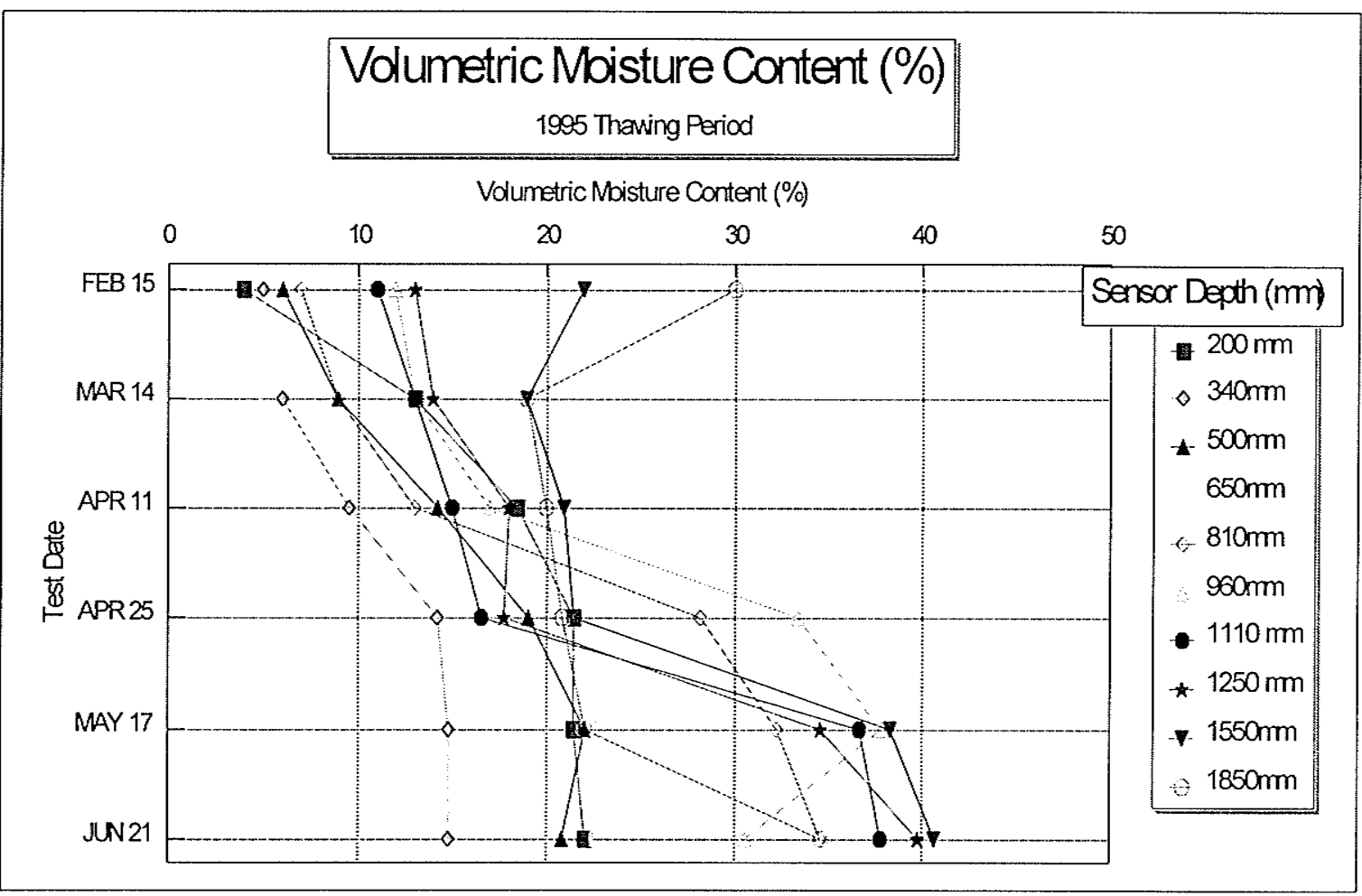

Figure 4.23 1995 Spring Moisture Content Readings

and electrical resistance respectively. The entire structure is considered to be frozen on the February 15, 1995 test date. The moisture content readings of 4 to $8 \%$ for the uppermost 5 sensors are well below their unfrozen baselines of between 12 and $35 \%$. The electrical resistance readings confirm this assumption with high values recorded all of the way down to the $1565 \mathrm{~mm}$ depth. The soil temperatures for this date are not available due to instrument malfunction. 


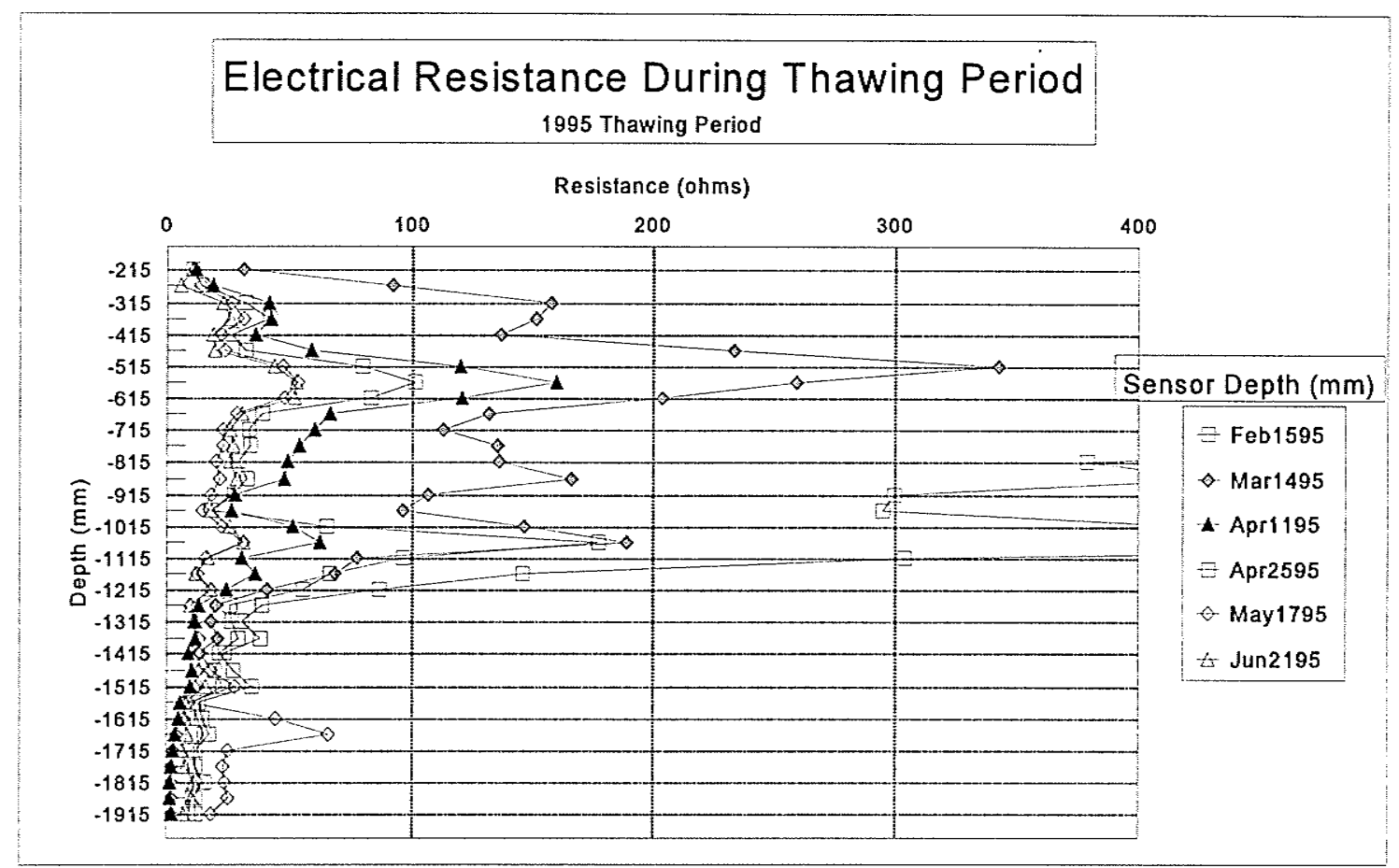

Figure 4.24 1995 Spring Resistance Data

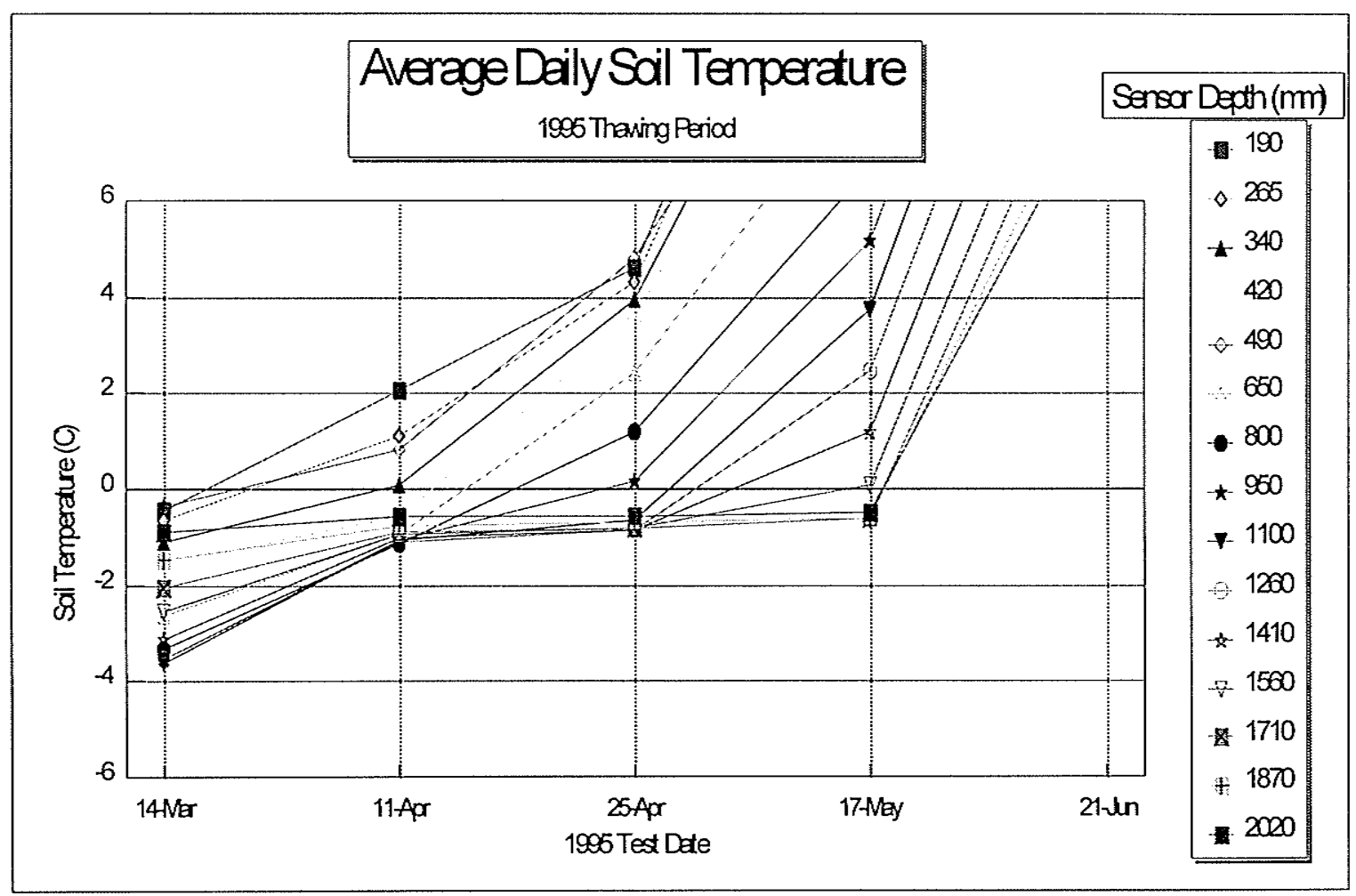

Figure 4.25 1995 Spring Soil Temperature 
For the March 14, 1995 date, the first moisture content sensor at the $200 \mathrm{~mm}$ depth in Figure 4.23 shows only a slight increase from 5 to $12 \%$. The $215 \mathrm{~mm}$ depth resistance measurement in Figure 4.24 shows a large decrease in resistance from the February 15 date which indicates thawing has occurred. However, immediately below this sensor the $265 \mathrm{~mm}$ depth reading is significantly higher which indicates that this depth has not thawed. Figure 4.25 shows the soil temperatures for the same thawing period of 1995 . The March 14 temperatures range from -1.5 to $-0.5^{\circ} \mathrm{C}$ over the range of sensors from $190 \mathrm{~mm}$ depth down to the $420 \mathrm{~mm}$ depth. The conclusion for this date then is that the thawing has just begun in the upper layer of the granular base creating a thawed layer of approximately $100 \mathrm{~mm}$.

Again referring to Figures 4.23 and 4.24 for the April 11, 1995 date, moisture contents of 13 $\%$ indicate thawing at the $500 \mathrm{~mm}$ depth. The $650 \mathrm{~mm}$ depth sensor has increased to $8 \%$ from $6 \%$ which is still well below the June value of just over $20 \%$ which indicates thawing has not occurred at this depth. The electrical resistance values for this date indicate that the frozen layer exists around the $615 \mathrm{~mm}$ depth. The temperatures are grouped around $-1{ }^{\circ} \mathrm{C}$ for the sensors locate at depths of $600 \mathrm{~mm}$ as shown in Figure 4.25. Therefore the frozen layer extent was chosen to begin at the $650 \mathrm{~mm}$ depth.

The April 25, 1995 data show that the moisture contents have reached $32 \%$ with their baseline value of $30 \%$ at the $960 \mathrm{~mm}$ depth which indicates thawing has occurred. The 1110 $\mathrm{mm}$ depth sensor has not reached the baseline value of $37 \%$ as it is still at $15 \%$. The electrical resistance values for the April 25, 1995 date indicate that the frozen layer exists around the $1100 \mathrm{~mm}$ depth. Figure 4.25 shows the temperatures are grouped around -0.8 ${ }^{\circ} \mathrm{C}$ for the sensors located at depths of $1100 \mathrm{~mm}$ to $2020 \mathrm{~mm}$. Therefore the frozen layer extent was chosen to begin at the $1100 \mathrm{~mm}$ depth.

Again referring to Figures 4.23 and 4.24 for the May 17, 1995 date moisture contents indicate that all of the frost has thawed above the $1500 \mathrm{~mm}$ depth as all of the sensors are 
reading close to their June 21, 1995 values. For example, the $1250 \mathrm{~mm}$ depth sensor is reading $35 \%$ compared to the unfrozen baseline value of $40 \%$. The electrical resistance values for this date show an increase in resistance around the $1700 \mathrm{~mm}$ depth which indicates thawing has occurred down to this depth. The temperatures are grouped around $-0.5^{\circ} \mathrm{C}$ for the sensors locate at depths of 1700 through $2020 \mathrm{~mm}$ as shown in Figure 4.25. Therefore the frozen layer extent was chosen to begin at the $1700 \mathrm{~mm}$ depth. This completes the analysis of frozen layers during the 1995 spring thaw period as the entire structure has thawed by the next test date of June 21, 1995.

\subsection{Backcalculation Using EVERCALC}

All of the data analysis to this point has been the environmental data of moisture content, electrical resistance, and temperatures together with FWD deflection trends discussed. All of this data was analysed to allow for the testing conditions of temperatures and frozen layer extents to be used as data inputs to the backcalculation program. The backcalculation program was used to calculate the resilient moduli of each of the layers on each test date to evaluate the seasonal variation of the layer moduli. The backcalculation program chosen for the present study was the Washington State Department of Transportation program EVERCALC. Information on the EVERCALC program Version 4.0 for Windows was taken from the Washington State DOT, (1995). The EVERCALC program uses the WESLEA program (provided by the Waterways Experiment Station, US Army Corps of Engineers) to compute the layered elastic solution of deflections. The algorithm used to optimize the solution is an Augmented Gauss-Newton.

The backcalculation approach used by EVERCALC is shown in Figure 4.26. An inverse solution technique is used calculate the layer moduli from FWD deflection data. The program is capable of using up to seven sensor deflections and eight load drops per station. A maximum of five pavement layers may be modelled. The program uses a set of initial or 


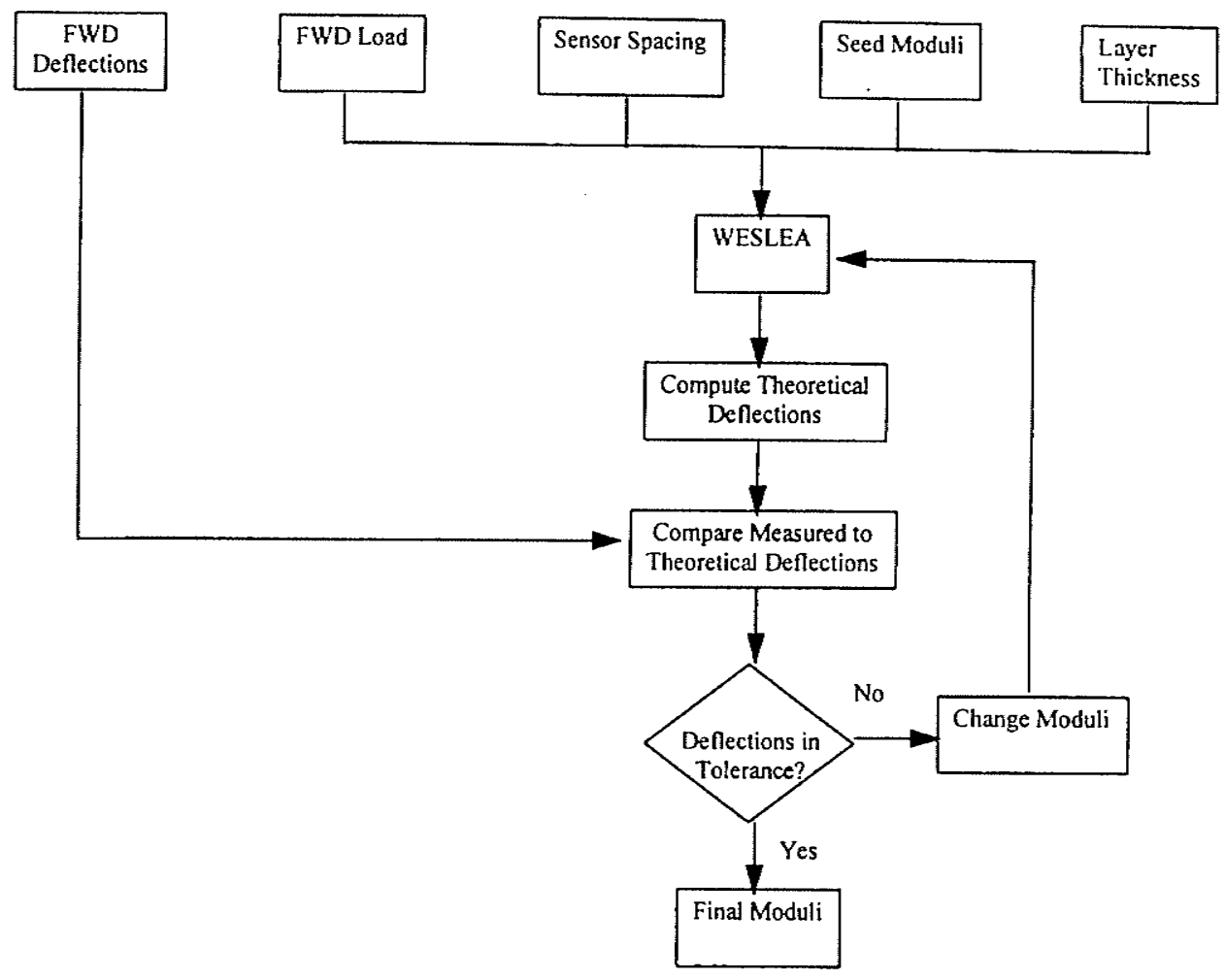

Figure 4.26 Schematic of Backcalculation Process

seed moduli as a beginning point to calculate the first generation of surface deflections. EVERCALC then searches for the final set of layer moduli whose deflections are within a specified tolerance of the FWD surface deflections. This tolerance is characterized by the root mean square (RMS) error, the changes in modulus falls within the allowable tolerance, or the number of iterations has reached its specified limit the program terminates. The program uses the final set of moduli to calculate the stresses and strains at the bottom of the AC layer, middle of the other layers except the subgrade, and at the top of the subgrade are calculated. Coefficients of stress sensitivity for unstabilized materials are computed when deflection data for more than one load level is available at a station. EVERCALC is capable of normalizing the $\mathrm{AC}$ layer modulus to a standard temperature condition.

The seed moduli required to begin the backcalculation process may be either be supplied by the user or if the pavement structure is of up to three layers, an internal set of regression equations can be used to select them. The regression equations determine a set of seed 
moduli from the relationship between layer modulus, surface deflection, applied load, and layer thickness. When more than one deflection set at a station is analysed, the final moduli set from the previous deflection set is used as the seed values for the next set.

The deflection tolerance as RMS (\%) is given by;

$$
\begin{gathered}
\left.R M S=\left(\sqrt{\frac{1}{n_{d}} \sum_{i=1}^{n}\left(\frac{\left(d_{c i}-d_{m i}\right)}{d_{m i}}\right)}\right)^{2}\right)(100) \\
d_{c i}, d_{m i} \text { are calculated, } \begin{array}{c}
\text { measured deflections at ith sensor } \\
n_{d} \text { is the number of deflection sensors }
\end{array}
\end{gathered}
$$

and a RMS value of $1 \%$ is usually used. The tolerance on the moduli is;

$$
\begin{gathered}
\epsilon_{m}=\frac{\left(E_{((k+1) i)}-E_{k i}\right)}{E_{k i}}(100) \\
\text { where } \\
E_{k i}, E_{((k+1) i)} \text { are the ith layer moduli at the kth, }(k+1) \text { th iteration } \\
m \text { is the number of layers with unknown moduli }
\end{gathered}
$$

The number of iterations will also terminate the search and the default value was set at a maximum of ten. EVERCALC estimates the depth to stiff layer using the scheme reported by Rhode and Scullion, (1990). This scheme assumes that no surface deflection occurs beyond the offset which corresponds to the intercept of the applied stress zone and a stiff layer. Thus the estimation of the depth to stiff layer assumes that the depth at which no deflection occurs is related to the offset at which no deflection occurs. Accounting for a stiff layer within $10 \mathrm{~m}$ usually reduces the subgrade modulus and increases the base course modulus. For multiple load drops and deflections at a station, EVERCALC estimates the depth to stiff layer for each basin adjusted to a $40 \mathrm{kN}$ load. The mean depth and standard deviation are calculated. Any depths outside of the value of the mean plus/minus one standard deviation are removed and the mean and standard deviation are re-calculated. The 
calculated depth to stiff layer is then used in the layer moduli calculations at that station.

Using EVERCALC to perform back calculations involves filling in details on the data which do not change from station to station in the general file (*.gen) such as the load plate radius, units, sensor offsets, etc.. A deflection file (*.def) is next created to hold the specific station data such as layer thickness, surface layer temperature, number of drops, plate load, and sensor deflections for each drop. The backcalculation process uses the *.gen and *. def files and runs the WESLEA elastic layer routine within a DOS window. When the depth to stiff layer option is being used the depth is calculated first, then used in the calculation of the layer moduli. The tolerances on the RMS deflection, moduli values and number of iterations is specified in the *.gen files by the user. The complete input and output summaries and plots are available within the print/plot output option of EVERCALC.

The present study used the deflection data for all of the test dates and modelled the pavement system as three layers throughout the year. Thus during periods when thawing was taking place, the portion of the unbound layer which was thawed was not separated from the frozen portion. The overall layer modulus was calculated for these two-phase layers. The range of allowable moduli along with the seed values for this first attempt is shown as Table 4.1

\begin{tabular}{|l|c|c|c|c|c|c|}
\hline Pavement & \multicolumn{5}{|c|}{ Moduli Ranges Used for 3 Layer Analyses (GPa) } \\
\hline Layer & \multicolumn{3}{|c|}{ First Run } & \multicolumn{3}{c|}{ Second Run } \\
\hline Description & Min & Max & Seed & Min & Max & Seed \\
\hline AC & 1.0 & 10.0 & 2.8 & 2.0 & 69.0 & 20.0 \\
\hline Base & 0.2 & 0.6 & 0.3 & 0.055 & 14.0 & 0.3 \\
\hline Subgrade & 0.08 & 0.2 & 0.1 & 0.055 & 1.5 & 0.1 \\
\hline
\end{tabular}

Table 4.1 Moduli Ranges for 3 Layer Analysis

The first analysis run had modulus ranges chosen without any regard for the presence of very low temperatures and frozen layer conditions. Janoo and Berg, (1992) used this approach in their study. The results of this analysis showed that the maximum values for the $\mathrm{AC}$ and 
granular base layers were too low for test dates in the months of December through March. At the same time the minimum values for the subgrade layers were too high.

The ranges were altered to account for higher ranges for the $\mathrm{AC}$ and granular base layers and lower for the subgrade. The backcalculated moduli results were that the $\mathrm{AC}$ and granular layers were at the maximum, while the subgrade was within its range during the test dates with frozen layers. However, the results for the $\mathrm{AC}$ and granular base layers drop to extremely low values and are inconsistent during thawed periods. On the other hand, the subgrade moduli values are quite reasonable. The results of the three layer analysis are shown plotted against the test date and pass number (eg. 021494-1 is February 14,1994 Pass 1) in Figures 4.27 and 4.28.

This approach proved to be erratic and it was determined that dividing the analysis up into test dates so that the presence of frozen layers could be accounted for in the analysis. Each test date had between one and four passes of the FWD taken on the outer wheelpath. The averaged deflection data from each FWD pass was input to the *.def files. The moisture content, electrical resistance, and temperature data was used to determine the frozen layer extents in the unbound layers and those layers were input to the *.gen files. The allowable ranges for the layer moduli for the frozen and thawed layers which are shown in Table 4.2.

\begin{tabular}{|l|l|l|l|l|l|l|}
\hline Pavement & \multicolumn{4}{|c|}{ Allowable Moduli Ranges for Frozen / Thawed Analyses (GPa) } \\
\hline Layer & \multicolumn{3}{|c|}{ Thawed Periods } & \multicolumn{3}{c|}{ Frozen Periods } \\
\hline Description & Min & Max & Seed & Min & Max & Seed \\
\hline AC & 1.0 & 20.0 & 10.0 & 10.0 & 70.0 & 20.0 \\
\hline Base & 0.055 & 0.6 & 0.3 & 0.6 & 15.0 & 8.0 \\
\hline Subgrade & 0.055 & 0.3 & 0.1 & 0.6 & 2.0 & 1.0 \\
\hline
\end{tabular}

Table 4.2 Allowable Moduli Ranges 


\section{BACKCALCULATION by Evercalc 4.0 - Moduli Plot}

\section{Route: Oak Lake LTPP - SMP test site - \#831801}

Layer 1

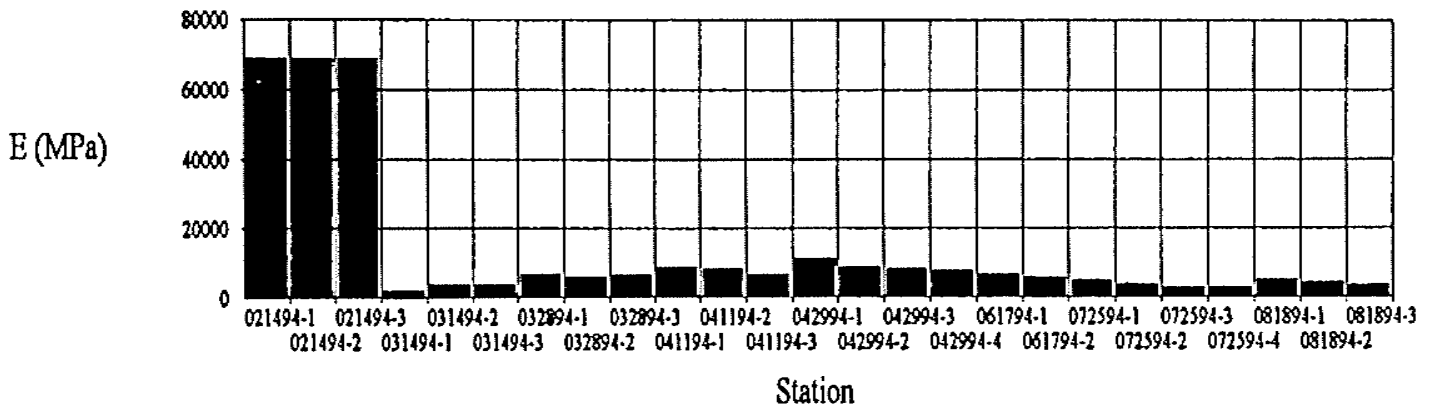

Layer 2

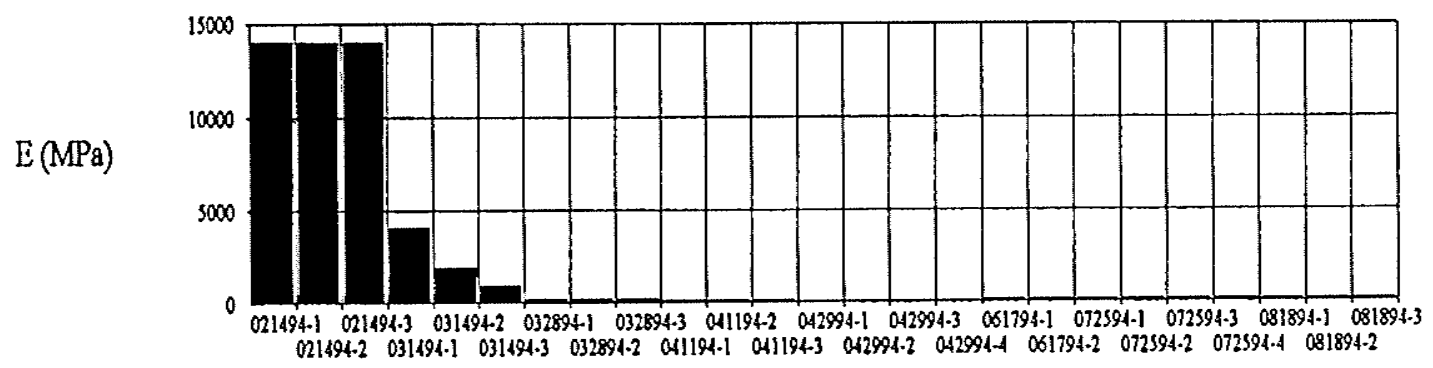

Station

Layer 3

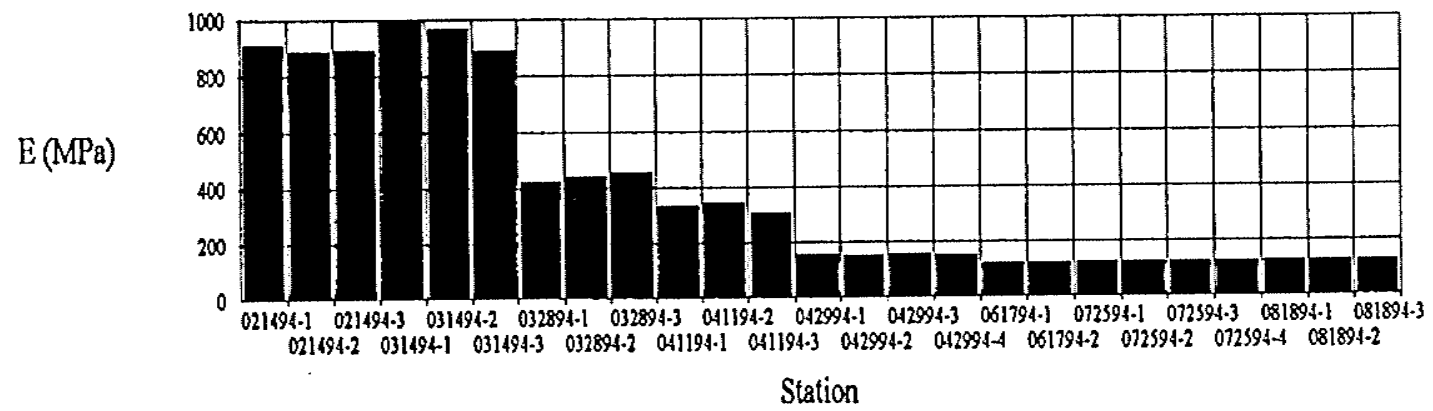

Figure 4.27 Backcalculated Layer Moduli February through August, 1994 
Route: Oak Lake LTPP - SMP test site - \#831801

Layer 1

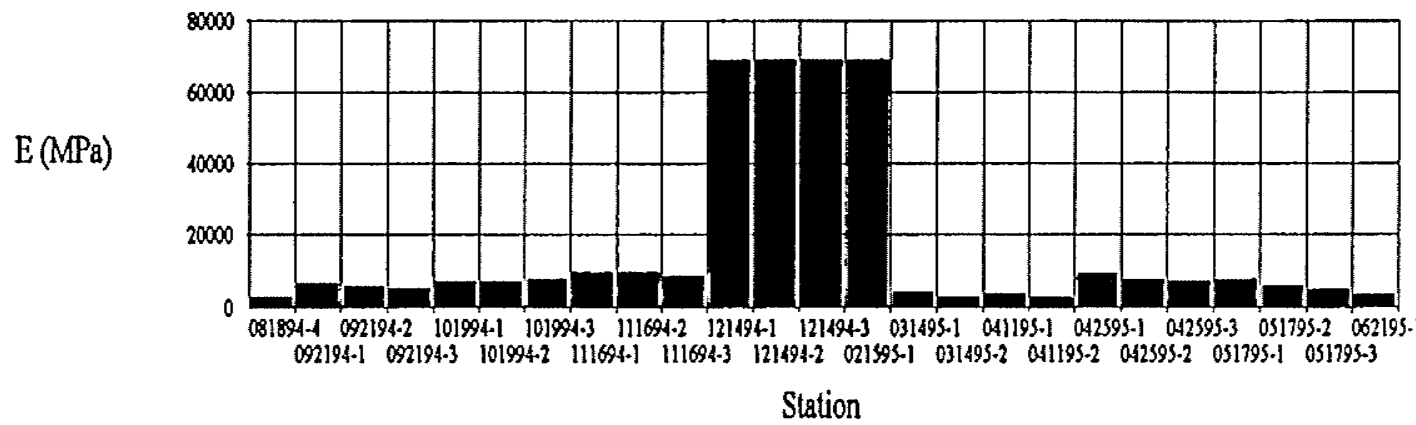

Layer 2

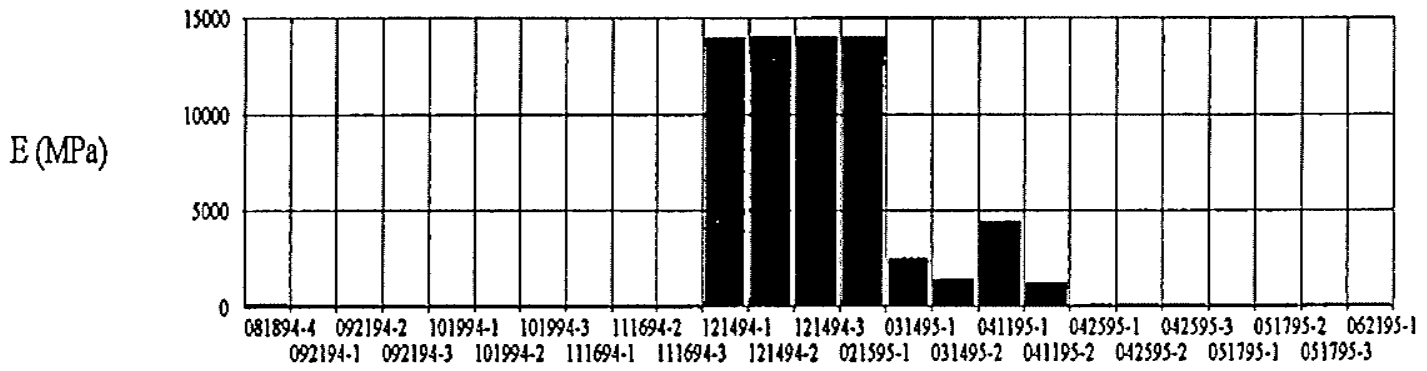

Station

Layer 3

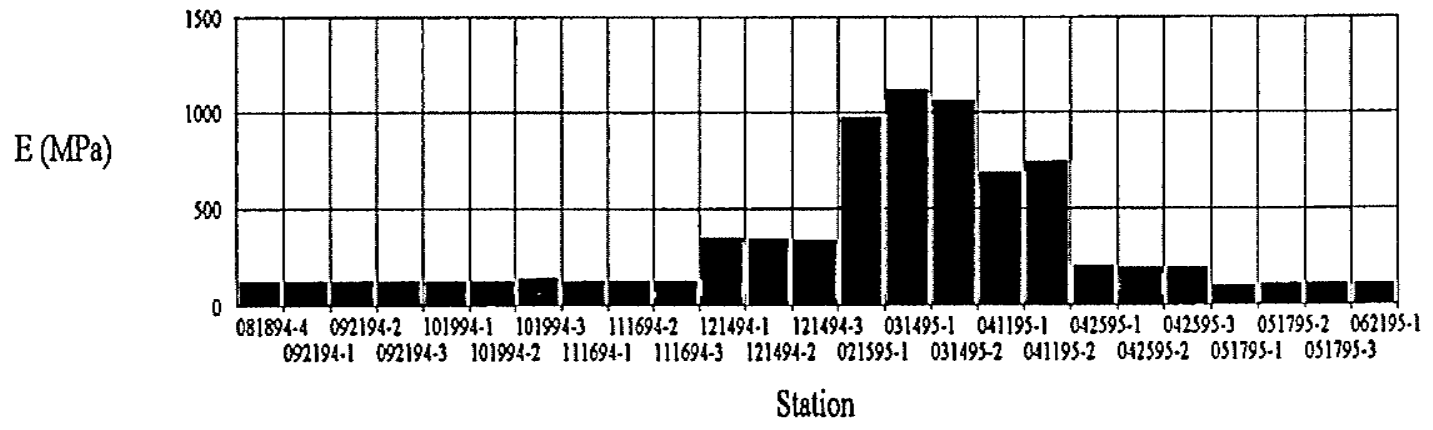

Figure 4.28 Backcalculated Layer Moduli September, 1994 through June, 1995 
Each test date had its deflection data from each FWD pass ran through the backcalculation process according to the above allowable ranges for the moduli. The results were quite good for thawed test dates with RMS errors around 1 to $2 \%$. The RMS errors for the test dates with both frozen and thawed layers present were much higher at between 8 and $24 \%$. These higher RMS errors could be attributed to the fact that backcalculation is difficult when a stiffer layer lies between two softer layers. The much higher moduli values of a frozen layer compared to thawed layers represent an ill-conditioned matrix which is used to solve for the elastic solution.

The analysis of the test dates with frozen layers present resulted in four layers being used to represent the pavement structure. This four layer analysis allowed for better backcalculated errors and results, however it would not allow for seasonal modelling of the thawed/frozen unbound layer as a whole. Thus once the four layer analysis was complete, the granular base or subgrade layer which had frozen and thawed portions (ie two-phase) were combined and the backcalculation re-run. The *.gen file was used to fix the asphalt and one-phase base and

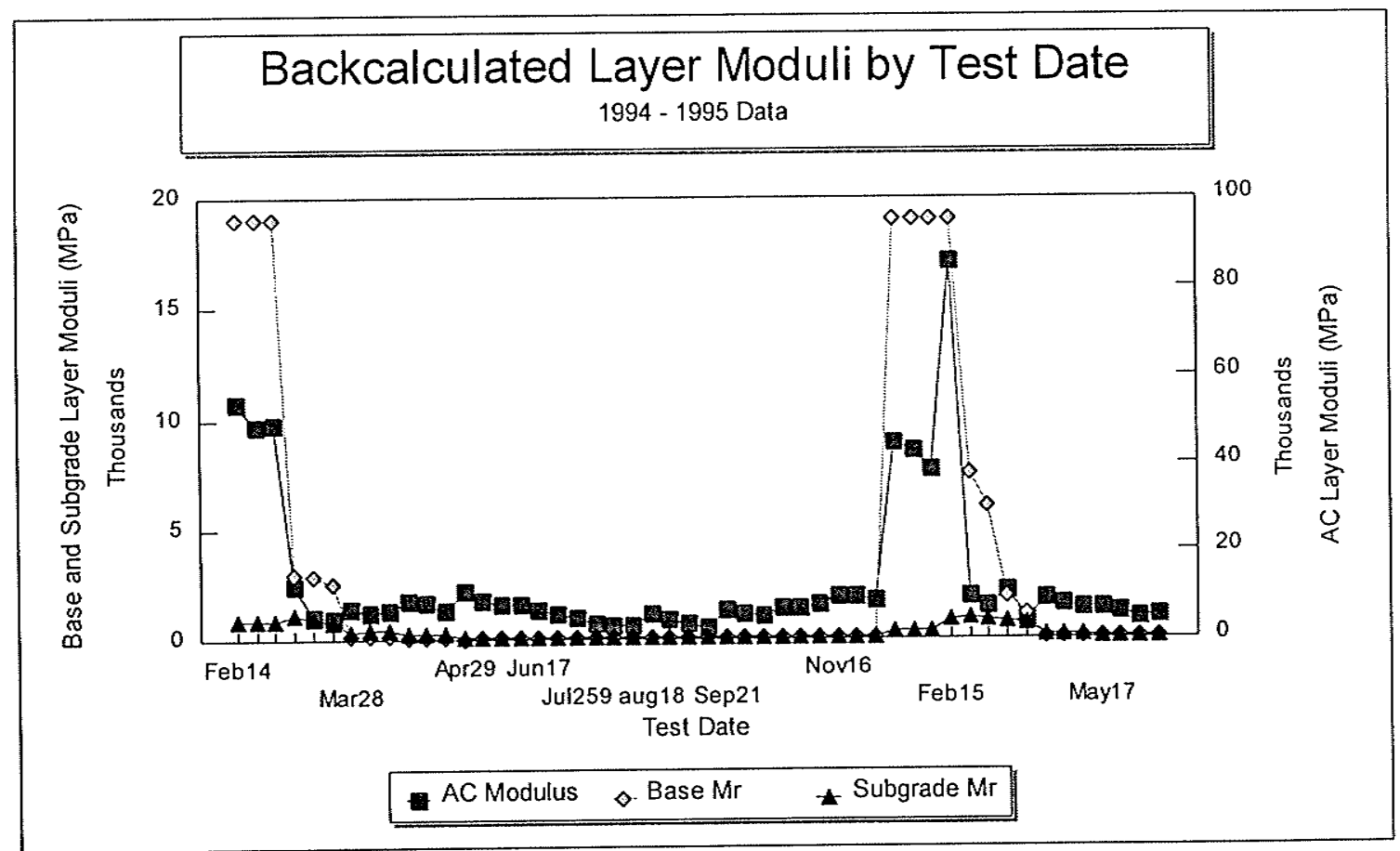

Figure 4.29 Backcalculated Layer Moduli 
subgrade layer moduli which had been calculated under the four layer analysis. The EVERCALC program then was run to minimize the error by searching for a solution for the two-phase layer between the thawed lower bound and frozen upper bound moduli values calculated in the four layer analysis. This is a compromised solution at best but the backcalculation approach did yield acceptable results in the four layer analysis. This compromise of turning the four layer analysis into three layers was done only to accomplish the modelling of the seasonal variation of the three layers throughout the year. This approach yielded much higher RMS errors ( up to 35\%) than the four layer analysis but the merit of the backcalculation approach should not be judged on this compromise for the modelling. The result of this four-layer analysis forced into three-layers is shown in Figure 4.29 and included as Appendix D.

The trends in the backcalculated values for the AC layer show a strong relationship to the variations in pavement layer temperature. The asphalt moduli decrease from the frozen values in February through July and August when the trend reverses. The values increase dramatically in December as the pavement freezes. The asphalt layer moduli also vary with temperature during each test date as the temperature increases or decreases. The granular base and subgrade layers follow the same temporal trends as the asphalt layer, however the variations are lagged behind the response of the asphalt layer with the increasing depth in the layers. The subgrade does not show the daily variation in moduli values while the granular base layer does show some daily variation. However, the variation is by no means as pronounced as that of the asphalt layer.

\subsection{Thawing Index}

An environmental factor which causes the seasonal variation in the stiffness of the pavement layers had to be determined. The literature review found that other researchers had used a Thawing Index to represent the independent variable representing the environmental factor. These Thawing Indices were summations of the air or pavement temperatures. The LTPP 
collects data on the air temperature at hourly and daily averages. Both of these summaries were evaluated for their potential benefit in representing the environmental effect. The daily average temperatures were assembled and the first day of positive average temperature was located. From this date forward the temperatures were summed and the values reported in Table 4.3. There is no data available for the February, 1995 temperatures due to instrument failure. The temperature data from the other Manitoba SMP site near Glenlea $300 \mathrm{~km}$ to the east was used in lieu of the lost data. The sum of the daily average temperatures did not show a very good relationship to the change in moduli which was occurring throughout March and April, 1994. The sum of the daily average temperature for the thawing period in

\begin{tabular}{|l|c|c|c|}
\hline Date & $\begin{array}{c}\text { Sum Avg Day } \\
\text { Temp (deg*day) }\end{array}$ & $\begin{array}{c}\text { Sum Avg Hourly } \\
\text { Temp (deg*hrs) }\end{array}$ & $\begin{array}{c}\text { Sum Positive Hour } \\
\text { Temp (deg*hrs) }\end{array}$ \\
\hline March 14, 1994 & 2 & 0 & 398 \\
\hline March 28, 1994 & -7 & -250 & 823 \\
\hline April 11, 1994 & 19 & 77 & 1840 \\
\hline April 29, 1994 & 130 & 2748 & 4775 \\
\hline March 14, 1995 & 0 & -2380 & 255 \\
\hline April 11, 1995 & -101 & -2700 & 538 \\
\hline April 25, 1995 & -57 & -1600 & 1705 \\
\hline May 17, 1995 & 128 & 2500 & 5863 \\
\hline
\end{tabular}

Table 4.3 Thawing Indices Values

1995 showed large negative values until the end of April, 1995. The next environmental data evaluated was the sum of the hourly average temperatures again shown in Table 4.3. Beginning on Mar 14, 1994 these values showed negative values to March 28 which was not indicative of the thawing which was ongoing. The third environmental data was the sum of the positive average hourly temperatures. It was postulated that once thawing has begun in the layers during the warmer daylight hours, cooler night time temperatures would not be 
able to freeze the mass again. Perhaps the more significant variable would be the solar radiation which is imparted to the pavement surface. However the only indicator of the environmental factor causing the thawing and collected by the LTPP was the air temperature. The sum of the positive average hourly air temperatures was modelled as the Thawing Index used in this study to quantify the thawing effect of the environment on the pavement structure. 


\section{5 : Modelling of Seasonal Variation of Material Properties}

All of the environmental and surface deflection data were analysed and processed in the previous chapters in order to arrive at a viable process for modelling the seasonal variation in the material properties on the SMP test site near Oak Lake, Manitoba. The backcalculated asphalt concrete layer moduli were used together with the asphalt layer temperatures to model the seasonal variation in the asphalt layer stiffness. The Thawing Index values on each test date together with the unbound layer moduli were used to model the seasonal variation in the base and subgrade layer stiffnesses.

The program CurveExpert 1.20 (C) 1995-96 by Daniel Hyams) was used to choose the model which best represented the environmental versus layer moduli data. CurveExpert uses its proprietary program CurveFinder to find the best regression model to fit whatever data is input to it. The user is free to specify which of the 30 types of regression models built-in to CurveFinder to evaluate the data fit. CurveFinder then ranks the specified models on the basis of standard error and correlation coefficient. Polynomial models are also used in the search and the user may specify the maximum degree of polynomial to use.

From the literature review and the data presented in the previous chapter, it was determined that the resilient modulus of the asphalt concrete layer would be most sensitive to the temperature of the asphalt layer. The LTPP collects temperature data within the asphalt layer at three depths; 25,55 , and $90 \mathrm{~mm}$. Each of these temperature depths were used as the independent variable against the resilient modulus of the asphalt concrete layer. The regression output for the third degree polynomial models of the form; $\mathrm{E}_{\mathrm{AC}}=\mathrm{a}+\mathrm{bT}+\mathrm{cT}^{2}+$ $\mathrm{dT}^{3}$, as selected by CurveExpert is shown as Table 5.1. 


\begin{tabular}{|c|c|c|c|c|c|c|}
\hline Temperature & Correlation & Standard & \multicolumn{4}{|c|}{ Regression Coefficients } \\
\cline { 3 - 7 } Depth (mm) & Coefficient & Error & a & b & c & d \\
\hline 25 & 0.93 & 6372 & 16663 & -2013 & 111 & -1.89 \\
\hline 55 & 0.94 & 5954 & 15615 & -1944 & 104.6 & -1.77 \\
\hline 90 & 0.95 & 5461 & 14302 & -1903 & 108 & -1.93 \\
\hline
\end{tabular}

Table 5.1 Correlation Values for AC Layer Temperature Models

The models all represent the environmental effect of layer temperature on the modulus of the $\mathrm{AC}$ layer as correlation coefficients are over 0.93 . Thus the selection of the temperature depth to use was the surface temperature as it is the easiest to measure. The surface temperature versus the $\mathrm{AC}$ layer moduli third degree polynomial fit is shown in Figure 5.1. Note that the polynomial model does not give a good fit above $20^{\circ} \mathrm{C}$ as it rises slightly with temperature to approximately $26^{\circ} \mathrm{C}$. When using the polynomial model one should ignore

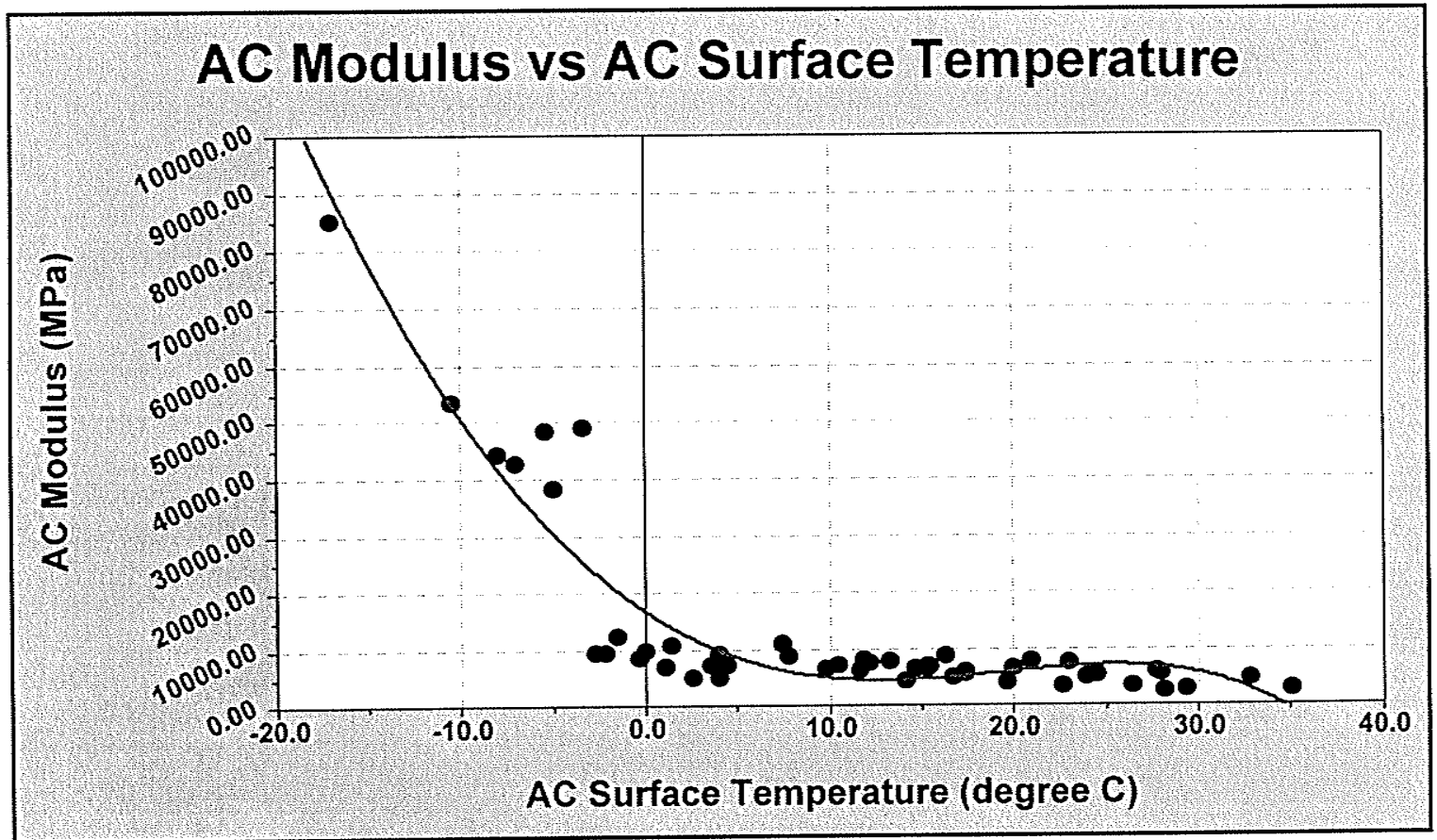

Figure 5.1 Third Degree Polynomial Fit of the Data

this portion of the curve and linearly interpolate the $\mathrm{AC}$ resilient model from $20^{\circ} \mathrm{C}$ to the modulus value at the highest temperature. 


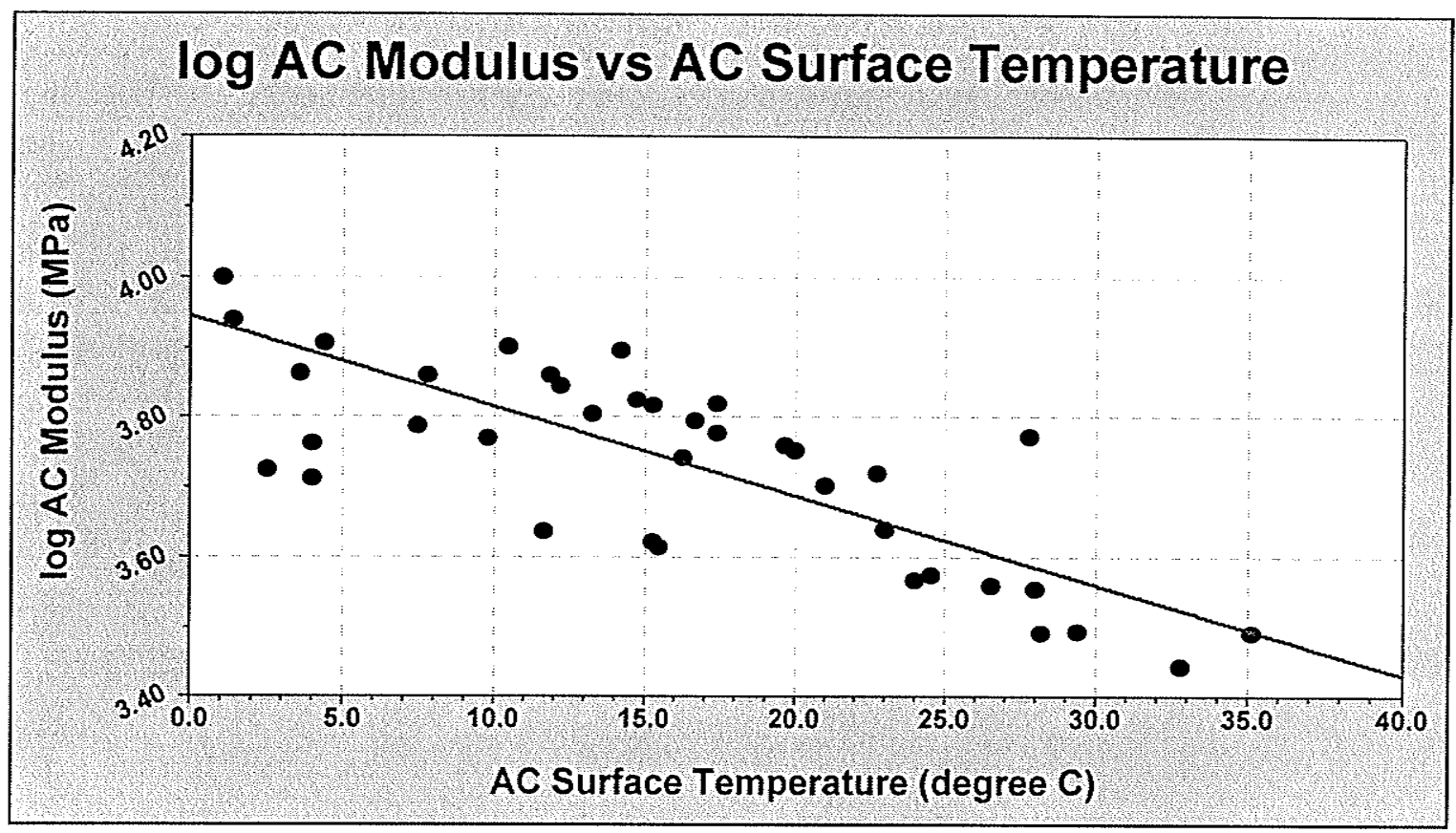

Figure 5.2 Semi-log Fit of the Data

The critical time of the year for the moduli values and thus the weakest condition of the pavement structure is during the spring thaw when unbound layers are melting and thus the pavement temperature is above $0{ }^{\circ} \mathrm{C}$. A simple semi-log linear model of the form $\log \left(\mathrm{E}_{\mathrm{AC}}\right)=\mathrm{a}+\mathrm{bT}$, that considers the temperature range from 0 to $30^{\circ} \mathrm{C}$ is shown in Figure 5.2. The regression coefficients of the model in Figure 5.2 are; standard error $=0.0964967$, correlation coefficient $=0.7858131$, and coefficients; $a=3.9448496, b=-0.012844353$.

The Thawing Index was used to represent the independent variable in modelling the resilient moduli of the base and subgrade layers. The Thawing Index chosen was the sum of the positive degree hours beginning from the first occurrence of positive hourly temperatures in the records. Using this Thawing Index as the independent variable versus the base layer as the dependant variable gives the non-linear model shown in Figure 5.3. 


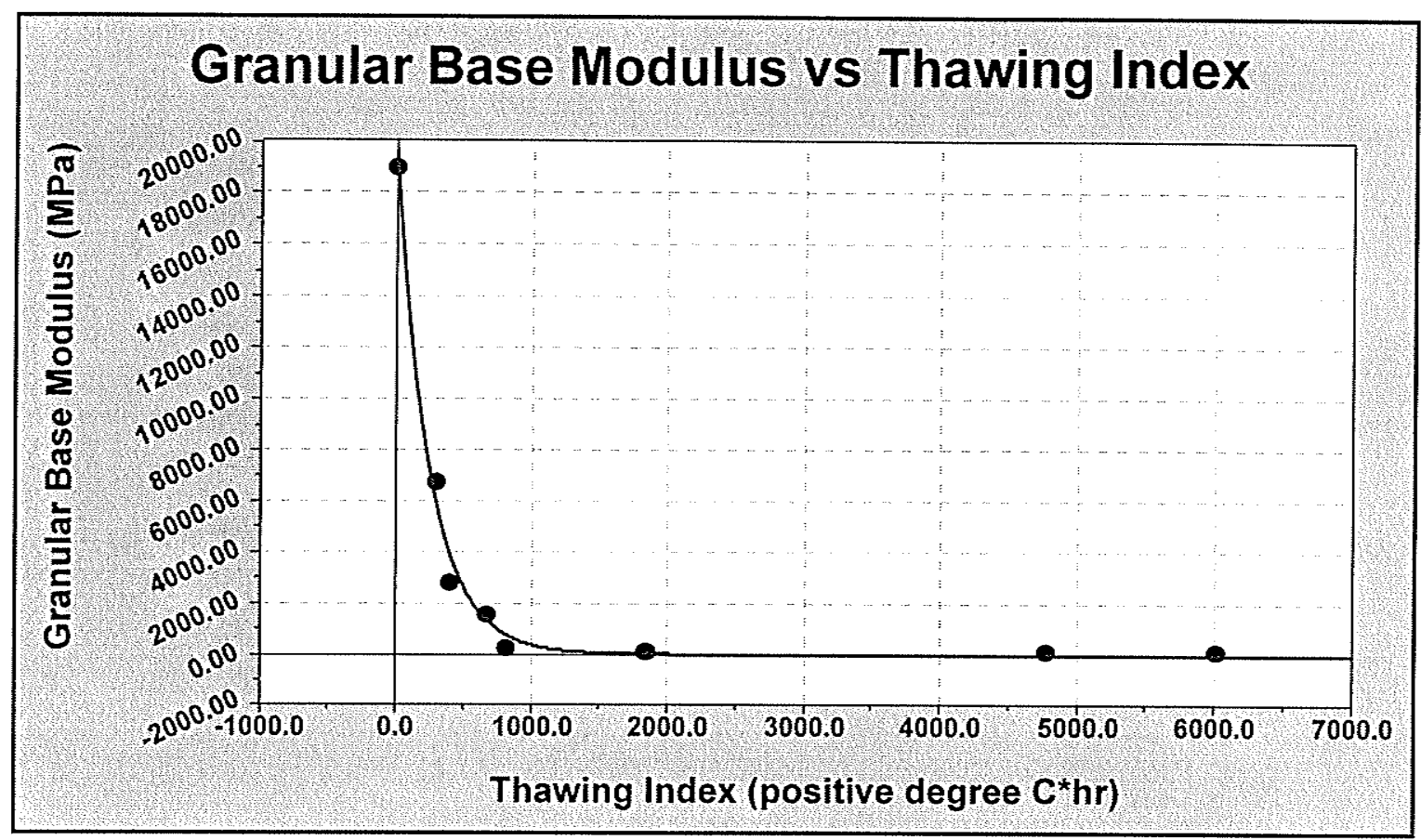

Figure 5.3 Exponential Fit of the Data

The regression coefficients for the model of the form $E_{B}=a e^{b T}$ shown in Figure 5.3 are; standard error: 598.7406540, correlation coefficient: 0.99596 , and coefficient data:

$\mathrm{a}=19076.115, \mathrm{~b}=-0.0039825$. Figure 5.3 shows that the granular base layer moduli becomes extremely weak in a very short time span. The modulus falls from 19,000 to under $227 \mathrm{MPa}$ in 823 degree*hrs. A review of the data for the 1994 and 1995 seasons demonstrated that the 823 degree*hrs of thawing occurred over a time span of as little as 27 days. This relationship reinforces the importance of seasonal effects in pavement performance as the dramatic reduction in the load-carrying capacity occurs after a small amount of positive hours of air temperature.

The subgrade layer modulus was modelled in a similar manner as the granular base and shown in Figure 5.6. The model shown is a third degree polynomial fit of the form $E_{S}=a+b T+c T^{2}+d T^{3}$ with coefficient data: $a=1067.0925, b=-0.66546415$, $c=0.00015066284$, and $d=-1.0996051 \mathrm{e}-08$, the standard error: 170.9329216 , and the correlation coefficient: 0.9450539 . The Thawing Index values are identical to those used for 


\section{Subgrade Modulus vs Thawing Index}

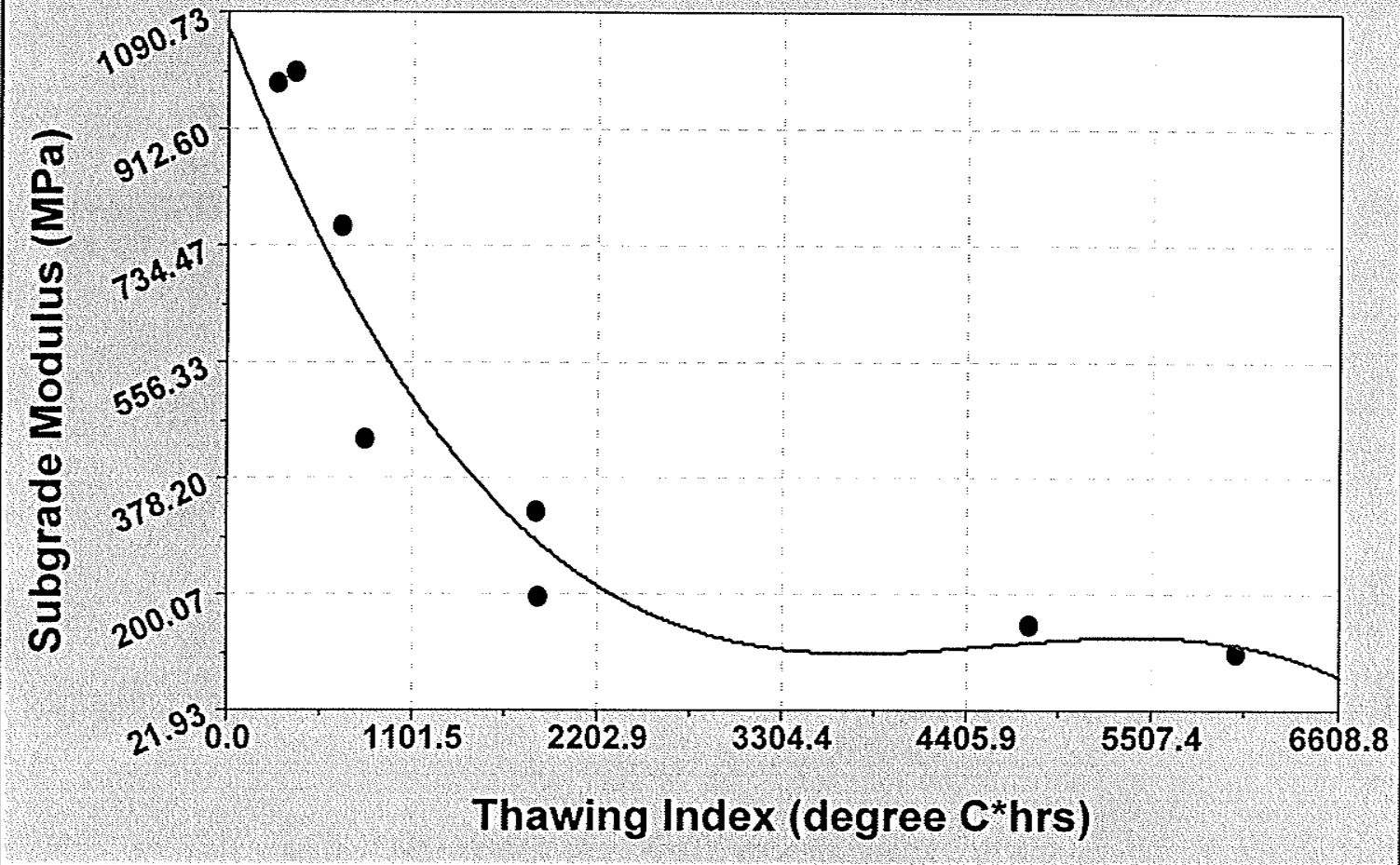

Figure 5.4 Third Degree Polynomial Fit of the Data

the granular base model however the moduli range is much lower for the subgrade layer.

Again the form of the polynomial relationship must be noted as it rises slightly above approximately 3800 degree*hrs and should be drawn horizontally from this point as the modulus has reached its minimum value. Although the range of moduli are small, it still represents a substantial decrease in the moduli of the layer. It is not as sudden of a decrease in moduli as the granular base as it takes about 2000 degree*hours to bring the moduli to their weakest state.

The literature review found two sets of models on the relationship between $\mathrm{AC}$ moduli and temperature, the first by Han et al, (1994) and the second by Van Deusen and Newcomb, (1994). The AC layer moduli results are compared to the two models proposed in the present 


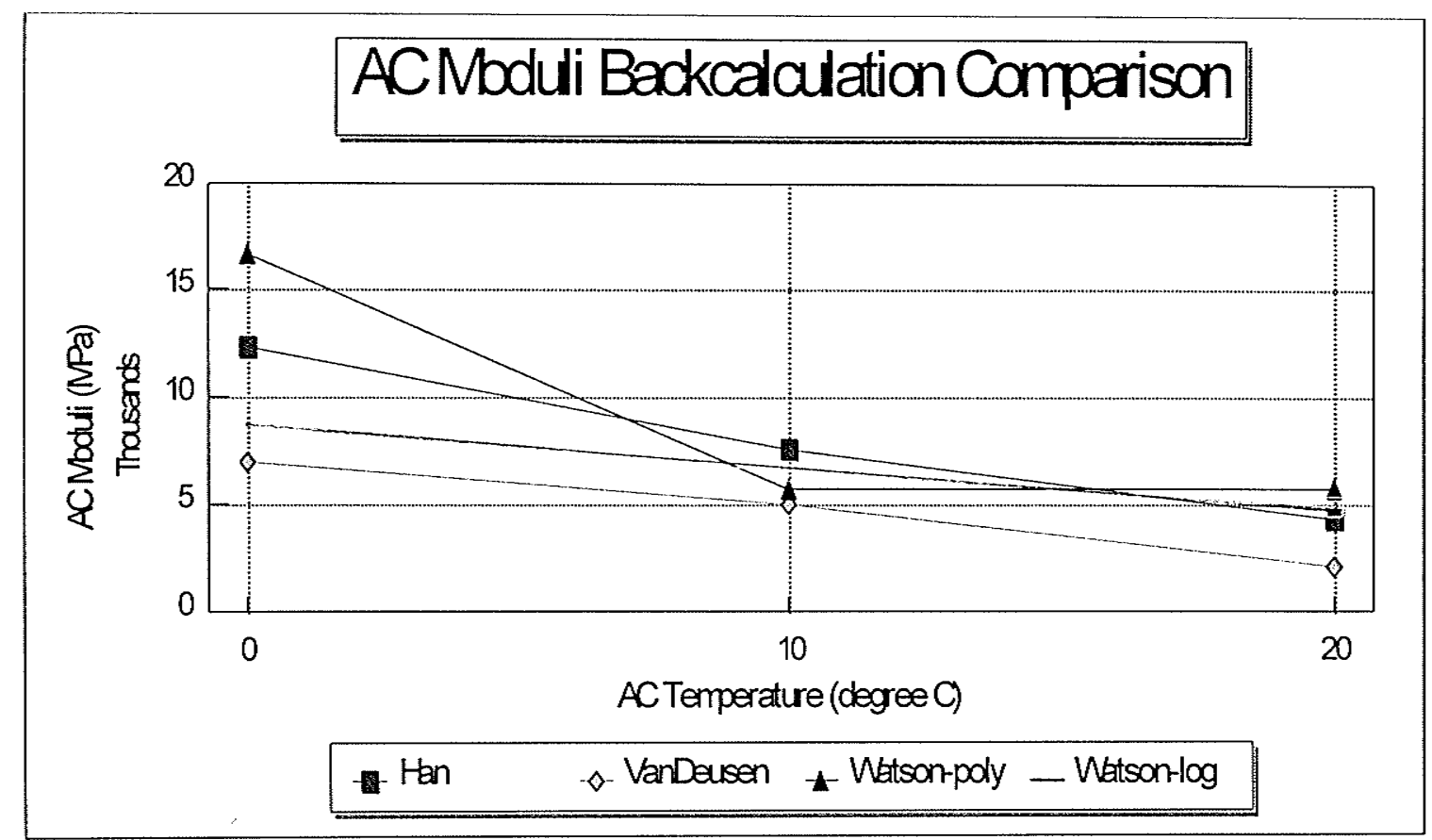

Figure 5.5 Comparison of AC Moduli from Past and Present Studies

study as summarized in Figure 5.5. The Watson-poly and Watson-log data ranges refer to the third degree polynomial model utilizing all of the data and the semi-log relationship utilizing the data taken above $0^{\circ} \mathrm{C}$. Comparison of the moduli results demonstrates a trend among the results. The Watson-poly model is higher than any of the other models at zero degrees which agrees with the observation previously made that it accounts for the extremely high values below zero degrees. This model thus overestimates the resilient moduli for the AC layer at zero degrees. Figure 5.5 shows that all of the models result in moduli that differ, however they do not vary by orders of magnitude. Note that the calculated moduli for the zero degree level vary from approximately 7,000 to $17,000 \mathrm{MPa}$. The moduli results for the twenty degree level vary even less from approximately 2,000 to 6,000 MPa. The comparison of the calculated moduli gives a reasonable amount of confidence to the use of these models., especially when considering the differences in the sites and variables in each of the studies. For example, Han et al (1994) used data from seven different sites (including the Oak Lake site) in the North Central Region of the LTPP. The physical differences in the pavement structure of the sites were ignored in the Han study. This indicates that seasonal variation 
of the material properties of pavements occurs independently of the structure of the site. Van Deusen and Newcomb, (1994) used the estimated mid-depth pavement temperature from the Southgate, (1969) method as the independent variable versus the resilient modulus of the AC layer. The surface layer temperature was used in the present study as the independent variable versus the resilient moduli. The Van Deusen results agree closely with the Watson$\log$ model shown in Figure 5.5 which suggests that the resilient modulus is related to the temperature of the $\mathrm{AC}$ layer at various points. This fact is confirmed by the modelling results shown in Table 5.1 from the present study. Van Deusen used a full-depth AC pavement which differs from the Oak Lake structure which confirms that the seasonal variation of the pavement material properties is independent of the type of structure. 


\section{6 : Conclusion}

The present study used environmental and pavement surface deflection data to model the variation in the resilient moduli of a flexible pavement in southwestern Manitoba. The data was provided by the Seasonal Monitoring Program of the U.S.A. Federal Highway Administration, Long-Term Pavement Performance study. Environmental data in the form of air, pavement, and soil temperatures was used to model the seasonal variation of the pavement layer stiffnesses. FWD deflection data was used to backcalculate the resilient moduli of each pavement layer through the elastic layer theory program EVERCALC. The seasonal variation in the stiffness of each layer was modelled against the temperature (for $\mathrm{AC}$ layer) and Thawing Index (for the base and subgrade layers). These models proved that this research approach may be successfully used to quantify the seasonal variation in pavement layer resilient moduli.

Some concerns arose from the LTPP data collection procedures. Collecting data on solar radiation or heating could provide a better indicator of the amount of thawing energy being imparted to the surface. Data on the rainfall and groundwater table were analysed within the course of the present study. No significant effect was found to arise out of these variables and their discussion was not included in the present study. The electrical resistance data was collected by a mobile datalogger and by manual means. The present study was not able to use the mobile datalogger-collected electrical resistance data to determine the extent of the frozen layers in the base and subgrade layers. The manually-collected data was very useful when used in conjunction with the TDR soil moisture readings. The TDR readings were found to give unreasonable results when the TDR probes came into contact with frost. The result was that the moisture content readings dropped significantly, and when these values were compared to the unfrozen readings it became a good indicator of frozen layer extent. 
The soil temperature readings were found to be of little to no use in determining frost layer locations as the temperatures established nearly isothermal conditions for much of the thawing period. The FWD deflection data was very useful as its processing into resilient moduli values provided for highly correlated models of seasonal variation. The approach taken to use averaged sensor deflections for each pass to overcome the strong locational variability problem in the readings. This approach could be used in project- and networklevel FWD data collections to resolve this major obstacle of locational variability of physical factors.

The trends in the seasonal variation of the resilient moduli have been modelled for each of the layers. These models of resilient moduli are now available for the pavement designers to use to design pavements according to the mechanistic-empirical approach. The use of these models together with environmental and load data would allow for mechanistic pavement design to occur. One such use of the models would be to select worst case scenarios of high pavement surface temperatures and appropriate values of Thawing Index to ensure thawing of the base and subgrade layers and determine the moduli of each of the layers. Pavement designers could then apply various loads to the pavement structure and calculate the deflection of the surface. The deflections obtained in this manner could then be compared to the Benkelman Beam Rebound charts to determine if the deflection is within the allowable limits of the charts. If the deflection is not within the allowable limit set by the Benkelman Beam chart then the pavement structure is not adequate for the load imposed upon it. The asphalt layer thickness could then be increased until such time as the maximum allowable deflection according to the Benkelman Beam chart theoretically occurs. This analysis would thereby predict the increase in asphalt layer thickness which would be required for this site to give the maximum allowable deflection as given in the Benkelman Beam chart.

Another use of this analysis would be to calculate the allowable loads for this set of surface 
temperatures and thaw weakened base and subgrade layers. These models could also be used to take a range of layer moduli and vary the layer thicknesses to calculate the minimum thicknesses which could carry the load without excessive deflection and therefore damage occurring. Thus the pavement design process could be analysed through the use of these models.

As the Thawing Index values which cause the thaw weakened base and subgrade layers have been determined for this site, the staff responsible for the Spring Weight Restrictions program could track the progression of the Thawing Index for each season and determine the timing and magnitude of the weight restrictions. This could be extended to other sites in Manitoba to justify the timing of the Weight Restrictions period during the spring thaw. Currently the Weight Restriction period is set by calender dates. The dates are chosen on the basis of historical Benkelman Beam Rebound tests and the judgement of Departmental staff responsible for the maintenance of the highway network. Of special interest to the staff of Manitoba Department of Highways and Transportation would be the modelling of seasonal variation of pavement layer moduli of thin membrane-surfaced roads also known as Asphalt Surface Treatments.

Recommendations for further research also include evaluating the seasonal variation in the stresses and strains in pavement layers caused by applied loads. Another topic which could use the results of the present study is varying the layer thicknesses to study the effect thickness has on the critical stresses and strains at different times of the year. The present study could be used to assess the pavement structural thickness strategy currently used by Manitoba Highways and Transportation.

Thus the use of these models will benefit Manitoba Highways and Transportation as it moves towards mechanistic pavement design and rehabilitation. As more of these models are developed the better the predictive capabilities in pavement design will become. 


\section{References}

Briggs, Robert C., Scullion, Tom, Maser, Kenneth R., Asphalt Thickness Variation on Texas

Strategic Highway Research Program Sections and Effect on Backcalculated Moduli, Transportation Research Record No. 1377, Washington, D.C., 1992, pp. 115-127 Irwin,

Han, Chunhua, Lukanen, Erland O., Van Sambeek, Robert, Seasonal Variation and Fatigue Damage of Flexible Pavements in the North Central Region of FHWA - LTPP Study, Braun Intertec Corporation, Transportation Research Board. 73rd Annual Meeting, Washington, D.C., January 9-13, 1994

Hasim, M.S., Hameed, A. M., Mustaffa, M.S., The Effect of Edge Restraint on FWD Deflection Values Tested on Asphalt Road Pavement, Public Works Institute, Proceedings of the 4th International Bearing Conference on the Bearing Capacity of Roads and Airfields, Minneapolis, Mn., 1994, pp. 259-272

Irwin, Lynne H., Practical Realities and Concerns Regarding Pavement Evaluation, Cornell University, Ithaca, New York, Proceedings of the 4th International Bearing Conference on the Bearing Capacity of Roads and Airfields, Minneapolis, Mn., 1994, pp. 19-45

Janoo, Vincent E. and Berg, Richard L., Layer Moduli Determination During Freeze-Thaw Periods, Transportation Research Record No. 1377, Washington, D.C., 1992, pp. 26-35

Lee, S.W., Mahoney, J.P., Jackson, N.C., Verification of Backcalculation of Pavement Moduli, Transportation Research Record 1196, 1988

McCullough, Frank, Taute, Arthur, Use of Deflection Measurements for Determining Pavement Material Properties, B., Transportation Research Record No. 852, Transportation 
Research Board, National Academy of Sciences, Washington, D.C., 1982, pp. 8-14

PCS/Law Engineering and Braun Intertec Pavement, Inc., Manual for FWD Testing in the Long-Term Pavement Performance Program, Strategic Highway Research Program, National Research Council, Washington, D.C., 1993

Rada, G.R., Elkins, G.E., Henderson, B., and Van Sambeek, R.J., Lopez, Jr., A., LTPP Seasonal Monitoring Program: Instrumentation Installation and Data Collection Guidelines, PCs/Law Engineering/ Office of Engineering and Highway Operations R\&D, Federal Highway Administration, McLean, Virginia, 1994

Rhode, G. T., and Scullion, T., MODULUS 4.0: Expansion and Validation of the Modulus Backcalculation System, Research Report 1123-3, Texas Transportation Institute, Texas A\&M University, College Station, Texas, 1990

Southgate, H. F., Deen, R.C., Temperature Distribution in Asphalt Pavements and its Relationship to Pavement Deflection, Highway Research Board 291, 1969

Van Deusen, David A., Newcomb, David, Strains Due to Load in Frozen and Thawed Flexible Pavements, Proceedings of the 4th International Bearing Conference on the Bearing Capacity of Roads and Airfields, Minneapolis, Mn., 1994, pp. 683-704

Washington State Department of Transportation, Materials Laboratory, WSDOT Pavement Guide, Volume 3 - Pavement Analysis Computer Software and Case Studies, 1995 , PO Box 167, Olympia, WA, February, 1995

Yue, Zhongqi, Svec, Otto J., Effect of Vertical Non-Homogeneity in Pavement Structural Layer Moduli on Non-Destructive Evaluation, Proceedings of the 4th International Bearing 
Conference on the Bearing Capacity of Roads and Airfields, Minneapolis, Mn., 1994, pp. $109-122$

Zhou, Haiping, Elkins, Gary, Pavement Responses to Seasonal variation, Proceedings of the 4th International Bearing Conference on the Bearing Capacity of Roads and Airfields, Minneapolis, Mn., 1994, pp. 705-720 


\section{Appendix A :}

\section{Surface Deflection Data}




\section{LOCATIONAL VARIABILITY BY SENSOR \#} 95HF F3 DATA - PASS 1

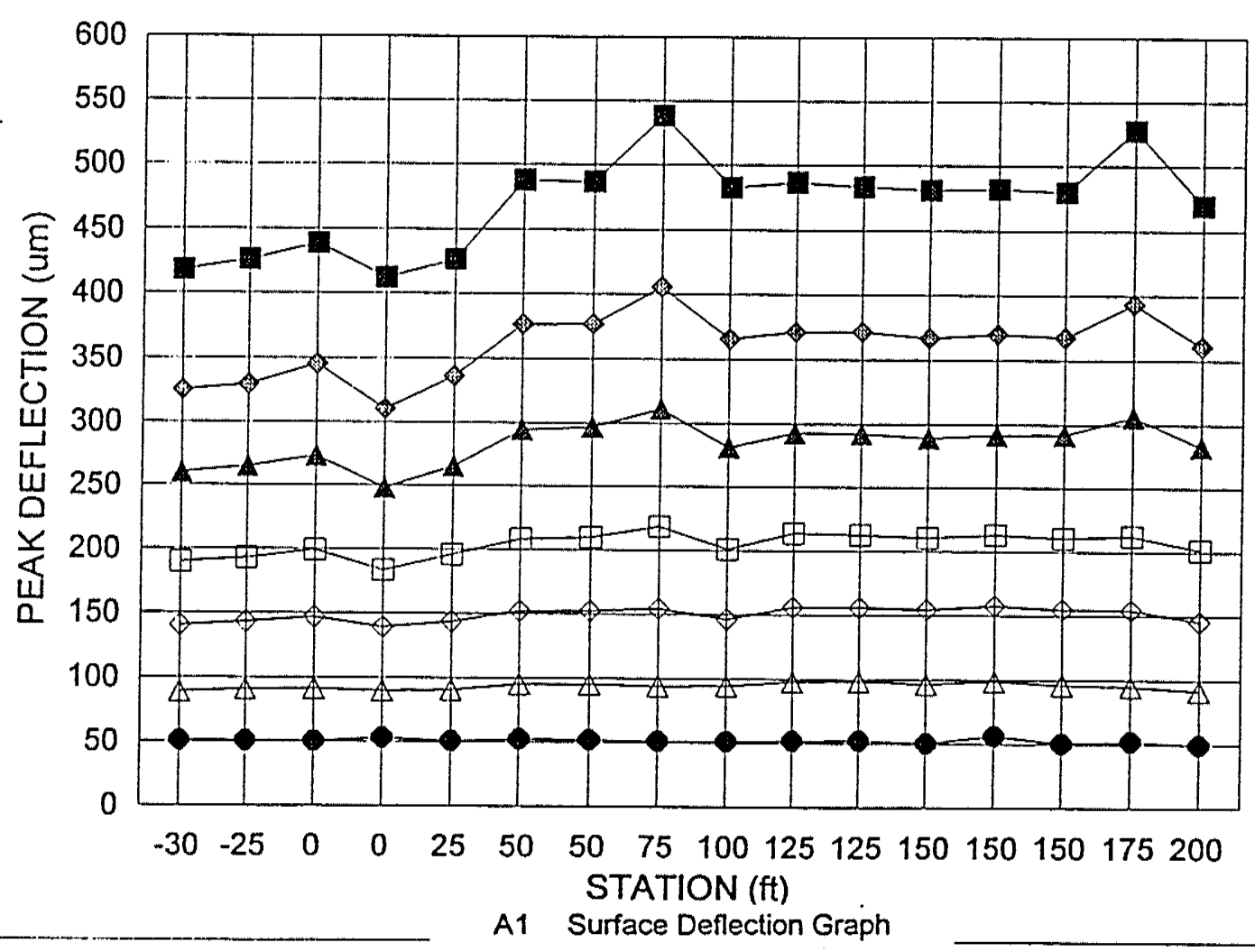




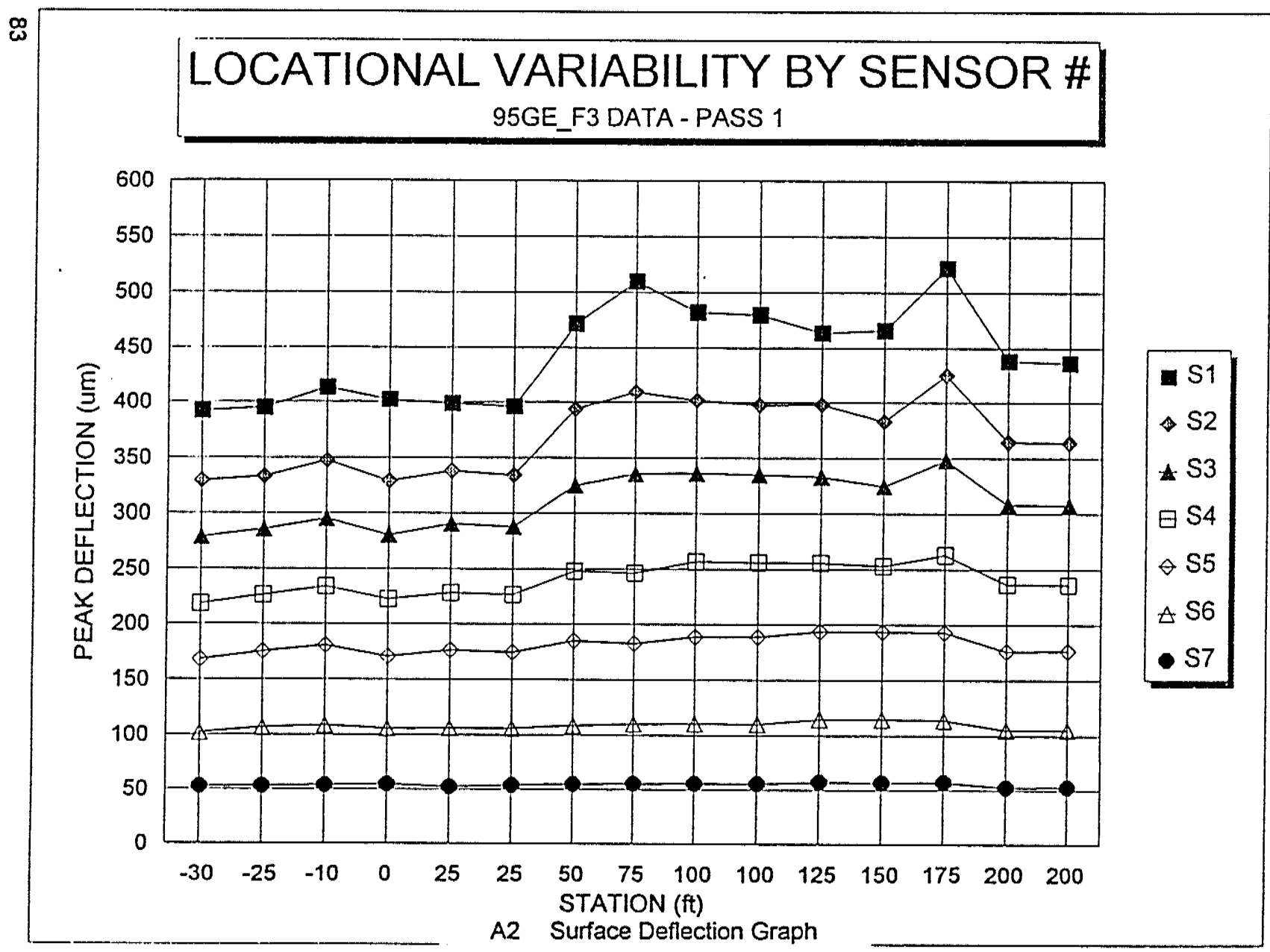




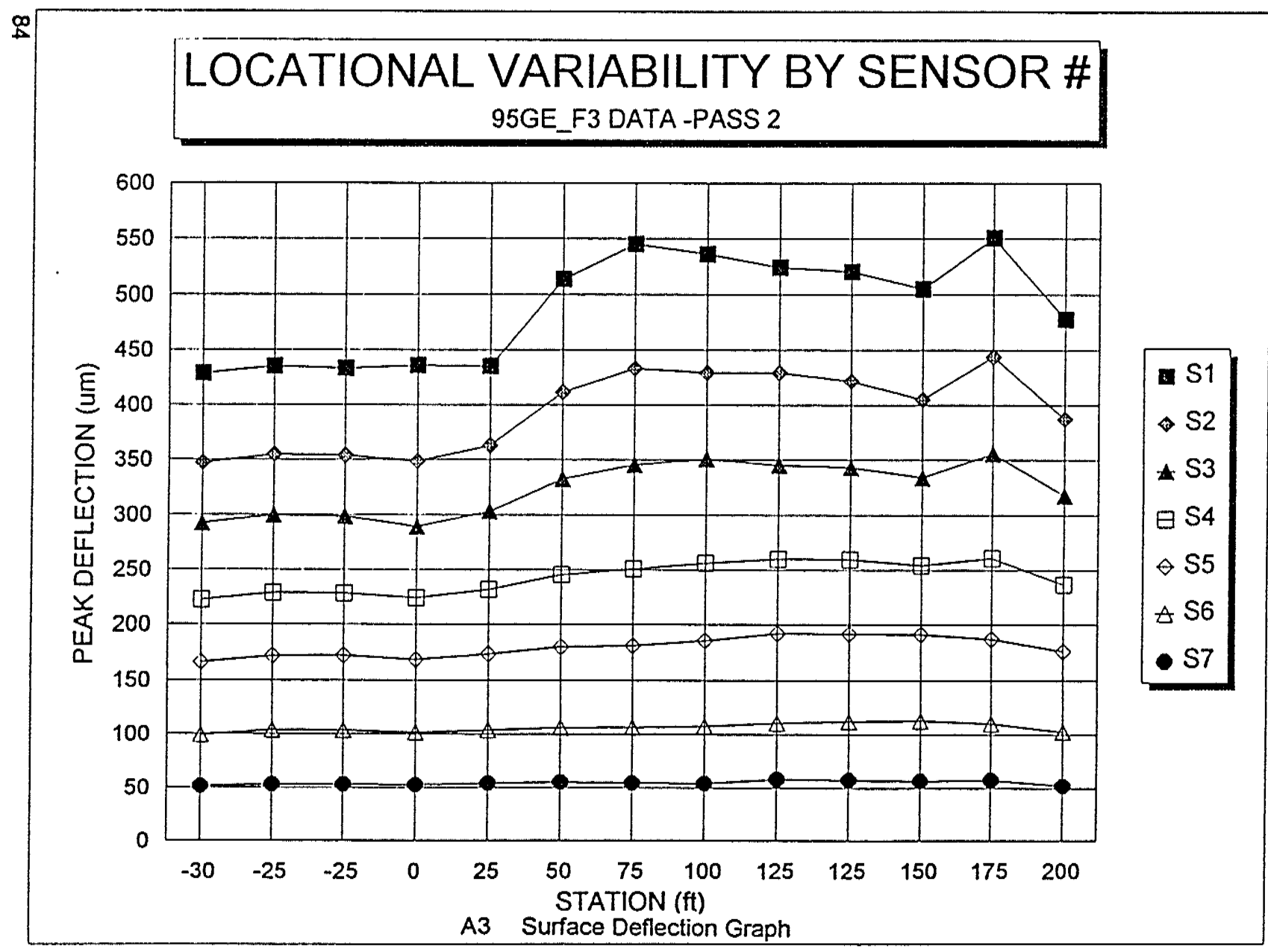




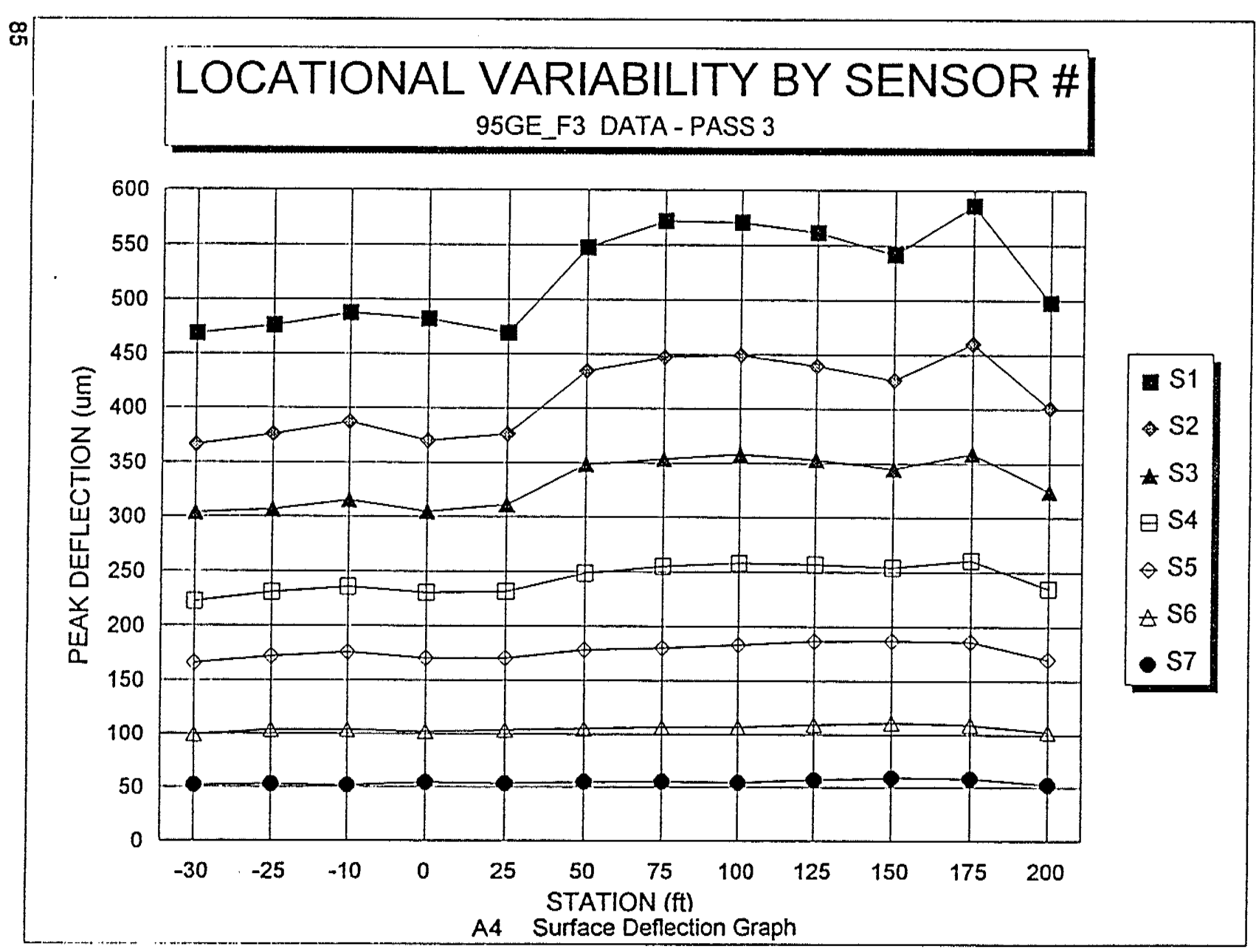




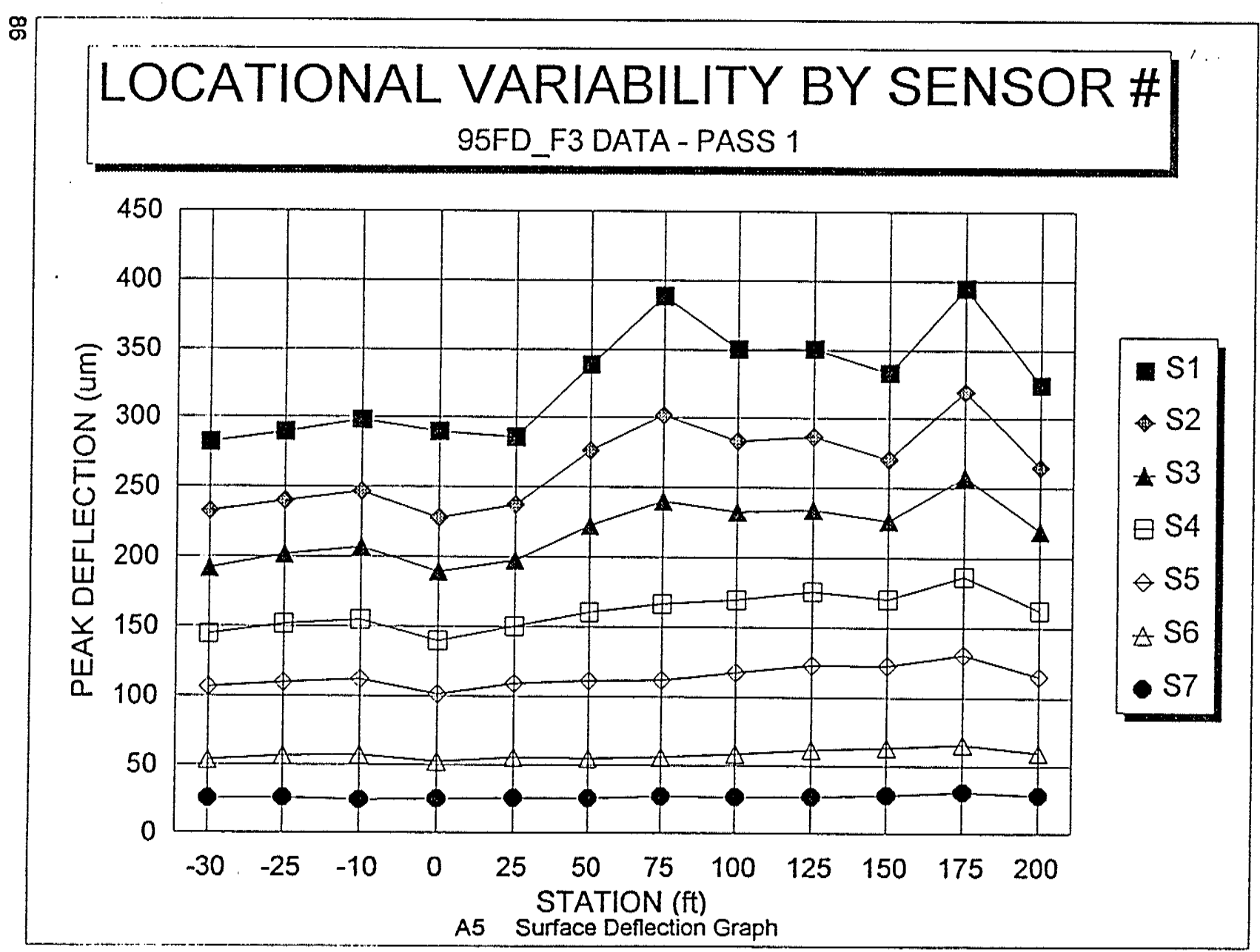




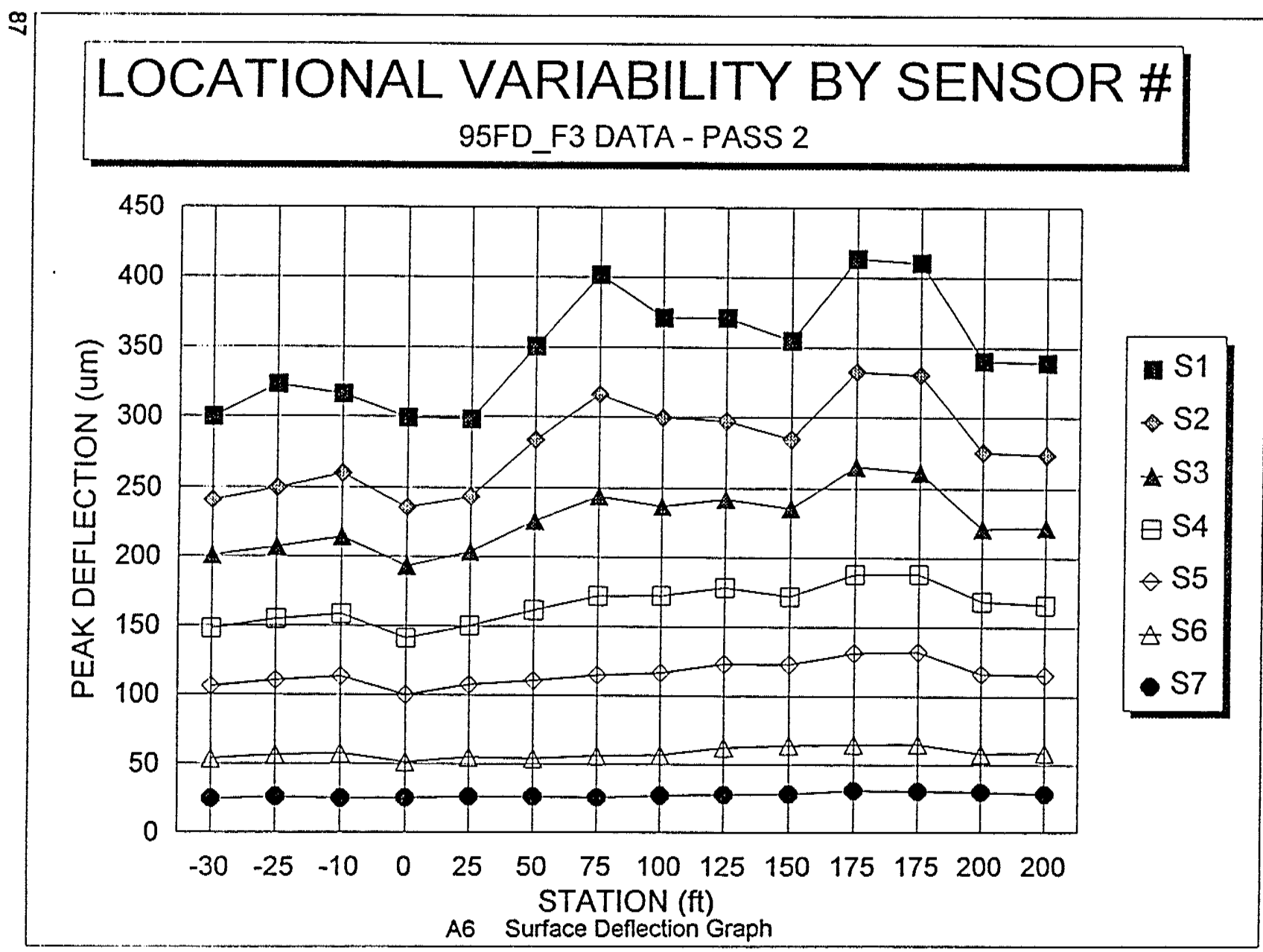




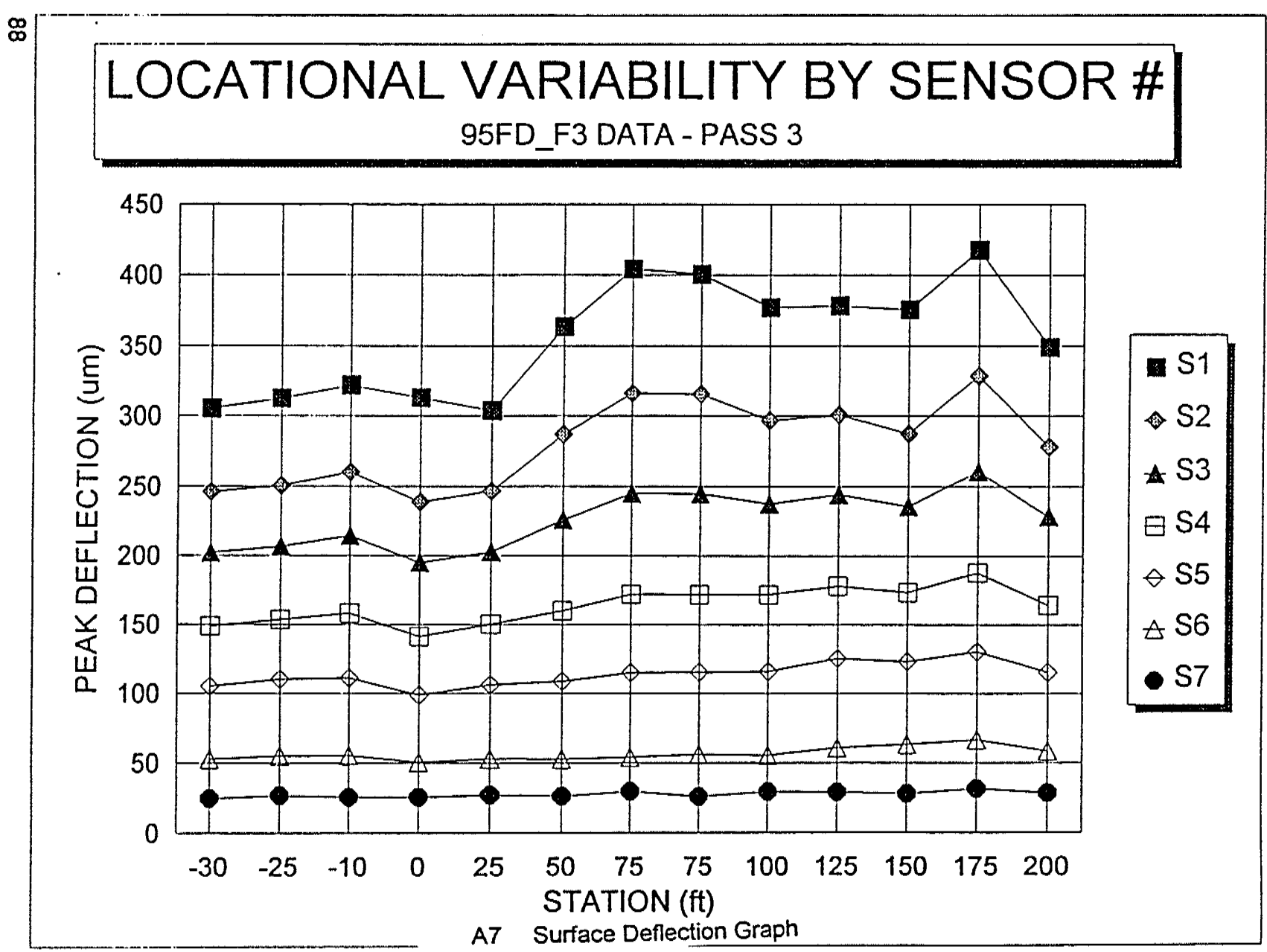




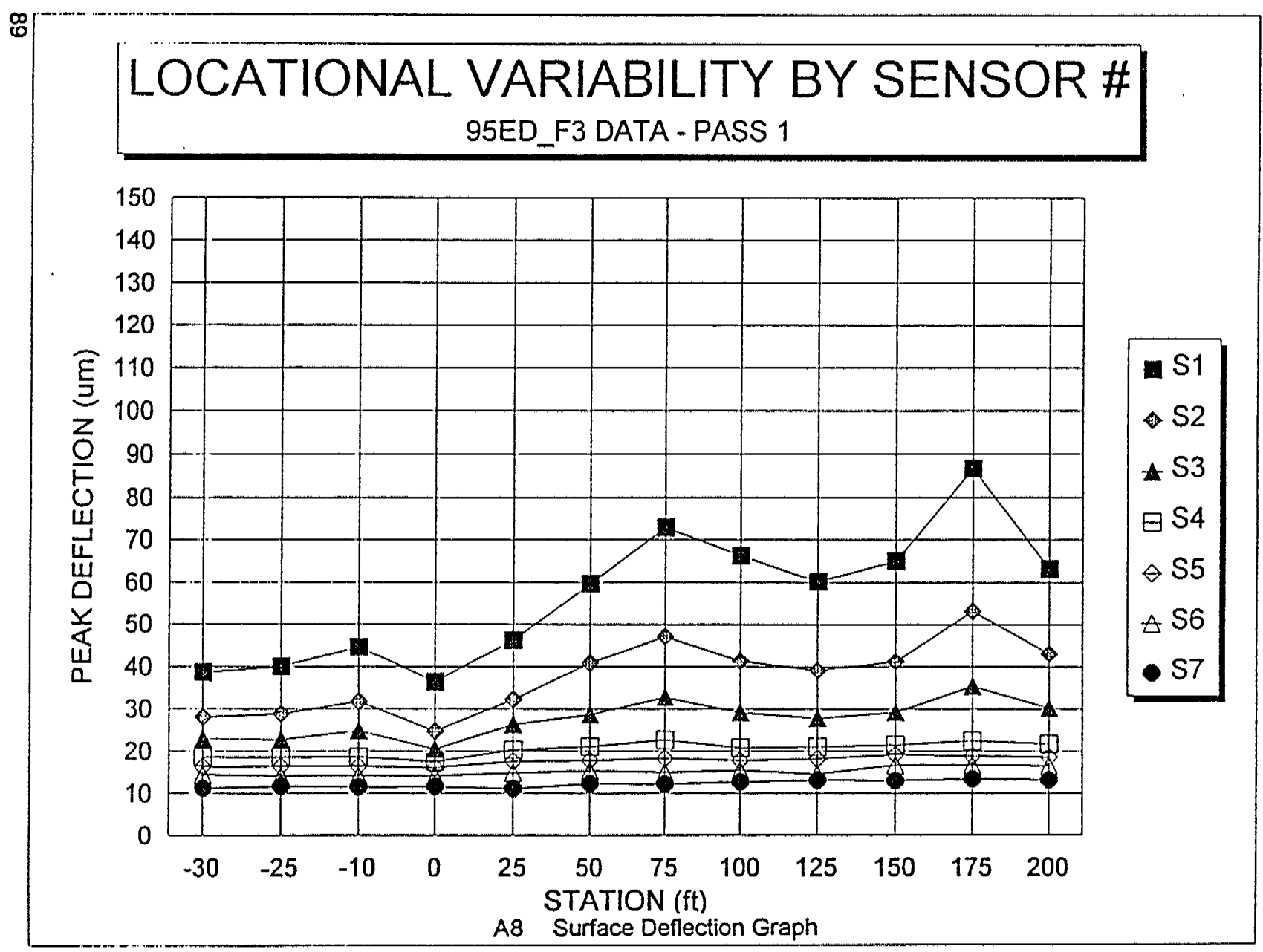




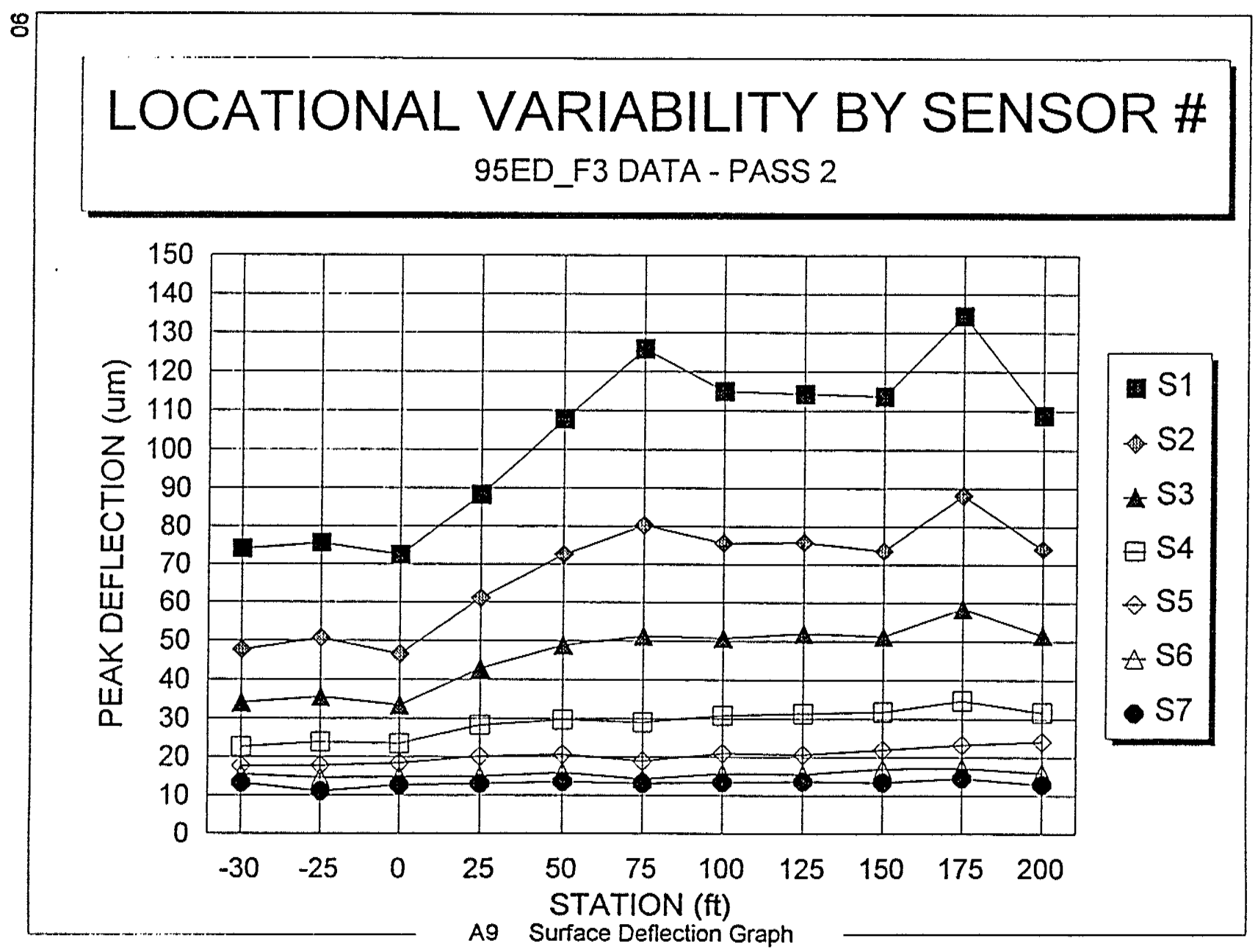




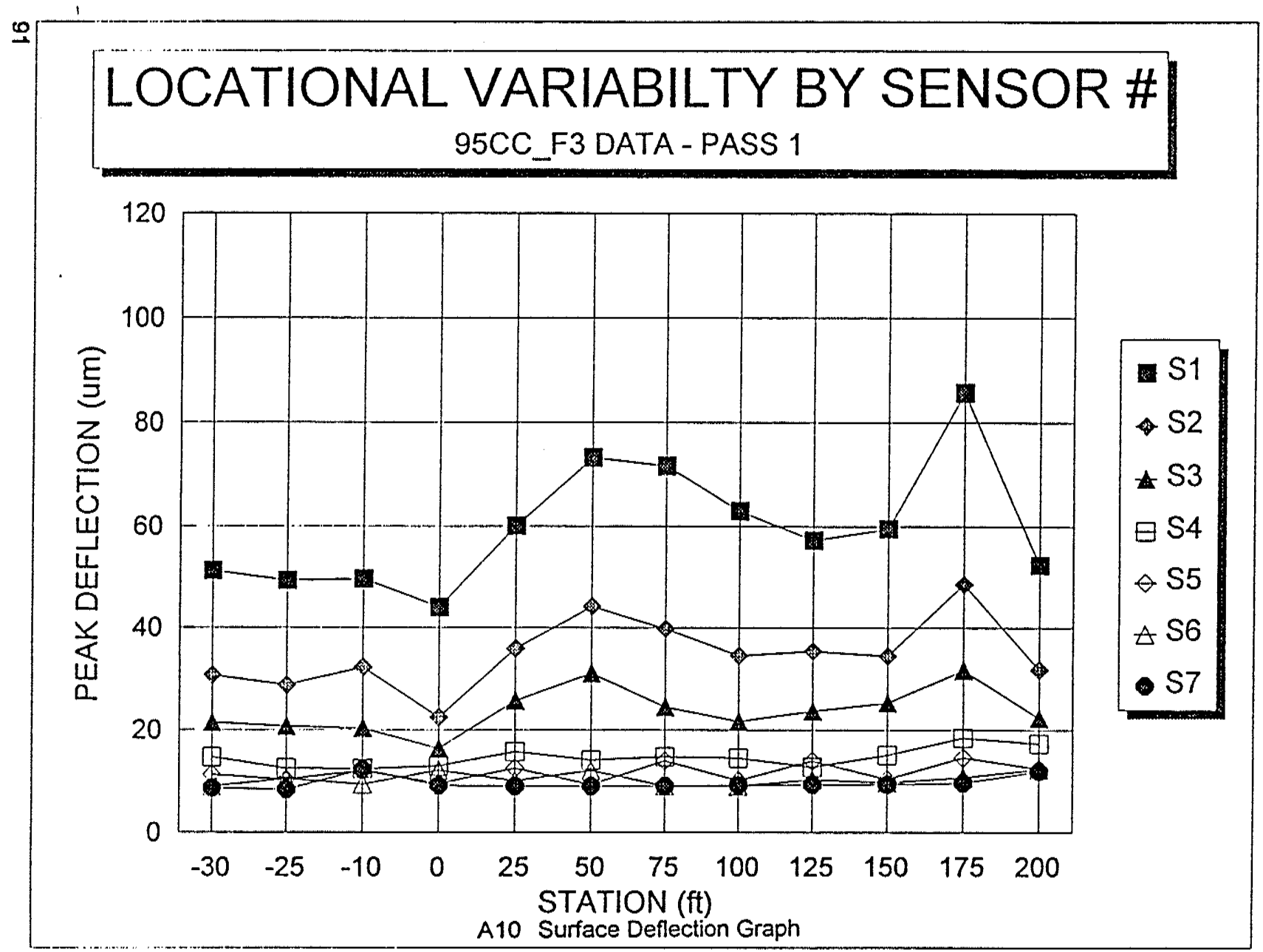




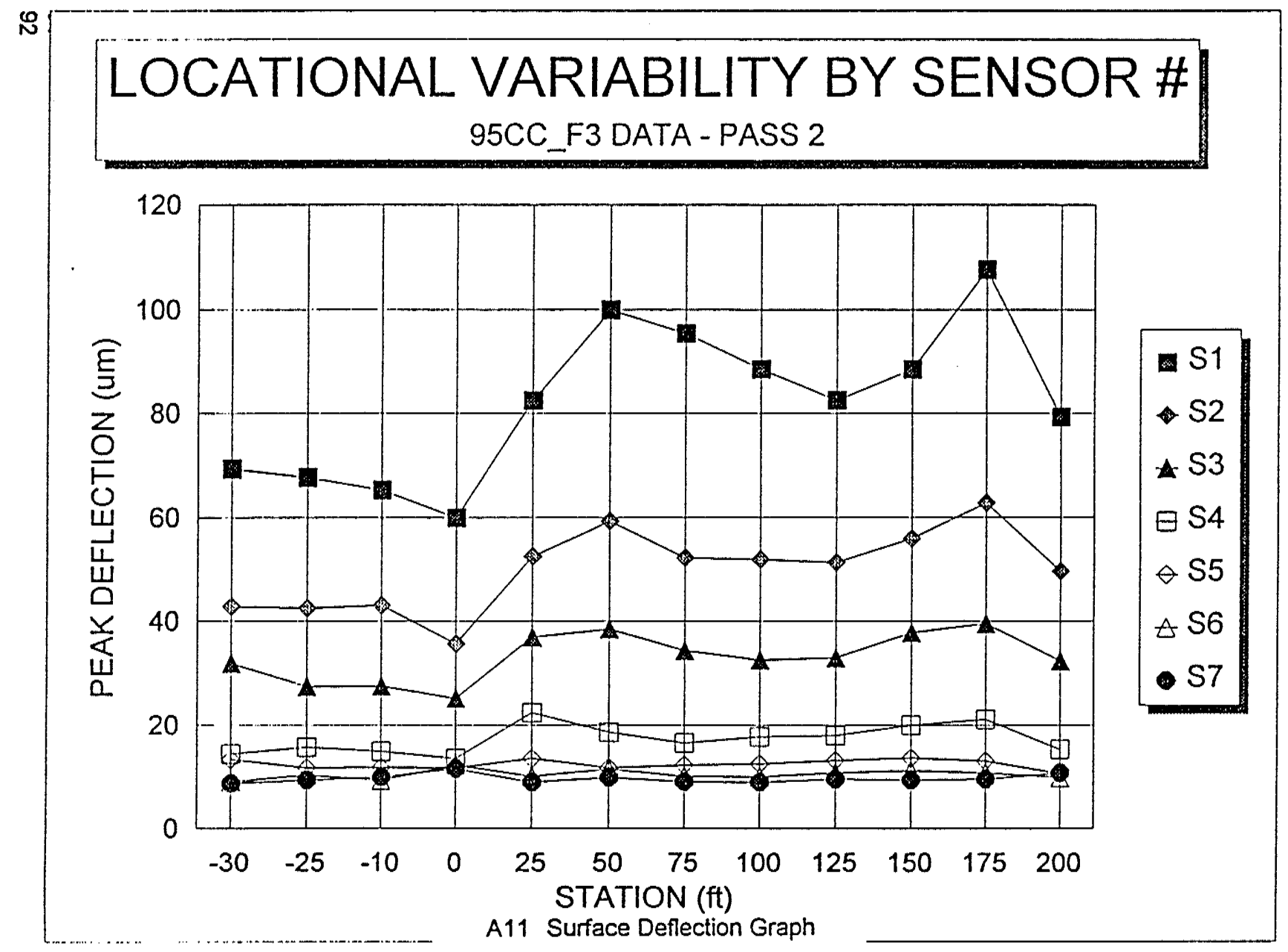




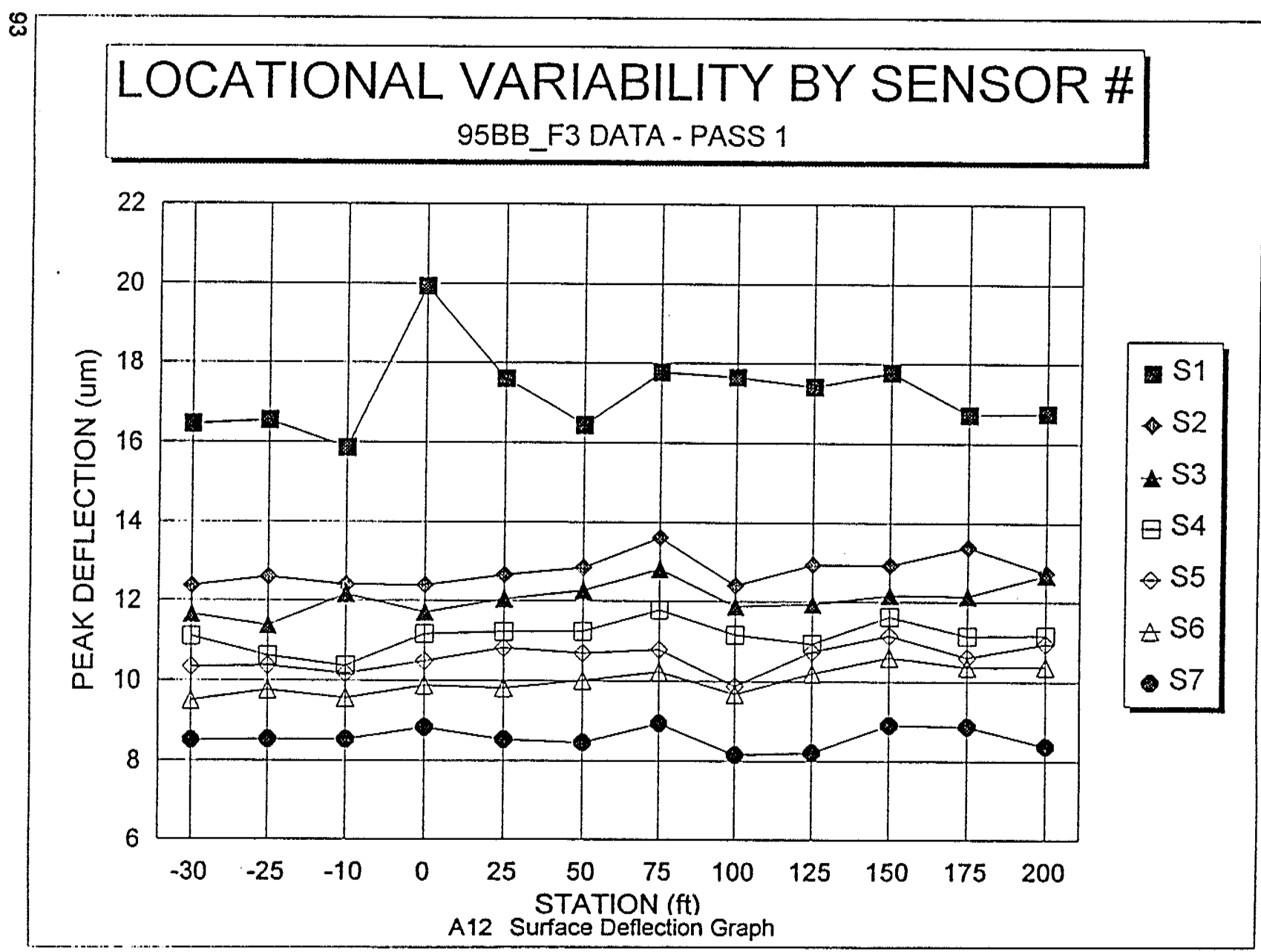




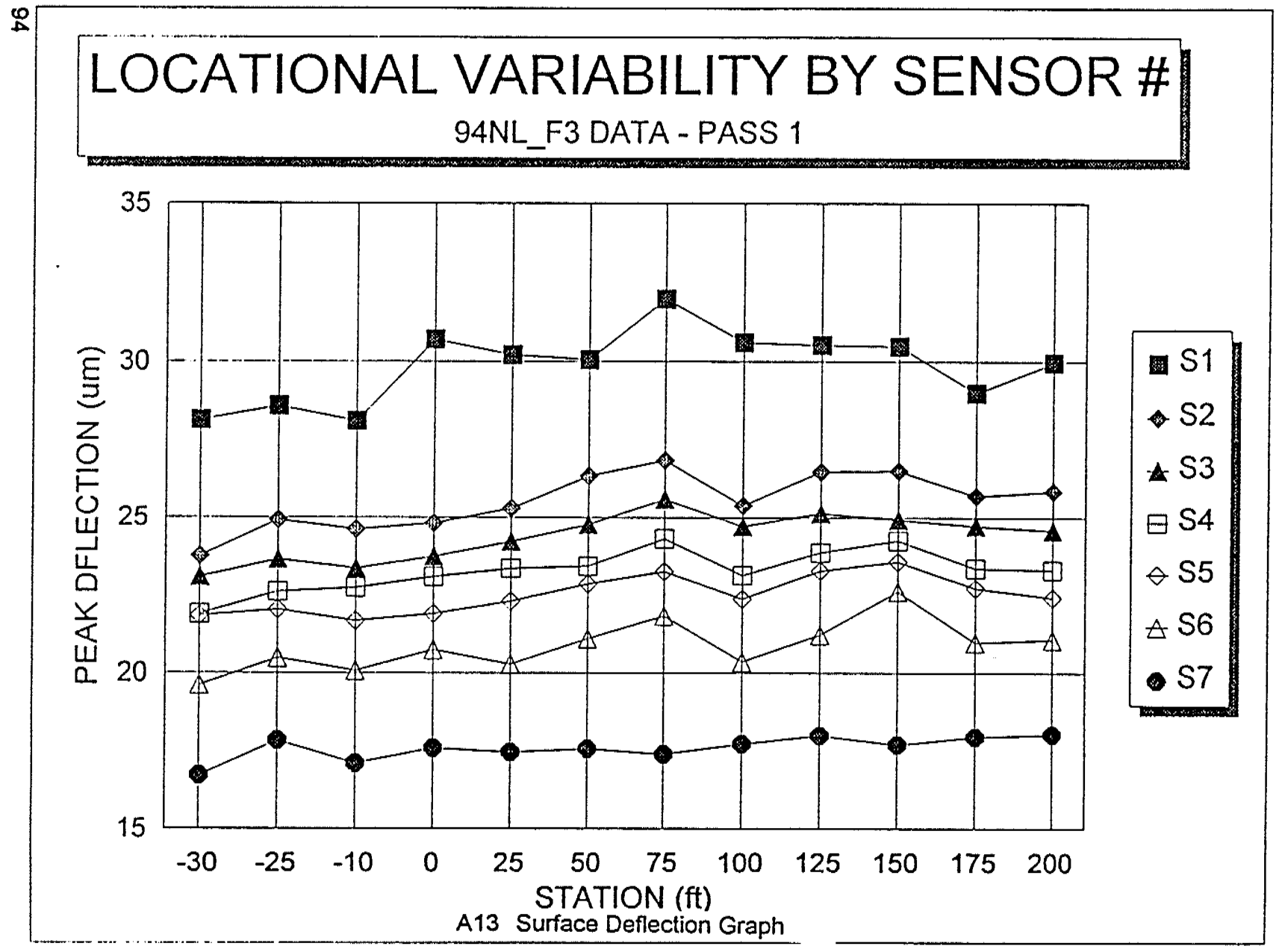




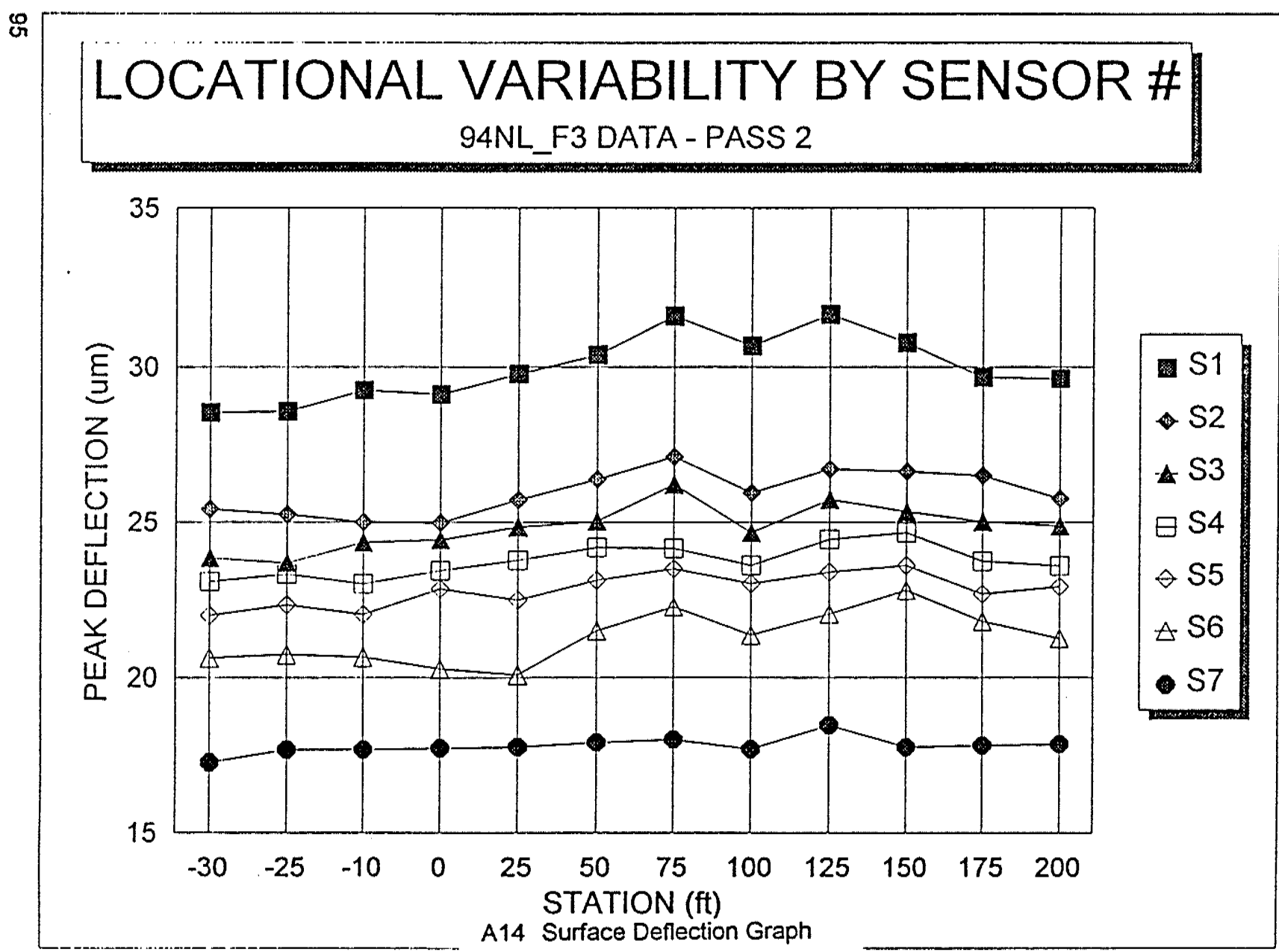




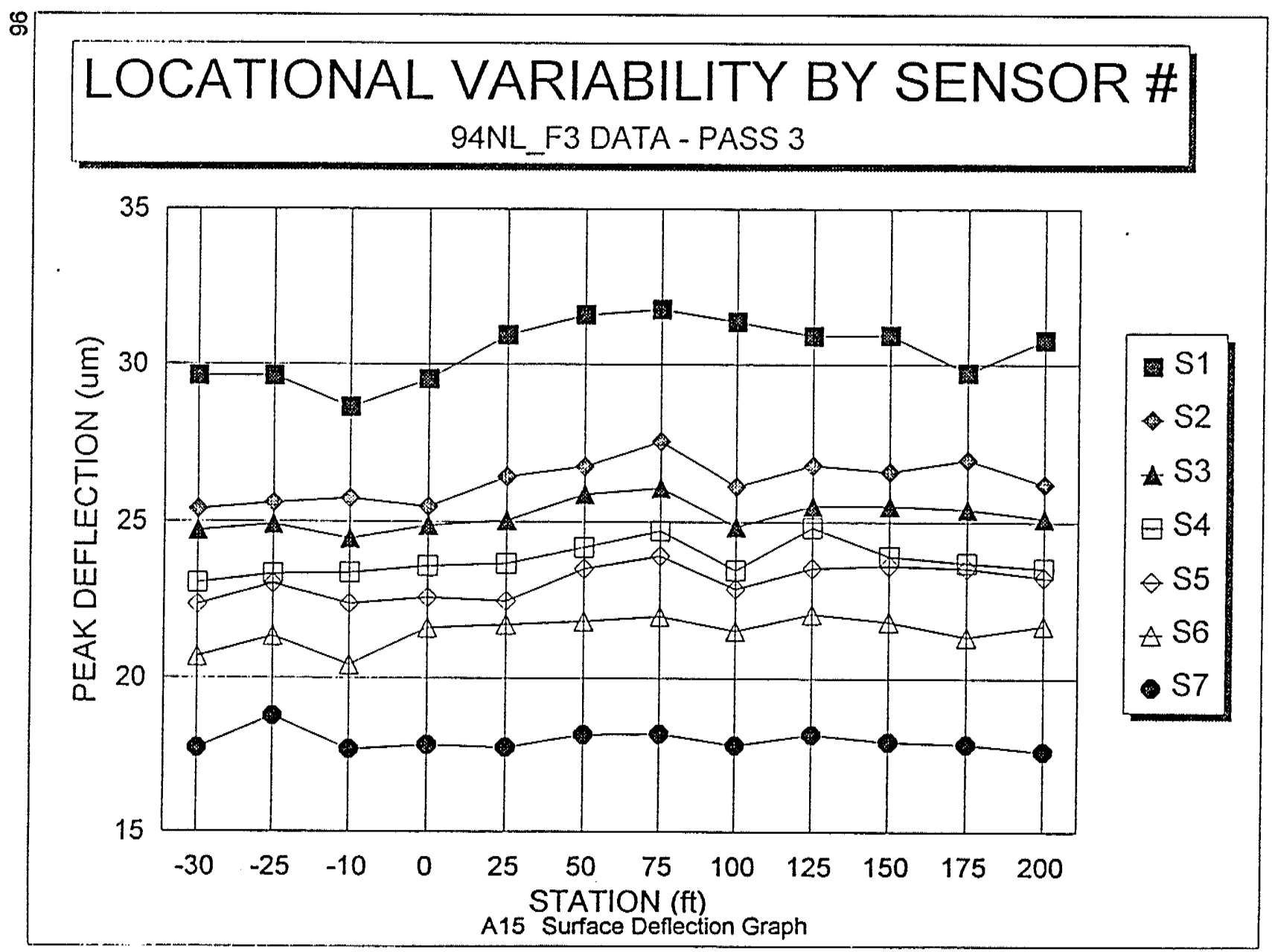




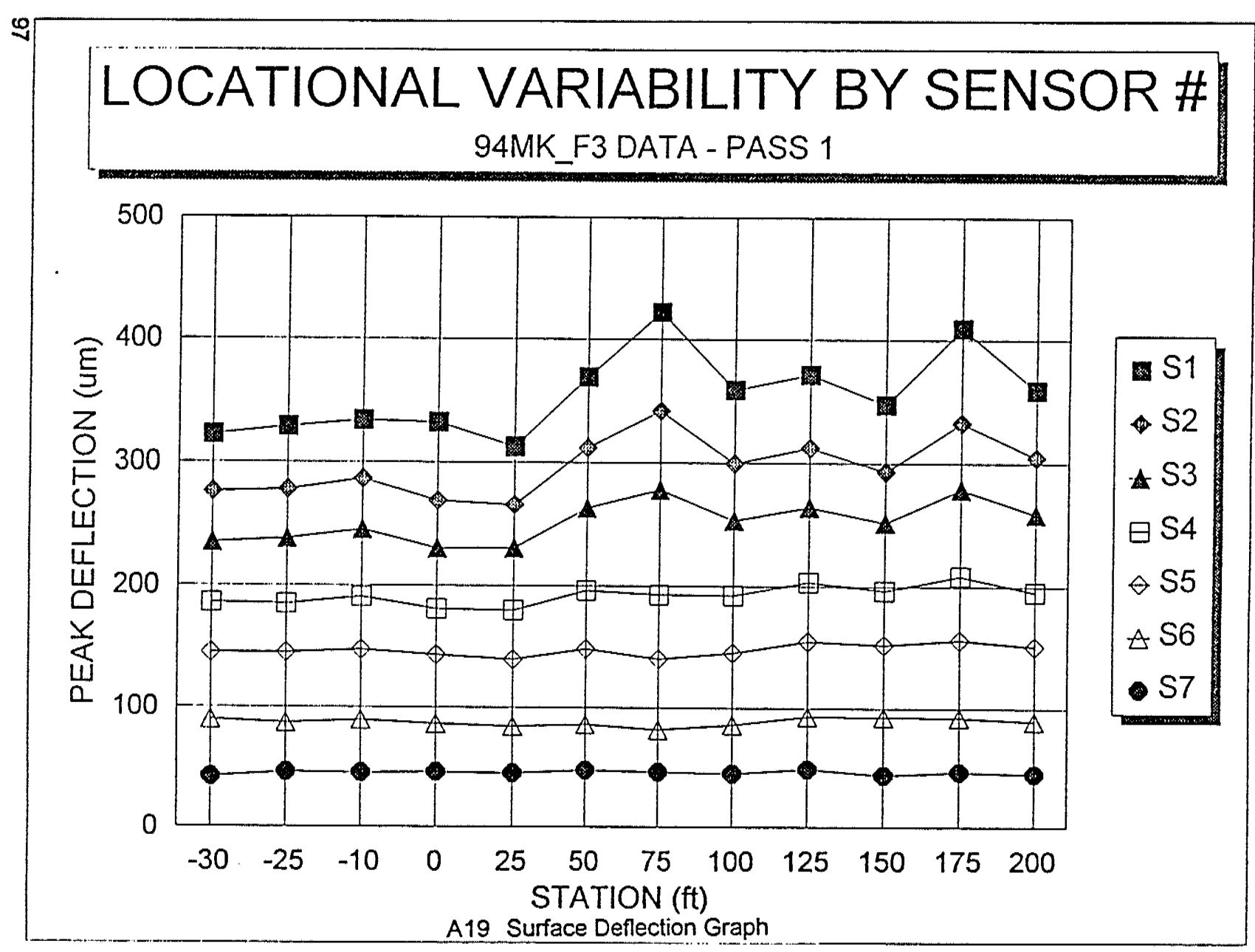




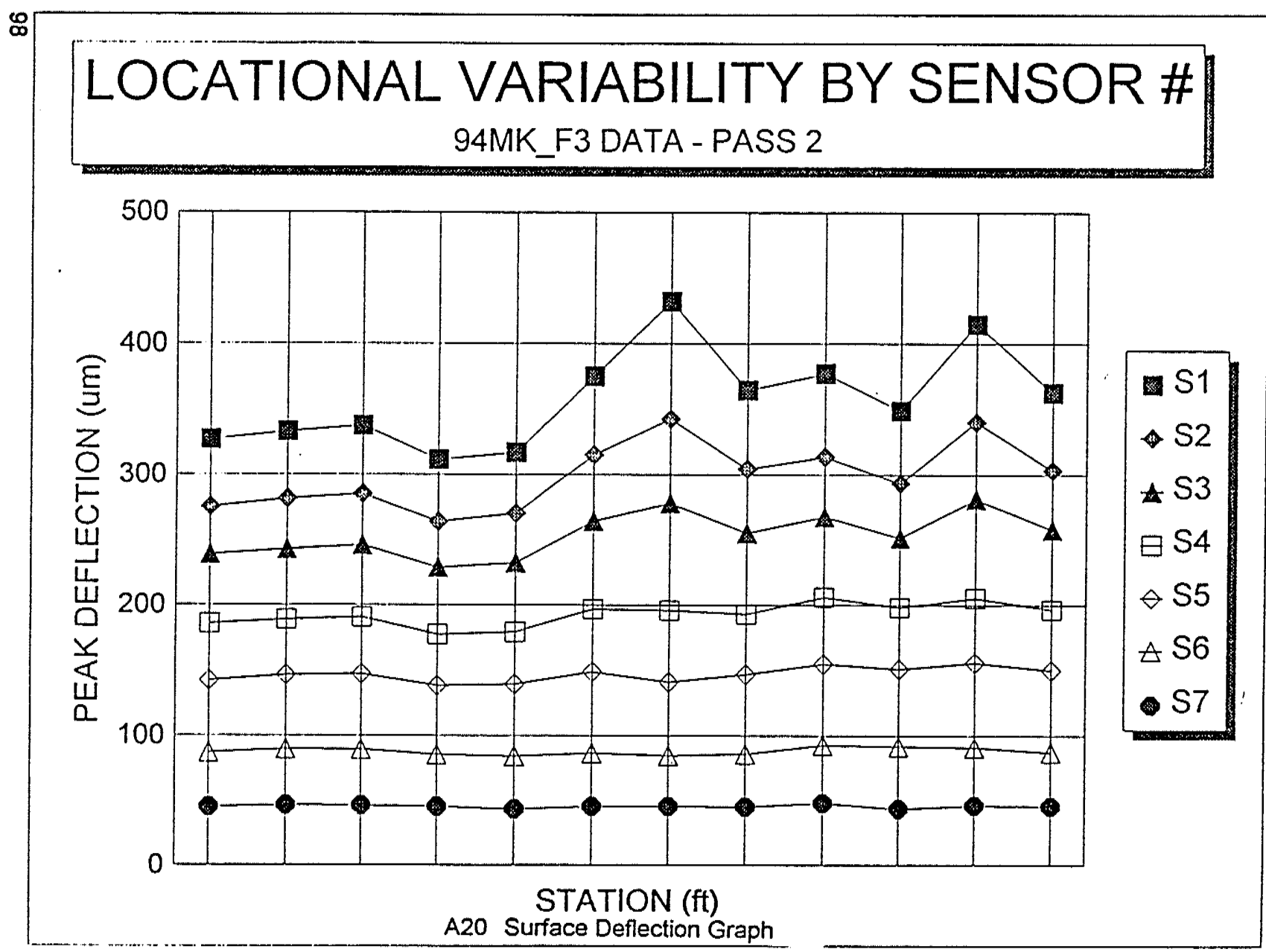




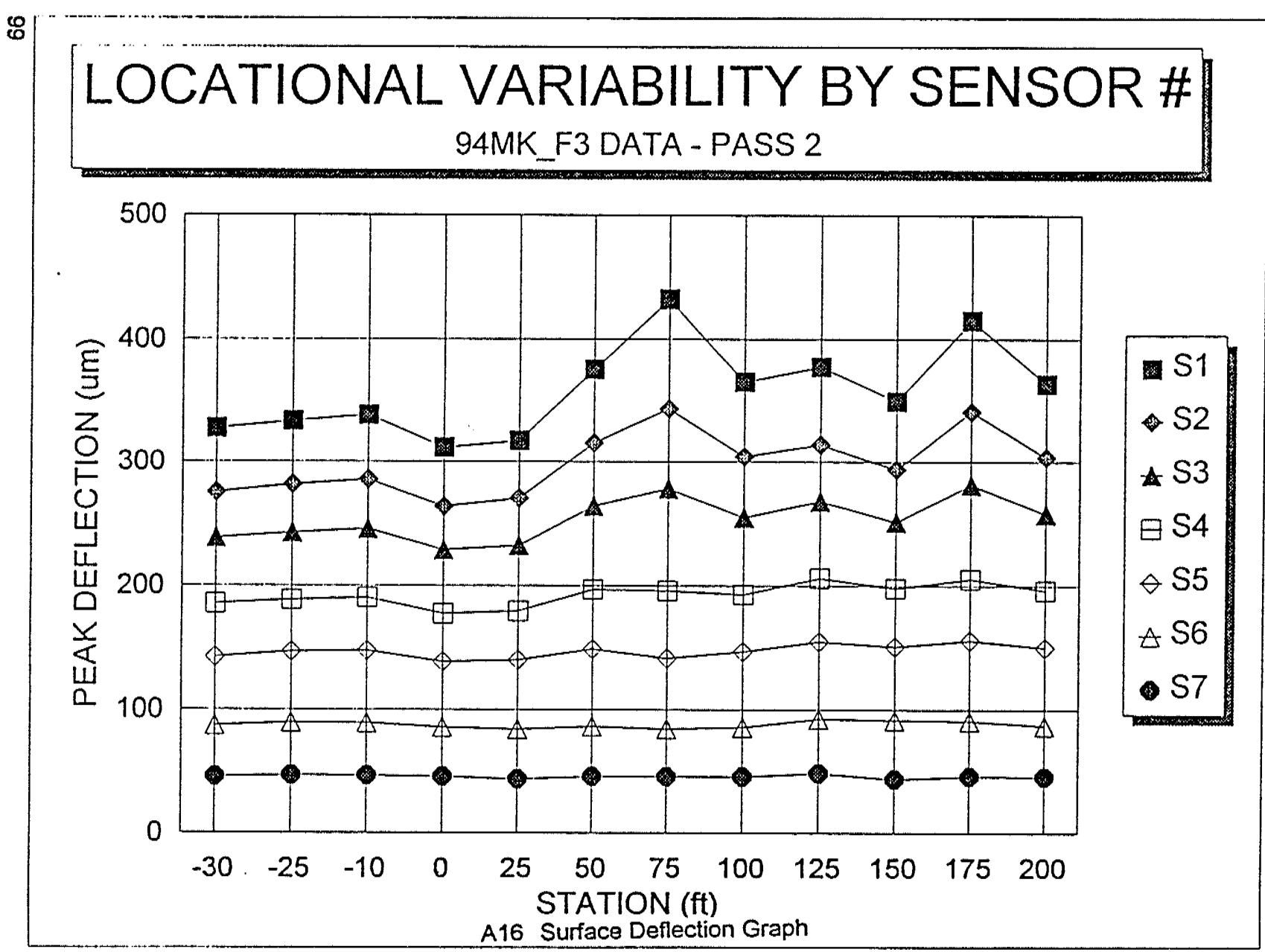




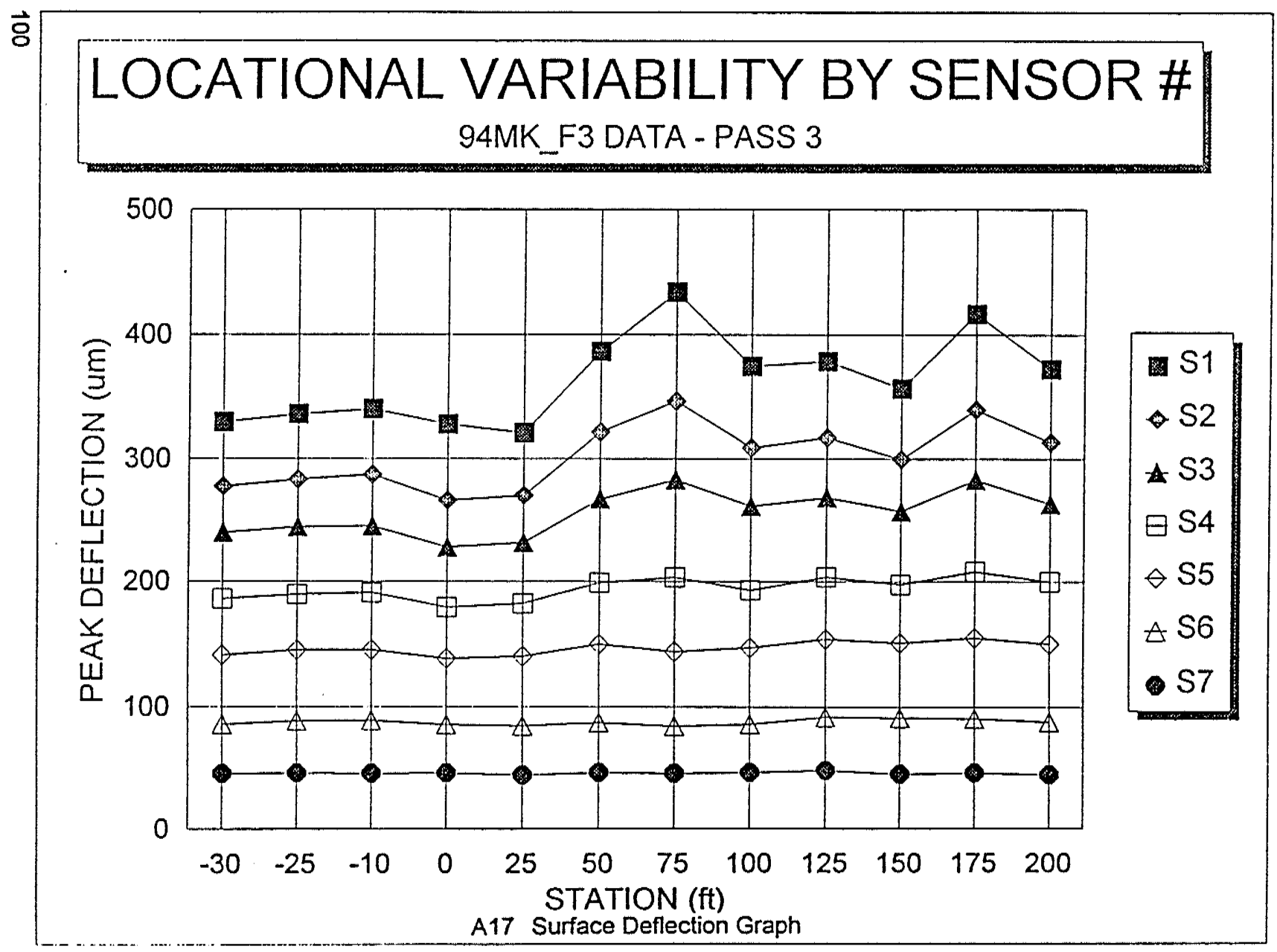




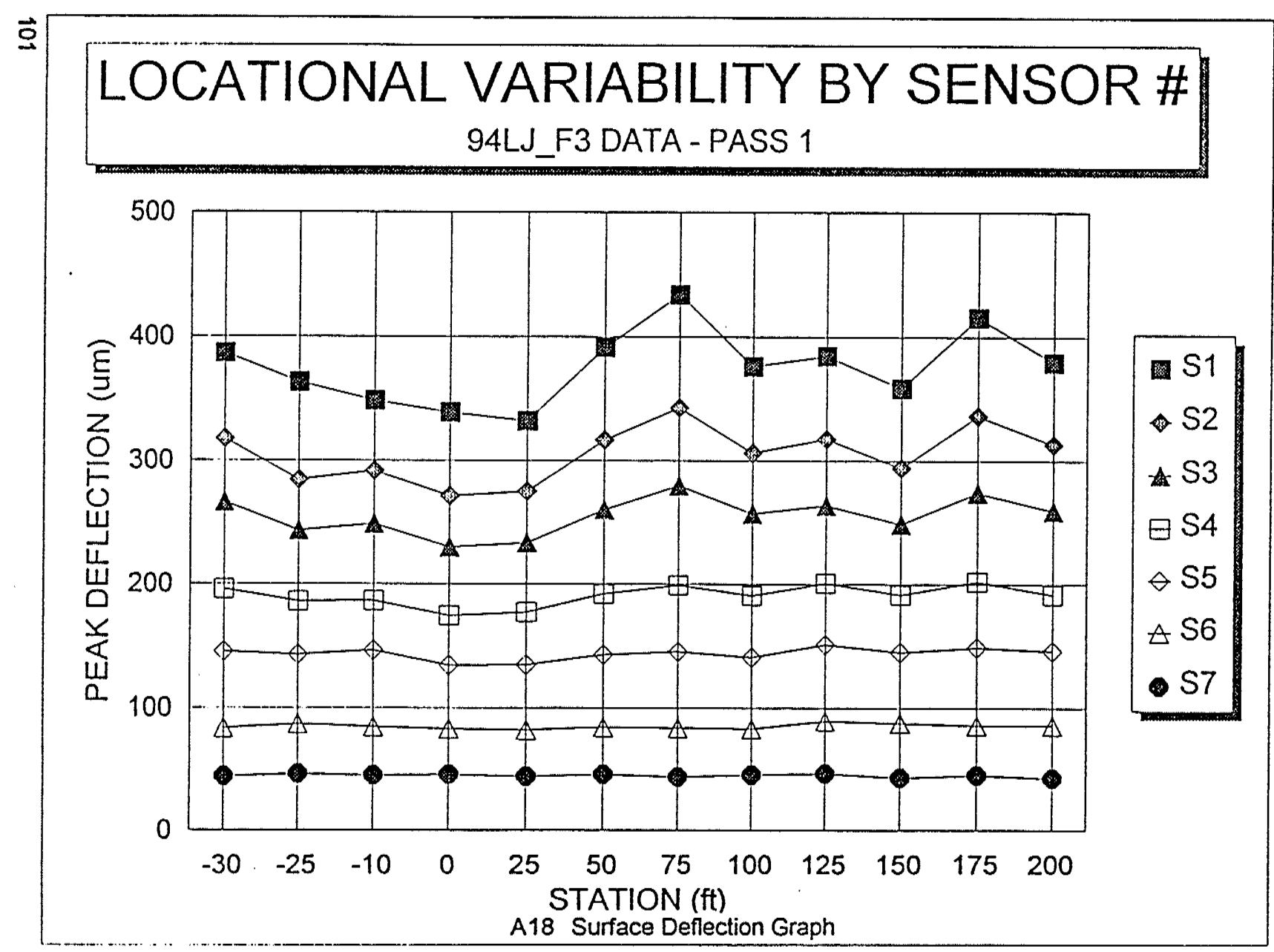




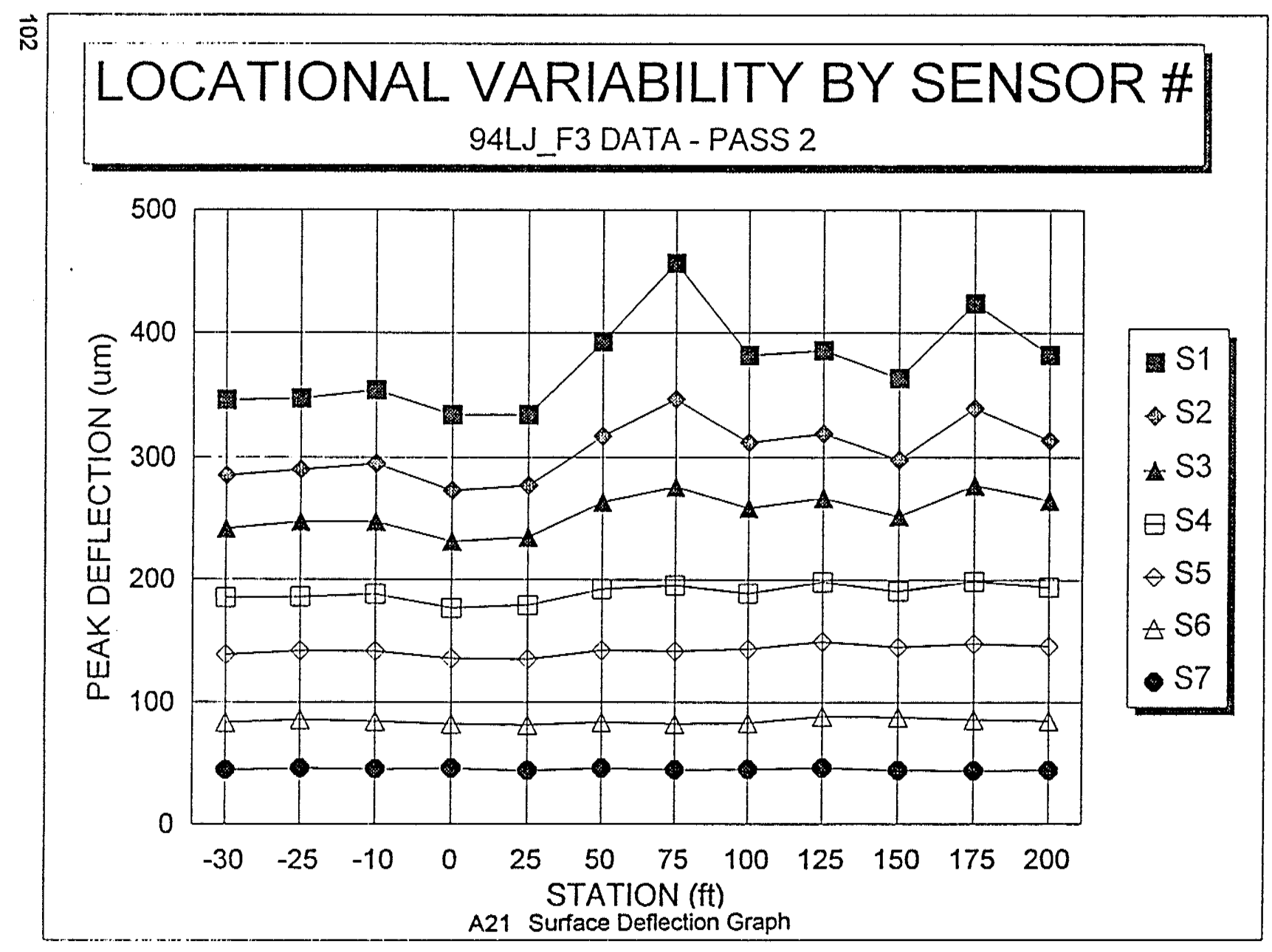




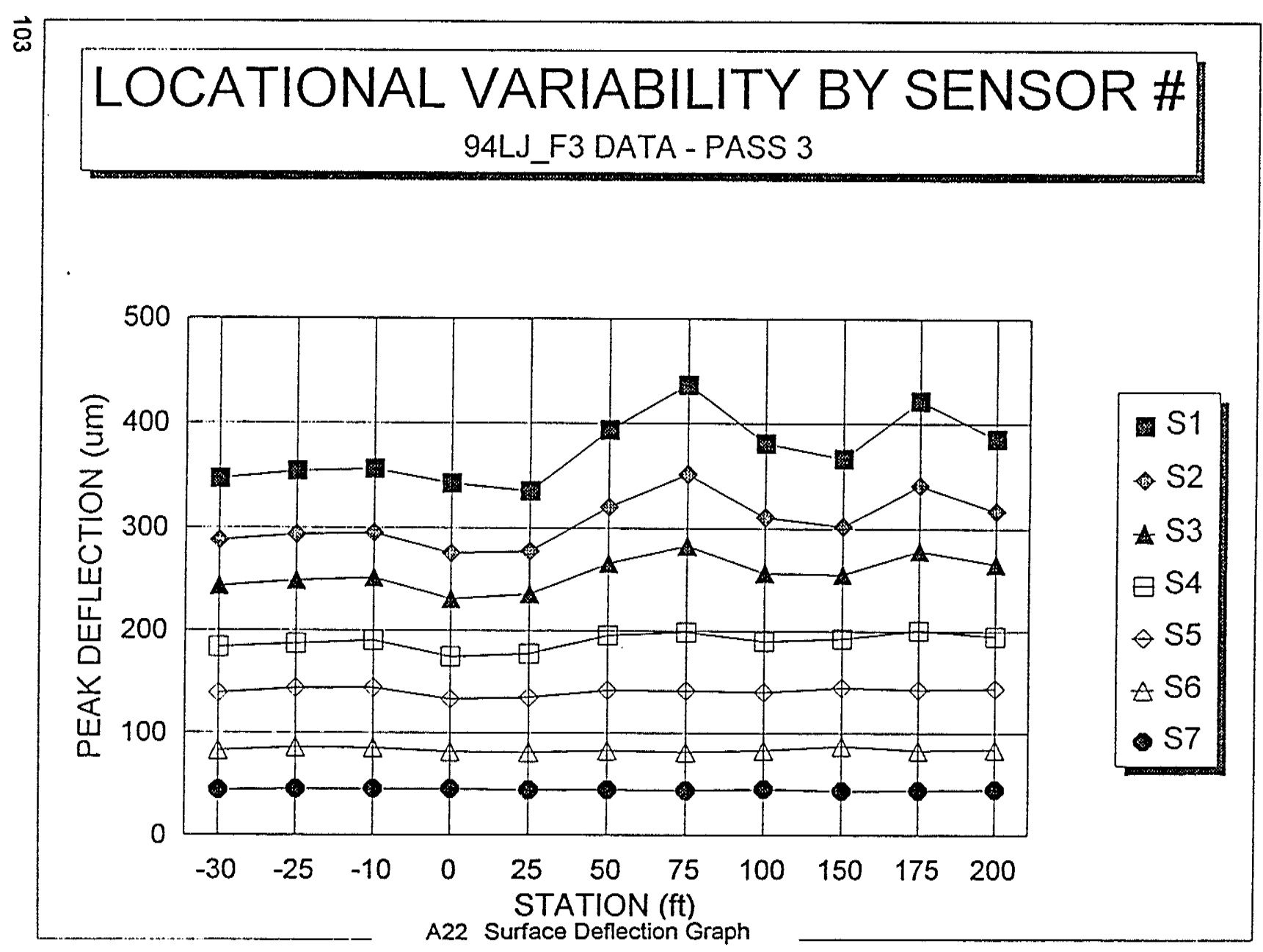




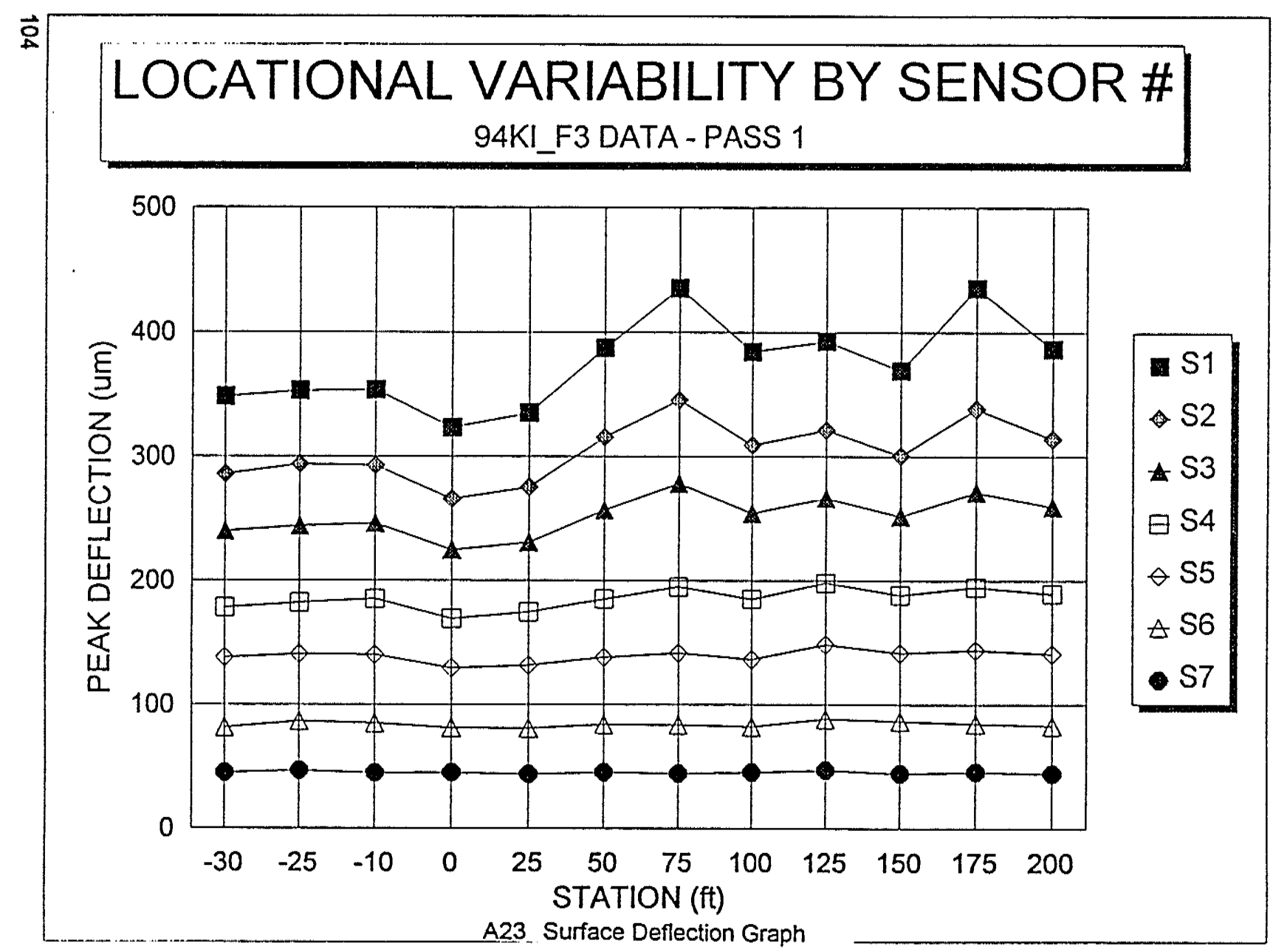




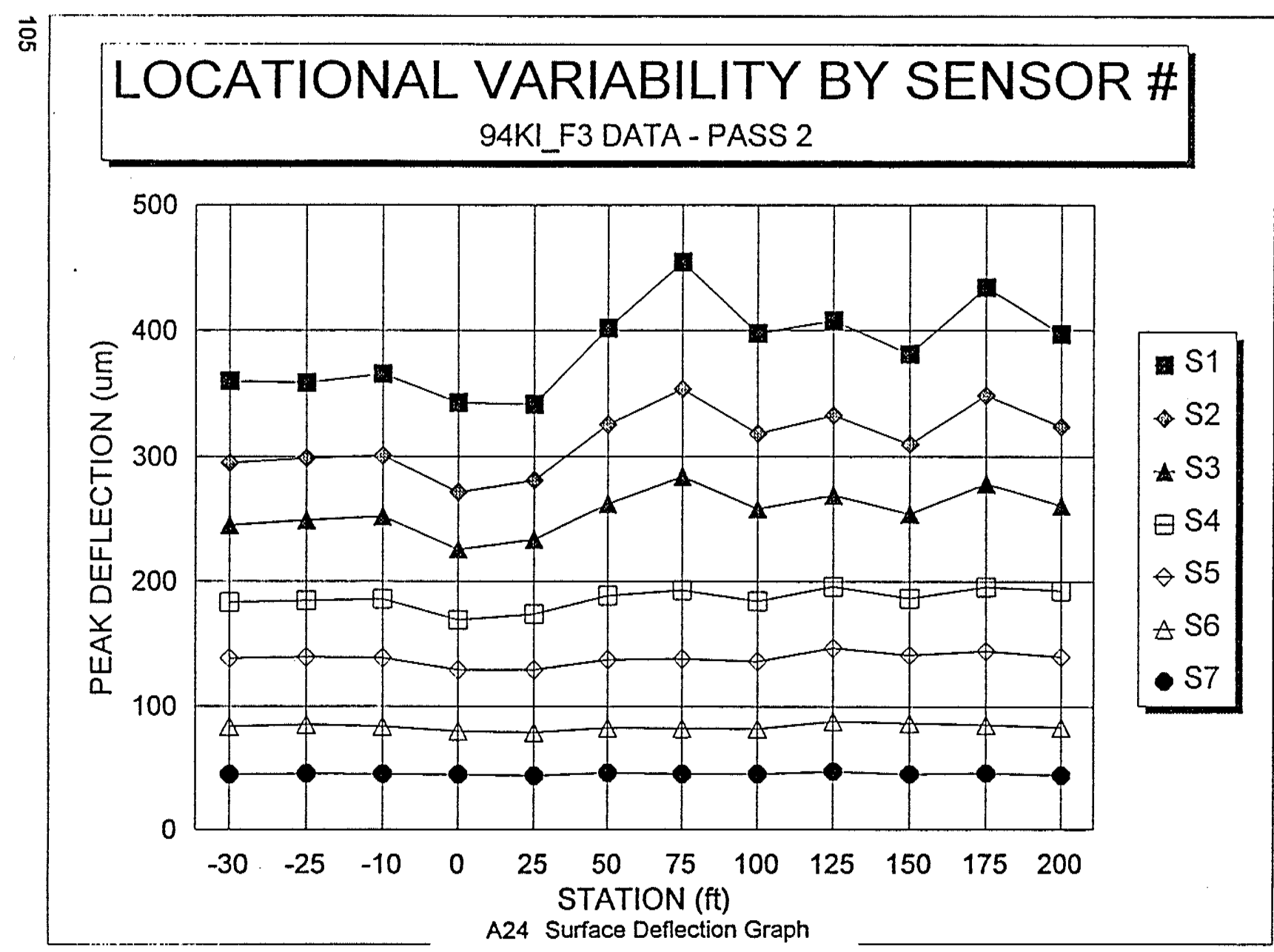




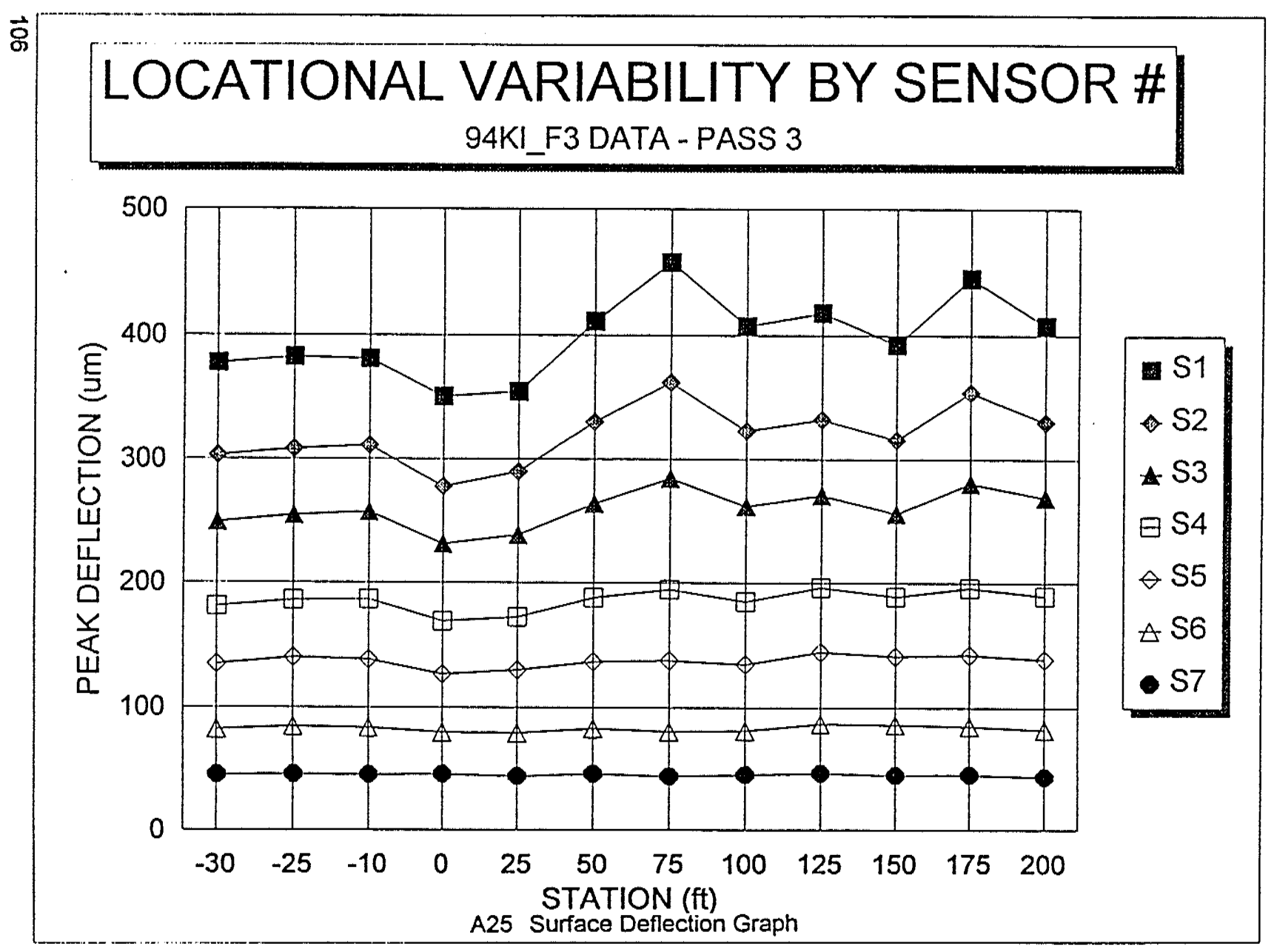




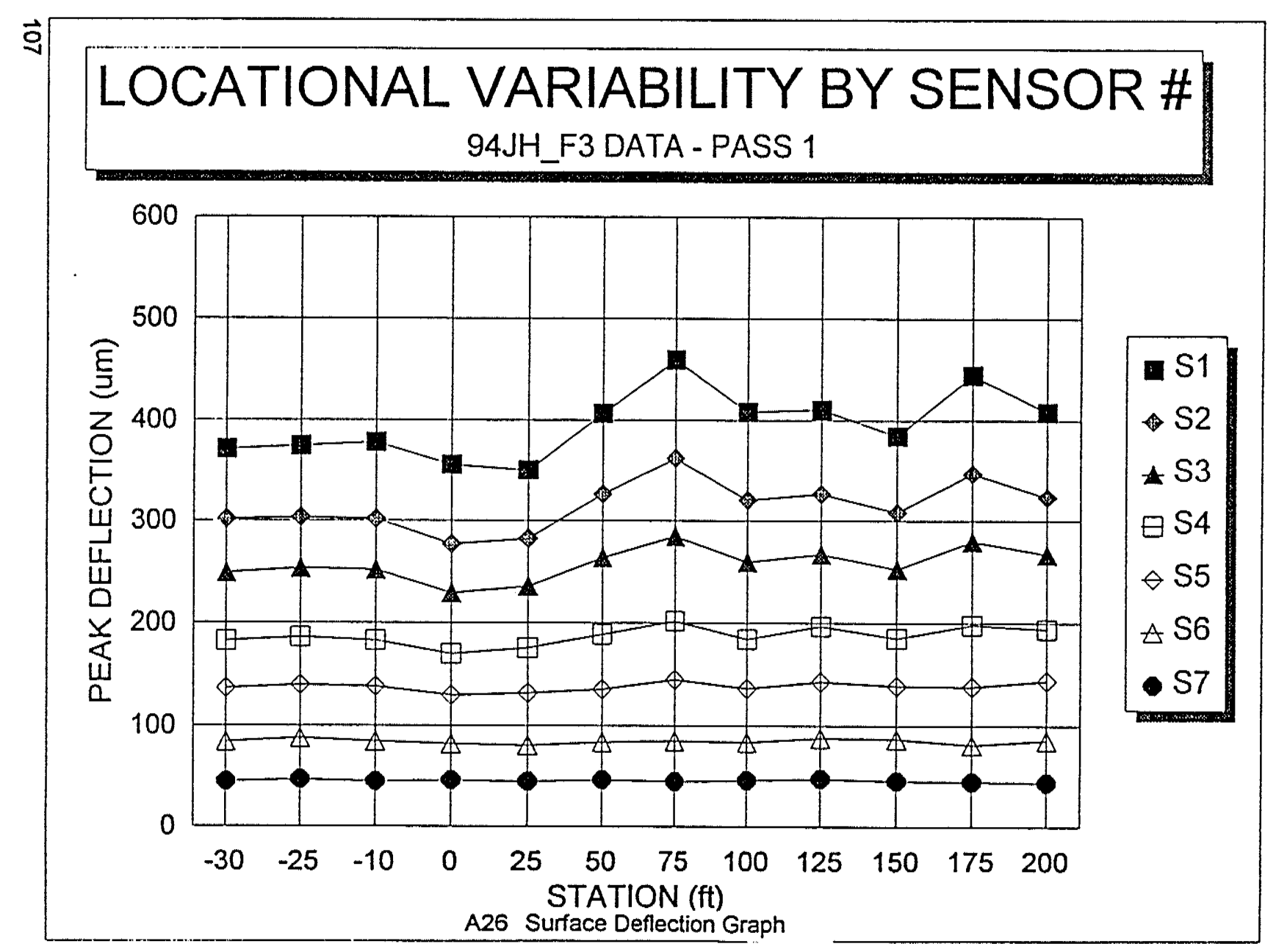




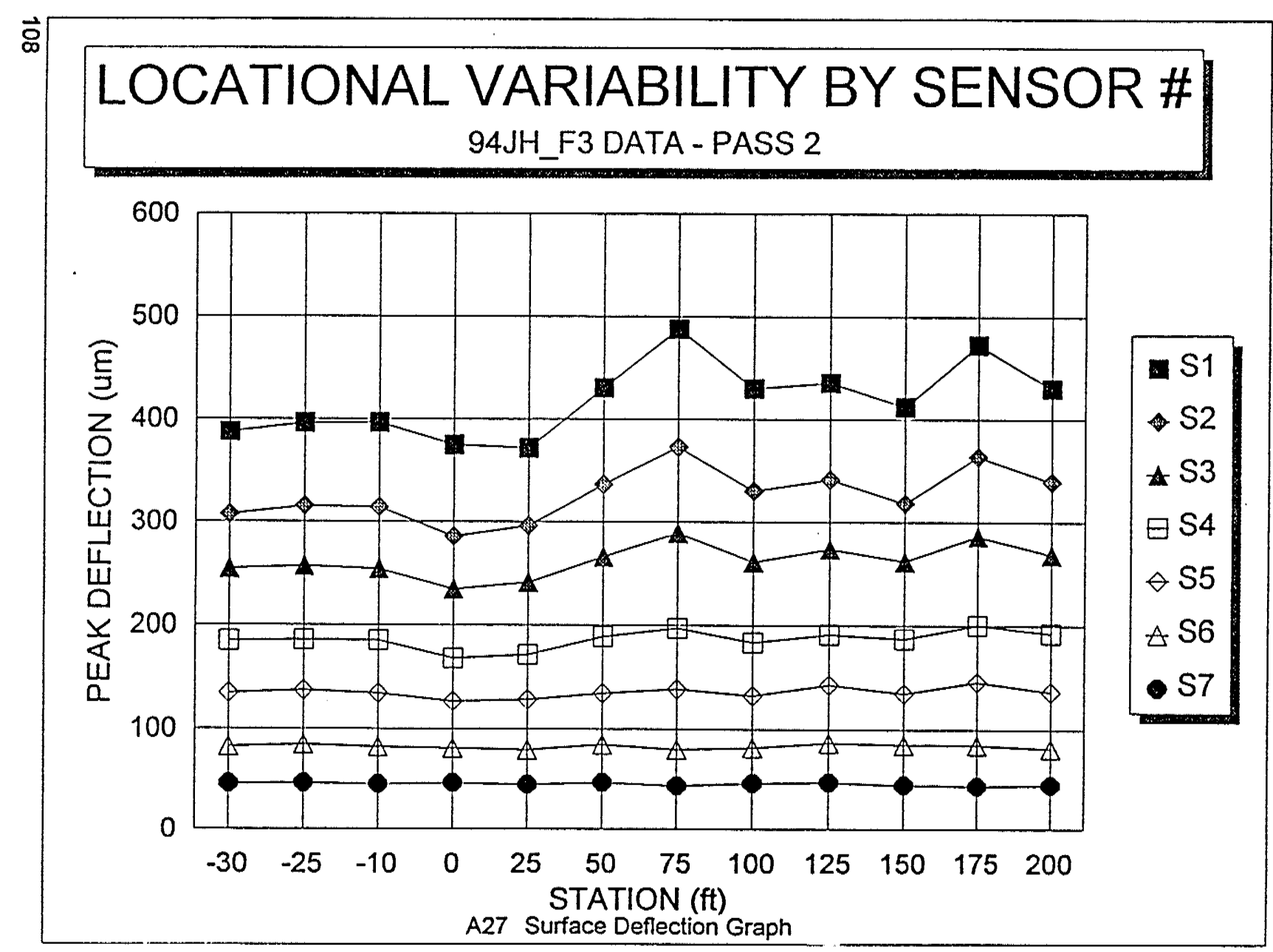




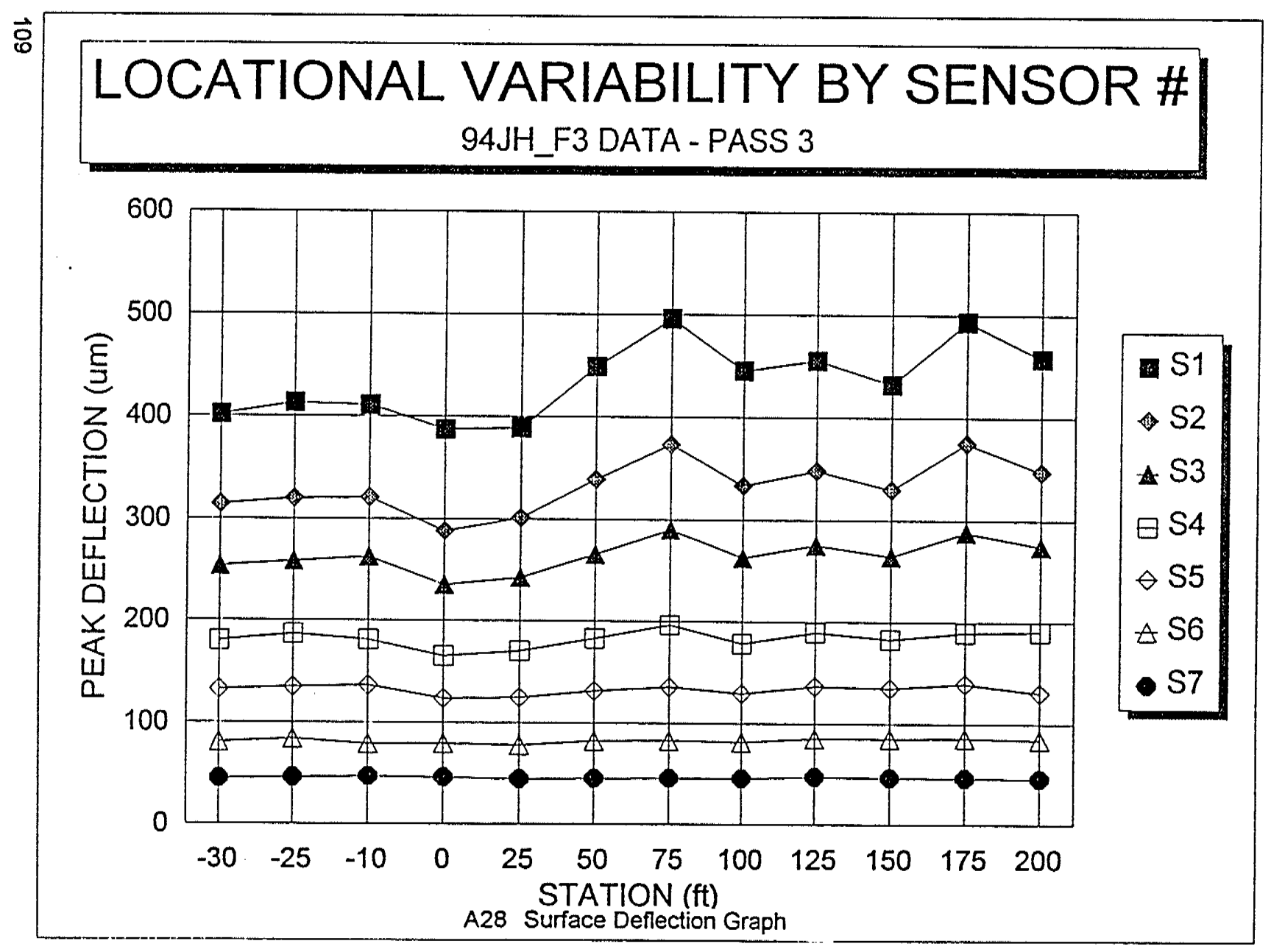




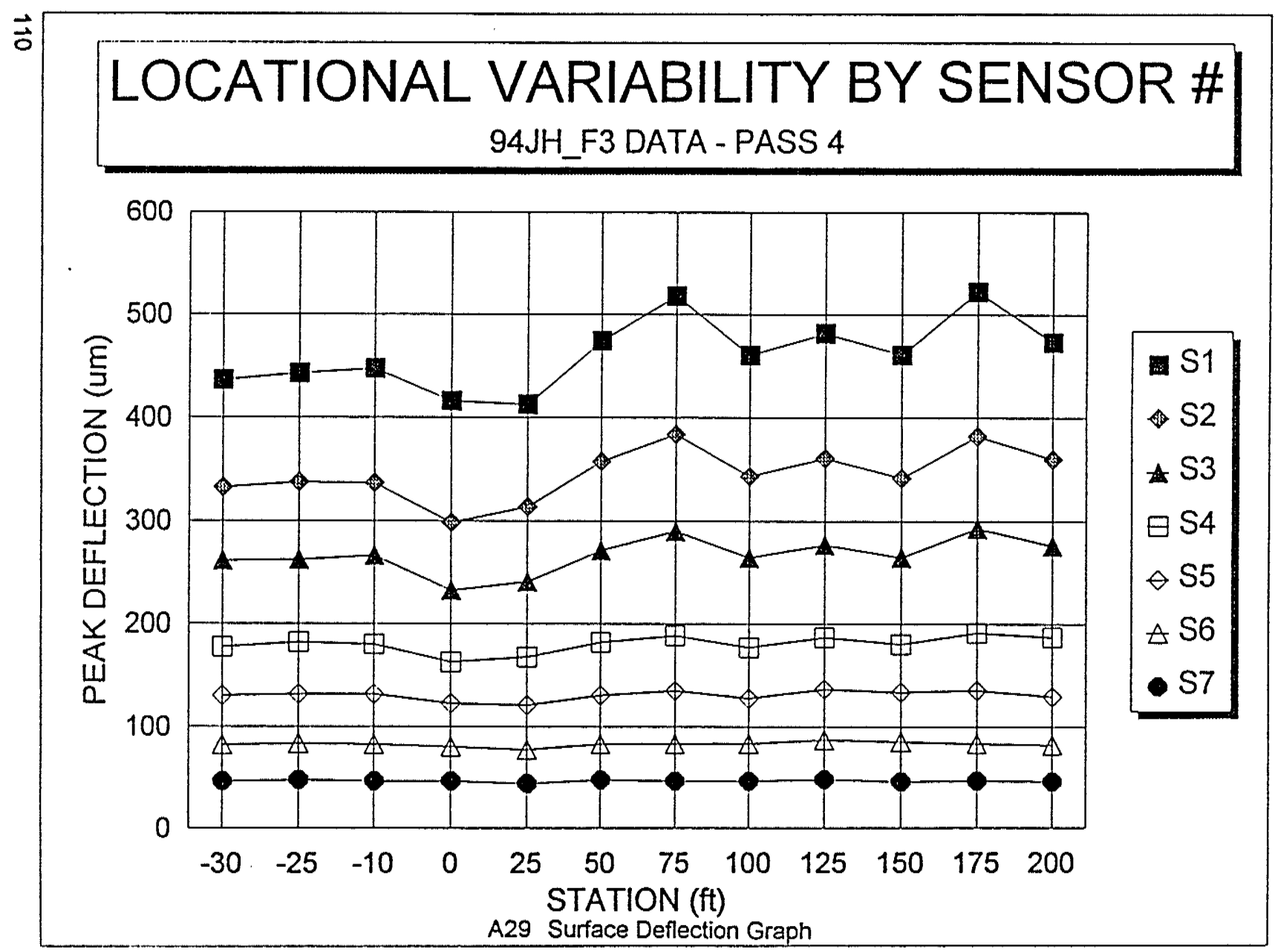




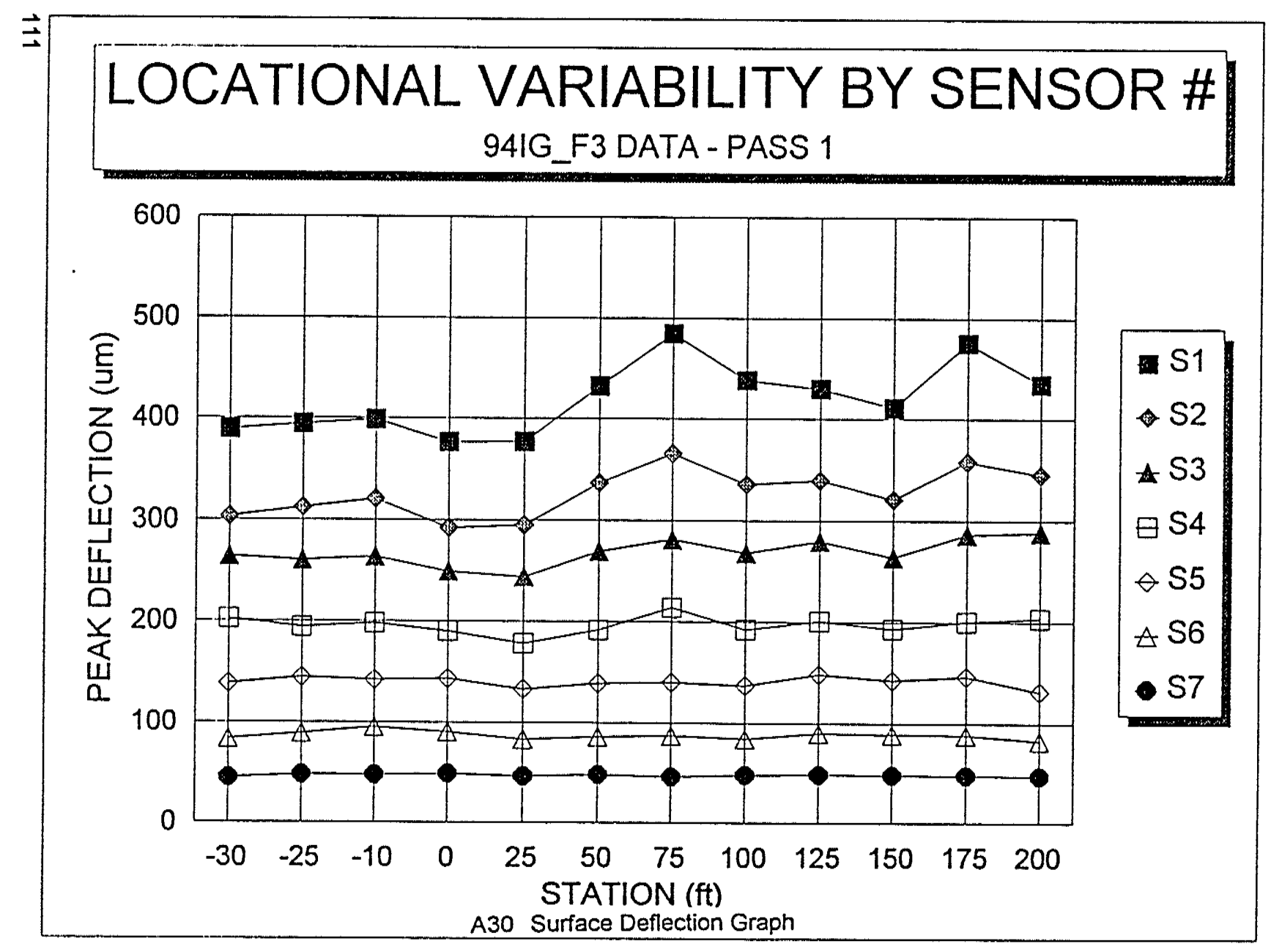




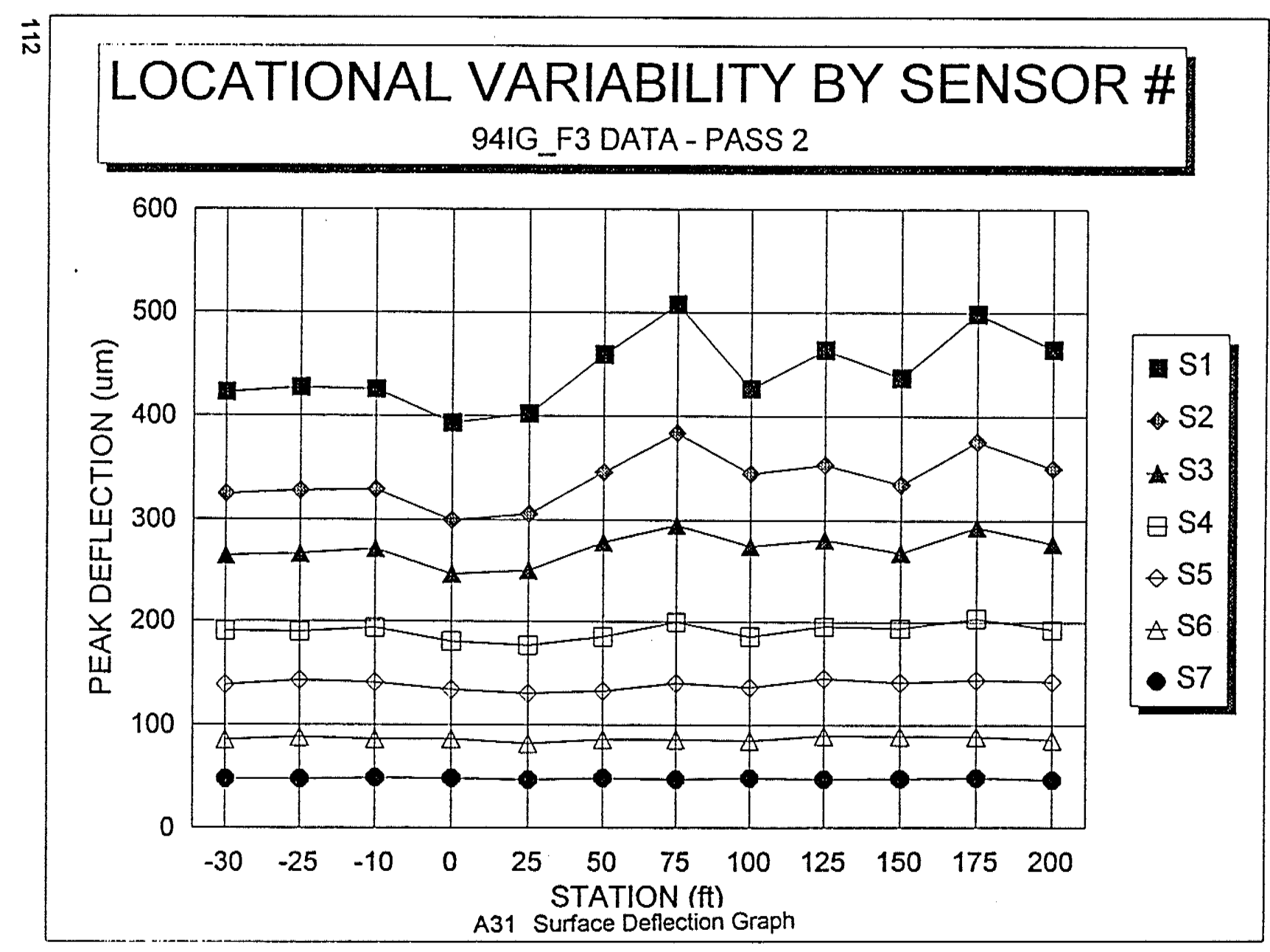




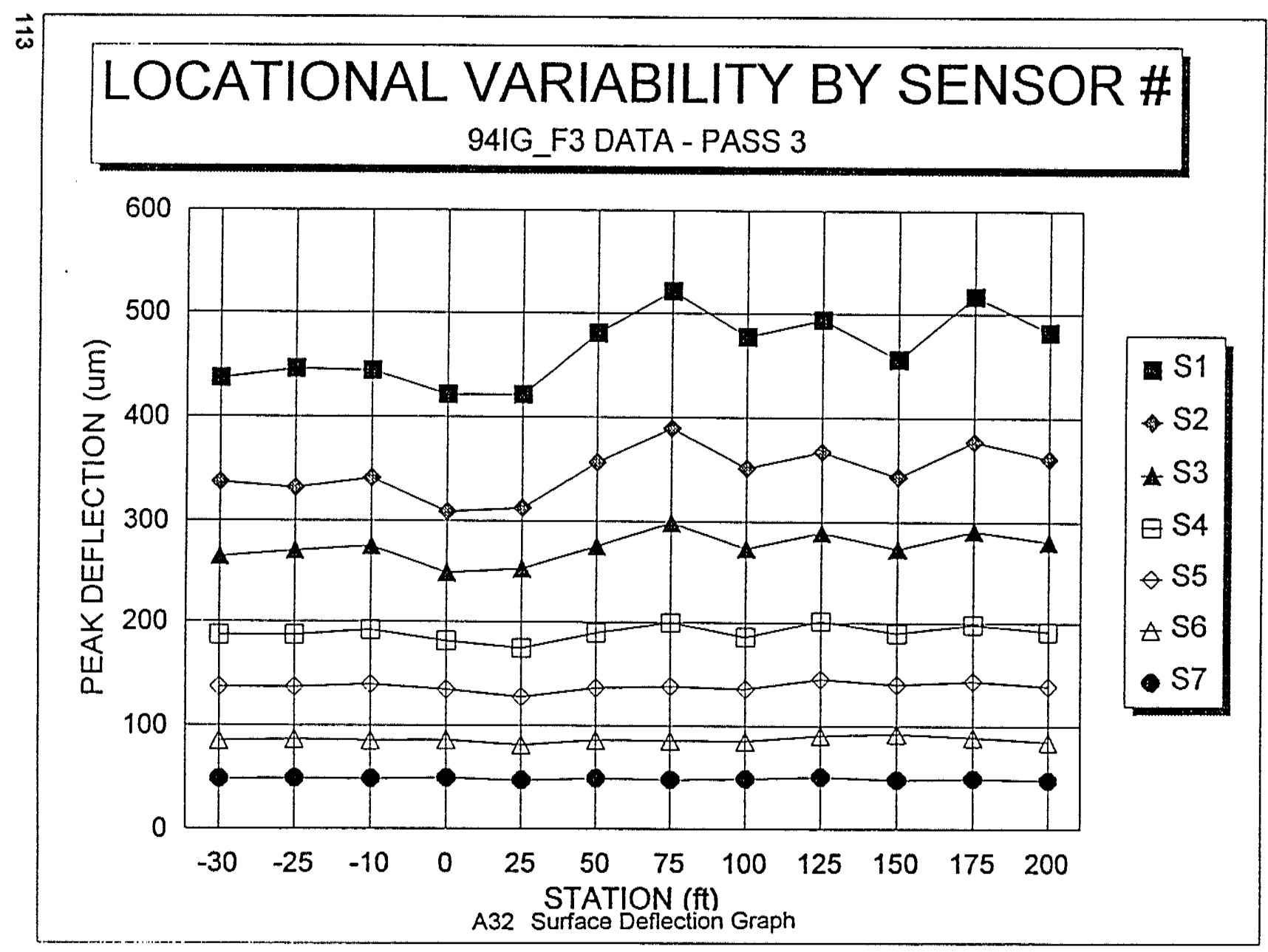




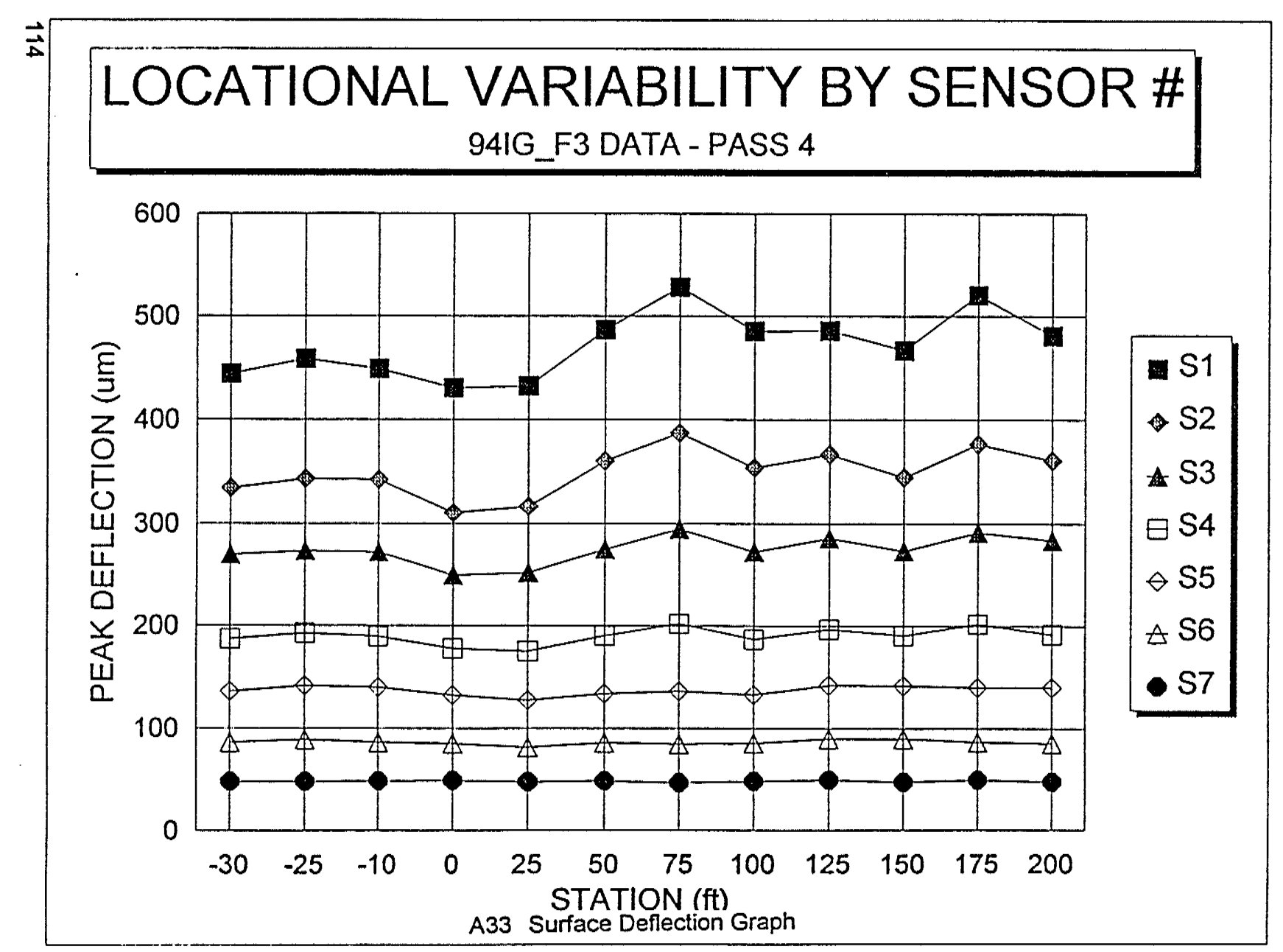




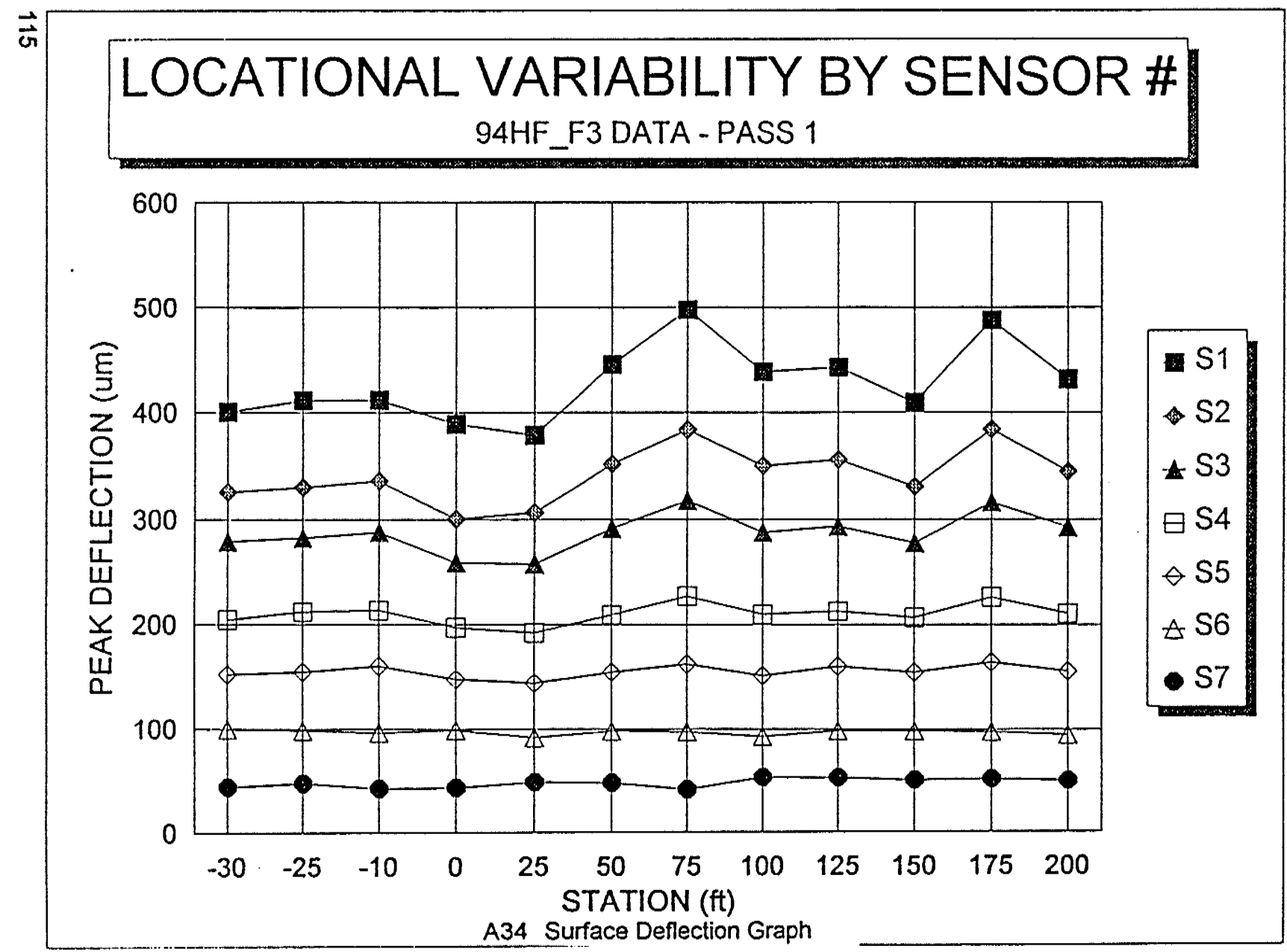




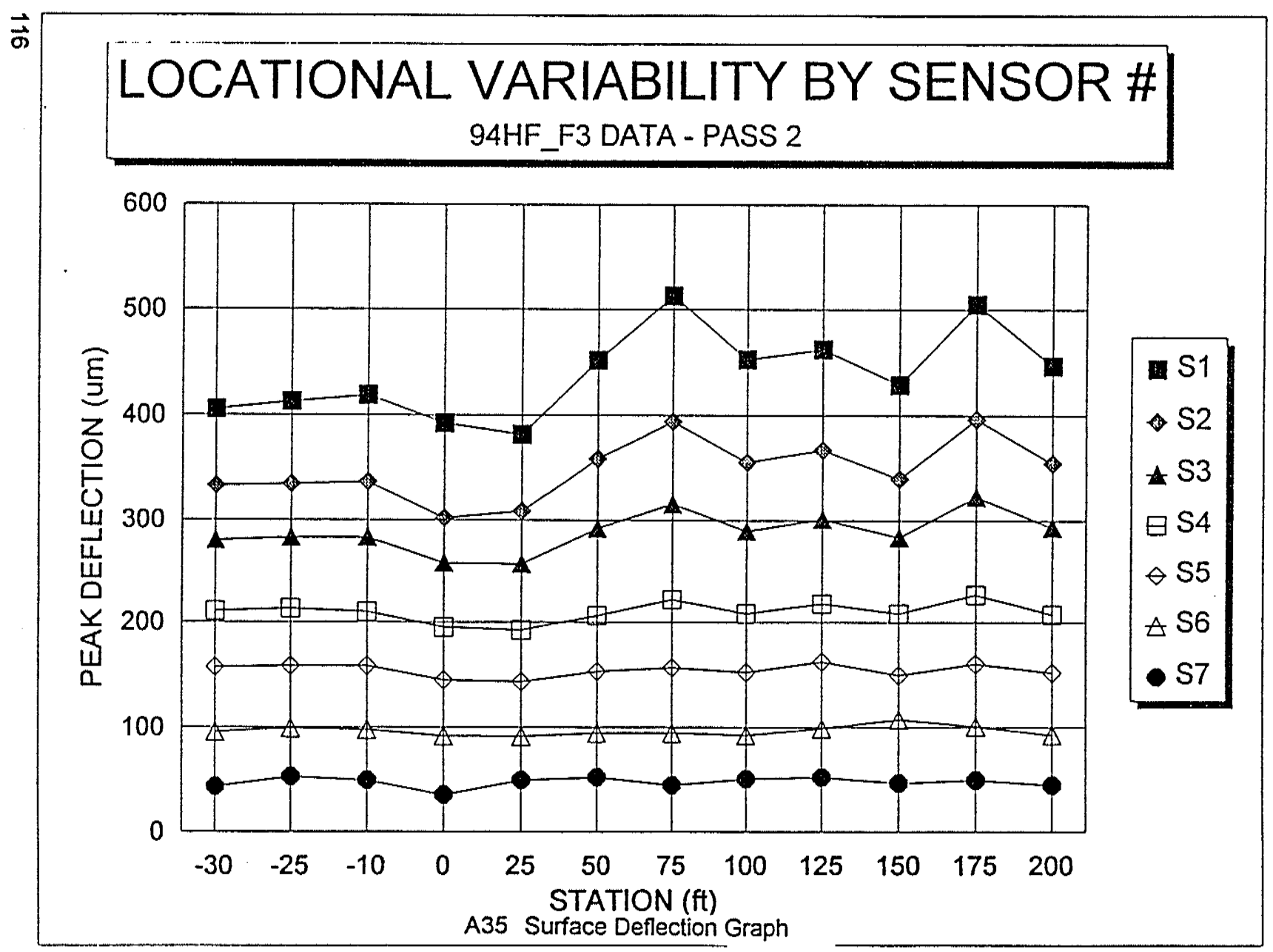




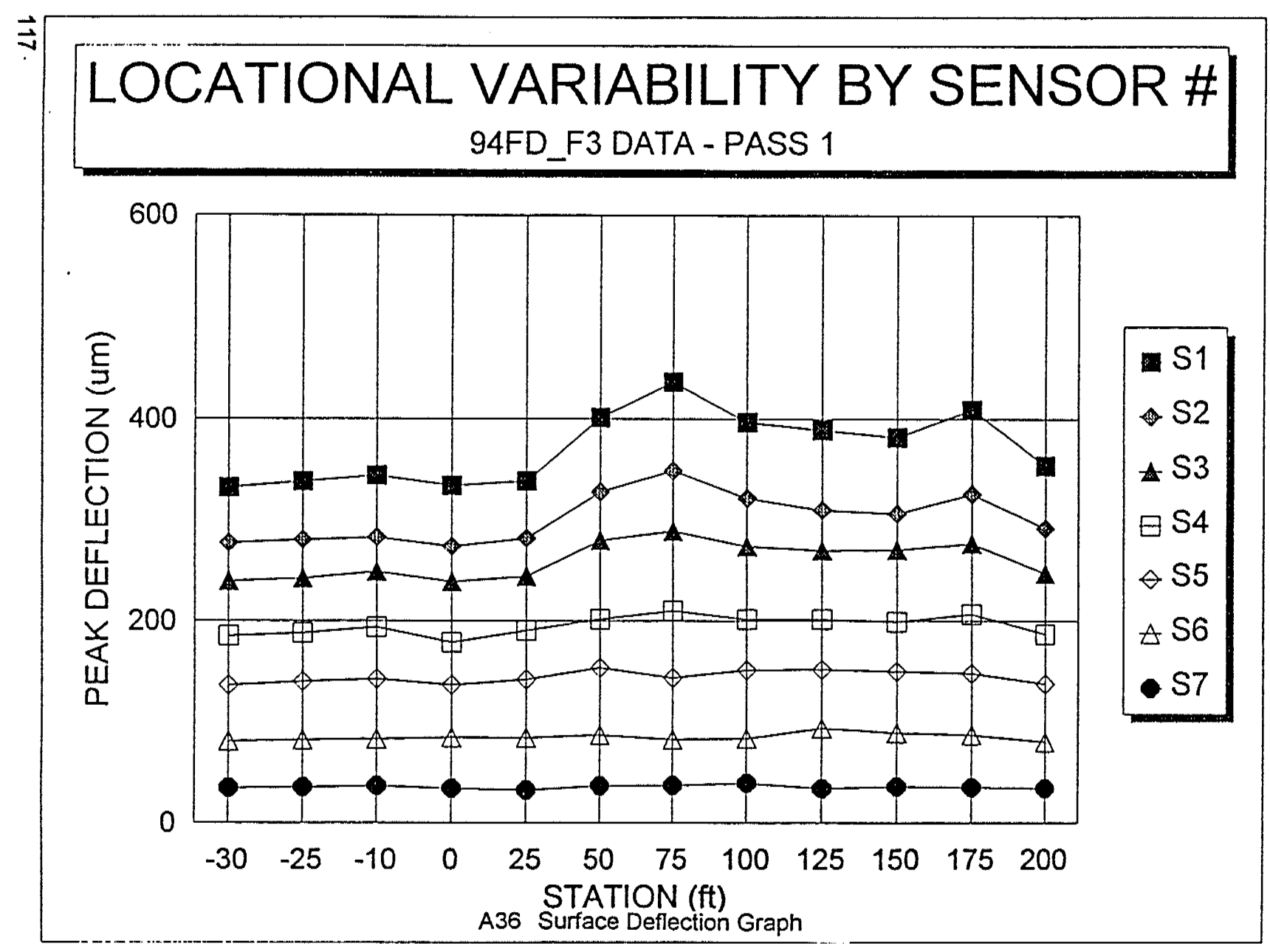




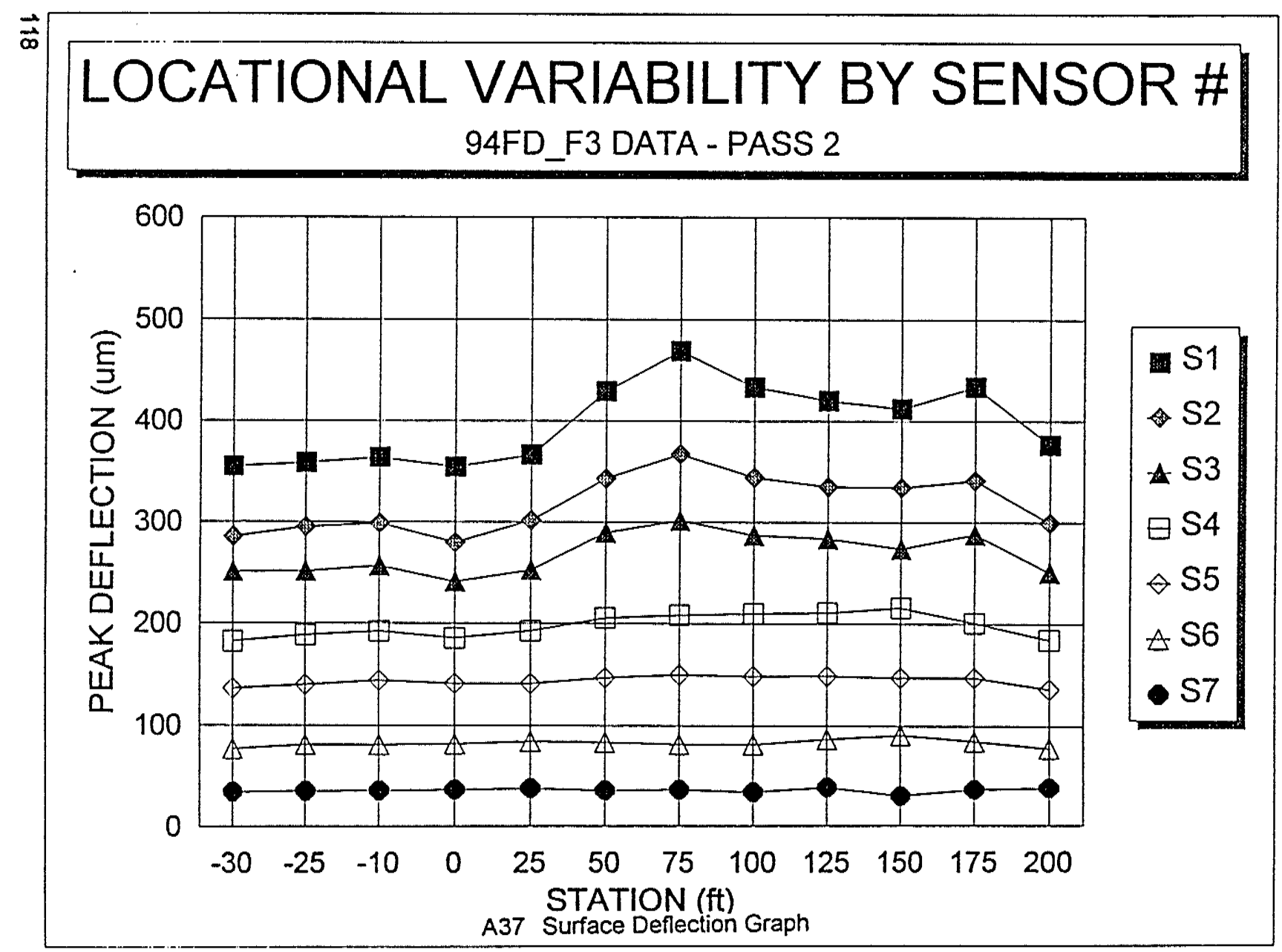




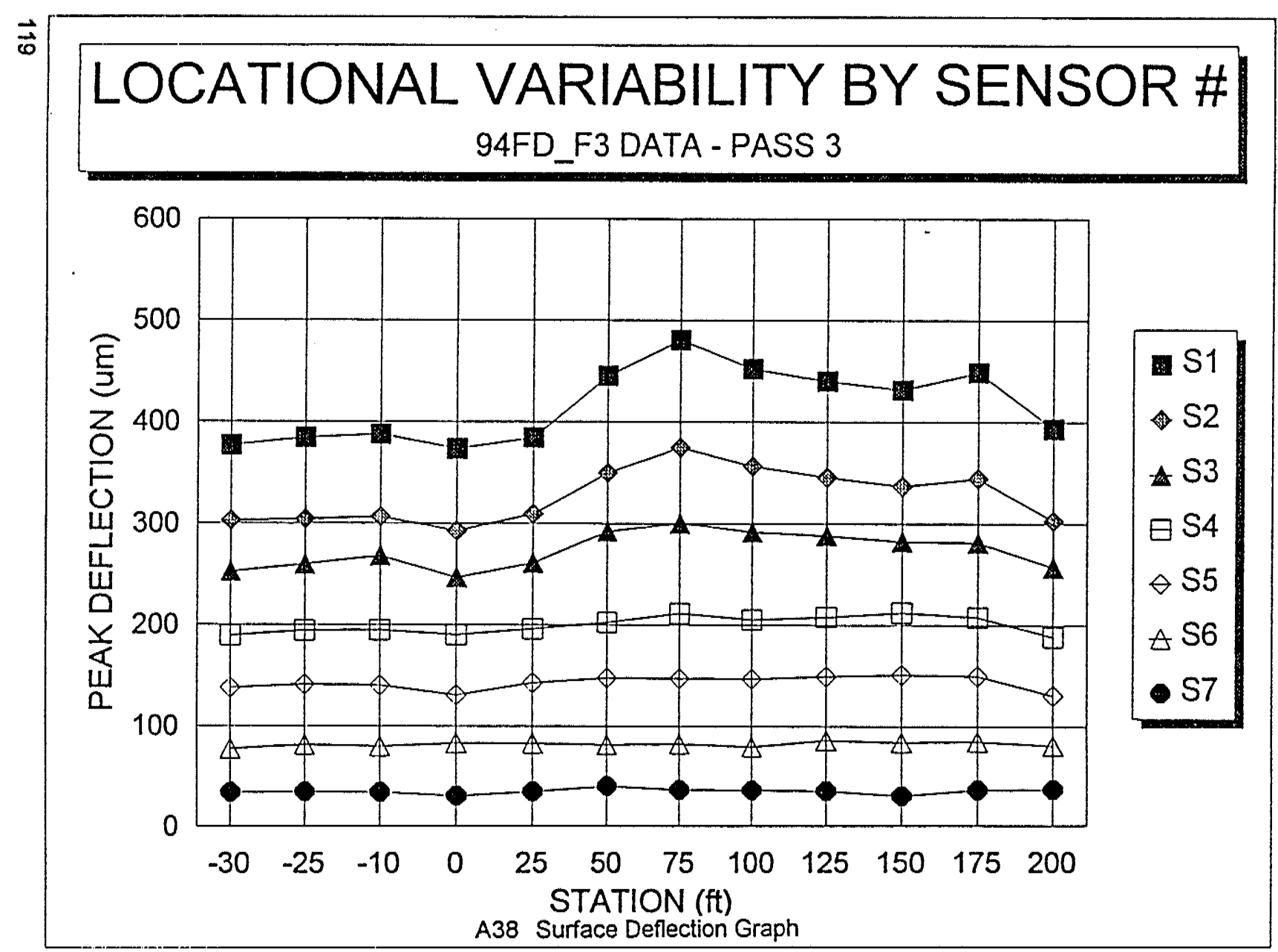




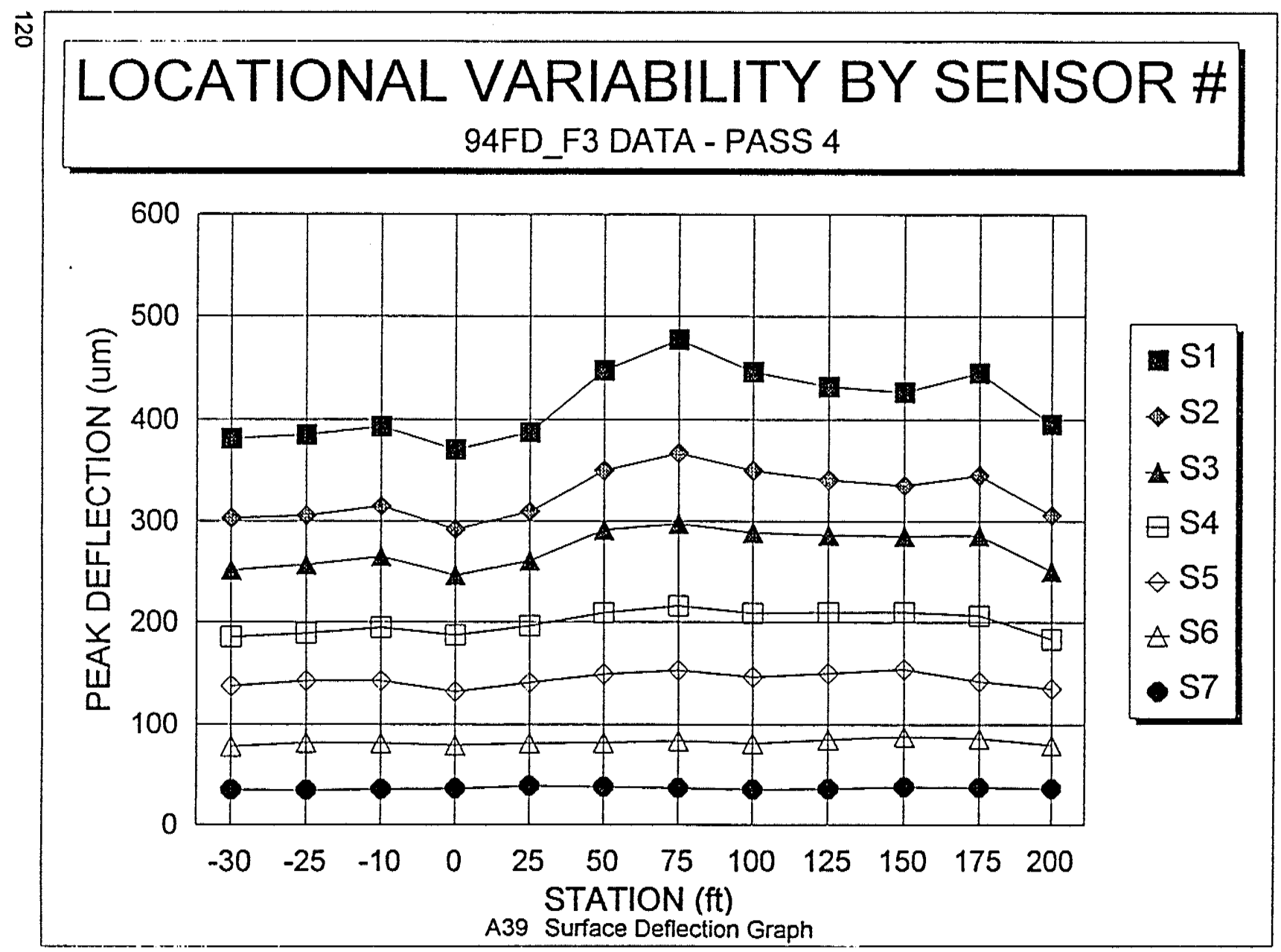




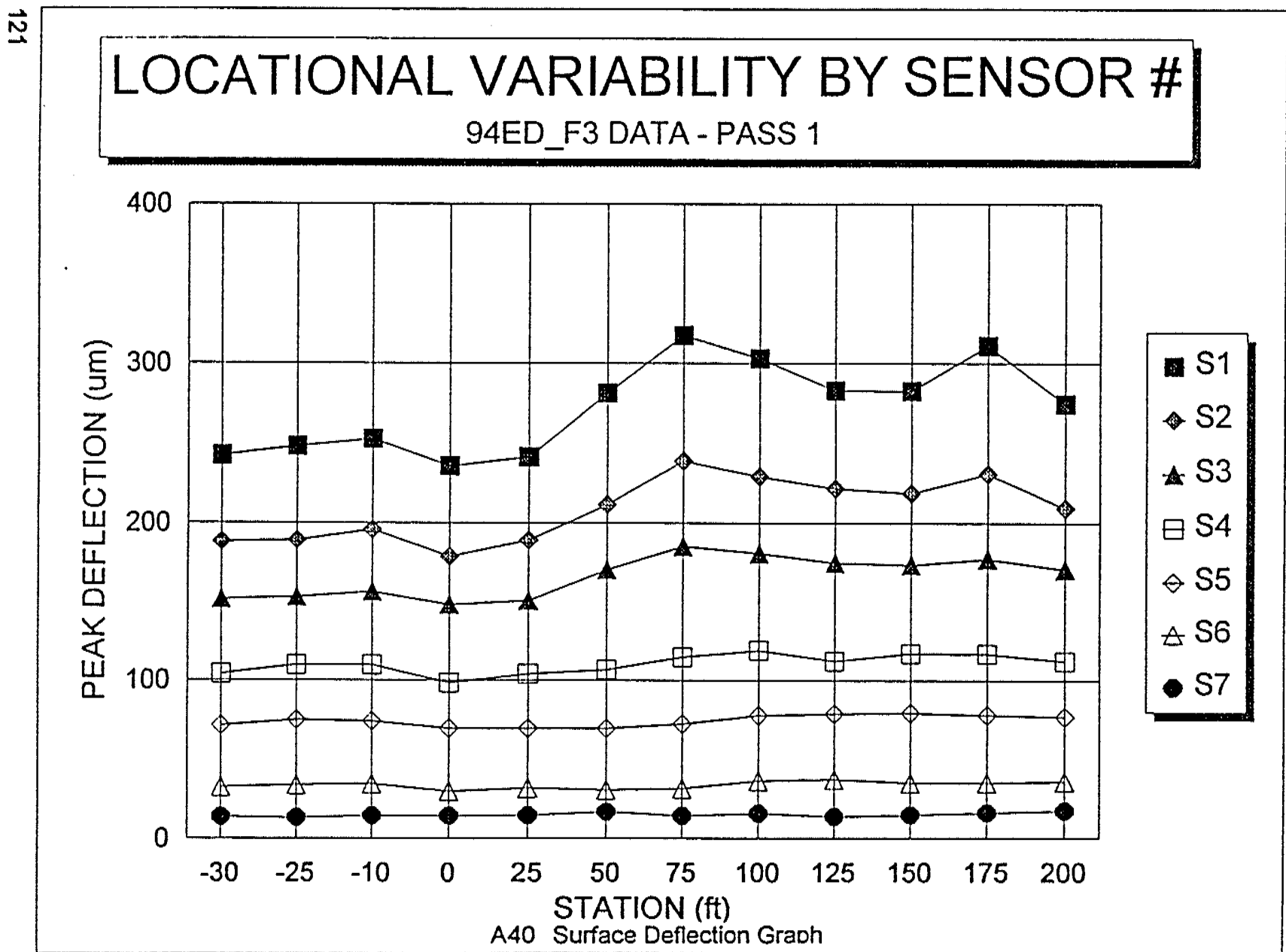




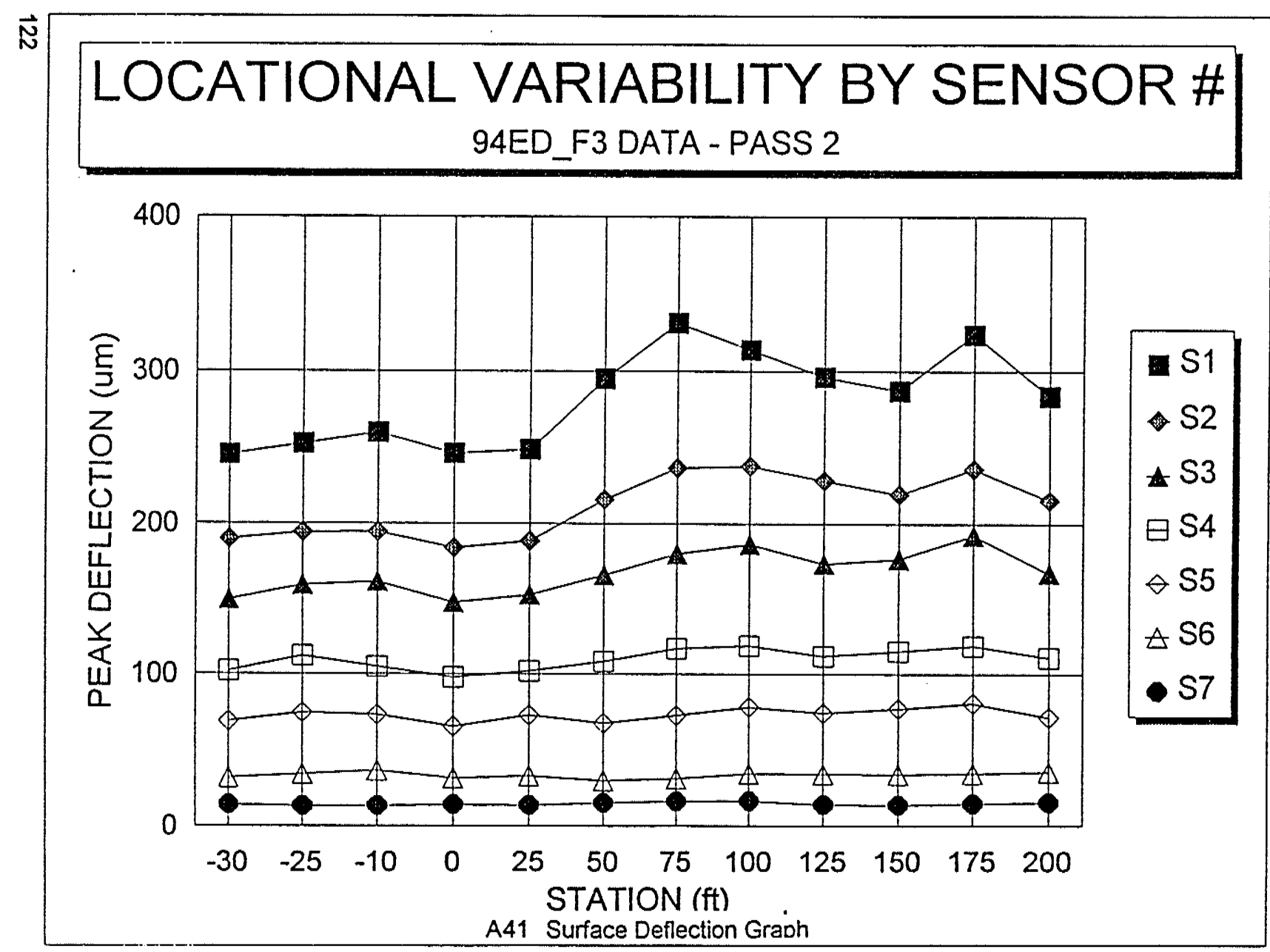




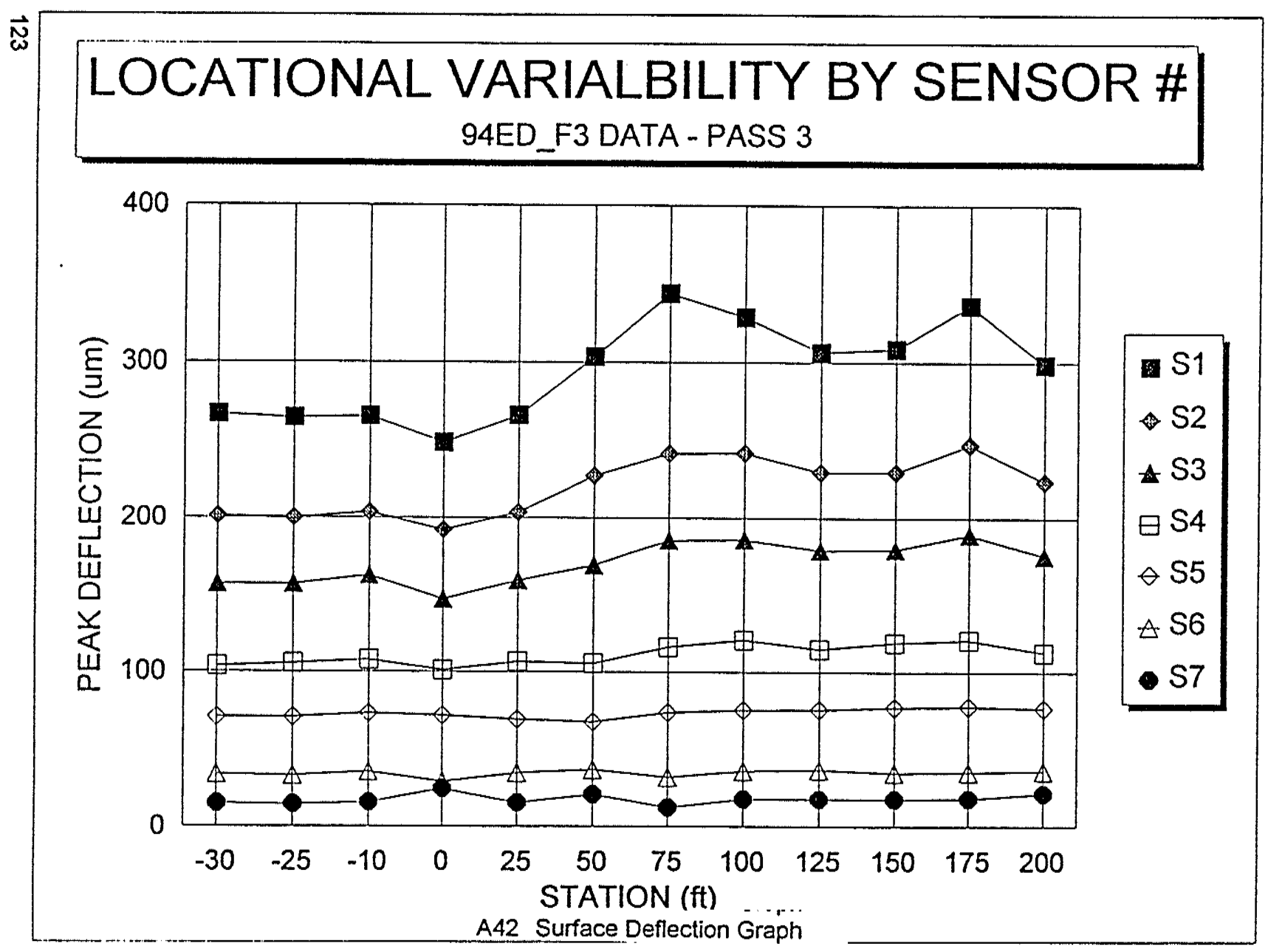




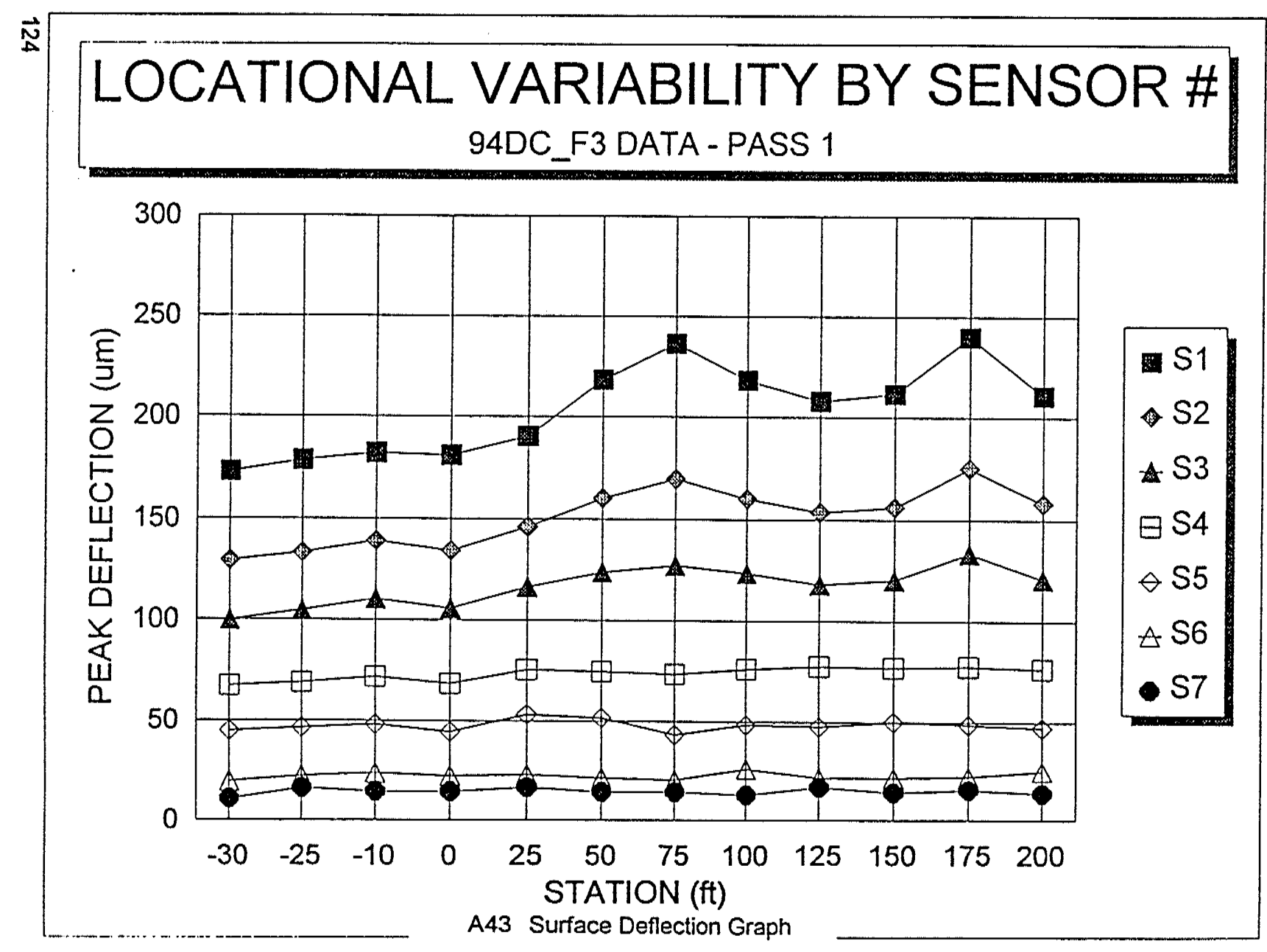




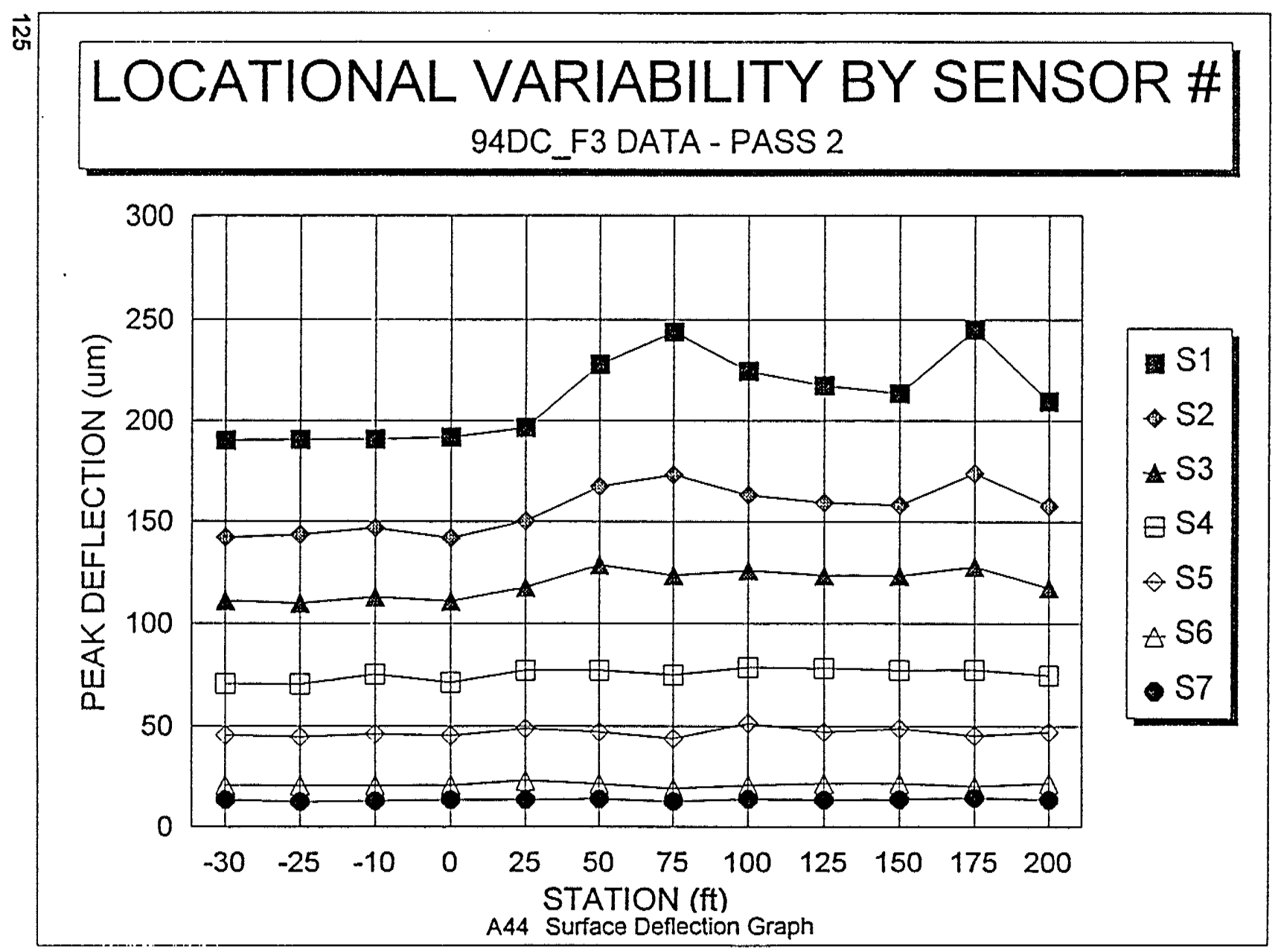




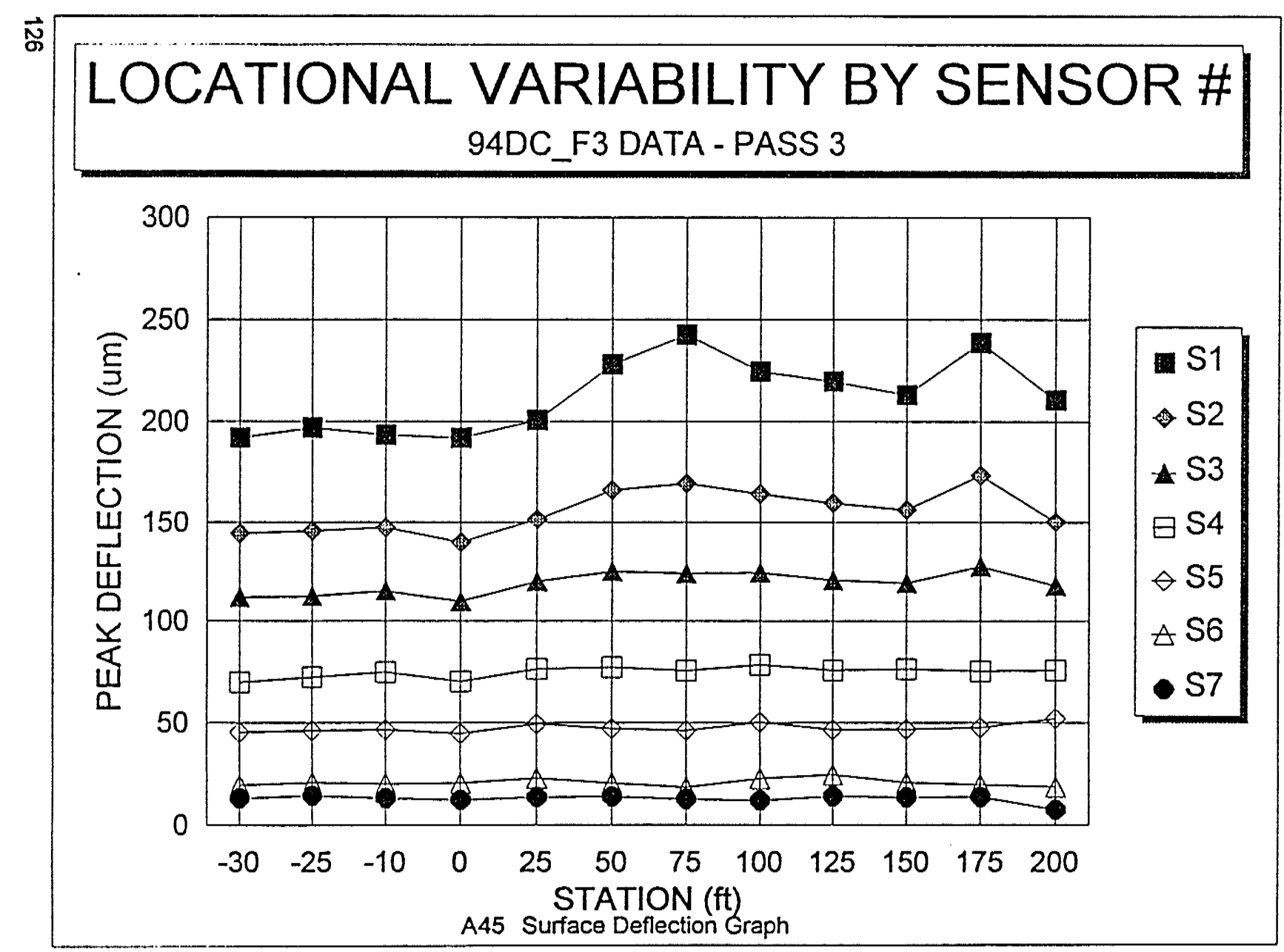




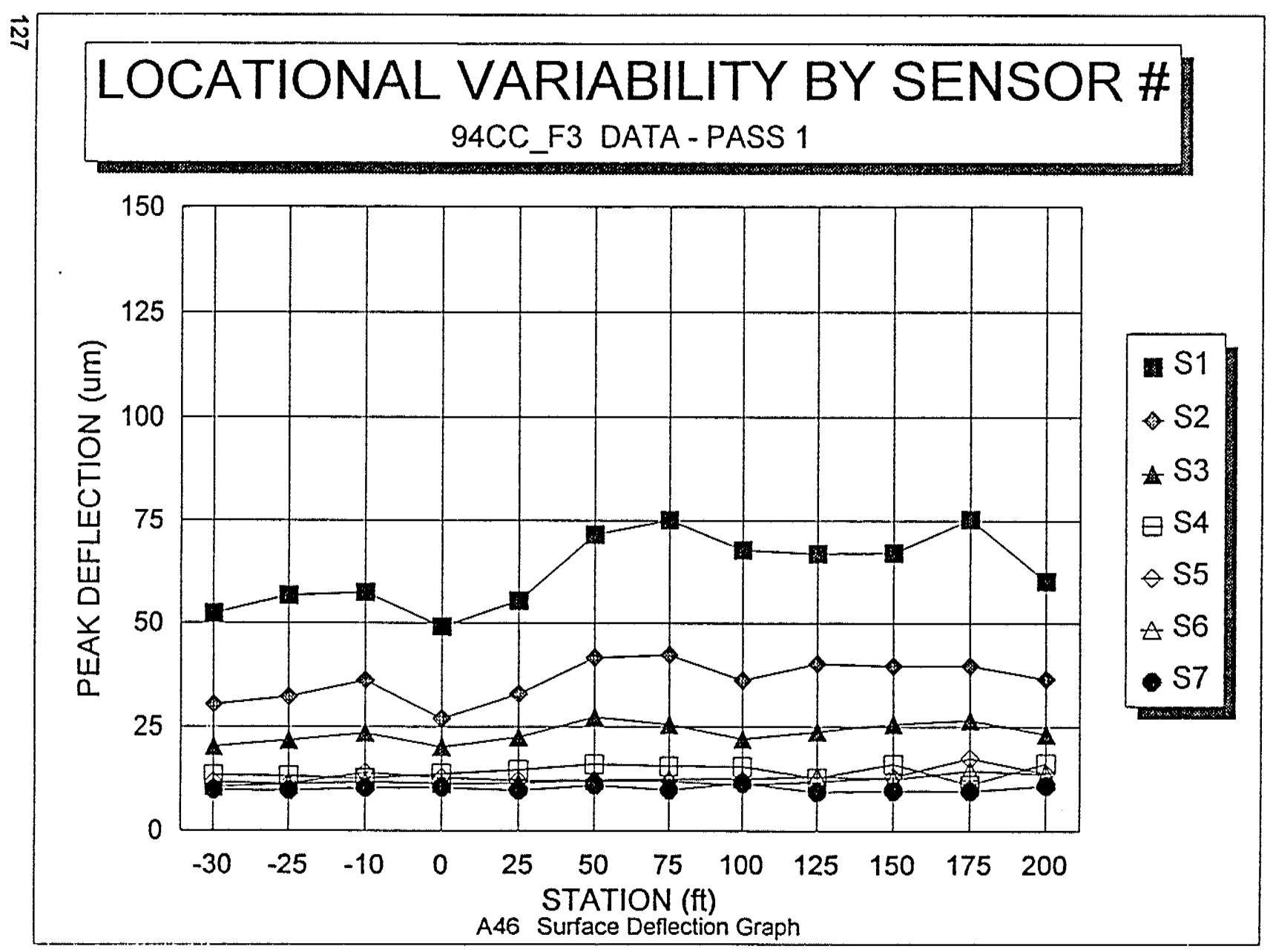




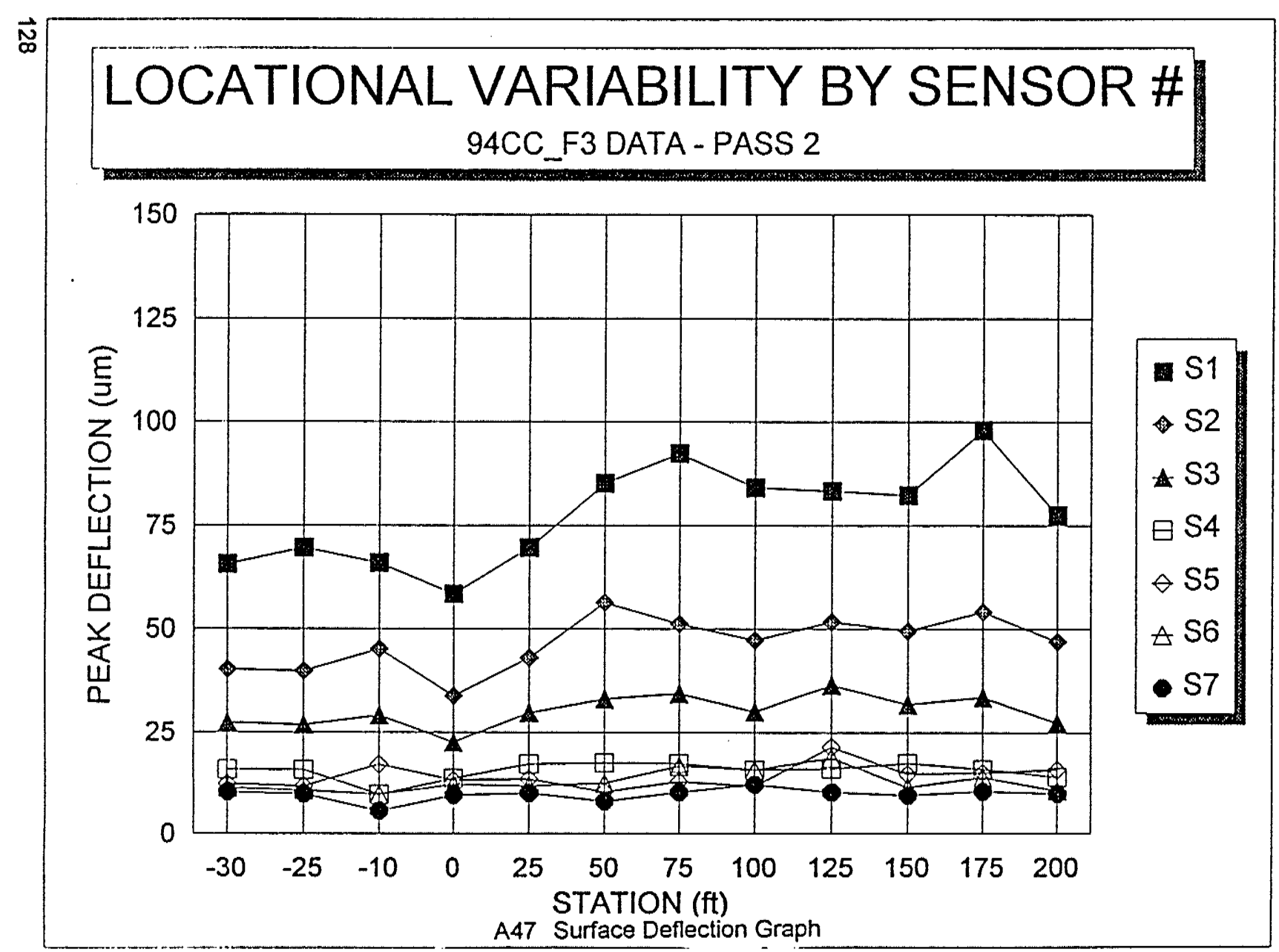




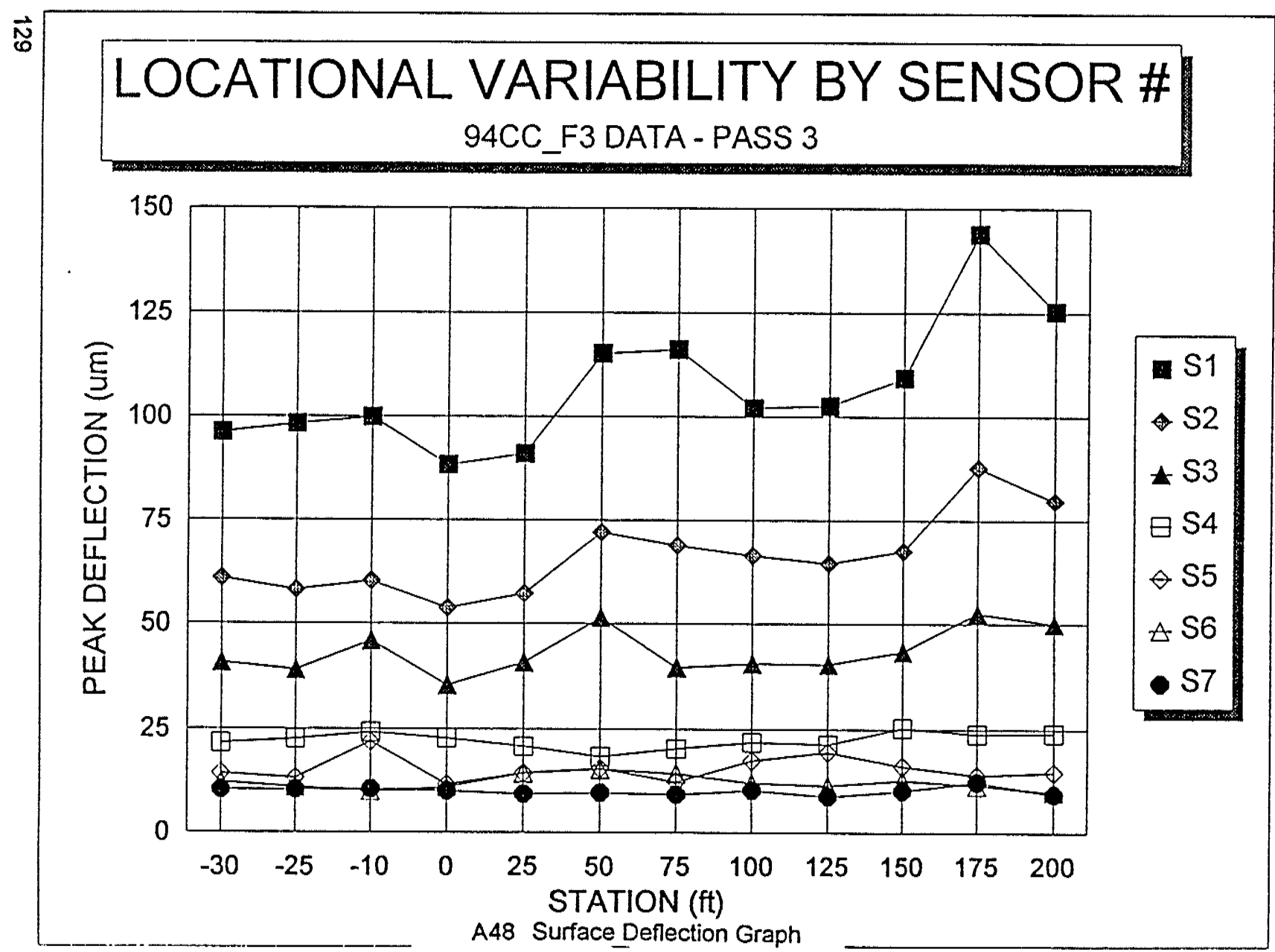




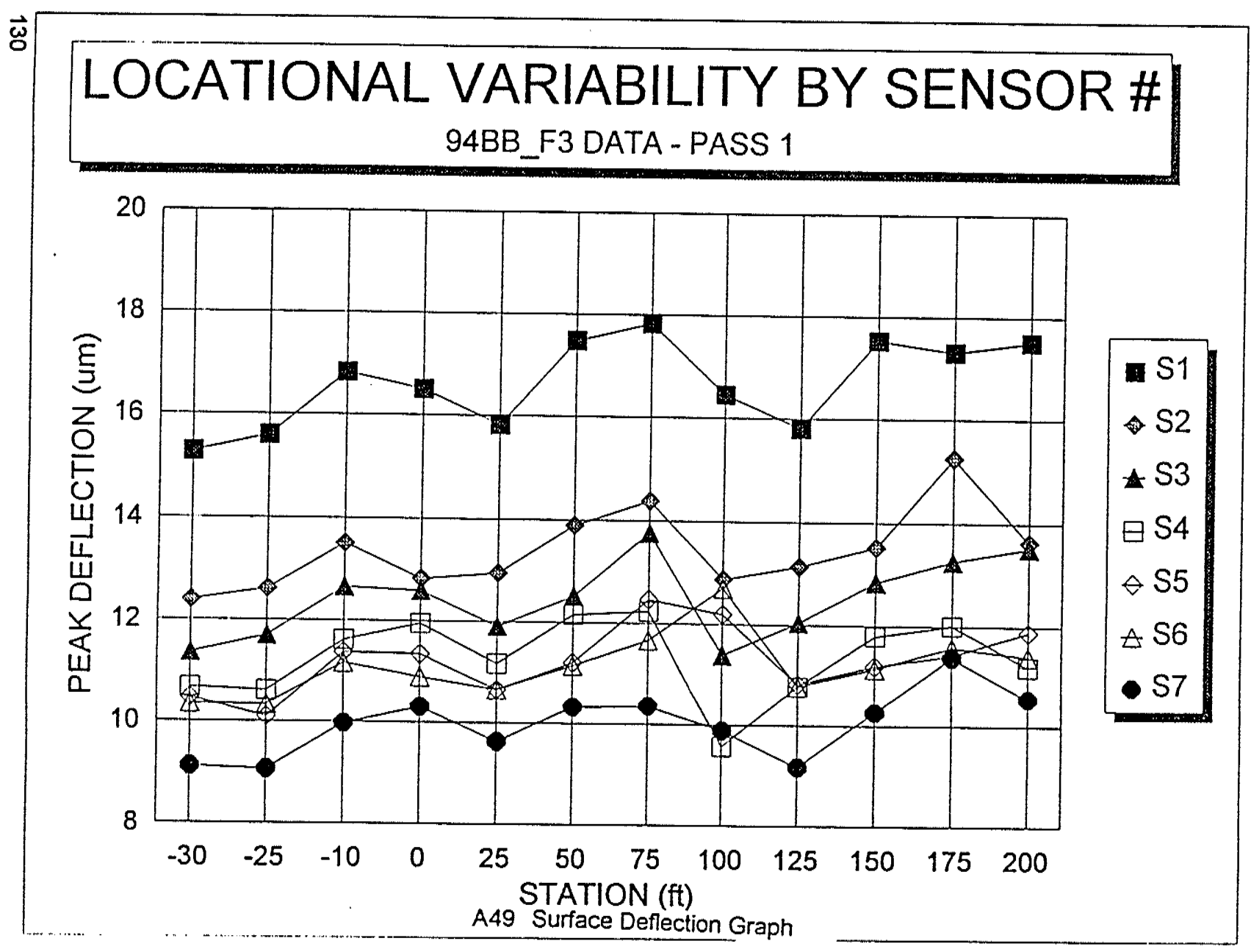




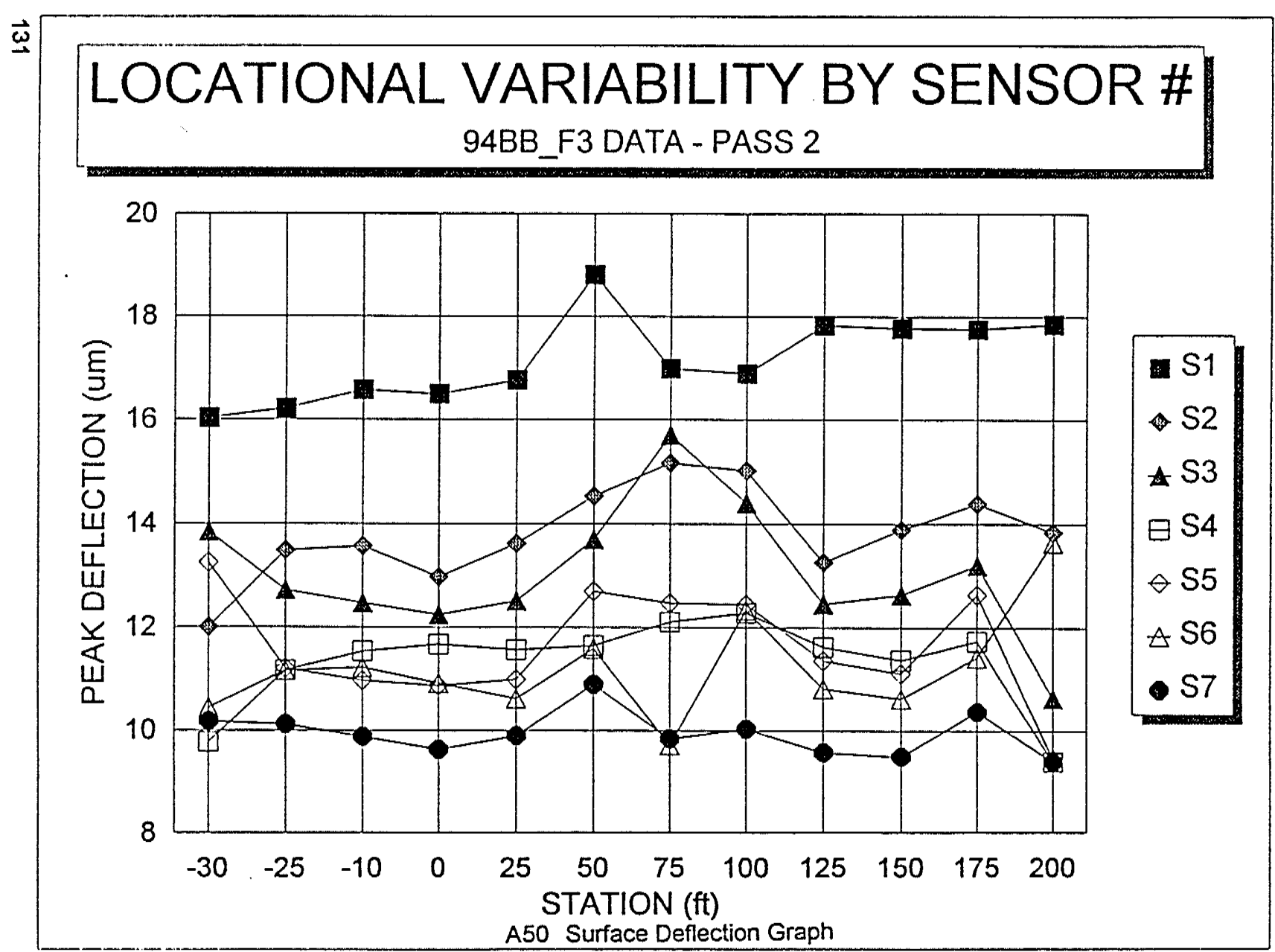




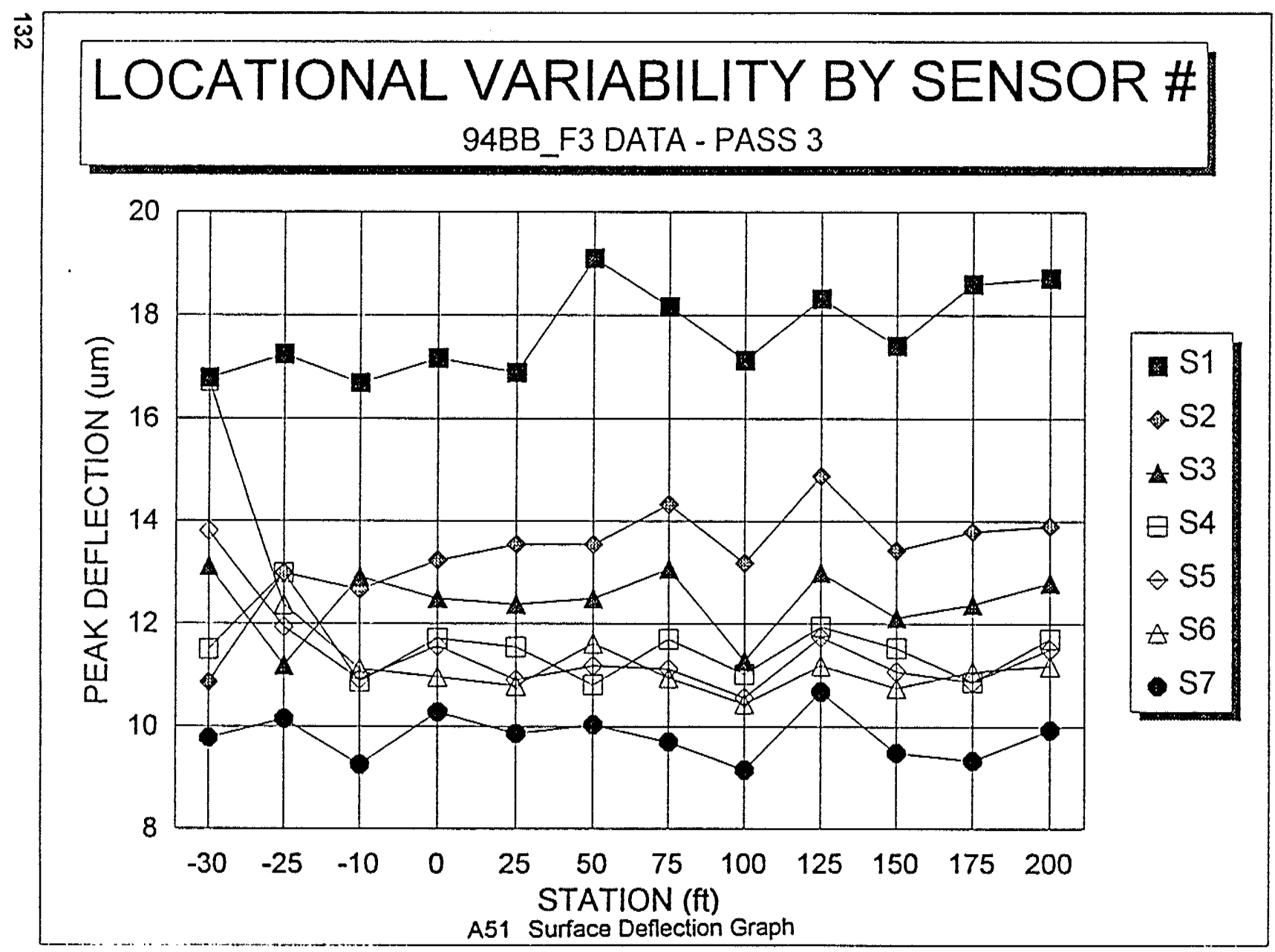


Appendix B :

\section{Electrical Resistance Data}




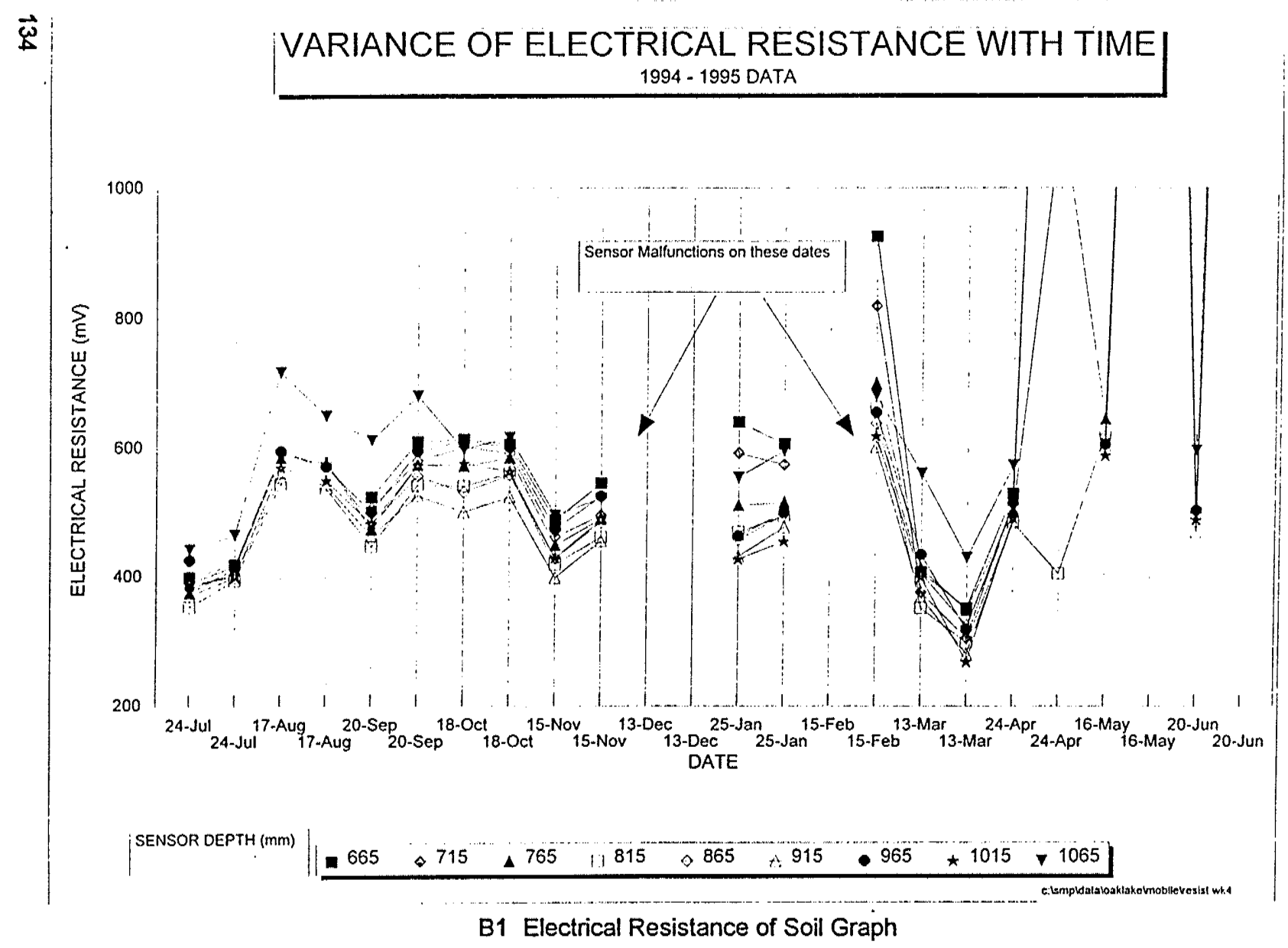




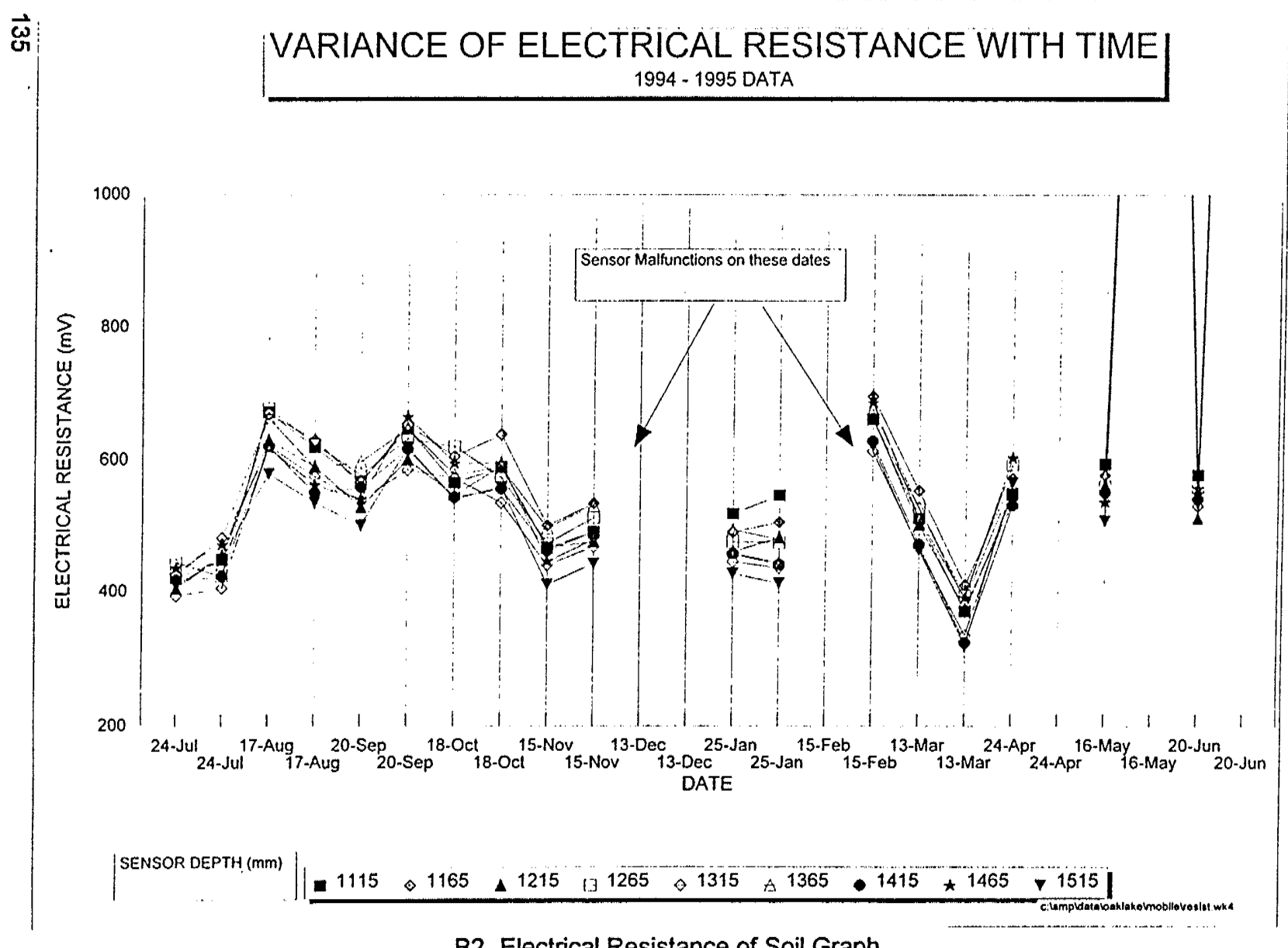

B2 Electrical Resistance of Soil Graph 


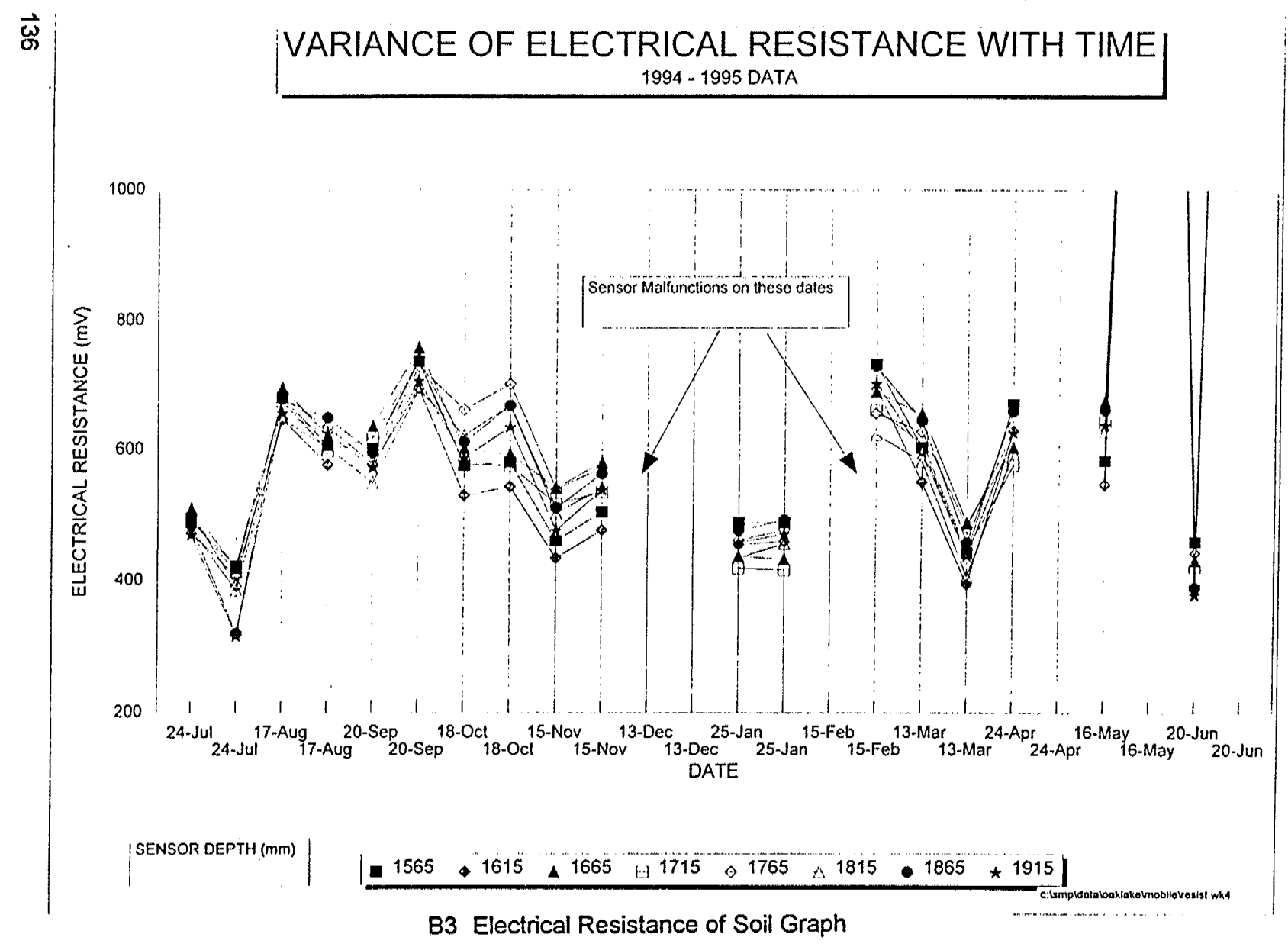




\section{Appendix C:}

\section{Soil Moisture Content Data}


NOV $30 / 95$ VOLUMETRIC MOISTURE CONTENTS FROM MOBFIELD PLOTS

Matrertata Manitoba AND REBIARCF Highways and

BRANTCH

Transportation

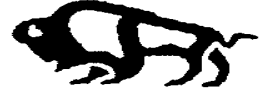

\begin{tabular}{l|l|l|l|l|l|l|l|l|}
\cline { 2 - 7 } \multicolumn{1}{c|}{ DOLUMETRIC MOISTURE CONTENT (\%) } \\
\hline TDR\#1 TDR\#2 & TDR\#3 & TDR\#4 & TDR $\$ 5$ & TDR\#6 & TDR $\$ 7$ & TDR\#8 & TDR\#9 & TDR\#10 \\
\hline
\end{tabular}

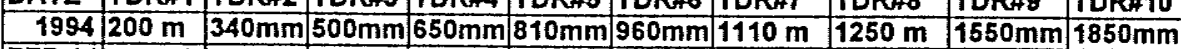

\begin{tabular}{|c|c|c|c|c|c|c|c|c|c|c|}
\hline FEB 14 & $\overline{8}$ & 4 & 5 & 5 & 9 & 9 & 11 & 13 & 16 & 19 \\
\hline & 5 & 5 & $\frac{7}{6}$ & 5 & 8 & 10 & 11 & 13 & $\frac{15}{15}$ & 17 \\
\hline MAR 14 & 14 & $\overline{8}$ & 10. & 7 & 12 & 14 & 16 & 16 & 19 & 20 \\
\hline & 15 & $\overline{9}$ & 10 & 8 & 14 & 15 & 15 & 14 & 18 & 19 \\
\hline MAR Z & 18.5 & 12.5 & 17.2 & 12 & 15 & 17 & 17 & 18 & 19 & 18 \\
\hline & 18.5 & 13 & 18.5 & 13 & 15 & 17 & 17 & 16 & 19 & 18 \\
\hline$\overline{\mathrm{APR}} 11$ & 18.5 & 13.6 & 19.1 & 17.8 & 26.4 & 17.8 & 18.5 & 19 & 20 & 18 \\
\hline & 19.1 & 13 & 18.5 & 17.8 & 27.6 & 18.5 & 17.8 & 20 & 19 & 19 \\
\hline APR 29 & 18.5 & 12.5 & 19.1 & 30 & 27.6 & 34.6 & 32.3 & 31.2 & 22.1 & 18.5 \\
\hline & 18.5 & 13 & 19.1 & 19.1 & 28.8 & 32.9 & 32.9 & 32.9 & 20.9 & 18.5 \\
\hline & 18.5 & 12.5 & 17.2 & 19.1 & 28.8 & 34 & 34.6 & 32.9 & 22.8 & 18.5 \\
\hline JUN 17 & 19.1 & 13.6 & 19.1 & 19.7 & 30.6 & 39.8 & 36.2 & 35.6 & 37.2 & 34 \\
\hline & 19.1 & 13 & 19.1 & 20.3 & 32.9 & 40.2 & 37.2 & 36.2 & 37.8 & 33.4 \\
\hline JUL 25 & 19.1 & 13 & 19.4 & $20 . \overline{3}$ & 35.1 & 40.2 & 38.3 & 39.8 & 39.8 & 34.6 \\
\hline & 19.1 & 13.6 & 19.1 & 20.3 & 34 & 44.3 & 41.2 & $\overline{41.2}$ & 41.2 & 35.1 \\
\hline AUG 1 & 19.1 & 13 & 19.7 & 19.1 & 32.9 & 46 & 40.2 & 42.1 & 41.7 & 36.7 \\
\hline & 19.1 & 13.6 & 19.1 & 19.7 & 35.1 & 41.2 & 40.7 & 42.1 & 42.6 & 36.2 \\
\hline SEP 21 & 19.7 & 13.6 & 19.1 & 19.7 & 32.3 & 42.6 & 38.3 & 40.2 & 40.7 & 36.2 \\
\hline & 19.1 & 13 & 19.7 & 19.7 & 29.4 & 40.2 & 39.3 & 41.7 & 40.7 & 37.8 \\
\hline OCT 19 & 18.5 & 13 & 19.7 & 18.5 & 28.2 & 39.3 & 35.6 & 36.2 & 38.3 & 34.6 \\
\hline & 18.5 & 13 & 20.3 & 18.5 & 28.8 & 38.8 & 36.7 & 36.7 & 38.3 & 34 \\
\hline NOV 1 & 17.8 & 12.5 & 18.5 & 17.2 & 25.8 & 34 & 33.4 & 32.9 & 36.2 & 32.3 \\
\hline & 17.8 & 12.5 & 18.5 & 17.8 & 25.8 & 33.4 & 34 & 33.4 & 36.2 & 32.9 \\
\hline$\overline{D E C} 14$ & 8 & 6 & 8 & 6 & 11 & 17 & 31 & 30.6 & 32.3 & 28.8 \\
\hline & 8 & 5 & 6 & 6 & 11 & 18 & 31 & 30.6 & 32.9 & 28.8 \\
\hline
\end{tabular}

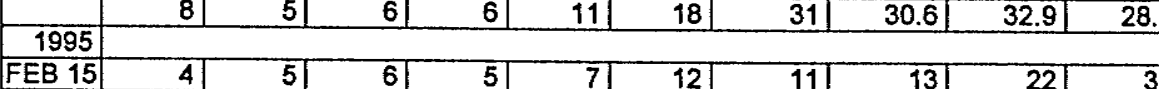

\begin{tabular}{|r|r|r|r|r|r|r|r|r|r|r|}
\hline FEB 15 & 4 & 5 & 6 & 5 & 7 & 12 & 11 & 13 & 22 & 30 \\
\hline & 6 & 5 & 5 & 4 & 8 & 12 & 11 & 15 & 21 & 28 \\
\hline MAR 14 & 13 & 6 & 9 & 6 & 9 & 13 & ERROR & 14 & 19 & 19 \\
\hline & 14 & 7 & 10 & 6 & 9 & 14 & ERROR & 14 & 19 & 19 \\
\hline APR 11 & 18.5 & 9.6 & 14.2 & 8.5 & 13 & 17 & 15 & 18 & 21 & 20 \\
\hline & 16.6 & 9.1 & 14.2 & 8.5 & 13 & 17 & 15 & 18 & 22 & 20 \\
\hline APR 25 & 21.5 & 14.2 & 19.1 & 20.9 & 28.2 & 33.4 & 16.6 & 17.8 & 21.5 & 20.9 \\
\hline & 21.5 & 13.6 & 19.1 & 20.3 & 28.8 & 34 & 16.6 & 18.5 & 22.8 & 20.9 \\
\hline MAY 17 & 21.5 & 14.8 & 22.1 & 22.8 & 32.3 & 37.8 & 36.7 & 34.6 & 38.3 & 22.1 \\
\hline & 21.5 & 14.2 & 19.1 & 22.1 & 32.3 & 38.3 & 34 & 34 & 36.2 & 22.1 \\
\hline & 21.5 & 14.8 & 19.1 & 22.8 & 32.3 & 37.8 & 34 & 34.6 & 36.2 & 21.5 \\
\hline JUN 21 & 22.8 & 14.2 & 20.9 & 23.4 & 38.3 & 36.7 & 37.2 & ERROR & NDATA $>>>>>>$ \\
\hline 1 & 22.1 & 14.8 & 20.9 & 22.8 & 34.6 & 30.6 & 37.8 & 39.8 & 40.7 & 34.6 \\
\hline 1 & 23.4 & 15.4 & 20.9 & 23.4 & 36.2 & 37.2 & 38.3 & 36.7 & 39.8 & 34 \\
\hline
\end{tabular}


Appendix D:

Backcalculated Layer

Moduli Output From

EVERcALC 
BACKCALCULATTON by EVERCaIC 4.0 - Summary Output

\begin{tabular}{|c|c|c|c|c|}
\hline \multicolumn{3}{|c|}{ 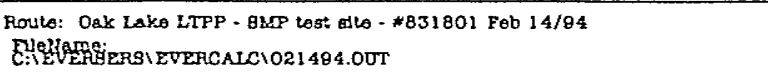 } & \multirow{2}{*}{\multicolumn{2}{|c|}{$\begin{array}{l}\text { Burr Layer: ho } \\
\text { Plato Racius: } 18.0 \\
\text { P-Ratio: } 0.36 \text { 0.38 } 0.3 .5\end{array}$}} \\
\hline $\begin{array}{l}\text { No of Layers: } 3 \\
81.0 \text { \&f. } \\
8182.420 .3 \quad 30.8 \quad 45.7\end{array}$ & No of Bansors: 7 & & & \\
\hline Lad of & $E(1)$ (MPB) & $E(2)(L P B)$ & $8(3)$ (affs $)$ & Rus Error \\
\hline $021484-1$ & 83878 & 18000 & 800 & 12.34 \\
\hline $021494-3$ & 48630 & 19000 & 000 & 11.48 \\
\hline $021494-3$ & 49111 & 19000 & 800 & 11.83 \\
\hline
\end{tabular}

BACKCALCULATTON by Evercalc 4.0 - Summary Output

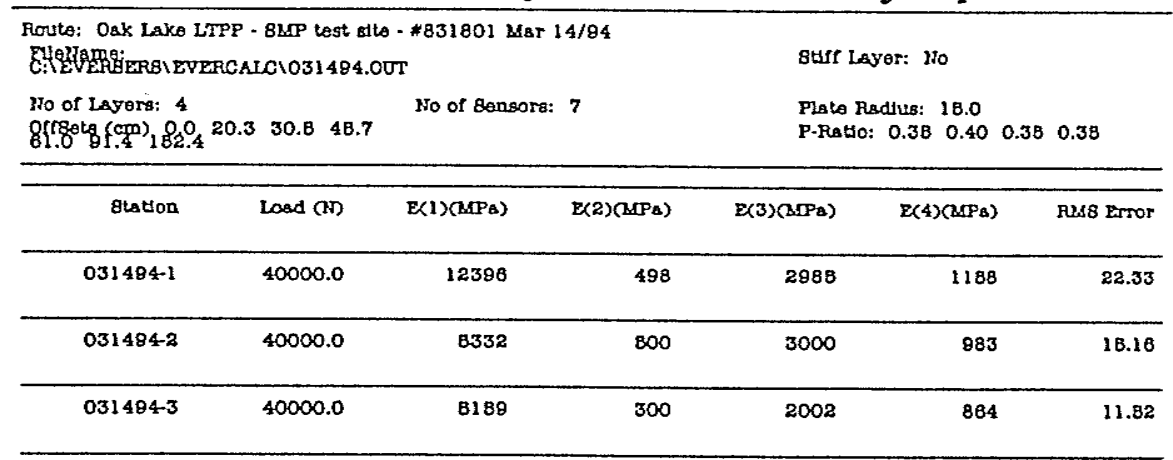

BACKCALCULATTON bY Evercalc 4.0 - Summary Output

\begin{tabular}{|c|c|c|c|c|}
\hline 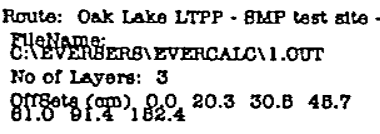 & $\begin{array}{l}\text { N331801 MaF 14/94 } \\
\text { No of Bensore: } 7\end{array}$ & & $\begin{array}{l}\text { Btaft Lager: Ho } \\
\text { Pusto Radius: } 18.0 \\
\text { P.Rsto: } 0.38 \quad 0.38 \quad 0.3 B\end{array}$ & \\
\hline Losd (in) & $E(I)(A P B)$ & $E(2)(M P B)$ & $E(3)(M P B)$ & Puss Error \\
\hline $031494-1$ & 12398 & $288 \mathrm{~B}$ & 1188 & 34.92 \\
\hline
\end{tabular}

140

D1 Backcalculated Layer Moduli 
BACKCALCULATTON by Evercalc 4.0 - Summary Output

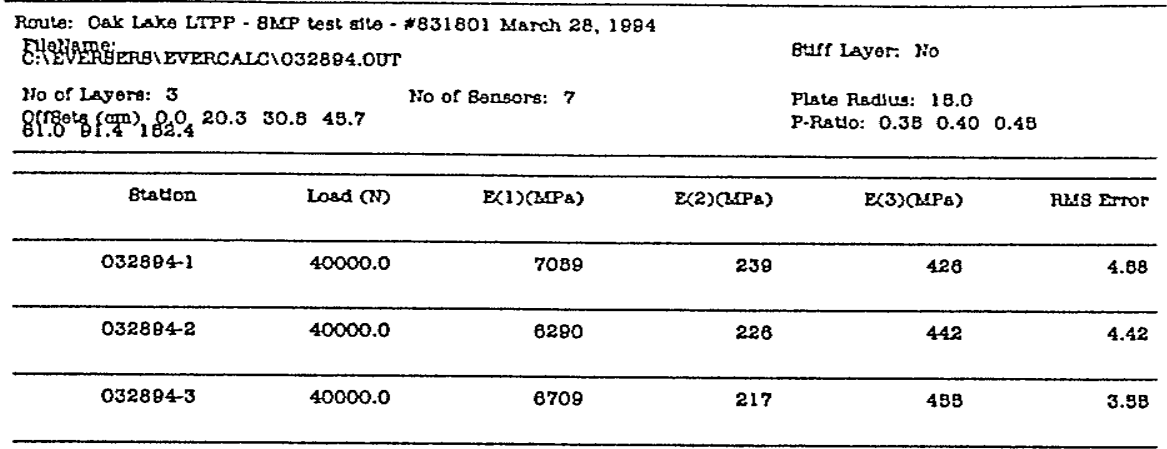

BACKCALCULATION by EVETCale 4.0 - Summary Output

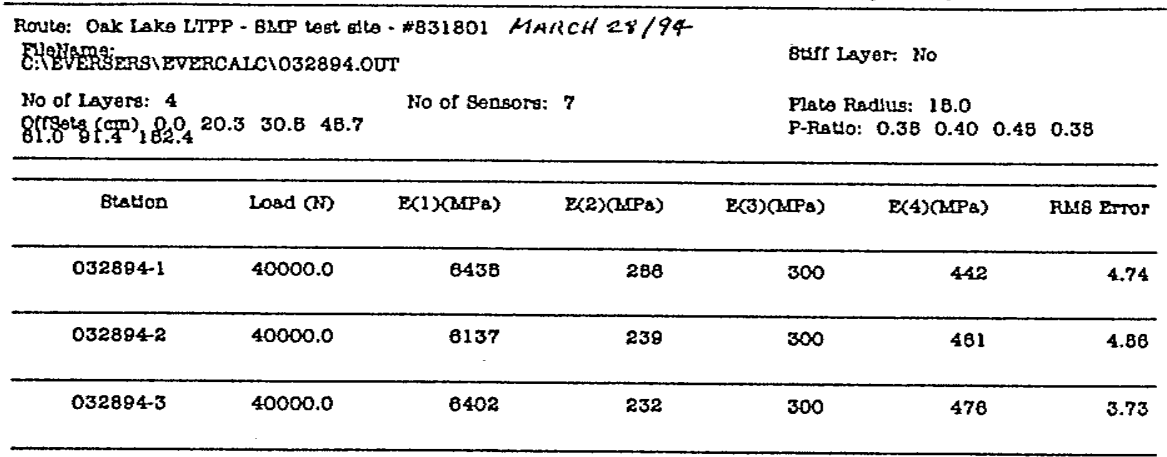

\section{BACKCALCULATTON by EverCsIc 4.0 - Summary Output}

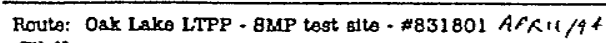

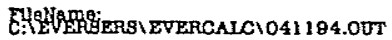

8utr Laget: No

No of Layers: 3

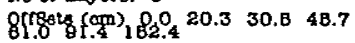

No of Bensors: 7

Flate Fadius: 18.0

P.Rstio: $0.38 \quad 0.40 \quad 0.48$

\begin{tabular}{|c|c|c|c|c|c|}
\hline Btation & Lasd (M) & $\mathrm{E}(1)\left(\mathrm{PP}_{8}\right)$ & $\mathrm{I}(2)(\mathrm{NP}(\mathrm{B})$ & $E(3)(\mathrm{MPB})$ & Fars Error \\
\hline $041194-1$ & 40000.0 & 8885 & 124 & 330 & 1.14 \\
\hline $041184-2$ & 40000.0 & 8348 & 123 & 343 & 1.78 \\
\hline $041194-3$ & 40000.0 & BeB & 139 & 308 & 0.88 \\
\hline
\end{tabular}

141

D2 Backcalculated Layer Moduli 
BACKCALCULATTON by EveTCalC 4.0 - Summary Output

\begin{tabular}{|c|c|c|c|c|}
\hline \multicolumn{3}{|c|}{ 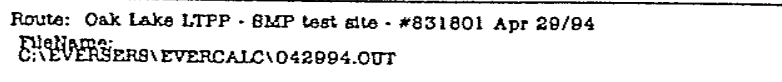 } & \multirow{2}{*}{$\begin{array}{l}\text { Butr Layar: Ho } \\
\text { Plato Radlus: } 18.0 \\
\text { P-Rratto: } 0.380 .40 \quad 0.48\end{array}$} & \\
\hline 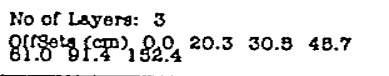 & No of Bensors: 7 & & & \\
\hline Laed $(m)$ & $E(1)$ (MPa) & $E(2)(A P B)$ & $\mathrm{E}(3) \Omega\left(\mathrm{P}_{\mathrm{P}}\right)$ & Rus Error \\
\hline $042894-1$ & 11221 & 77 & 186 & 2.00 \\
\hline $042994-2$ & 8911 & 83 & 182 & 1.88 \\
\hline $042994-3$ & B1Bg & 79 & $18 B$ & 2.87 \\
\hline 042994 & 7868 & 84 & 181 & 2.13 \\
\hline
\end{tabular}

BACKCALCUTATTON by EVEerade 4.0 - Summary Output

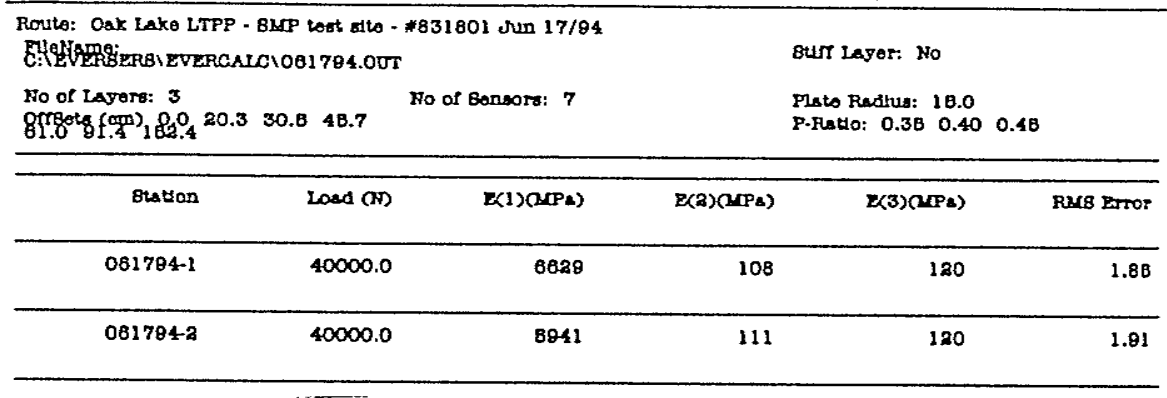

BACKCALCULATTON by EvercaIC 4.0 - Summary Output

Routo: Oak Lako LTPP - Bup lost atso - \$231801 jul 28/94

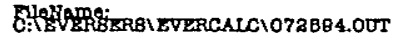

No of Lavers: 3

Ho of Bendors: 7

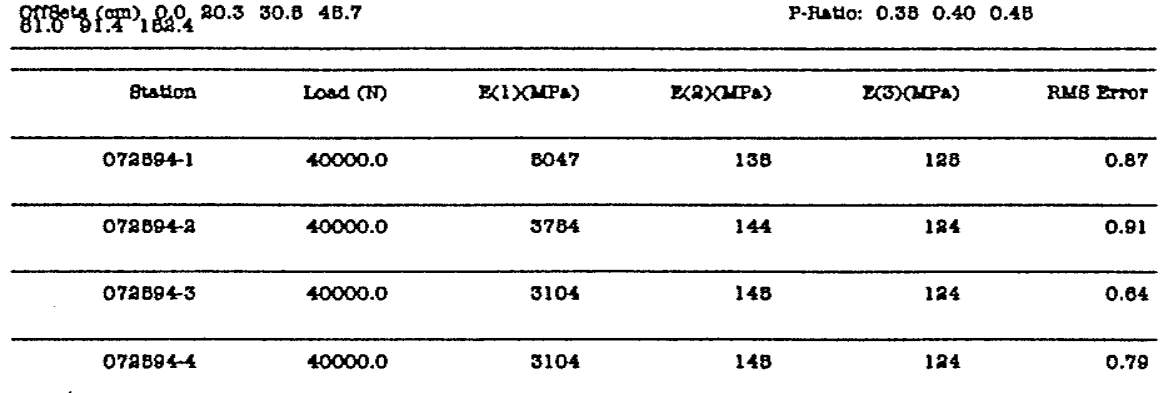

142

D3 Backcalculated Layer Moduli

Gutr Lagor: NO

PLeto Redtua: 18.0

$\begin{array}{llll}\text { P.Futio: } & 0.38 & 0.40 \quad 0.48\end{array}$ 
BACKCALCULATTON by EVETCalC 4.0 - Summery Ottput

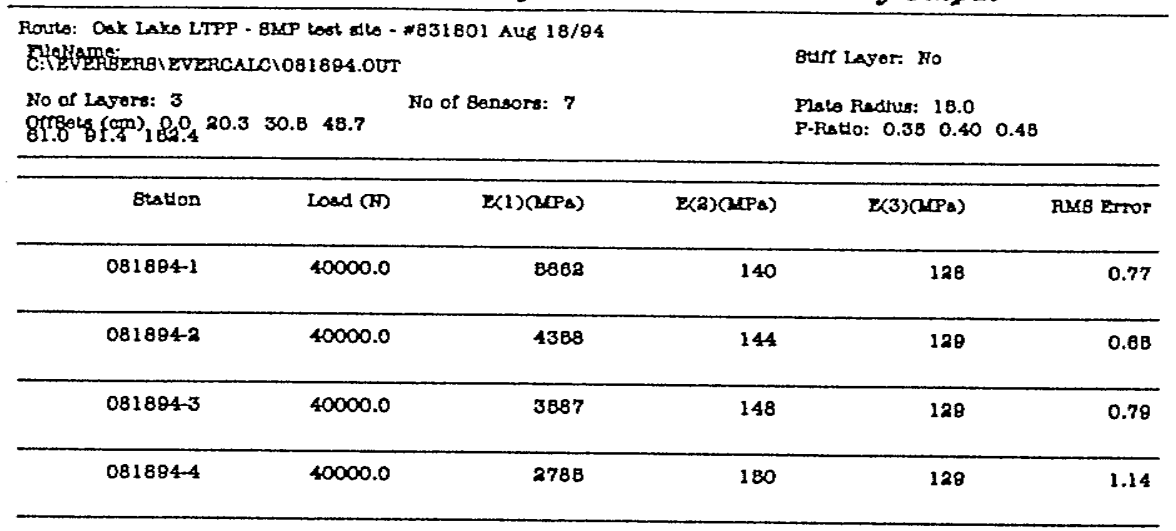

BACKCALCULATTON bJ Evercalc 1.0 - Summary Output

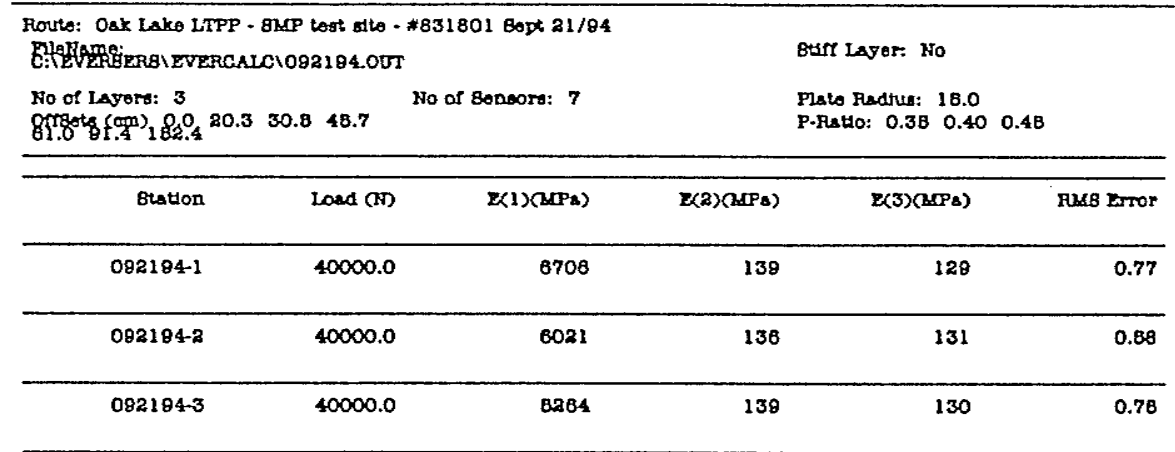

BACKCALCULATTON by strercale 4.0 - Summary Output

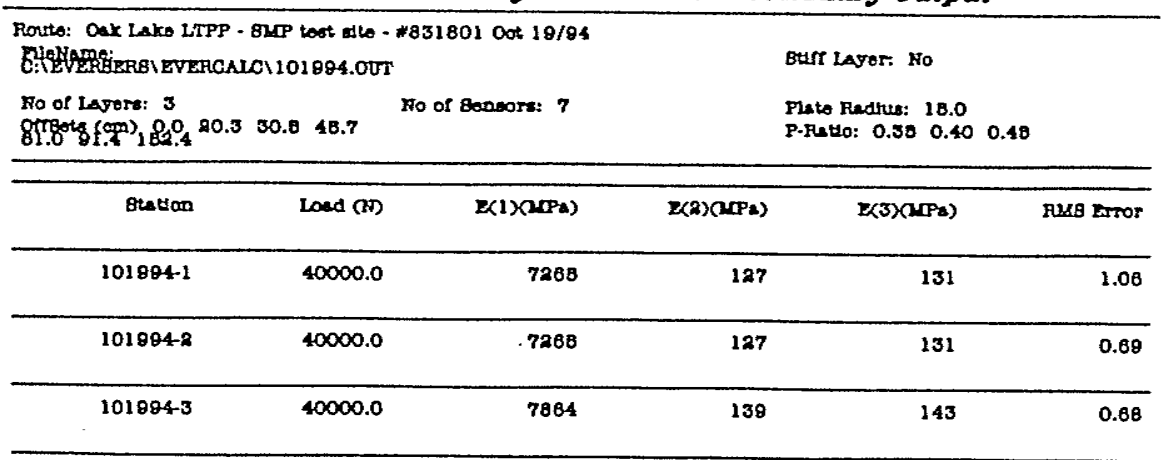

143 D4 Backcalculated Layer Moduli 
BACKCALCULATION by Evercalc 4.0. Summary Output

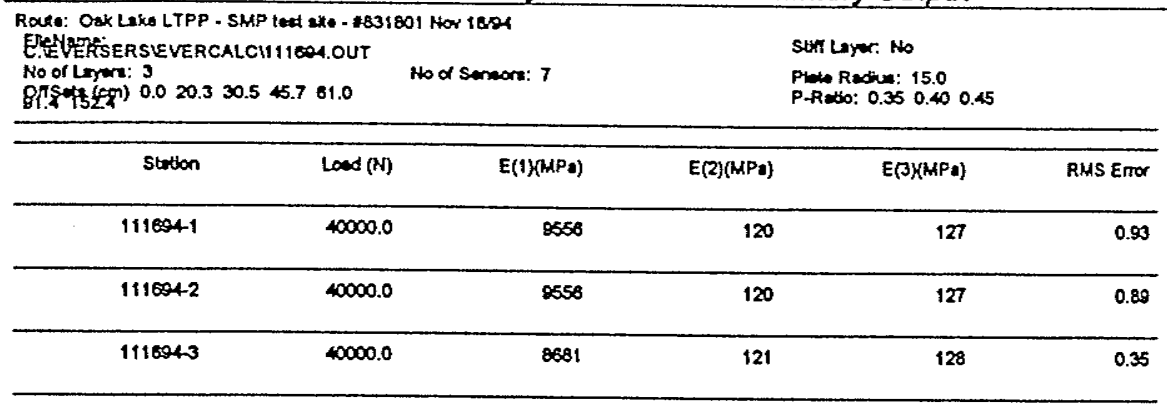

BACKCALCULATION by EVercalc 4.0 - Summary Output

Houte: Oak Lake LTPP - BMP test alto - $\$ 831801$ Deo 14/84

BIEUTRETERIEVERCALCI $4.00 \mathrm{~T}$

No or Layers: 3

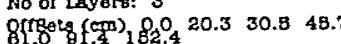

Wo of Bensors: 7

But Layer: Ho

Flate Radjus: 18.0

P-Ratto: $0.35 \quad 0.38 \quad 0.38$

\begin{tabular}{|c|c|c|c|c|c|}
\hline Btation & Ioad (A) & $R(1)(\mathrm{APB})$ & $E(2)(\triangle A P B)$ & $E(3)(M(P B)$ & RHS Etror \\
\hline $121494-1$ & 40000.0 & 44384 & 18000 & $3 B 1$ & 2.38 \\
\hline
\end{tabular}

BACKCALCULATTON by Evercalc 4.0 - Stummary Output

Route: Gak Lake LTPP - BMP test $\$ 1$ to - \$831801 Fob 18/8B

E:LYRER

No of Lavers: 3

No of Bensors: 7

gurf Layer: No

orrgetg (cm) $90_{4} 20.3 \quad 30.8 \quad 48.7$

Plate Radtus: 18.0

P-Fst10: $0.38 \quad 0.38 \quad 0.35$

\begin{tabular}{cccccc}
\hline Btation & Losd on & E(1)(MPa) & E(2)(MPa) & E(3)(MPa) & Rus Error \\
\hline $021898-1$ & 40000.0 & 80432 & 10000 & 800 & 8.31 \\
\hline
\end{tabular}

BACKCALCULATION by EVERCaIC 4.0 - SummarY Output

Fouta: Oak Lake LTPP - BLSP test alto - $\$ 831801$ Mar $14 / 88$

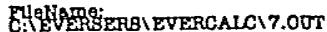

No of Lavere: 3

graets fom $0.0,20.3 \quad 30.8 \quad 48.7$

Fo of Bansore: 7

8are Lager: No

Fiste Radius: 18.0

P-Ratio: $0.38 \quad 0.40 \quad 0.38$

\begin{tabular}{|c|c|c|c|c|c|}
\hline Etation & Lasd (N) & E(1)(MPa) & $E(2)(A(P A)$ & $\left.E(3) \cap \Delta P_{\Delta}\right)$ & pous ETtor \\
\hline $031408-1$ & 40000.0 & 9843 & 7498 & 1011 & 31.72 \\
\hline
\end{tabular}


BACKCALCULATTON by EVercalc 4.0 - Summary Output

\begin{tabular}{|c|c|c|c|}
\hline \multicolumn{2}{|c|}{ 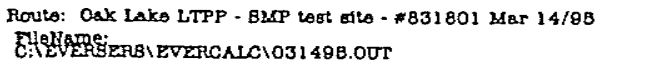 } & \multicolumn{2}{|l|}{ Btert Lager: Ho } \\
\hline $\begin{array}{l}\text { No of Larers: } 4 \\
\text { 81rgats } \\
61.0418 .420 .3 \quad 30.5 \quad 48.7\end{array}$ & Ho of Bensors: 7 & $\begin{array}{l}\text { Plate Radius: } 13.0 \\
\text { P-Ratio: } 0.38 \quad 0.40 \quad 0.38\end{array}$ & 0.36 \\
\hline Laed an & $E(1)\left(A_{P B}\right)$ & $E(4)(A C P B)$ & Rug Error \\
\hline $031488-1$ & 9843 & 10000 & 12.09 \\
\hline $031498-2$ & 7424 & 10000 & 11.87 \\
\hline \multicolumn{4}{|c|}{ BACKCALCULATION by Evercalc 4.0-Summary Output } \\
\hline \multicolumn{2}{|c|}{ 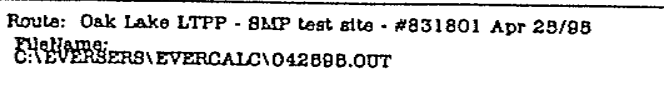 } & Burr lager: No & \\
\hline $\begin{array}{l}\text { Ho of Layers: } 3 \\
\text { Or(sots (om) }{ }_{18} 0_{2} 20.3 \quad 30.8 \quad 48.7\end{array}$ & No of Bensers: 7 & $\begin{array}{l}\text { Flace Radlus: } 18.0 \\
\text { P-Fla do: } 0.38 \quad 0.40 \quad 0.49\end{array}$ & \\
\hline Losd on & $E(1)(M(P)$ & E(3)OMPa) & Raus Error \\
\hline 40000.0 & 8388 & 204 & 0.87 \\
\hline $042898-2$ & $782 \theta$ & 188 & 0.82 \\
\hline 40000.0 & 7220 & 187 & 1.10 \\
\hline
\end{tabular}

BACKCALCULATTON by Everagle 4.0 - Summery Output

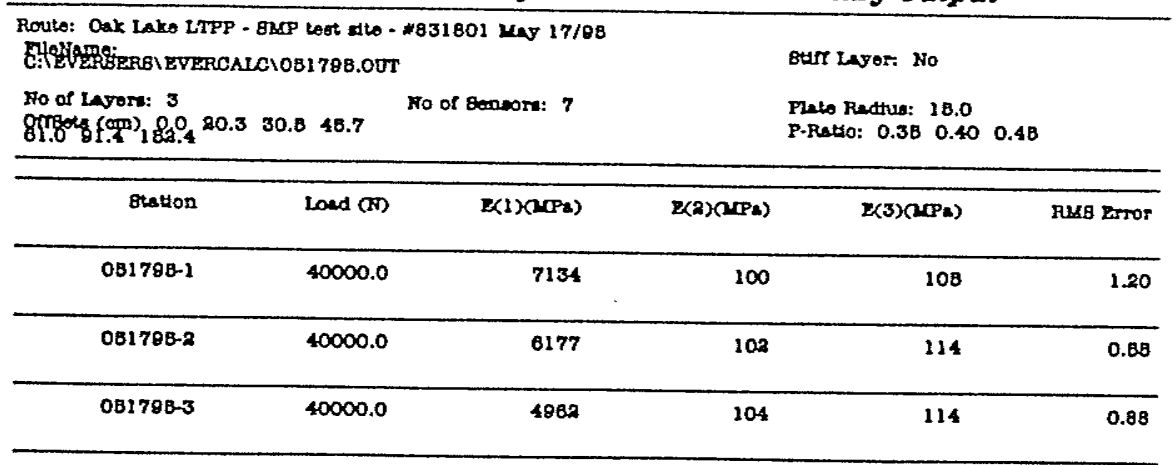

145

D6 Backcalculated Layer Moduli 
BACKCALCULATION by Evercalc 4.0 - Summary Output

\begin{tabular}{|c|c|c|c|c|c|}
\hline \multicolumn{4}{|c|}{ 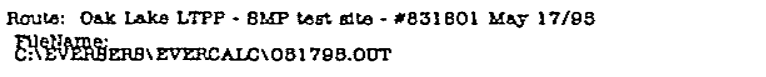 } & \multirow{2}{*}{\multicolumn{2}{|c|}{$\begin{array}{l}\text { Etift Laver: Jo } \\
\text { Plate Radiug: } 19.0 \\
\text { P-Ratio: } 0.38 \text { o.40 } 0.48\end{array}$}} \\
\hline 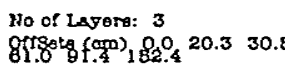 & 94.7 & Ho of Bonsors: 7 & & & \\
\hline Btstion & losd as & P(1)(MTa) & $E(2)(a r p a)$ & $E(3)(X(P B)$ & RM8 ETror \\
\hline $081780-1$ & 40000.0 & 4112 & 180 & 100 & 7.00 \\
\hline $08178 \mathrm{~B}-2$ & 40000.0 & 3894 & 180 & 107 & 6.11 \\
\hline $081798-3$ & 40000.0 & 3124 & 180 & 108 & 6.47 \\
\hline
\end{tabular}

BACKCALCULATION by Everealc 4.0 - Summary Output

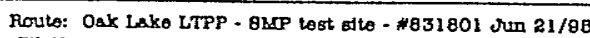

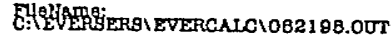

Ho ot Layers: 3

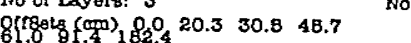

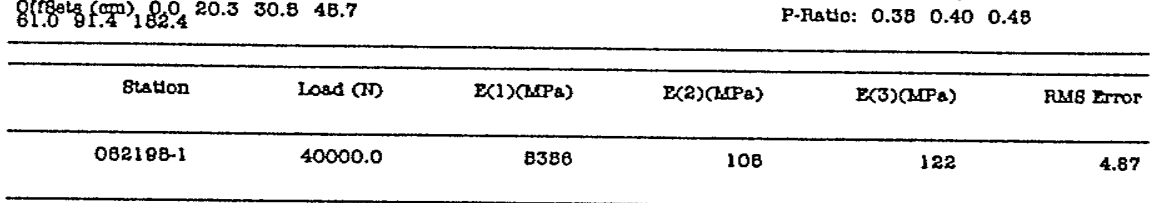

